RAFAEL MADIO

MODELAGEM E CONTROLE DE UMA MICROMÁQUINA A VAPOR

São Paulo

2017 
RAFAEL MADIO

\section{MODELAGEM E CONTROLE DE UMA MICROMÁQUINA A VAPOR}

Dissertação apresentada à Escola Politécnica da Universidade de São Paulo para obtenção do titulo de Mestre em Ciências

São Paulo 
RAFAEL MADIO

\section{MODELAGEM E CONTROLE DE UMA MICROMÁQUINA A VAPOR}

Dissertação apresentada à Escola Politécnica da Universidade de São Paulo para obtenção do titulo de Mestre em Ciências

Área de concentração:

Engenharia de Controle e Automação Mecânica

Orientador:

Prof. Dr. Demetrio Cornilios Zachariadis

São Paulo 
Este exemplar foi revisado e corrigido em relação à versão original, sob responsabilidade única do autor e com a anuência de seu orientador.

São Paulo, de de

Assinatura do autor:

Assinatura do orientador:

Catalogação-na-publicação

\section{Madio, Rafael}

Modelagem e Controle de uma Micromáquina a Vapor / R. Madio -versão corr. -- São Paulo, 2017.

$228 \mathrm{p}$.

Dissertação (Mestrado) - Escola Politécnica da Universidade de São Paulo. Departamento de Engenharia Mecânica.

1.Máquinas a Vapor 2.Motores a Vapor 3.Dinâmica de Máquinas 4.Vibrações de Máquinas I.Universidade de São Paulo. Escola Politécnica. Departamento de Engenharia Mecânica Il.t. 


\section{DEDICATÓRIA}

Dedico este trabalho à minha família. 


\section{AGRADECIMENTOS}

Ao professor Demetrio Cornilios Zachariadis pela orientação, paciência e compreensão.

Ao laboratório Sisea (Laboratório de Sistemas Energéticos Alternativos) e seus integrantes, dentre os quais tiveram grande influência para a realização deste trabalho. Pode-se citar o prof. José Roberto Simões Moreira e Thyago Reynaldo José Miranda.

Aos amigos pela participação direta e indireta. Pode-se citar Felipe Augusto de Souza Kleine e Tamara de Medeiros Dantas.

À família pelo apoio e incentivo.

À Universidade de São Paulo pela oportunidade de poder fazer parte de uma das maiores universidades do mundo.

À Coordenação de Aperfeiçoamento de Pessoal de Nível Superior pela bolsa de mestrado - pelo apoio financeiro - que me permitiu realizar esta pesquisa.

À equipe Baja da Escola Politécnica pelo empréstimo de diversos equipamentos. 
"Eu posso não ter ido para onde eu pretendia ir, mas eu acho que acabei terminando onde eu pretendia estar."

(Douglas Adams) 


\section{RESUMO}

Este trabalho apresenta o estudo multidisciplinar de uma micromáquina a vapor concebida para a utilização em sistemas de geração distribuída. $O$ foco da pesquisa é o desenvolvimento do modelo matemático da micromáquina, que requereu conhecimentos da termodinâmica e suas leis, e a aplicação de conceitos de dinâmica, vibrações e controle, entre outros. Para a validação experimental do modelo foi reconstruída uma micromáquina já existente; também foi realizado o projeto da bancada, a seleção da instrumentação e a sua calibração. O estudo apresenta ainda a comparação entre os resultados teóricos e experimentais, bem como a sua análise e interpretação.

Palavras-chave: Máquina a vapor; Modelagem; Simulação; Estudo experimental; Controle. 


\section{ABSTRACT}

A multidisciplinary study of a micro steam engine conceived for distributed generation systems is presented. The research focuses on the development of the mathematical model of the micro engine, which required the knowledge of Thermodynamics and its laws, and concepts of dynamics, vibration and control, among others. In order to experimentally validate the model, a previous micro engine was redesigned and rebuilt; likewise, a new bench was designed, together with the selection and calibration of the measurement systems. The study also presents the comparison between experimental and theoretical results, as well as their analysis and discussion.

Keywords: Steam engine; Modelling; Simulation; Experimental study; Control. 


\section{LISTA DE FIGURAS}

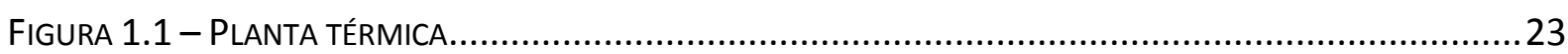

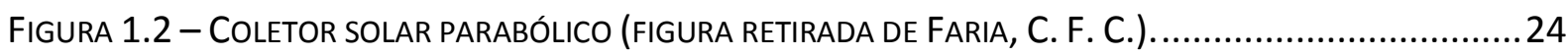

FIGURA 1.3 - SISTEMA MECÂNICO DA MICROMÁQUINA A VAPOR: (A) PROJETO E (B) PROTÓTIPO...................25

FIGURA 1.4 - ESQUEMA DO GERADOR ELÉTRICO (FIGURA RETIRADA DE BIM, E.) ..................................2

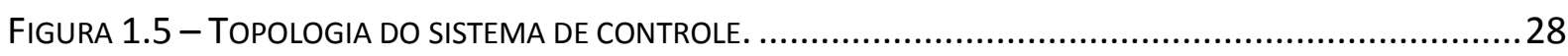

FIGURA 2.1 - CICLO PXV REAL DE UMA MÁQUINA A VAPOR PRESSURIZADA EM AMBOS OS LADOS DO PISTÃO

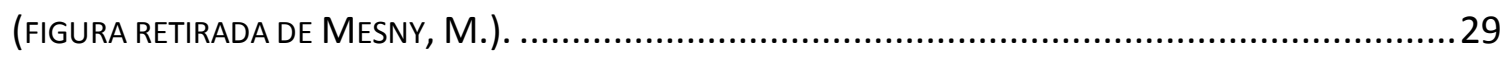

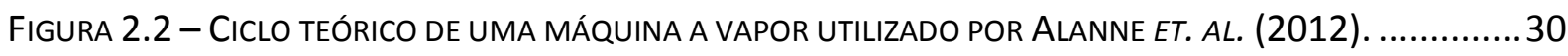

FIGURA 2.3 - CIClO TEÓRICO DE UMA MÁQUINA A VAPOR UTILIZADO POR TRAJKOVIC ET. Al. (2010)............31

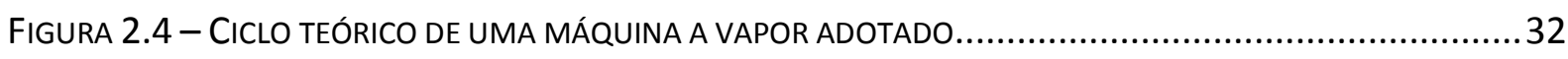

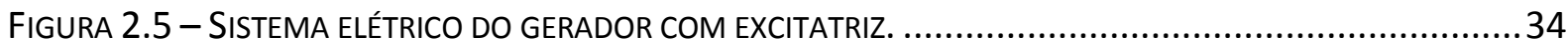

FIGURA 3.1 - PROJETO E PROTÓTIPO DA MICROMÁQUINA A VAPOR: (A) ORIGINAL E (B) MODIFICADO.............36

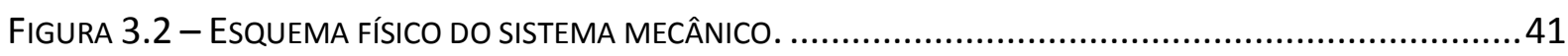

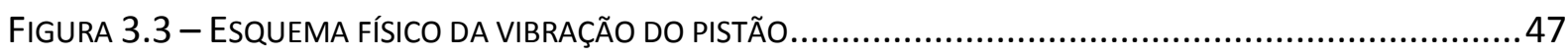

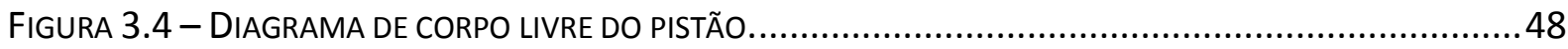

FIGURA 4.1 - DIAGRAMA DE BLOCOS PARA AS SIMULAÇÕES DO SISTEMA TÉRMICO..................................55

FIGURA 4.2 - SIMULAÇÃO DO DIAGRAMA INDICADO DA MÁQUINA A VAPOR........................................56

FIGURA 4.3 - SIMULAÇÃO DA PRESSÃO EM AMBOS OS LADOS DO PISTÃO............................................57

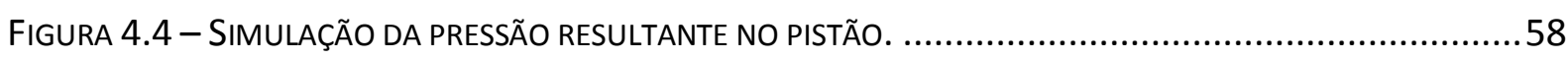

FIGURA 4.5 - SIMULAÇÃO DA PRESSÃO APROXIMADA POR SÉRIE DE FOURIER.......................................59

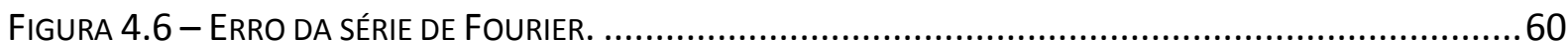

FIGURA 4.7 - DIAGRAMA DE BLOCOS PARA AS SIMULAÇÕES DO SISTEMA MECÂNICO.................................63

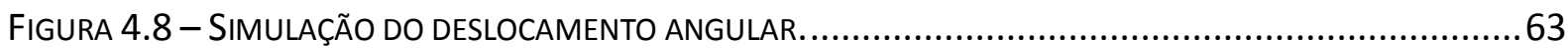

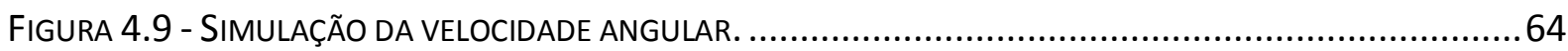

FIGURA 4.10 - SIMULAÇÃO DO TORQUE EM FUNÇÃO DA VELOCIDADE ANGULAR......................................65

FIGURA 4.11 - SIMULAÇÃO DA POTÊNCIA EM FUNÇÃO DA VELOCIDADE ANGULAR....................................66

FIGURA 4.12 - DIAGRAMA DE BLOCOS PARA AS SIMULAÇÕES DA VIBRAÇÃO DO PISTÃO................................68

FIGURA 4.13 - SIMULAÇÃO DA FORÇA DO FLUIDO EM FUNÇÃO DO TEMPO. ............................................68

FIGURA 4.14 - COEFICIENTES DA SÉRIE DE FOURIER DA FORÇA DO FLUIDO.............................................69 
FIGURA 4.15 - SIMULAÇÃO DA FORÇA INERCIAL EM FUNÇÃO DO TEMPO................................................. 70

FIGURA 4.16 - CoEFICIENTES DA SÉRIE DE FOURIER DA FORÇA INERCIAL. ............................................71

FIGURA 4.17 - SIMULAÇÃO DA FORÇA RESULTANTE EM FUNÇÃO DO TEMPO............................................72

Figura 4.18 - CoefiCIENTES DA SÉRIE De Fourier DA FORÇA RESULtANTE........................................73

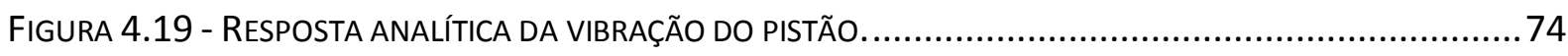

FIGURA 4.20 - SIMULAÇÃO NUMÉRICA DA VIBRAÇÃO DO PISTÃO ......................................................75

FIGURA 4.21 - FATOR DE AMPLIFICAÇÃO EM FUNÇÃO DA VELOCIDADE ANGULAR.....................................76

FIGURA 4.22 - DIAGRAMA DE BLOCOS PARA AS SIMULAÇÕES DO SISTEMA ELÉTRICO. ...............................77

FIGURA 4.23 - SIMULAÇÃO DA TENSÃO EFICAZ EM FUNÇÃO DO TEMPO..............................................78

FIGURA 4.24 - SIMULAÇÃO DA CORRENTE EFICAZ EM FUNÇÃO DO TEMPO.............................................79

FIGURA 4.25 - SIMULAÇÃO DA VELOCIDADE ANGULAR EM FUNÇÃO DO TEMPO. ...................................... 80

FIGURA 4.26 - SIMULAÇÃO DA FREQUÊNCIA ELÉTRICA EM FUNÇÃO DO TEMPO........................................ 81

FIGURA 4.27 - SIMULAÇÃO DA VELOCIDADE ANGULAR VARIANDO O MOMENTO DE INÉRCIA..........................84

FIGURA 4.28 - SIMULAÇÃO DA VELOCIDADE ANGULAR VARIANDO O COEFICIENTE DE ATRITO VISCOSO. ............85

FIGURA 4.29 - SIMULAÇÃO DO DIAGRAMA INDICADO DA MÁQUINA VARIANDO A PRESSÃO DE ENTRADA...........86

FIGURA 4.30 - SIMULAÇÃO DA PRESSÃO RESULTANTE VARIANDO A PRESSÃO DE ENTRADA. .........................87

FIGURA 4.31 - SIMULAÇÃO DA VELOCIDADE ANGULAR VARIANDO A PRESSÃO DE ENTRADA...........................8

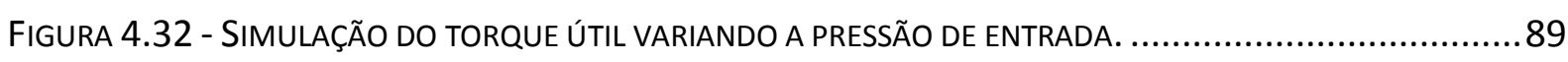

FIGURA 4.33 - SIMULAÇÃO DA POTÊNCIA VARIANDO A PRESSÃO DE ENTRADA........................................90

FIGURA 4.34 - POTÊNCIA E TORQUE MÁXIMOS EM FUNÇÃO DA PRESSÃO DE ENTRADA. ...............................91

FIGURA 4.35 - SIMULAÇÃO DA VELOCIDADE ANGULAR VARIANDO A TENSÃO DE ENTRADA. ..........................92

FIGURA 4.36 - SIMULAÇÃO DA TENSÃO EXCITATRIZ VARIANDO A TENSÃO DE ENTRADA. ..............................93

FIGURA 4.37 - SIMULAÇÃO DA TENSÃO GERADOR VARIANDO A TENSÃO DE ENTRADA................................94

FIGURA 4.38 - SIMULAÇÃO DA FREQUÊNCIA ELÉTRICA VARIANDO A TENSÃO DE ENTRADA............................95

FIGURA 4.39 - SIMULAÇÃO DA CORRENTE EFICAZ VARIANDO A TENSÃO DE ENTRADA..................................96

FIGURA 4.40 - TENSÃO DO GERADOR, TENSÃO DA EXCITATRIZ, FREQUÊNCIA ELÉTRICA E CORRENTE DO GERADOR

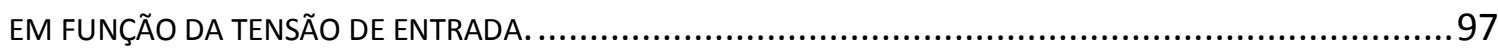

FigURA 5.1 - PROJETO dA MICROMÁQUINA A VAPOR : (A) ORIGINAL E (B) MODIFICADO...........................99

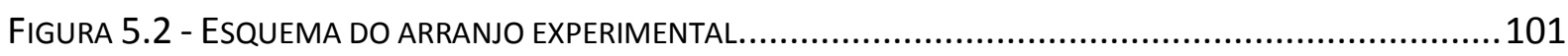

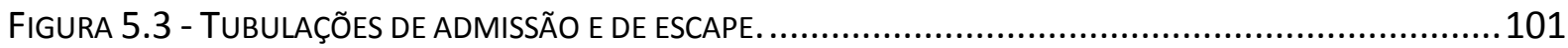

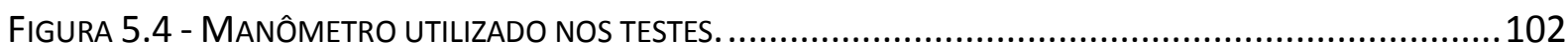


Figura 5.5 - Esquema do fReIO de PRONY. 103

FIGURA 5.6 - BALANÇAS DE GANCHO UTILIZADAS NOS TESTES 104

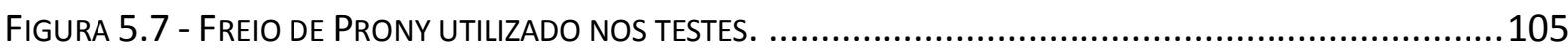

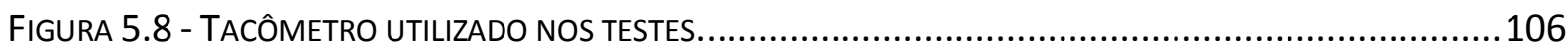

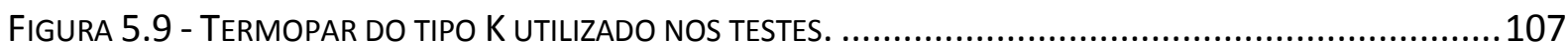

FIGURA 5.10 - MódULO CONTROLAdOR DE TEMPERATURA N1040 ................................................... 108

FIGURA 5.11 - PROJETO dO BOCAL CONVERGENTE PARA MEDIÇÃO DA VAZÃO CONFORME A NORMA

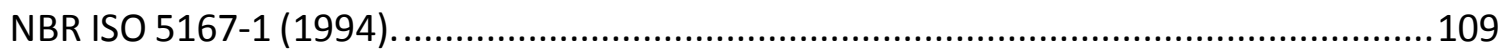

FIGURA 5.12 - BOCAL CONVERGENTE PARA MEDIÇÃO DA VAZÃO UTILIZADO NOS TESTES. ...........................110

FIGURA 5.13 - ESQUEMA DO BOCAL CONVERGENTE PARA MEDIÇÃO DE VAZÃO ACOPLADO À EXTREMIDADE DA

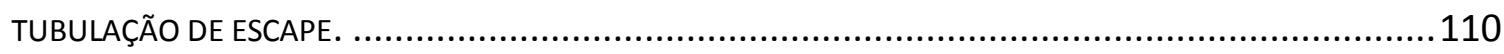

FIGURA 5.14 - MANÔMETRO EM U UTILIZADO NOS TESTES.............................................................111

FIGURA 5.15 - MANÔMETRO DE PRESSÃO ABSOLUTA UTILIZADO COMO REFERÊNCIA PARA A CALIBRAÇÃO. ....113

FIGURA 5.16 - ESQUEMA DO SISTEMA DE CALIBRAÇÃO DO MANÔMETRO..............................................114

FIGURA 5.17 - TERMOPARES CONECTADOS AOS MÓDULOS CONTROLADORES DE TEMPERATURA.................115

FIGURA 5.18 - TERMÔMETRO DE MERCÚRIO UTILIZADO COMO REFERÊNCIA PARA A CALIBRAÇÃO..................115

FIGURA 5.19 - BANHO-MARIA NT245 UTILIZADO PARA A CALIBRAÇÃO. ...............................................116

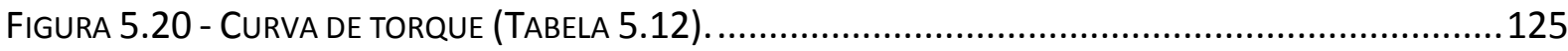

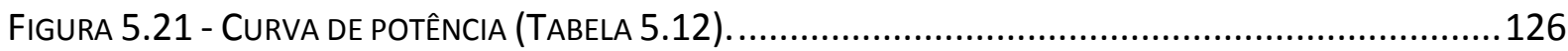

FIGURA 5.22 - CURVA DE EFICIÊNCIA ISOENTRÓPICA (TABELA 5.12) .....................................................126

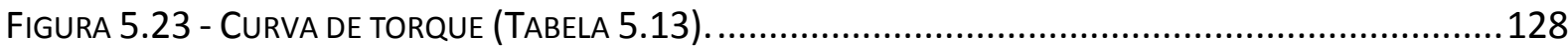

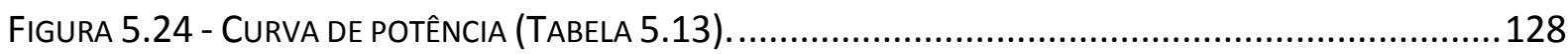

FIGURA 5.25 - CURVA DE EFICIÊNCIA ISOENTRÓPICA (TABELA 5.13) ................................................... 129

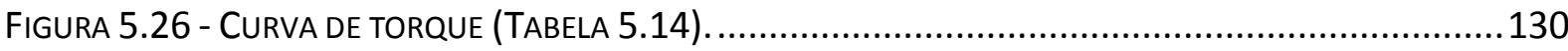

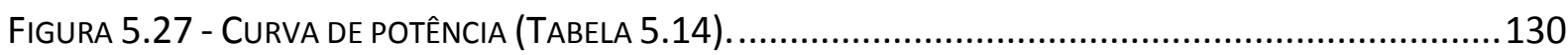

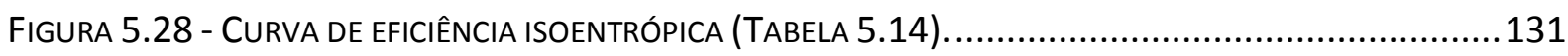

FIGURA 5.29 - TORQUE MÁXIMO EM FUNÇÃO DA PRESSÃO DE ADMISSÃO COM LINHA DE TENDÊNCIA............133

FIGURA 5.30 - POTÊNCIA MÁXIMA EM FUNÇÃO DA PRESSÃO DE ADMISSÃO COM LINHA DE TENDÊNCIA.........133

FIGURA 5.31 - EFICIÊNCIA ISOENTRÓPICA MÁXIMA EM FUNÇÃO DA PRESSÃO DE ADMISSÃO COM LINHA DE

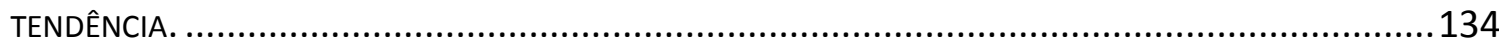

FIGURA 5.32 - COMPARATIVO DA ROTAÇÃO SEM CARGA ENTRE A MÁQUINA ORIGINAL E A MODIFICADA. ......135 
FIGURA 5.33 - COMPARATIVO DO TORQUE MÁXIMO ENTRE A MÁQUINA ORIGINAL E A MODIFICADA.............136

FIGURA 5.34 - COMPARATIVO DA POTÊNCIA MÁXIMA ENTRE A MÁQUINA ORIGINAL E A MODIFICADA.

FIGURA 5.35 - COMPARATIVO DA EFICIÊNCIA ISOENTRÓPICA ENTRE A MÁQUINA ORIGINAL E A MODIFICADA. .137

FIGURA 6.1 - CURVAS DE TORQUE: (A) SIMULAdO E (B) EXPERIMENTAL...........................................138

FIGURA 6.2 - CURVAS DE POTÊNCIA: (A) SIMULADO E (B) EXPERIMENTAL..........................................139

FIgURA 6.3 - PotêNCIA E TORQUE MÁXIMOS EM FUNÇão dA PRESSÃo DE ENTRADA: (A) SIMULAdO E

(B) EXPERIMENTAL.

FIGURA 6.4 - VELOCIDADE ANGULAR SIMULADA PARA A PRESSÃO DE ADMISSÃO DE 2,53 BAR.

FiguRA 6.5 - CURVA DE TORQUE PARA A PRESSÃO DE ADMISSÃO DE 2,53 BAR (A) SIMULADO E

(B) EXPERIMENTAL.

FIGURA 6.6 - CURVA DE POTÊNCIA PARA A PRESSÃO DE ADMISSÃO DE 2,53 BAR (A) SIMULAdO E

(B) EXPERIMENTAL.

FIGURA 6.7 - DiAGRAMA PXV DISTORCIDO ENTRE O FIM DA COMPRESSÃO E O INÍCIO DA EXPANSÃO.

FIGURA 6.8 - VELOCIDAdE ANGULAR EM FUNÇÃO dO COEFICIENTE DE ATRITO VISCOSO PARA A PRESSÃO DE ADMISSÃO DE 2,53 BAR.

FIGURA 6.9 - COEFICIENTE DE ATRITO VISCOSO EM FUNÇÃO DA VELOCIDADE ANGULAR PARA A PRESSÃO DE ADMISSÃO DE 2,53 BAR.

FIGURA 6.10 - VELOCIDADE ANGULAR MÁXIMA EM FUNÇÃO DA PRESSÃO DE ADMISSÃO COM LINHA DE TENDÊNCIA.

FIGURA 6.11 - VELOCIDADE ANGULAR EM FUNÇÃO DO COEFICIENTE DE ATRITO VISCOSO PARA A PRESSÃO DE ADMISSÃO DE 3,0 BAR.

FIGURA 6.12 - COEFICIENTE DE ATRITO VISCOSO EM FUNÇÃO DA VELOCIDADE ANGULAR PARA A PRESSÃO DE ADMISSÃO DE 3,0 BAR.

FIGURA 6.13 - VELOCIDADE ANGULAR EM FUNÇÃO DO COEFICIENTE DE ATRITO VISCOSO PARA A PRESSÃO DE ADMISSÃO DE 3,5 BAR.

FIGURA 6.14 - CoEFICIENTE DE ATRITO VISCOSO EM FUNÇÃO DA VELOCIDADE ANGULAR PARA A PRESSÃO DE ADMISSÃO DE 3,5 BAR.

FIGURA 6.15 - VELOCIDADE ANGULAR EM FUNÇÃO DO COEFICIENTE DE ATRITO VISCOSO PARA A PRESSÃO DE ADMISSÃO DE 4,0 BAR.

FIGURA 6.16 - COEFICIENTE DE ATRITO VISCOSO EM FUNÇÃO DA VELOCIDADE ANGULAR PARA A PRESSÃO DE ADMISSÃO DE 4,0 BAR. 
FIGURA 6.17 - VELOCIDADE ANGULAR EM FUNÇÃO DO COEFICIENTE DE ATRITO VISCOSO PARA A PRESSÃO DE ADMISSÃO DE 4,5 BAR.

FIGURA 6.18 - COEFICIENTE DE ATRITO VISCOSO EM FUNÇÃO DA VELOCIDADE ANGULAR PARA A PRESSÃO DE ADMISSÃO DE 4,5 BAR.

FIGURA 6.19 - VELOCIDADE ANGULAR EM FUNÇÃO DO COEFICIENTE DE ATRITO VISCOSO PARA A PRESSÃO DE ADMISSÃO DE 5,0 BAR.

FiguRA 6.20 - CoEfICIENTE DE ATRITO VISCOSO EM FUNÇÃO DA VELOCIDADE ANGULAR PARA A PRESSÃO DE ADMISSÃO DE 5,0 BAR. 156

FIGURA 6.21 - COEFICIENTE DE ATRITO VISCOSO EM FUNÇÃO DA VELOCIDADE ANGULAR. 157

FIGURA 6.22 - COEFICIENTE DE ATRITO VISCOSO EM FUNÇÃO DA PRESSÃO DE ADMISSÃO. 158

FIGURA 7.1 - DIAGRAMA DE BLOCOS DO SISTEMA DE CONTROLE. 160

FIGURA 7.2 - EXEMPLO DE TACÔMETRO. 161

FigURA 7.3 - EXEMPLO DE VOLTíMETRO. 162

FIGURA 7.4 - EXEMPLO DE VÁLVULA REGULADORA DE PRESSÃO. 163

FIGURA 7.5 - CIRCUITO EXCITATRIZ. 164

FIGURA 7.6 - REGRESSÃO LINEAR DA VARIAÇÃO DA RESPOSTA PELO GANHO DE PRESSÃO. 166

FIGURA 7.7 - REGRESSÃO LINEAR DA VARIAÇÃO DA RESPOSTA PELO GANHO DE TENSÃO. 167

FIGURA 7.8 - VELOCIDADE ANGULAR PARA CADA ITERAÇÃO. 169

FIGURA 7.9 - FREQUÊNCIA ELÉTRICA PARA CADA ITERAÇÃO. 170

FIGURA 7.10 - TENSÃO EFICAZ PARA CADA ITERAÇÃO. 171

FIGURA 7.11 - CORRENTE EFICAZ PARA CADA ITERAÇÃO. 172

FIGURA 7.12 - FREQUÊNCIA ELÉTRICA CONTROLADA. 173

FIGURA 7.13 - TENSÃO ELÉTRICA CONTROLADA. 174

Figura A.1 - Projeto do PISTÃo biPARTIDO COM ANEL DE TEFLON. 184

FIGURA A.2 - PISTÃo BIPARTIDO COM ANEL DE TEFLON. 185

FIgURA A.3 - PISTÃO MONTADO. 185

FIGURA A.4 - PROJETO dA TAMPA DO PISTÃo COM O-RING E ANEL DE TEFLON. 186

FIGURA A.5 - TAMPA DO PISTÃO COM O-RING E ANEL DE TEFLON. 186

Figura A.6 - Projeto da haste do PISTÃo. 187

FIGURA A.7 - HASTE DO PISTÃO FEITO COM EIXO RETIFICADO DE AÇO. 187

Figura A.8 - ROLAMENTO LINEAR LM06UU. 188 


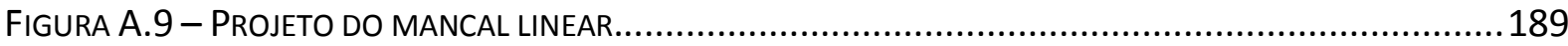

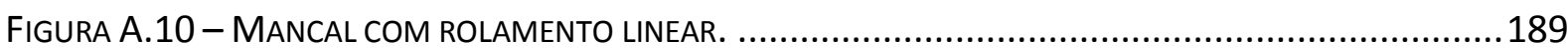

Figura A.11 - Projeto dA TAMPA DA VÁlVULA COM O-RING E ANEL DE TEFLON.................................190

FIGURA A.12 - TAMPA DA VÁLVULA COM O-RING E ANEL DE TEFLON .............................................. 190

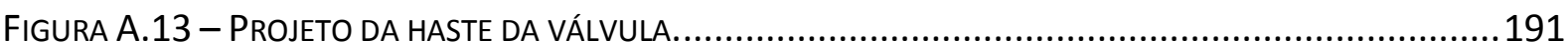

FIGURA A.14 - HASTE DA VÁLVULA FEITO COM EIXO RETIFICADO DE AÇO .............................................191

FIGURA A.15 - PROJETO DA BIELA DE AÇO COM ANÉIS DE LATÃO...................................................192

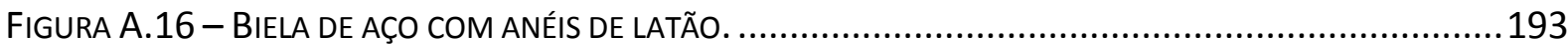

FIGURA A.17 - PROJETO DOS ESPAÇADORES DA BIELA FEITO EM LATÃO..............................................194

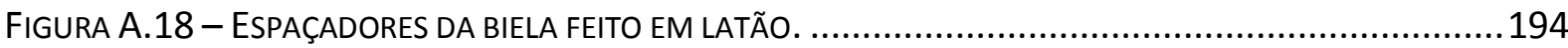

FIGURA A.19 - ANEL ELÁSTICO DE ENCAIXE FORÇADO E DE ENCAIXE COM ALICATE..................................195

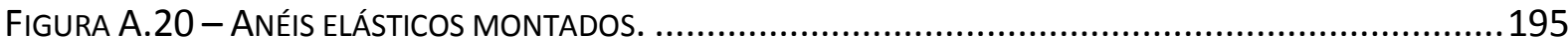

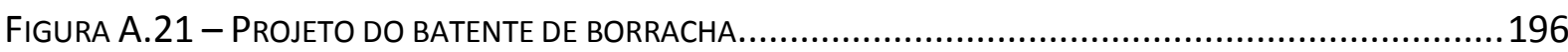

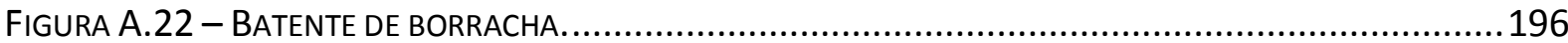

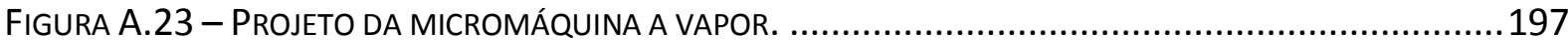

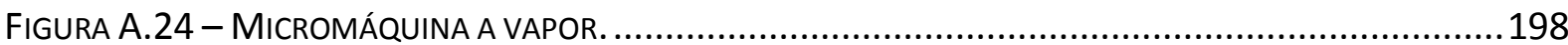




\section{LISTA DE TABELAS}

TABELA 4.1 - MEDIDAS DO ÂNGULOS DO CICLO DA MÁQUINA. 54

TABELA 4.2 - AMPLITUdE E FASE dOS 10 PRIMEIROS TERMOS DA SÉRIE DE FOURIER DA PRESSÃO RESULTANTE. 59

TABELA 4.3 - AMPLITUDE E FASE DA SÉRIE DE FOURIER DA FORÇA DO FLUIDO. 69

TABELA 4.4 - AMPLITUDE E FASE DA SÉRIE DE FOURIER DA FORÇA INERCIAL........................................71

TABELA 4.5 - AMPLITUDE E FASE DA SÉRIE DE FOURIER DA FORÇA RESULTANTE. ......................................73

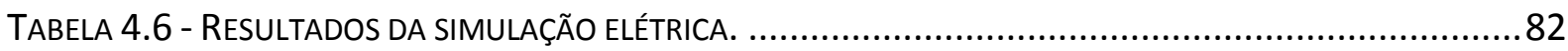

TABELA 4.7 - PRINCIPAIS RESULTAdOS DA VARIAÇÃO DA PRESSÃO DE ENTRADA.......................................91

TABELA 4.8 - PRINCIPAIS RESULTADOS DA VARIAÇÃO DA TENSÃO DE ENTRADA ......................................97

TABELA 4.9 - PRINCIPAIS RESULTAdOS DA ANÁLISE DE SENSIBILIDADE.................................................98

TABELA 5.1 - CoEFICIENTES DE CALIBRAÇÃO Do MANÔMETRO.......................................................115

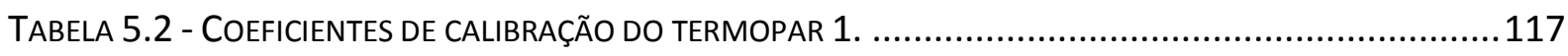

TABELA 5.3 - CoefiCIENTES DE CALIBRAÇÃo do TERMOPAR 2...................................................117

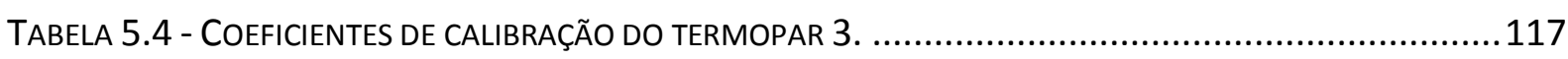

TABELA 5.5 - CURVA DE CALIBRAÇÃo do TACÔMETRO. ................................................................118

TABELA 5.6 - MedIDAS OBTIDAS PARA A PRIMEIRA SEQUÊNCIA DE TESTE. ..........................................119

TABELA 5.7 - MEDIDAS OBTIDAS PARA A SEGUNDA SEQUÊNCIA DE TESTE. ...........................................120

TABELA 5.8 - MEDIDAS OBTIDAS PARA A TERCEIRA SEQUÊNCIA DE TESTE..........................................120

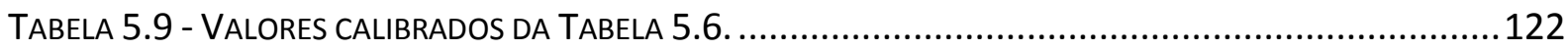

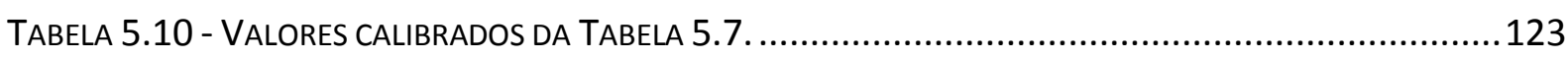

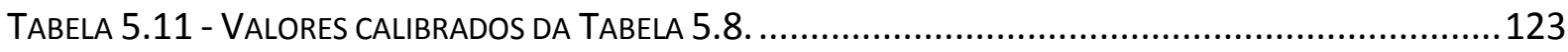

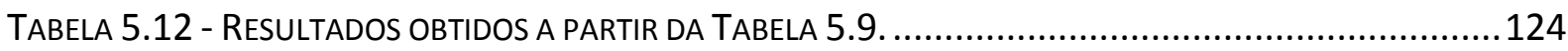

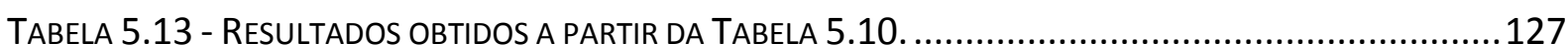

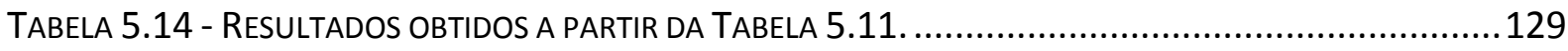

TABELA 5.15 - PRINCIPAIS RESULTADOS DA VARIAÇÃO DA PRESSÃO DE ENTRADA......................................132

TABELA 5.16 - COMPARAÇÃO DOS PRINCIPAIS RESULTADOS ENTRE A MÁQUINA ORIGINAL E A MÁQUINA

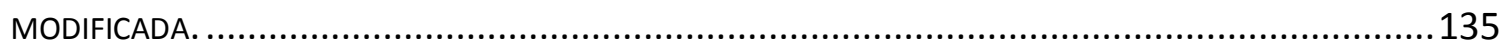

TABELA 6.1 - CoMPARAÇÃO ENTRE A SIMULAÇÃO E O ESTUdo EXPERIMENTAL..........................................143

TABELA 6.2 - RESULTADOS OBTIDOS PARA A PRESSÃO DE ADMISSÃO DE 2,53 BAR.................................145

TABELA 6.3 - EXTRAPOLAÇÃO DOS RESULTADOS EXPERIMENTAIS. .....................................................147 
TABELA 6.4 - RESULTADOS OBTIDOS PARA A PRESSÃO DE ADMISSÃO DE 3,0 BAR. 148

TABELA 6.5 - RESULTADOS OBTIDOS PARA A PRESSÃO DE ADMISSÃO DE 3,5 BAR. 150

TABELA 6.6 - RESULTADOS OBTIDOS PARA A PRESSÃO DE ADMISSÃO DE 4,0 BAR. 152

TABELA 6.7 - RESULTADOS OBTIDOS PARA A PRESSÃO DE ADMISSÃO DE 4,5 BAR. 154

TABELA 6.8 - RESULTADOS OBTIDOS PARA A PRESSÃO DE ADMISSÃO DE 5,0 BAR. 156

TABELA 6.9 - RESULTADOS OBTIDOS PARA A ESTIMATIVA DO COEFICIENTE DE ATRITO VISCOSO. 157

TABELA 7.1 VALORES LIMITES PARA A FREQUÊNCIA E A TENSÃO ELÉTRICA. 159

TABELA 7.2 RESPOSTAS VARIANDO O GANHO DE PRESSÃO. .165

TABELA 7.3 RESPOSTAS VARIANDO O GANHO DE TENSÃO. 166

TABELA 7.4 GANHOS E RESPOSTAS PARA CADA ITERAÇÃO. 168

TABELA C.1 - PRINCIPAIS RESULtAdDOS DA ANÁLISE DE SENSIBILIDADE. 221

TABELA D.1 - PRIMEIRA SEQUÊNCIA DE TESTE PARA A CALIBRAÇÃO DO MANÔMETRO 222

TABELA D. 2 - SEgUNDA SEQUÊNCIA DE TESTE PARA A CALIBRAÇÃO DO MANÔMETRO 222

TABELA D.3 - TERCEIRA SEQUÊNCIA DE TESTE PARA A CALIBRAÇÃO do MANÔMETRO 223

TABELA D.4 - PRIMEIRA SEQUÊNCIA DE TESTE PARA A CALIBRAÇÃo DOS TERMOPARES. 224

TABELA D.5 - SEgUNDA SEQUÊNCIA DE TESTE PARA A CALIBRAÇÃO DOS TERMOPARES. .225

TABELA D.6 - TERCEIRA SEQUÊNCIA DE TESTE PARA A CALIBRAÇÃO DOS TERMOPARES. 226

TABELA D.7 - PRIMEIRA SEQUÊNCIA DE TESTE PARA A CALIBRAÇÃO DO TACÔMETRO 227

TABELA D.8 - SEGUNDA SEQUÊNCIA DE TESTE PARA A CALIBRAÇÃO DO TACÔMETRO 227

TABELA D.9 - TERCEIRA SEQUÊNCIA DE TESTE PARA A CALIBRAÇÃO DOS TERMOPARES 228 


\section{LISTA DE SÍMBOLOS}

\section{Símbolos Latinos}

a

$a_{i}$

A

$b_{i}$

C

$\mathrm{C}_{\mathrm{p}}$

d

E

f

F

FP

g

i

$J$

k

$\mathrm{K}$

K1

$\mathrm{K} 2$

L

m

$\dot{\mathrm{m}}$
Aceleração $\left[\mathrm{m} / \mathrm{s}^{2}\right]$

Coeficientes da série de Fourier

Área [mm²]; Amplitude

Coeficientes da série de Fourier

Coeficiente de atrito viscoso [N.m.s/rad]

Calor específico a pressão constante [kJ/kg.K]

Diâmetro [mm]

Módulo de elasticidade [GPa]

Frequência elétrica [Hz]

Força $[\mathrm{N}]$

Fator de potência

gravidade $\left[\mathrm{m} / \mathrm{s}^{2}\right]$

Corrente $[\mathrm{A}]$

Momento de inércia [kg.m²]

Razão entre calores específicos; Coeficiente do fluxo magnético

Energia cinética; Coeficiente de rigidez [N/m]; Parâmetro elétrico definido

Ganho relativo à pressão de entrada

Ganho relativo à tensão de entrada

Função de Lagrange; Comprimento (da biela e da haste) [mm]; Indutância $[\mathrm{H}]$

Massa [g]

Vazão mássica $[\mathrm{g} / \mathrm{s}]$ 
Indutância mútua [H]

$\mathrm{n}$

Número de termos da série de Fourier

$\mathrm{N}$

Total de espiras em série no enrolamento do campo

$\mathrm{P}$

Pressão $[\mathrm{Pa}]$

PE

Ponto de ebulição da água

Pot

Potência [W]

Força generalizada

Comprimento da manivela [mm]; Raio [mm]; Parâmetro de frequência adimensional

$\mathrm{R}$

Função Rayleigh; Resistência [ $\Omega$ ]; Constante particular do gás $[\mathrm{kJ} / \mathrm{kg} \cdot \mathrm{K}]$

S

Função de saturação da excitatriz

$\mathrm{t}$

Tempo [s]

$\mathrm{T}$

Temperatura [K]; Torque [N.m]; Parâmetro elétrico definido

T1-T3

Termopar numerado

v

Tensão [V]; Velocidade [m/s]

$\mathrm{V}$

Volume $\left[\mathrm{m}^{3}\right]$; Energia potencial

w

trabalho específico $[\mathrm{kJ} / \mathrm{kg}]$

$x$

Deslocamento (movimento linear) [m]

$\dot{\mathrm{x}}$

Velocidade (movimento linear) $[\mathrm{m} / \mathrm{s}]$

$\ddot{\mathrm{x}}$

Aceleração (movimento linear) $\left[\mathrm{m} / \mathrm{s}^{2}\right]$ 


\section{Símbolos Gregos}

$\begin{array}{ll}\alpha & \text { Posição angular da manivela [rad] } \\ \beta & \text { posição angular da biela [rad] } \\ \eta & \text { Eficiência } \\ \theta & \text { Coordenada generalizada de posição angular [rad] } \\ \dot{\theta} & \text { Velocidade angular [rad/s] } \\ \ddot{\theta} & \text { Aceleração angular [rad/s²] } \\ \lambda & \text { Relação entre comprimentos da biela e da manivela } \\ \rho & \text { Densidade } \\ \sigma & \text { Fração do fluxo de campo que atravessa o entreferro } \\ \omega & \text { Velocidade angular [rpm]; Frequência [rad/s] } \\ \varphi & \text { Diferença de fase entre a válvula e o pistão [rad]; Fase } \\ \phi & \text { Fluxo Magnético [Wb] } \\ \Phi & \text { Ângulo de defasagem elétrica [ำ }\end{array}$




\section{SUBSCRITO}

\begin{tabular}{|c|c|}
\hline $1-6$ & Pontos do diagrama PxV \\
\hline $\mathrm{adm}$ & Admissão \\
\hline atm & Atmosférico \\
\hline $\mathrm{b}$ & Biela \\
\hline $\mathrm{cr}$ & Corpo rígido \\
\hline disp & Dispersão \\
\hline ef & Entreferro da excitatriz \\
\hline esc & Escape \\
\hline$E$ & Excitatriz \\
\hline$f$ & Fluido; Enrolamento de campo do gerador \\
\hline $\mathrm{fd}$ & Armadura da excitatriz \\
\hline $\mathrm{F}$ & Enrolamento de campo da excitatriz \\
\hline G & Gerador \\
\hline $\mathrm{h}$ & Haste \\
\hline iso & Isoentrópico \\
\hline med & Valor médio \\
\hline morto & Relacionado ao volume morto \\
\hline $\mathrm{n}$ & natural \\
\hline $\mathrm{p}$ & Pistão \\
\hline r & Resistivo \\
\hline ri & Roda de inércia \\
\hline $\mathrm{R}$ & Entrada \\
\hline $\mathrm{t}$ & Terminal \\
\hline$v$ & Válvula \\
\hline$\theta$ & Angular \\
\hline
\end{tabular}




\section{SUMÁRIO}

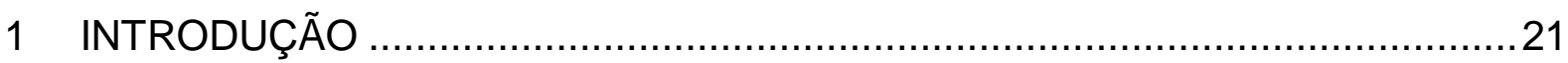

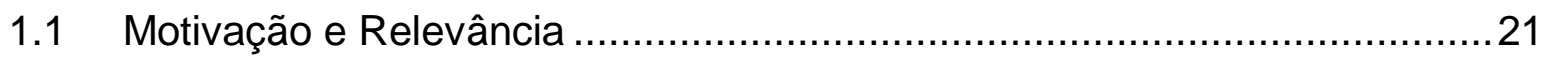

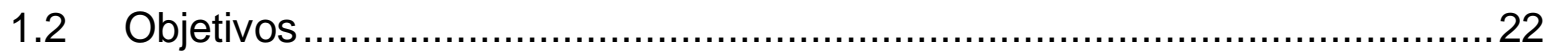

1.3 Descrição dos Componentes do Sistema .................................................23

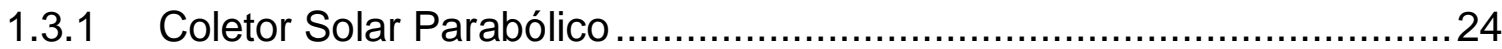

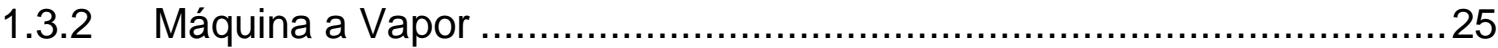

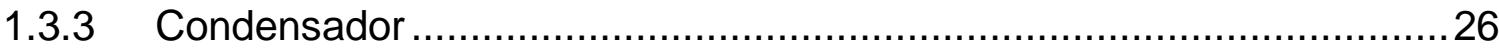

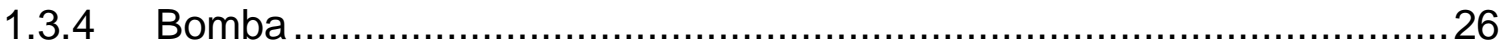

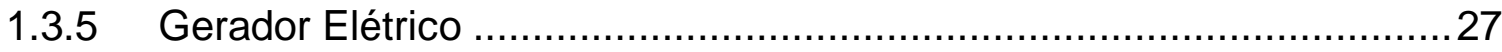

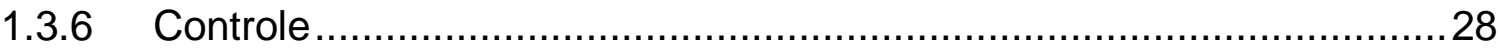

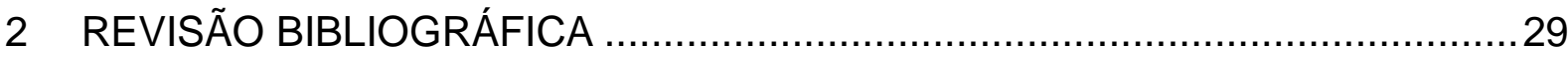

2.1 Ciclos Teóricos de uma Máquina a Vapor ................................................29

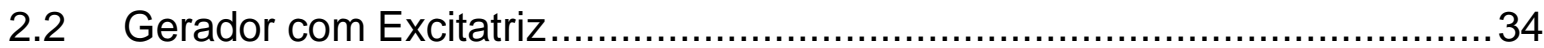

2.3 Série de Fourier ............................................................................. 35

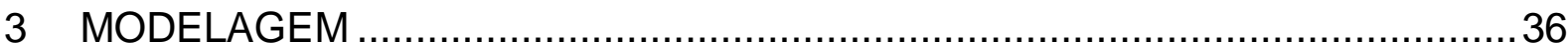

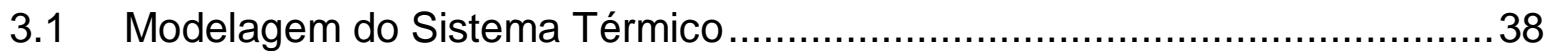

3.2 Modelagem do Sistema Mecânico …………..................................... 41

3.2.1 Equação de Movimento ……............................................................... 41

3.2.2 Vibração do Pistão e Respectiva Haste ...............................................47

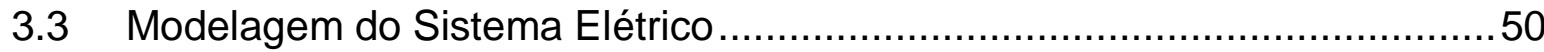

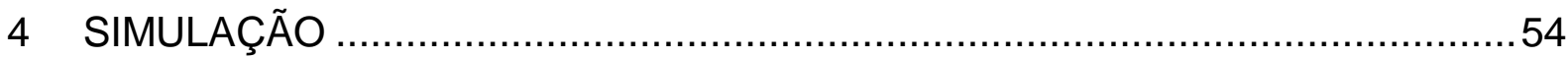

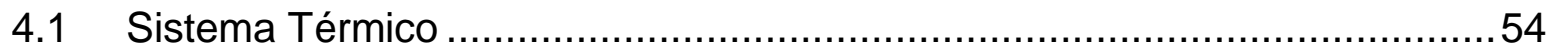

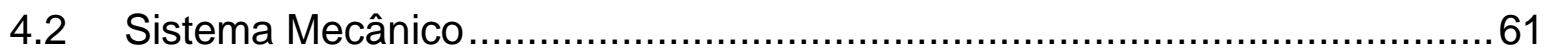

4.2.1 Propriedades para a Simulação Dinâmica ...........................................61 


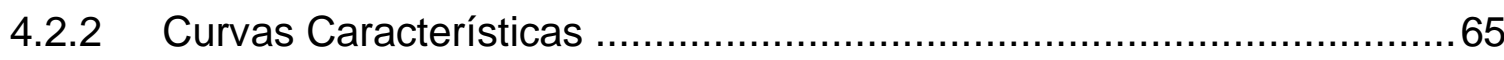

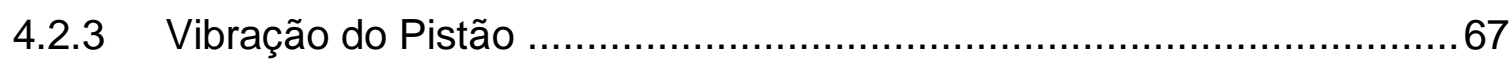

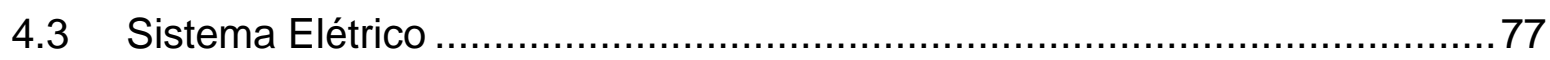

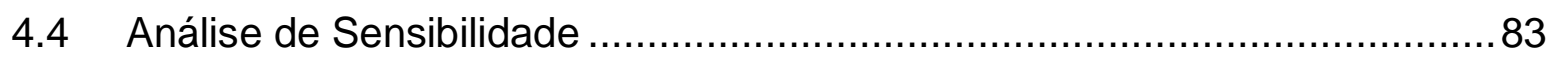

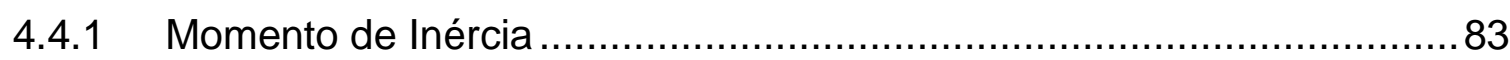

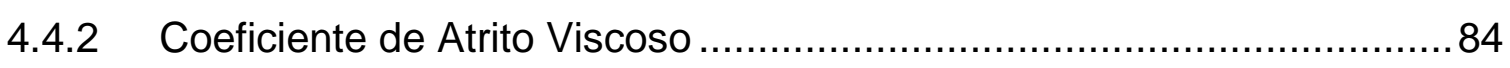

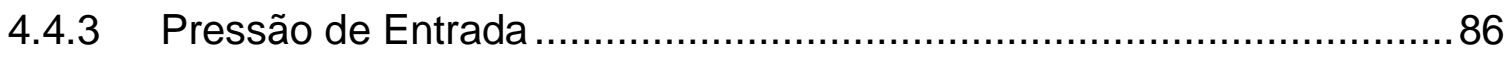

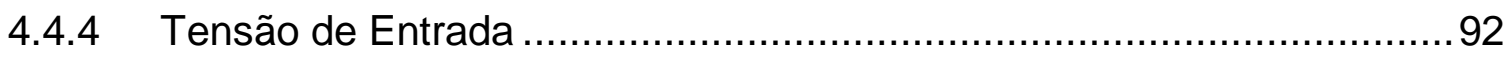

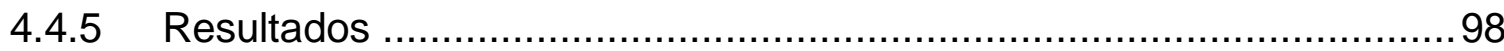

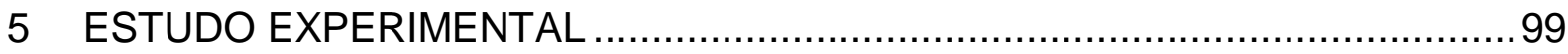

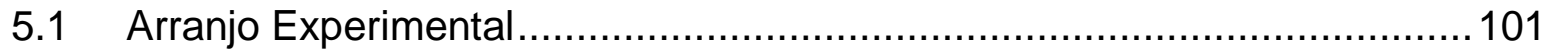

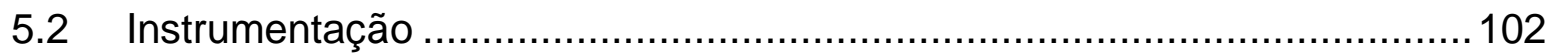

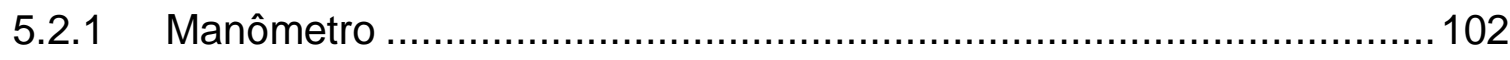

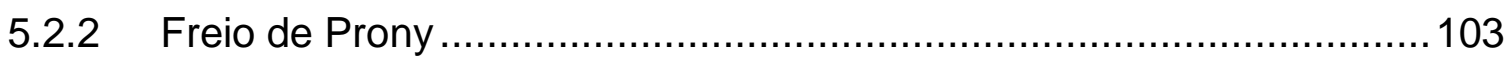

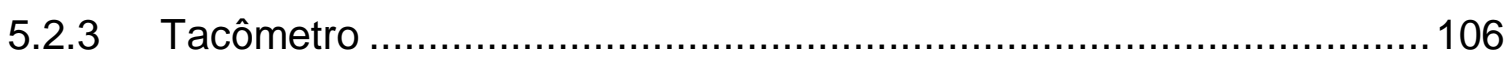

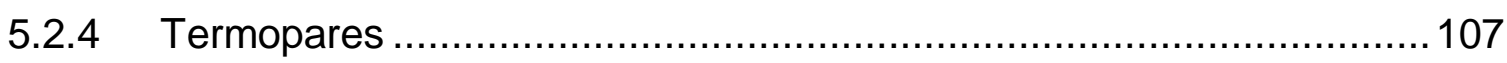

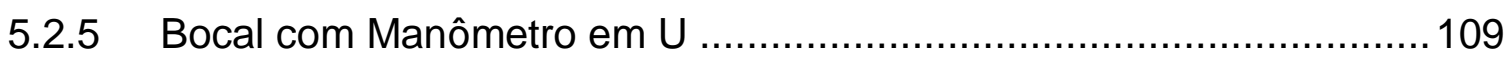

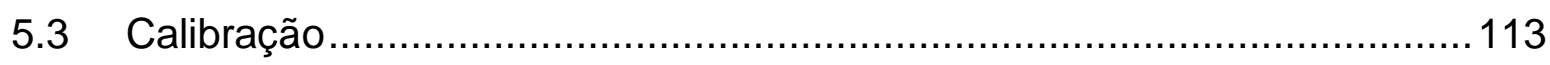

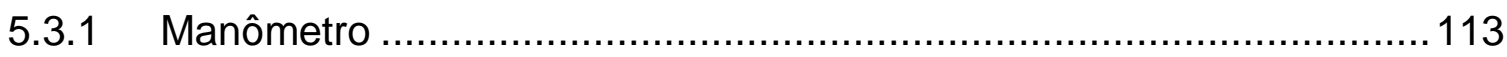

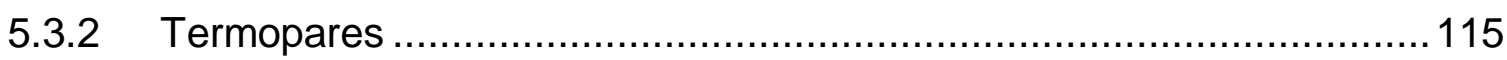

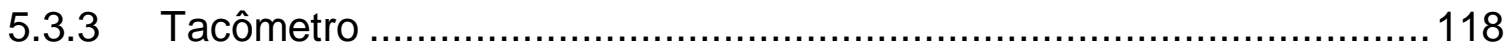

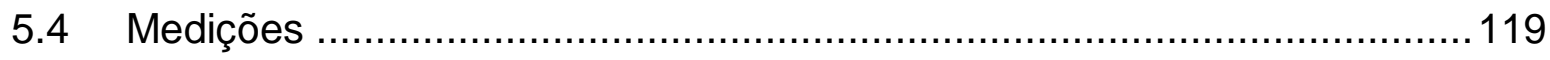

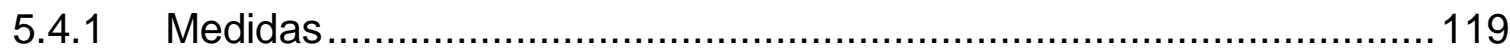

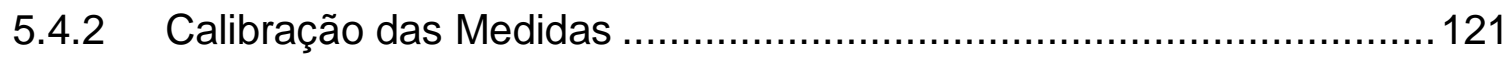

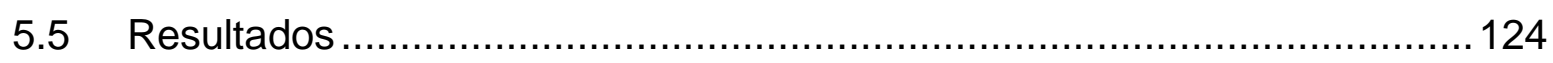

6 COMPARAÇÃO ENTRE RESULTADOS TEÓRICOS E EXPERIMENTAIS ....138

6.1 Estimativa do Coeficiente de Atrito Viscoso ...........................................144 


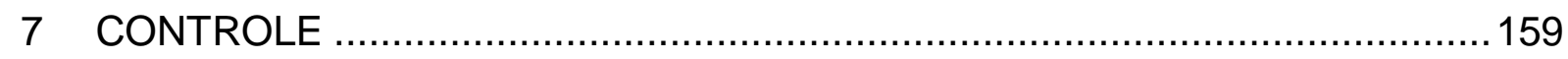

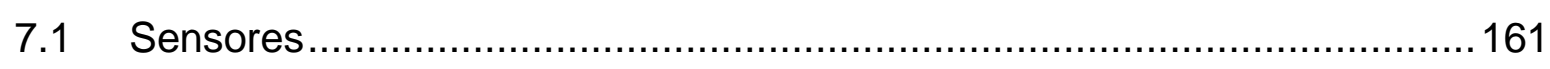

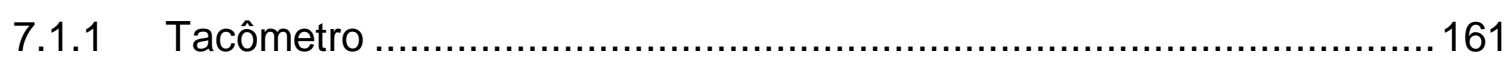

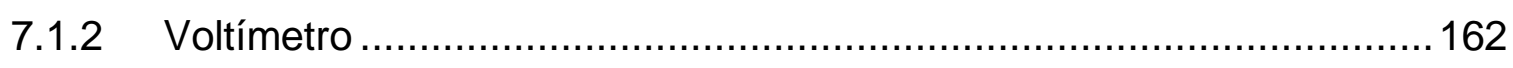

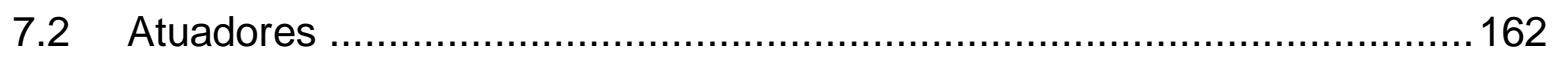

7.2.1 Válvula Reguladora de Pressão ……………...............................163

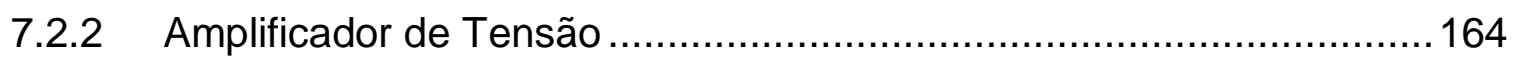

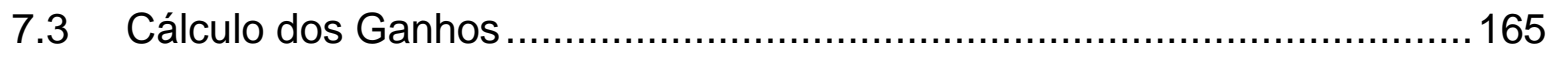

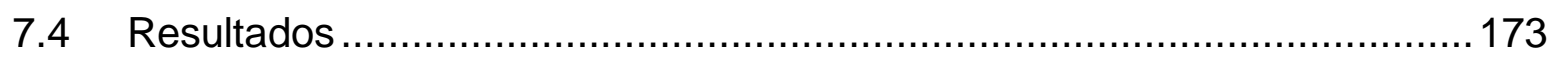

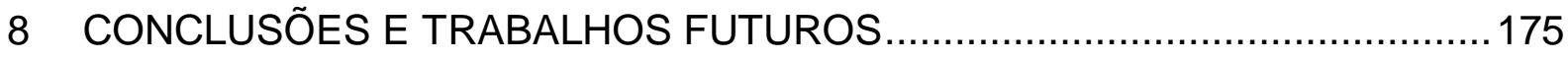

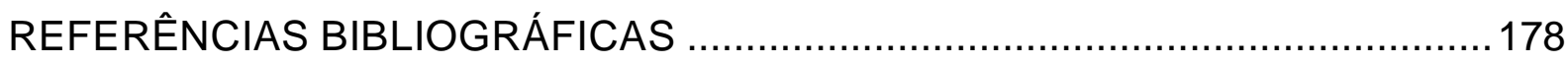

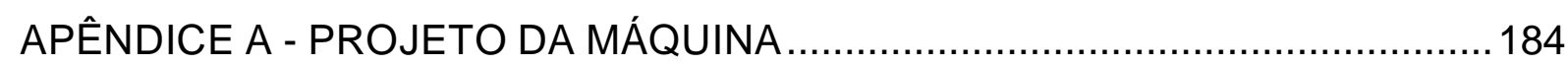

APÊNDICE B - ALGORITMO DAS SIMULAÇÕES EM MATLAB .........................199

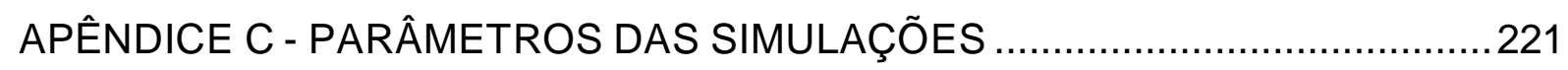

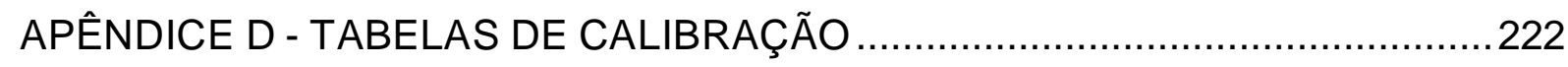




\section{INTRODUÇÃO}

\subsection{Motivação e Relevância}

Devido à crescente demanda de energia e preocupação com a preservação do meio ambiente, o aproveitamento da energia solar tem se mostrado uma das possíveis fontes de energia limpa e renovável. A micromáquina a vapor quando comparada com uma turbina a vapor apresenta melhor desempenho para baixas potências (da ordem de centenas de quilowatts) de acordo com Prasad et. al. (1993). Portanto, uma das vantagens da micromáquina a vapor é que cada pequeno consumidor, por exemplo, uma residência, pode possuir seu próprio gerador, tornando-se uma "célula" geradora de energia elétrica.

Atualmente, os Ciclos Orgânicos de Rankine (ORCs) possibilitam o aproveitamento de energia térmica de baixa temperatura. Nos ORCs, ao invés de água, se utiliza um fluido orgânico como fluido de trabalho, pois possui baixa temperatura de evaporação. Deste modo, os ORCs permitem a produção de energia elétrica para instalações de pequena potência, bem como o aproveitamento de calor em processos industriais. A máquina a vapor é naturalmente considerada como uma alternativa interessante para máquina de expansão do ORC.

Para tornar esta tecnologia viável, a proposta deste trabalho é desenvolver um modelo que represente de forma satisfatória o ciclo da máquina a vapor e sua resposta dinâmica. Com base no modelo é possível prever seu funcionamento e desta forma identificar as melhores condições de operação. 


\subsection{Objetivos}

O objetivo final deste trabalho é desenvolver e validar um modelo para micromáquina a vapor. Este modelo deve ser versátil, porém simples, e deve prever o funcionamento da máquina, tal como a sua velocidade de operação, a magnitude dos esforços que deverão ser suportados pelos componentes, a potência de eixo e a tensão e corrente elétrica gerada em função do gerador adotado.

Os objetivos parciais são enumerados abaixo:

- Modelagem do sistema térmico;

- Modelagem do sistema mecânico;

- Modelagem do sistema elétrico;

- Integração dos modelos e simulação do sistema completo;

- Análise de sensibilidade à variação de parâmetros dos modelos;

- Análise do projeto original e reconstrução da micromáquina;

- Projeto da instrumentação e monitoramento do experimento;

- Calibração dos sensores;

- Medições e análises dos resultados;

- Comparação entre resultados teóricos e experimentais;

- Projeto do sistema de controle. 


\subsection{Descrição dos Componentes do Sistema}

Este subcapítulo apresenta uma descrição sucinta dos componentes da planta térmica (Figura 1.1):

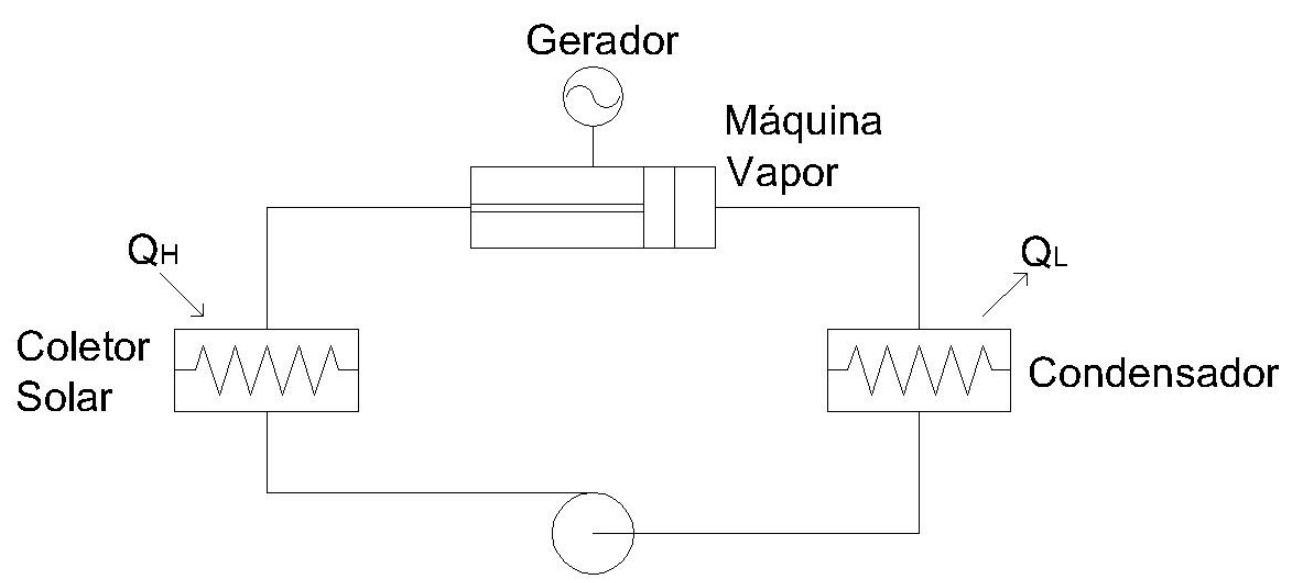

Bomba

Figura 1.1 - Planta térmica.

O ciclo Rankine clássico é composto por: caldeira, turbina a vapor, condensador e bomba. Distintamente, o ciclo orgânico Rankine proposto possui um coletor parabólico solar ao invés de uma caldeira, tornando a fonte de energia limpa e renovável.

Segundo Badr et. al. (1991), máquinas de expansão são classificadas em dois tipos: os motores de deslocamento positivo e as turbinas. Seu estudo mostra que os motores de deslocamento positivo são lentos, até 5.000 rpm, e são utilizados para potências de até $10 \mathrm{~kW}$. Já as turbinas são empregadas para altas rotações, acima de 5.000 rpm, e são utilizadas para potências acima de $10 \mathrm{~kW}$.

Portanto, como a potência proposta é baixa, a máquina a vapor torna-se mais interessante que uma turbina. 


\subsubsection{Coletor Solar Parabólico}

Simplificadamente, um coletor solar parabólico reflete toda radiação luminosa para seu ponto focal, aquecendo o fluido de trabalho. O vapor produzido pode alcançar temperaturas da ordem de $400^{\circ} \mathrm{C}$. Na planta térmica em questão o coletor solar parabólico substituirá a caldeira comum, sendo a fonte de calor do sistema, isto é, o gerador de vapor. A Figura 1.2 mostra um coletor real:

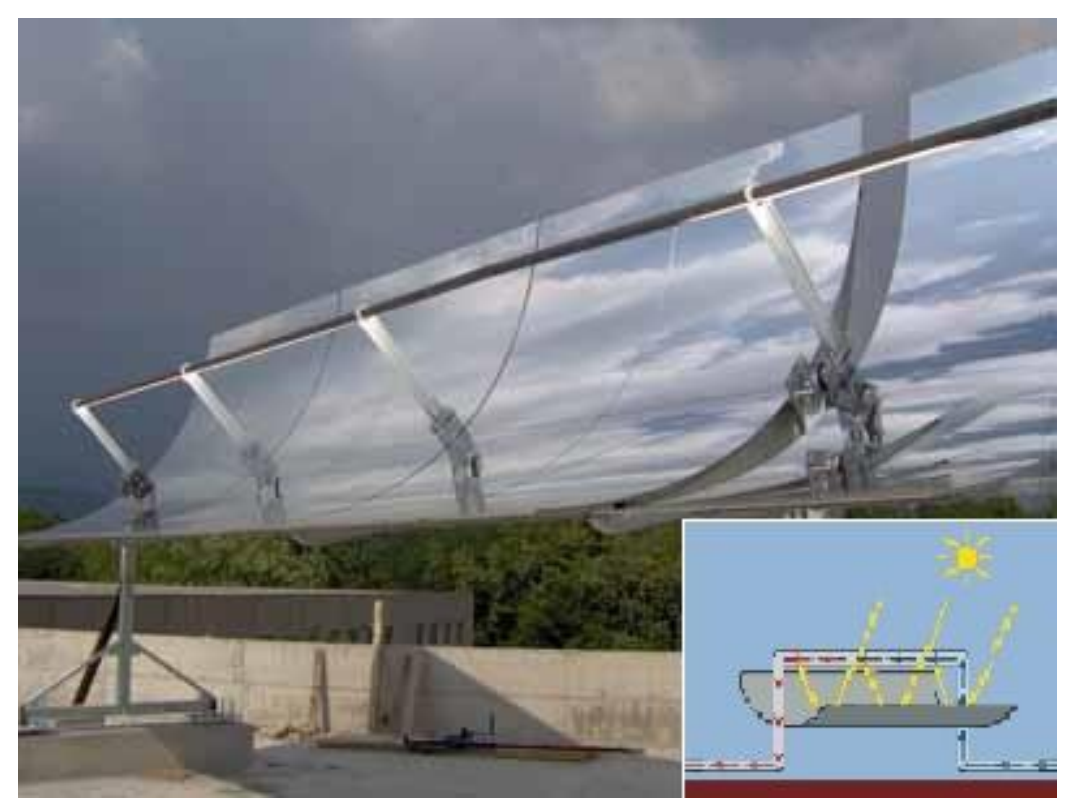

Figura 1.2 - Coletor solar parabólico (figura retirada de Faria, C. F. C.).

Observa-se no canto direito inferior da Figura 1.2, o esquema do funcionamento do coletor solar parabólico. 


\subsubsection{Máquina a Vapor}

A máquina a vapor foi fundamental para a Revolução Industrial, e nessa época era utilizada em diversos setores industriais, bem como em transporte, através das locomotivas a vapor.

Porém, com o surgimento dos motores de combustão interna e das turbinas, houve a decadência do uso das máquinas a vapor, e deste modo a tecnologia das mesmas permaneceu estagnada.

A micromáquina a vapor consiste basicamente em um pistão que apresenta movimento alternativo. Através de um mecanismo biela-manivela transmite este movimento para uma roda de inércia, que aciona um gerador elétrico. Pode-se observar o projeto e protótipo iniciais (Bassi e Machado (2011)) da micromáquina a vapor na Figura 1.3:
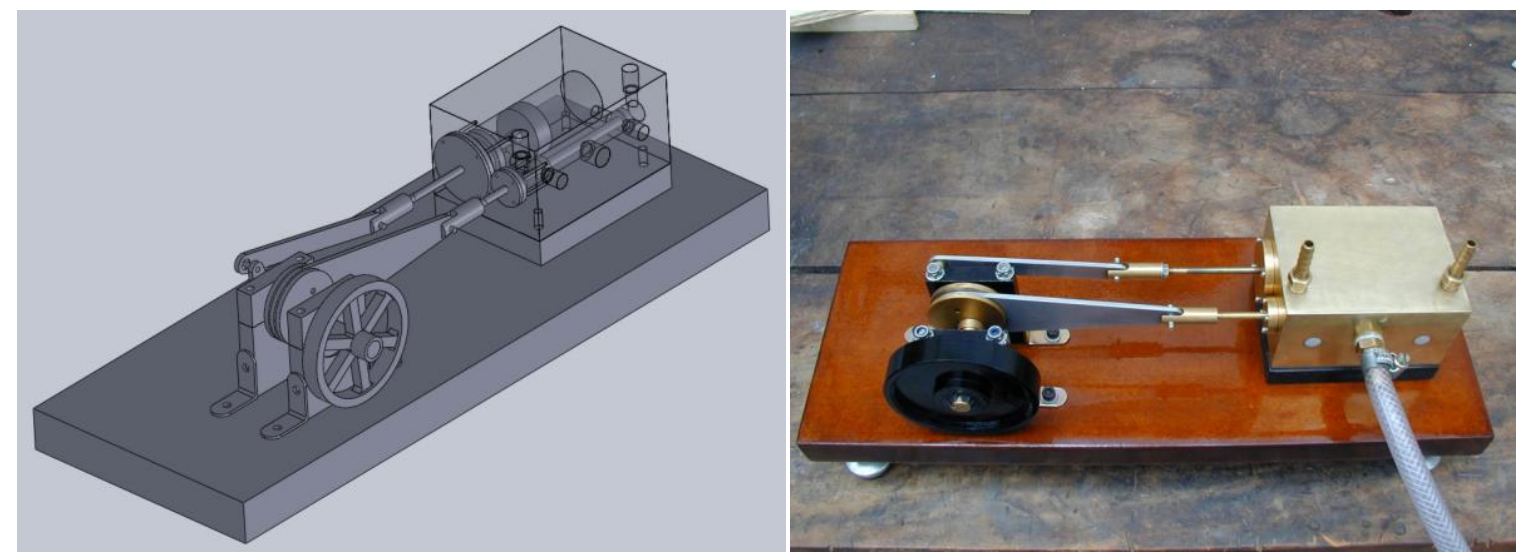

Figura 1.3 - Sistema mecânico da micromáquina a vapor: (a) projeto e (b) protótipo. 


\subsubsection{Condensador}

O condensador é fundamentalmente um trocador de calor, no qual se rejeita calor, transformando vapor em líquido. De acordo com o Enunciado de Kelvin-Planck da segunda lei da termodinâmica:

"É impossível para qualquer sistema operar em um ciclo termodinâmico e entregar uma quantidade líquida de trabalho para suas vizinhanças, enquanto recebe energia por transferência de calor de um único reservatório térmico".

Portanto, de acordo com esta lei da termodinâmica, em qualquer planta térmica que tem por finalidade gerar trabalho são necessários dois reservatórios térmicos. Como dito anteriormente, neste caso as duas fontes são o coletor parabólico solar (fonte de calor) e o condensador (rejeita calor).

\subsubsection{Bomba}

A bomba é o componente responsável por impor pressão e vazão mássica sobre o fluido na entrada do gerador de vapor. Caso o fluido esteja no estado gasoso durante este processo, costuma-se utilizar um compressor. Para acionar a bomba é necessário utilizar parte da energia gerada. 


\subsubsection{Gerador Elétrico}

O gerador síncrono é capaz de converter energia mecânica em elétrica, quando operado como gerador; e energia elétrica em mecânica, quando operado como motor. Os geradores síncronos são utilizados na grande maioria das centrais hidrelétricas e termoelétricas.

O nome síncrono se deve ao fato de que esta máquina opera com uma velocidade angular constante. $E$ a frequência da tensão elétrica alternada gerada é sincronizada com a sua rotação.

Para que a máquina síncrona seja capaz de efetivamente converter a energia mecânica aplicada no seu eixo, é necessário que o enrolamento de campo localizado no rotor da máquina seja alimentado por uma fonte de tensão contínua de forma que ao girar, o campo magnético gerado pelos polos do rotor tenha um movimento relativo aos condutores dos enrolamentos do estator. A corrente elétrica utilizada para alimentar o campo (enrolamento do rotor) é denominada corrente de excitação. Na Figura 1.4 é apresentado um esquema para ilustrar o funcionamento do gerador síncrono:

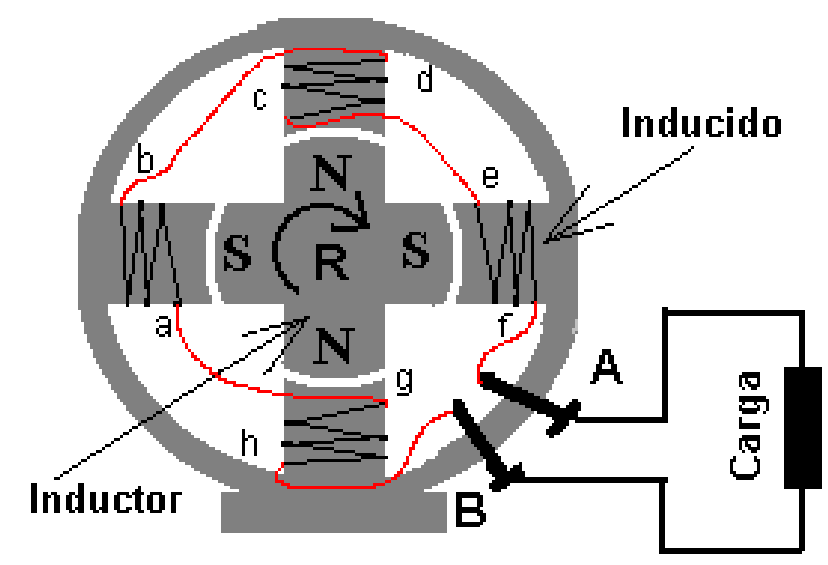

Figura 1.4 - Esquema do gerador elétrico (figura retirada de Bim, E.). 


\subsubsection{Controle}

Em conjunto à máquina a vapor será implementado um sistema de controle, visto que para a energia elétrica ser útil, é necessário que a frequência e tensão elétrica estejam de acordo com as normas de consumo (International Standard, IEC 60034-1:2004). Portanto, a frequência elétrica deve ser de $60 \mathrm{~Hz}$, com variações inferiores a $2 \%$, e a tensão elétrica de $110 \mathrm{~V}$, com variações inferiores a $5 \%$. $\mathrm{O}$ sistema de controle proposto neste trabalho é por retroalimentação, utilizando a topologia básica apresentada na Figura 1.5:

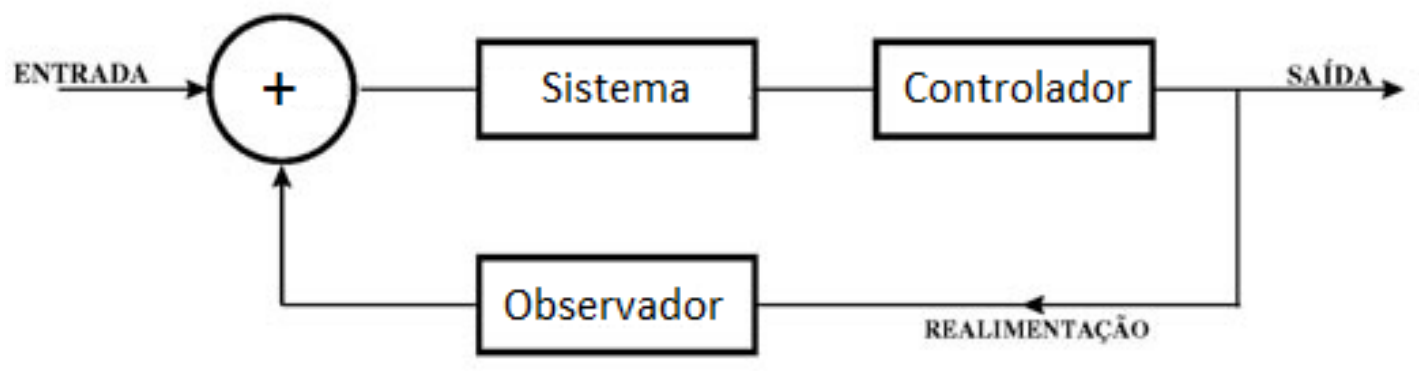

Figura 1.5 - Topologia do sistema de controle. 


\section{REVISÃO BIBLIOGRÁFICA}

Este capítulo apresenta os principais conceitos utilizados para a modelagem da máquina a vapor encontrados na literatura. A pesquisa bibliográfica, feita em trabalhos científicos e em livros, aborda os diferentes ciclos teóricos da máquina, além do esquema físico do gerador com excitatriz e suas principais características.

\subsection{Ciclos Teóricos de uma Máquina a Vapor}

Apesar de existirem inúmeros estudos sobre a máquina a vapor, muitos deles são desatualizados, superficiais ou apresentam divergências. Isto ocorre pois os conceitos de termodinâmica foram consolidados ao longo do século XIX. Porém, no início do século $X X$, as máquinas a vapor caíram em desuso, devido ao advento das turbinas e dos motores de combustão interna.

O ciclo real de uma máquina a vapor, segundo Mesny et. al. (1949) é descrito pelo diagrama PxV na Figura 2.1:

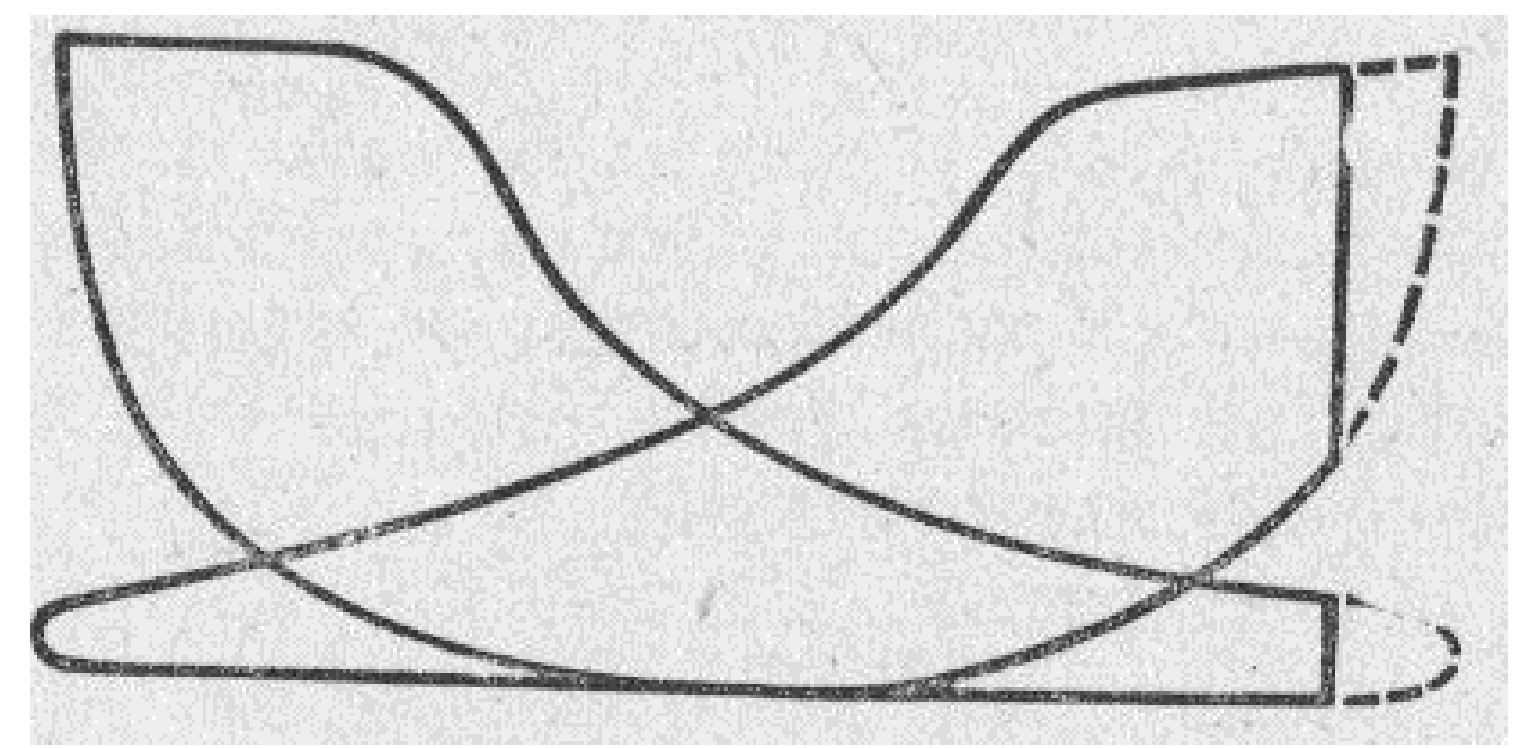

Figura 2.1 - Ciclo $P_{X} V$ real de uma máquina a vapor pressurizada em ambos os lados do pistão (figura retirada de Mesny, M.). 
Diversos ciclos teóricos são encontrados na literatura, como o ilustrado no diagrama indicado na Figura 2.2:

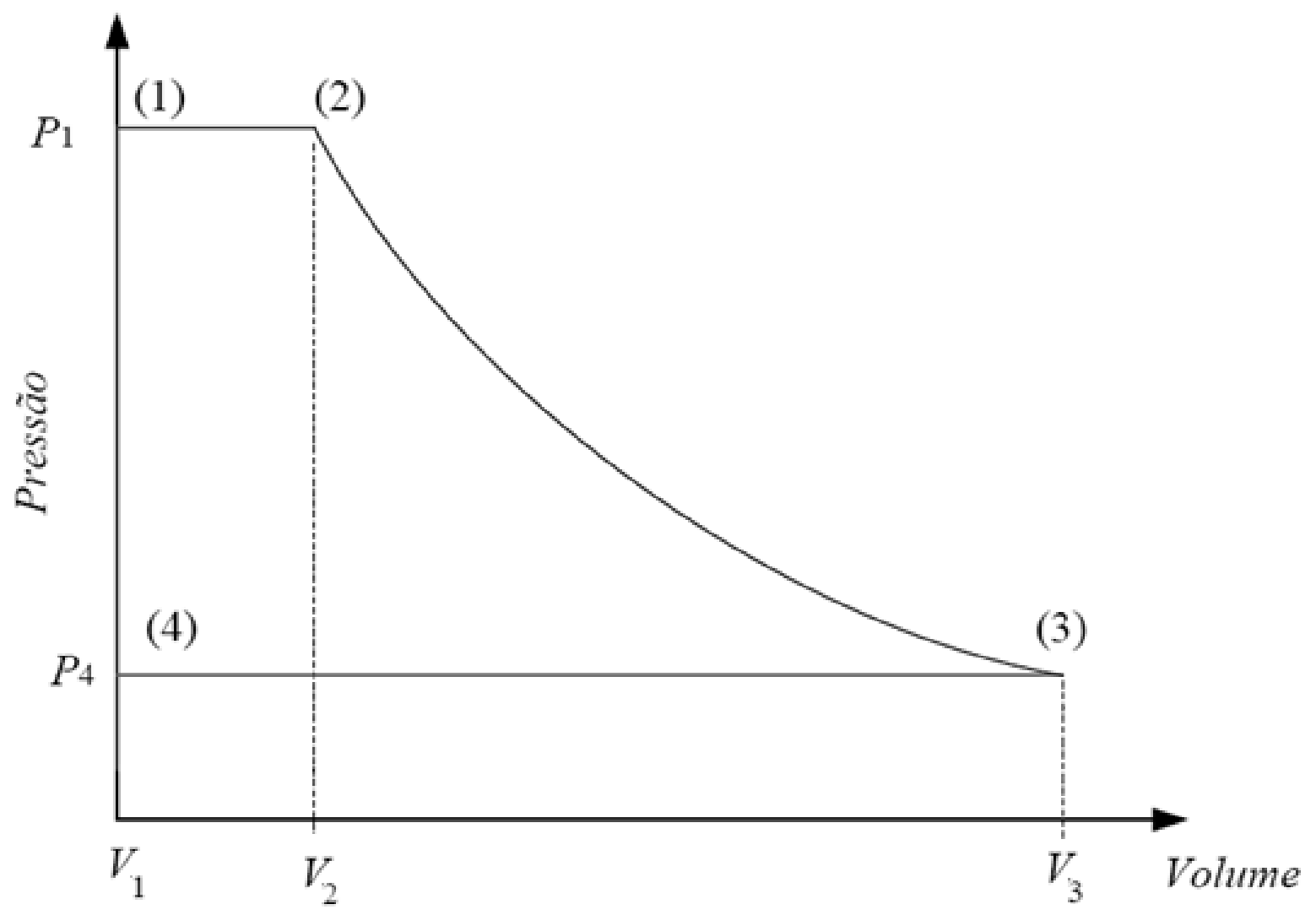

Figura 2.2 - Ciclo teórico de uma máquina a vapor utilizado por Alanne et. al. (2012).

O ciclo apresentado na Figura 2.2 é formado por dois processos isobáricos e dois processos isoentrópicos, e foi utilizado por Alanne et. al. (2012), Prasad et. al. (1993) e Mariño et. al. (1948); segundo Prasad et. al. (1993), este ciclo é o ideal. 
Outro ciclo padrão encontrado na revisão bibliográfica é mostrado na Figura 2.3:

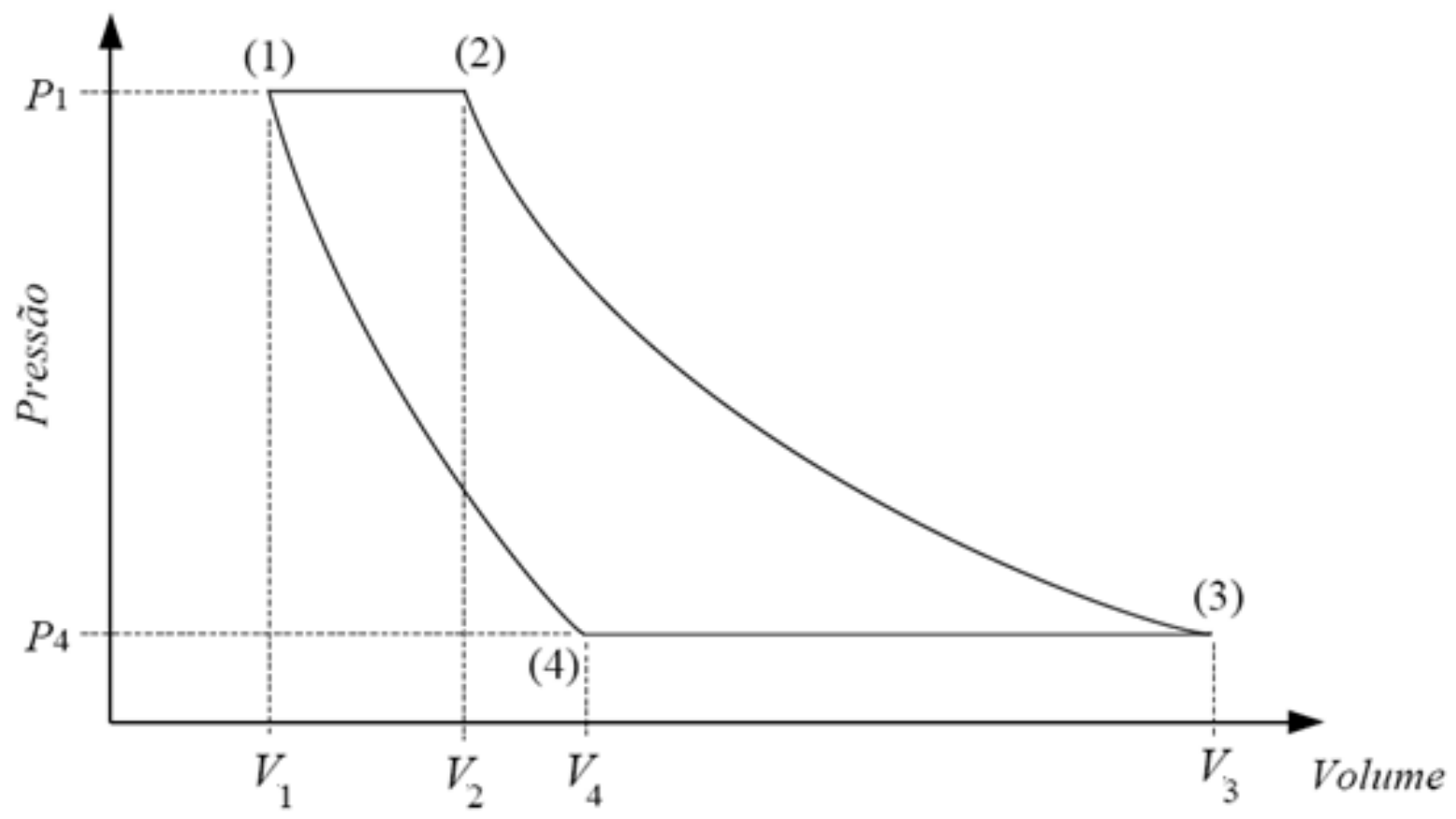

Figura 2.3 - Ciclo teórico de uma máquina a vapor utilizado por Trajkovic et. al. (2010).

O ciclo apresentado na Figura 2.3 é composto por dois processos isobáricos e dois processos isoentrópicos (a expansão e a compressão), e foi utilizado por Trajkovic et. al. (2010) e por Keenan et. al. (1966). Segundo Keenan (1966), todos os processos desse ciclo são adiabáticos e reversíveis, ou seja, é um diagrama de um motor isoentrópico. 
Antonelli et. al. (2012) e Basbous et. al. (2012) adotam o diagrama PxV da Figura 2.4, sendo mais semelhante ao ciclo real de uma máquina a vapor. Este diagrama é mostrado abaixo:

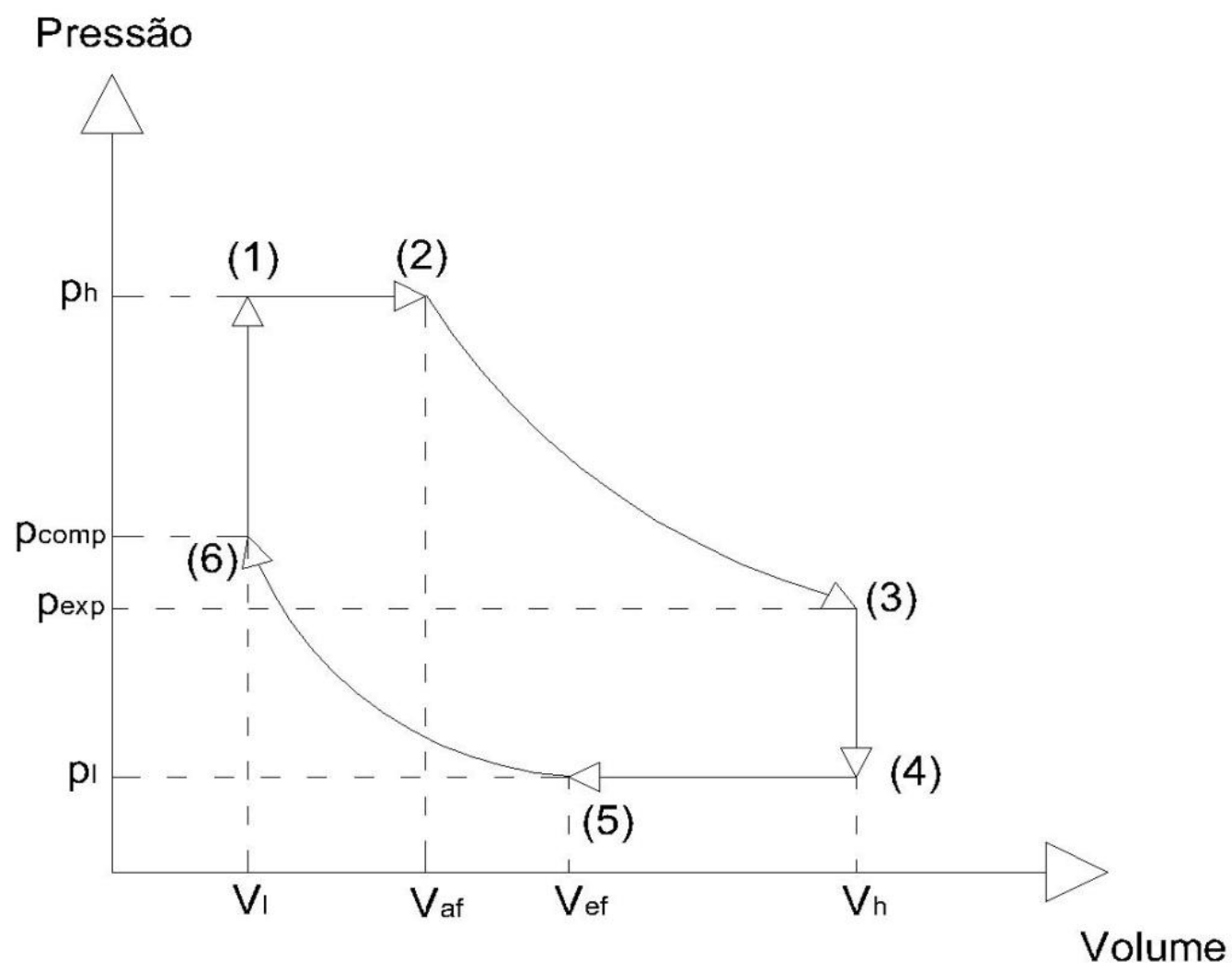

Figura 2.4 - Ciclo teórico de uma máquina a vapor adotado.

Conforme a literatura, são propostos diversos ciclos teóricos para a máquina a vapor. No entanto, segundo Unzueta et. al. (2012), o ciclo apresentado na Figura 2.4 é o mais geral, abrangendo os demais casos de acordo com os parâmetros adotados, os quais são definidos abaixo:

$\mathbf{V}_{\mathbf{l}}$ é o menor volume ocupado pelo vapor dentro do cilindro, também chamado de volume morto;

$\mathbf{V}_{\mathbf{h}}$ é o volume máximo ocupado pelo vapor, ou seja, o volume do cilindro da máquina a vapor;

$\mathbf{V}_{\mathrm{af}}$ é volume no qual a válvula de admissão fecha; 
$V_{\text {ef }}$ é o volume no qual a válvula de escape fecha;

$\mathbf{P}_{\mathbf{h}}$ é a pressão com que o vapor entra no cilindro. Em um ciclo fechado, é a pressão da caldeira;

$\mathbf{P}_{\mathbf{I}}$ é a pressão com que o vapor deixa o cilindro. Em um ciclo fechado, é a pressão do condensador;

$\mathbf{P}_{\exp }$ é a pressão atingida pela expansão total do vapor no cilindro;

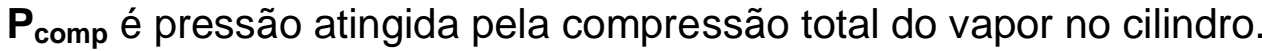

No ponto (6), a válvula de admissão é aberta e então se inicia a entrada de vapor no cilindro. Durante o processo (6)-(1), a pressão do vapor aumenta a volume constante, até que atinja a pressão da caldeira $\left(P_{h}\right)$. Após atingir tal pressão, o vapor começa a expandir a pressão constante (processo (1)-(2)).

No ponto (2), a válvula de admissão é fechada. Ao longo do processo (2)-(3), o vapor é expandido até o volume máximo do cilindro (processo politrópico).

No ponto (3), a válvula de escape é aberta e então se inicia a saída de vapor do cilindro. Durante o processo (3)-(4), a pressão do vapor diminui a volume constante até que atinja a pressão do condensador $\left(\mathrm{P}_{\mathrm{I}}\right)$. Após atingir tal pressão, o vapor começa a comprimir a pressão constante (processo (4)-(5)).

No ponto (5), a válvula de escape é fechada. Ao longo do (5)-(6), o vapor é comprimido até o volume morto (processo politrópico). 


\subsection{Gerador com Excitatriz}

A função da excitatriz é estabelecer a tensão interna do gerador síncrono. Consequentemente, o sistema de excitação é responsável não somente pela tensão de saída da máquina, mas também pela magnitude da corrente gerada e pelo fator de potência. Portanto, foi proposto o sistema elétrico descrito na Figura 2.5, conforme adaptado de Costa \& Silva (2000):

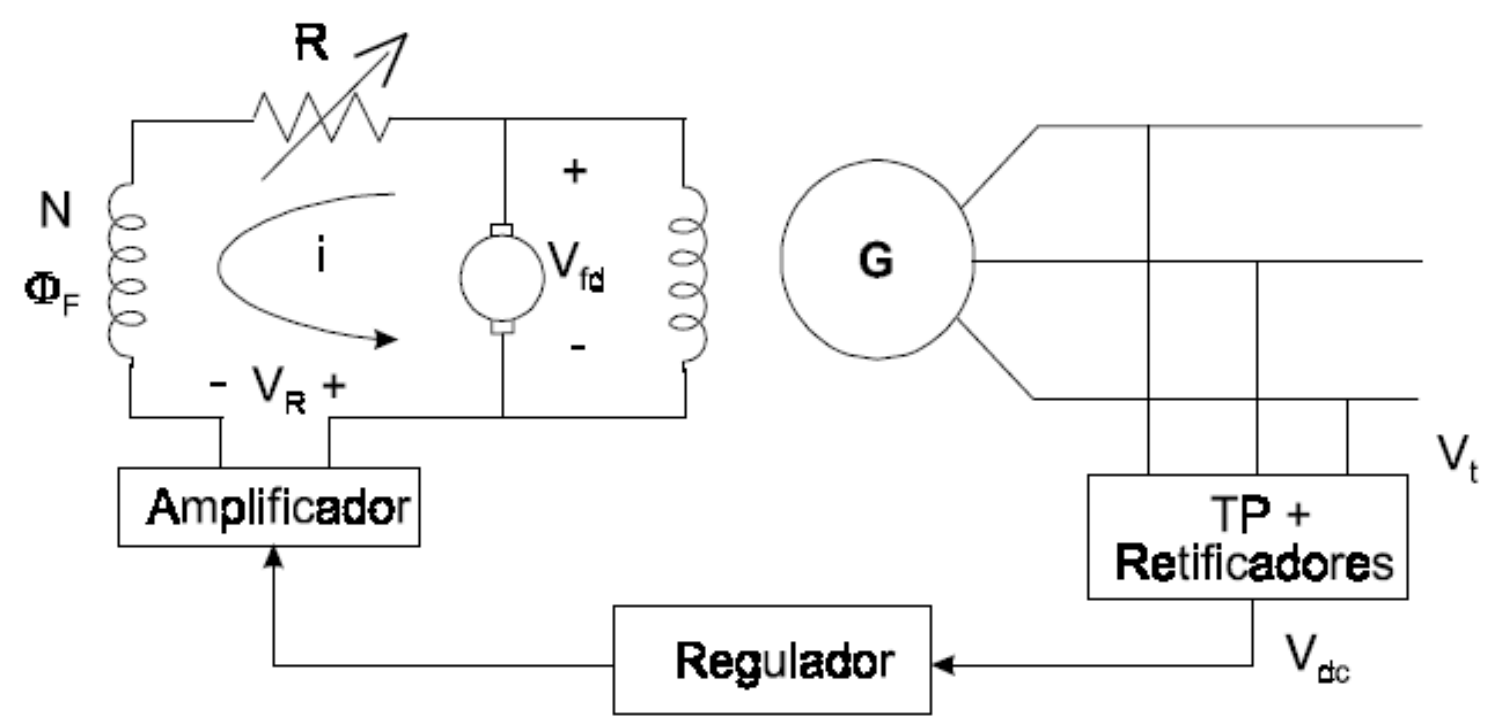

Figura 2.5 - Sistema elétrico do gerador com excitatriz.

A frequência é um indicador de que o balanço de potência ativa está sendo adequadamente cumprido, isto é, a potência ativa fornecida pelos geradores do sistema é igual à potência ativa solicitada pelas cargas. Cargas nobres, como computadores, bem como a maioria dos motores de corrente alternada industriais, são dependentes da frequência para o bom funcionamento. Logo, controlar a frequência para que permaneça em seu valor nominal é de extrema importância. 


\subsection{Série de Fourier}

Alguns dos desenvolvimentos apresentados empregaram a expansão em Série de Fourier, que de acordo com Spiegel et. al. (1976), é uma forma de representar uma dada função periódica $f(x)$ como uma somatória de senos e cossenos. Os cálculos dos coeficientes da série de Fourier são apresentados abaixo.

Termo $\mathrm{a}_{0}$ da série de Fourier:

$$
a_{0}=\frac{1}{L} \int_{-L}^{L} f(x) d x
$$

Termo $a_{n}$ da série de Fourier:

$$
a_{n}=\frac{1}{L} \int_{-L}^{L} f(x) \cdot \cos \left(\frac{n \cdot \pi \cdot x}{L}\right) d x
$$

Termo $b_{n}$ da série de Fourier:

$$
b_{n}=\frac{1}{L} \int_{-L}^{L} f(x) \cdot \sin \left(\frac{n \cdot \pi \cdot x}{L}\right) d x
$$

Finalmente, temos a série de Fourier:

$$
f(x)=\frac{a_{0}}{2}+\sum_{n=1}^{\infty} a_{n} \cdot \cos \left(\frac{n \cdot \pi \cdot x}{L}\right)+b_{n} \cdot \sin \left(\frac{n \cdot \pi \cdot x}{L}\right)
$$




\section{MODELAGEM}

Os modelos desenvolvidos neste capítulo serão simulados com parâmetros do protótipo fabricado, e posteriormente, comparados com valores experimentais. $\mathrm{O}$ novo protótipo foi projetado para o estudo experimental, mantendo características do protótipo já existente, porém com muitas modificações visando torná-lo apto a suportar mais esforços, melhorar a vedação e reduzir as perdas por atrito. As modificações são mostradas na Figura 3.1:
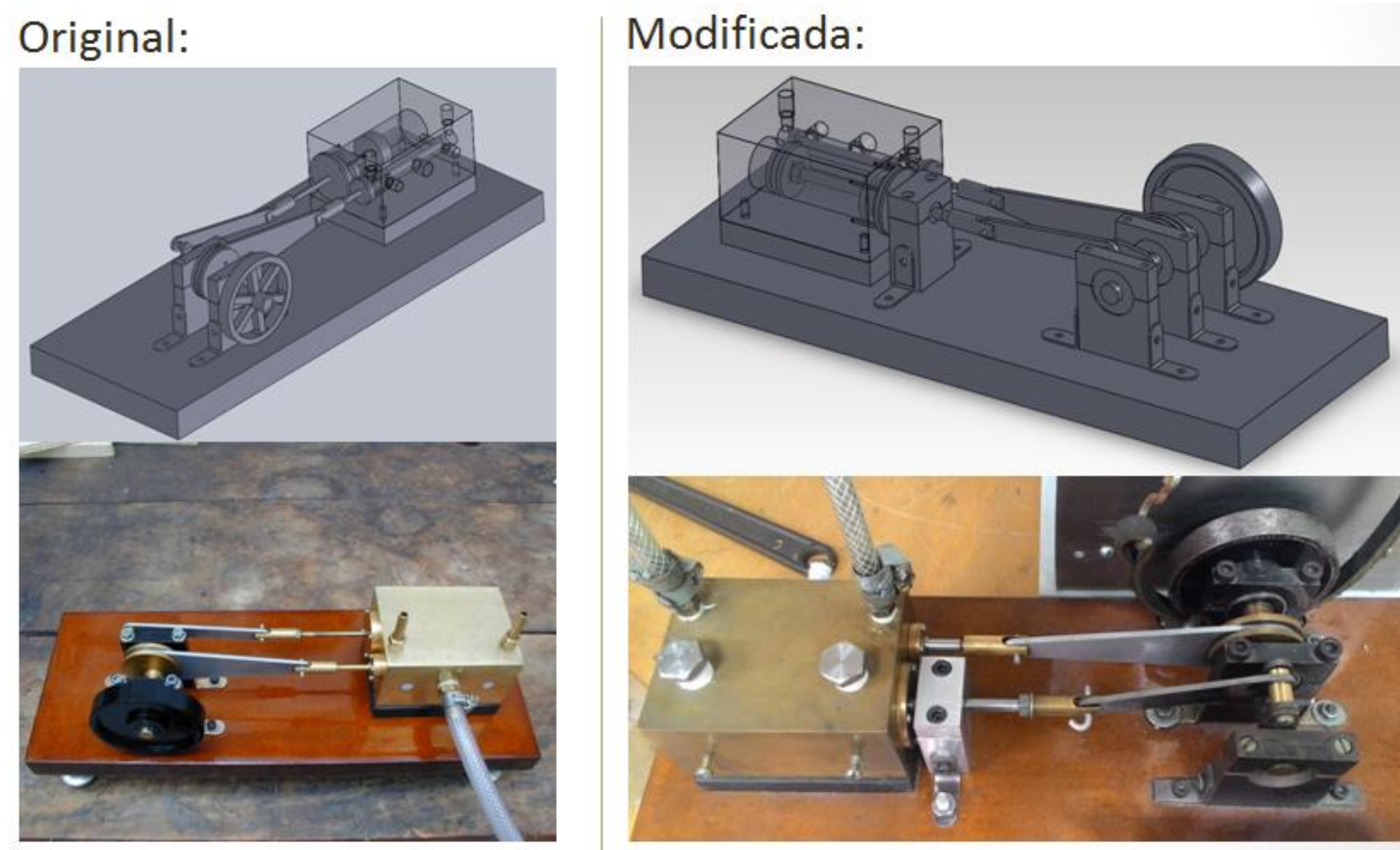

Figura 3.1 - Projeto e protótipo da micromáquina a vapor: (a) original e (b) modificado.

As seguintes peças foram modificadas ou acrescentadas para atingir os objetivos estipulados anteriormente:

- Pistão bipartido com anel de Teflon;

- Tampa do pistão com O-ring;

- Haste do pistão feita com eixo retificado de aço;

- Mancal com rolamento linear;

- Tampa da válvula com O-ring; 
- Haste da válvula feita com eixo retificado de aço;

- Biela de aço;

- Anéis da biela feito em latão;

- Espaçadores da biela de latão;

- Anéis elásticos para fixação dos rolamentos;

- Anéis de Teflon para as tampas;

- Batente de borracha.

Os desenhos, fotos e mais detalhes de cada uma das modificações são apresentados no APÊNDICE A - PROJETO DA MÁQUINA; algumas das alterações são visíveis na Figura 3.1.

A modelagem da micromáquina a vapor foi baseada em princípios da termodinâmica, mecânica clássica e eletricidade. Os subsistemas térmico, mecânico e elétrico, inicialmente, serão modelados separadamente, e serão acoplados em um modelo mais complexo para máquina toda no final. 


\subsection{Modelagem do Sistema Térmico}

A modelagem térmica da micromáquina a vapor possibilitará prever 0 diagrama $P x V$, o perfil de pressão que atua sobre o pistão, o trabalho específico isoentrópico e o rendimento isoentrópico.

Para o equacionamento do ciclo, visualizado no diagrama da Figura 2.4, foi admitido que o fluido de trabalho se comporta como gás perfeito com propriedades constantes, bem como que não há troca de calor com o meio externo nem perda de carga nas válvulas.

Processo (1) - (2):

$$
P_{12}(\theta)=P_{a d m}
$$

Processo (2) - (3):

$$
P_{23}(\theta)=P_{a d m}\left(\frac{V_{2}}{V(\theta)}\right)^{k}
$$

Processo (3) - (4):

$$
P_{34}(\theta)=\frac{P_{e s c}-P_{3}}{\theta_{4}-\theta_{3}}\left(\theta-\theta_{3}\right)+P_{3}
$$

Processo (4) - (5):

$$
P_{45}(\theta)=P_{e s c}
$$

Processo (5) - (6):

$$
P_{56}(\theta)=P_{e s c}\left(\frac{V_{5}}{V(\theta)}\right)^{k}
$$


Processo (6) - (1):

$$
P_{61}(\theta)=\frac{P_{a d m}-P_{6}}{\theta_{1}-\theta_{6}}\left(\theta-\theta_{6}\right)+P_{6}
$$

Porém, como a pressão será a entrada do sistema mecânico, é interessante que seja contínua e em função de $\theta$; para isto aproxima-se a curva da pressão por uma série de Fourier.

Termo $a_{0}$ da série de Fourier:

$$
a_{0}=\frac{1}{\pi} \int_{0}^{2 \pi} P(\theta) d \theta
$$

Termo $a_{i}$ da série de Fourier:

$$
a_{i}=\frac{1}{\pi} \int_{0}^{2 \pi} P(\theta) \cdot \cos (i \cdot \theta) d \theta
$$

Termo $b_{i}$ da série de Fourier:

$$
b_{i}=\frac{1}{\pi} \int_{0}^{2 \pi} P(\theta) \cdot \sin (i \cdot \theta) d \theta
$$

Finalmente, temos a série de Fourier:

$$
P(\theta)=\frac{a_{0}}{2}+\sum_{i=1}^{n} a_{i} \cdot \cos (i \cdot \theta)+b_{i} \cdot \sin (i \cdot \theta)
$$

Onde $n$ é o índice máximo da série. Em geral, quanto maior $n$ maior será o refinamento da série, e consequentemente, melhor será a aproximação. 
O trabalho máximo que uma máquina a vapor pode realizar seria o trabalho de uma única expansão isoentrópica da pressão de admissão até a pressão de escape. De acordo com Unzueta et. al. (2012), o trabalho específico isoentrópico é calculado através da seguinte equação:

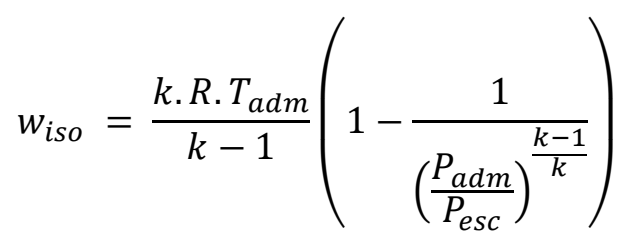

O cálculo do trabalho isoentrópico é de suma importância, pois possibilita calcular a eficiência isoentrópica. A eficiência isoentrópica permite avaliar o desempenho da máquina a vapor e compará-la com outros equipamentos de expansão, como por exemplo uma turbina. 


\subsection{Modelagem do Sistema Mecânico}

\subsubsection{Equação de Movimento}

O modelo do sistema mecânico possibilitará prever a velocidade de operação, o torque e a potência da máquina. A estimativa das perdas será feita com base em dados experimentais do protótipo.

Com base no protótipo foi proposto o esquema físico ilustrado na Figura 3.2:

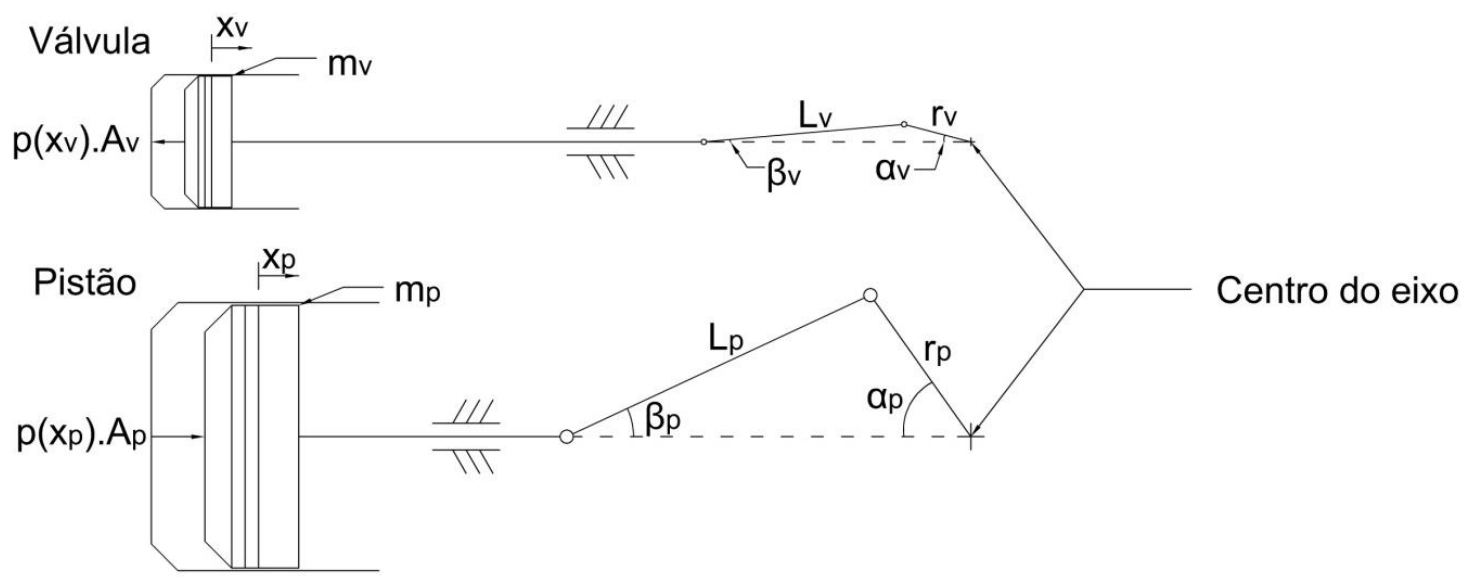

Figura 3.2 - Esquema físico do sistema mecânico.

Assim, da geometria do sistema, tem-se:

$$
\begin{aligned}
& x_{v}=\left(L_{v}+r_{v}\right)-\left(L_{v} \cdot \cos \beta_{v}+r_{v} \cdot \cos \alpha_{v}\right) \\
& x_{p}=\left(L_{p}+r_{p}\right)-\left(L_{p} \cdot \cos \beta_{p}+r_{p} \cdot \cos \alpha_{p}\right)
\end{aligned}
$$

Porém, das relações trigonométricas:

$$
\begin{aligned}
& \sin \beta_{v}=\frac{r_{v}}{L_{v}} \sin \alpha_{v} \\
& \sin \beta_{p}=\frac{r_{p}}{L_{p}} \sin \alpha_{p}
\end{aligned}
$$


Definido-se a relação biela-manivela:

$$
\begin{aligned}
& \lambda_{v}=\frac{r_{v}}{L_{v}} \\
& \lambda_{p}=\frac{r_{p}}{L_{p}}
\end{aligned}
$$

Substituindo as relações trigonométricas e biela-manivela na equação inicial:

$$
\begin{aligned}
& x_{v}=r_{v}\left[\left(1-\cos \alpha_{v}\right)+\frac{L_{v}}{r_{v}}\left(1-\sqrt{1-\lambda_{v}^{2} \cdot \sin ^{2} \alpha_{v}}\right)\right] \\
& x_{p}=r_{p}\left[\left(1-\cos \alpha_{p}\right)+\frac{L_{p}}{r_{p}}\left(1-\sqrt{1-\lambda_{p}^{2} \cdot \sin ^{2} \alpha_{p}}\right)\right]
\end{aligned}
$$

Utilizando a hipótese de barras rígidas e conhecendo a diferença de fase entre válvula e pistão é possível usar uma única coordenada generalizada:

$$
\begin{gathered}
\theta=\alpha_{v} \\
\alpha_{p}=\alpha_{v}+\varphi
\end{gathered}
$$

Reescrevendo as equações (3.18) e (3.19) em função da coordenada generalizada:

$$
\begin{gathered}
x_{v}=r_{v}\left[(1-\cos \theta)+\frac{1}{\lambda_{v}}\left(1-\sqrt{1-\lambda_{v}^{2} \cdot \sin ^{2} \theta}\right)\right] \\
x_{p}=r_{p}\left[(1-\cos (\theta+\varphi))+\frac{1}{\lambda_{p}}\left(1-\sqrt{1-\lambda_{p}^{2} \cdot \sin ^{2}(\theta+\varphi)}\right)\right]
\end{gathered}
$$

Derivando as equações (3.22) e (3.23) obtém-se a velocidade de cada uma das partes:

$$
\begin{gathered}
\dot{x}_{v}=r_{v}\left[\sin \theta \cdot \dot{\theta}+\frac{\lambda_{v}}{2}\left(1-\lambda_{v}^{2} \cdot \sin ^{2} \theta\right)^{-\frac{1}{2}} \cdot \sin (2 \cdot \theta) \cdot \dot{\theta}\right] \\
\dot{x}_{p}=r_{p}\left[\sin (\theta+\varphi) \cdot \dot{\theta}+\frac{\lambda_{p}}{2}\left(1-\lambda_{p}^{2} \cdot \sin ^{2}(\theta+\varphi)\right)^{-\frac{1}{2}} \cdot \sin (2 \cdot \theta+2 \cdot \varphi) \cdot \dot{\theta}\right]
\end{gathered}
$$


Conhecidas as velocidades e as massas de cada componente, calculam-se suas respectivas energias cinética:

$$
\begin{gathered}
K=K_{p}+K_{v}+K_{r i} \\
K=\frac{1}{2}\left(m_{p} \cdot \dot{x}_{p}^{2}+m_{v} \cdot \dot{x}_{v}^{2}+J_{r i} \cdot \dot{\theta}^{2}\right) \\
K=\frac{1}{2}\left\{m_{v} \cdot r_{v}^{2}\left[\sin \theta \cdot \dot{\theta}+\frac{\lambda_{v}}{2}\left(1-\lambda_{v}^{2} \cdot \sin ^{2} \theta\right)^{-\frac{1}{2}} \cdot \sin (2 \cdot \theta) \cdot \dot{\theta}\right]^{2}\right. \\
+m_{p} \cdot r_{p}^{2}[\sin (\theta+\varphi) \cdot \dot{\theta} \\
\left.\left.+\frac{\lambda_{p}}{2}\left(1-\lambda_{p}^{2} \cdot \sin ^{2}(\theta+\varphi)\right)^{-\frac{1}{2}} \cdot \sin (2 \cdot \theta+2 \cdot \varphi) \cdot \dot{\theta}\right]^{2}+J_{r i} \cdot \dot{\theta}^{2}\right\}
\end{gathered}
$$

Utilizando a hipótese de que as barras têm massa desprezível, pode-se concluir que a energia potencial é nula:

$$
V=0
$$

A partir da energia cinética e potencial do sistema, determina-se a função Lagrangeana:

$$
\begin{aligned}
& L=K-V \\
& L=\frac{1}{2}\left\{m_{v} \cdot r_{v}^{2}\left[\sin \theta \cdot \dot{\theta}+\frac{\lambda_{v}}{2}\left(1-\lambda_{v}^{2} \cdot \sin ^{2} \theta\right)^{-1 / 2} \cdot \sin (2 \cdot \theta) \cdot \dot{\theta}\right]^{2}\right. \\
& +m_{p} \cdot r_{p}^{2}[\sin (\theta+\varphi) \cdot \dot{\theta} \\
& \left.\left.+\frac{\lambda_{p}}{2}\left(1-\lambda_{p}^{2} \cdot \sin ^{2}(\theta+\varphi)\right)^{-\frac{1}{2}} \cdot \sin (2 \cdot \theta+2 \cdot \varphi) \cdot \dot{\theta}\right]^{2}+J_{r i} \cdot \dot{\theta}^{2}\right\}
\end{aligned}
$$

Cálculo da função de Rayleigh:

$$
R=\frac{1}{2} c_{\theta} \cdot \dot{\theta}^{2}
$$


Cálculo das forças generalizadas:

$$
\begin{gathered}
Q_{\theta}=P\left(x_{p}\right) \cdot A_{p} \frac{\partial x_{p}}{\partial \theta}-P\left(x_{v}\right) \cdot A_{v} \frac{\partial x_{v}}{\partial \theta} \\
Q_{\theta}=P\left(x_{p}\right) \cdot A_{p} \cdot r_{p}\left[\sin (\theta+\varphi)+\frac{\lambda_{p}}{2}\left(1-\lambda_{p}^{2} \cdot \sin ^{2}(\theta+\varphi)\right)^{-\frac{1}{2}} \cdot \sin (2 \cdot \theta+2 \cdot \varphi)\right] \\
-P\left(x_{v}\right) \cdot A_{v} \cdot r_{v}\left[\sin \theta+\frac{\lambda_{v}}{2}\left(1-\lambda_{v}^{2} \cdot \sin ^{2} \theta\right)^{-\frac{1}{2}} \cdot \sin (2 \cdot \theta)\right]
\end{gathered}
$$

Pelo teorema de Lagrange:

$$
\frac{\partial}{\partial t}\left(\frac{\partial L}{\partial \dot{\theta}}\right)-\frac{\partial L}{\partial \theta}+\frac{\partial R}{\partial \dot{\theta}}=Q_{\theta}
$$

Portanto, desmembrando os termos da equação anterior:

$$
\begin{aligned}
\frac{\partial L}{\partial \dot{\theta}}=\left\{m_{v} \cdot r_{v}^{2}[\right. & \left.\sin \theta+\frac{\lambda_{v}}{2}\left(1-\lambda_{v}^{2} \cdot \sin ^{2} \theta\right)^{-\frac{1}{2}} \cdot \sin (2 \cdot \theta)\right]^{2} \\
& +m_{p} \cdot r_{p}^{2}\left[\sin (\theta+\varphi)+\frac{\lambda_{p}}{2}\left(1-\lambda_{p}^{2} \cdot \sin ^{2}(\theta+\varphi)\right)^{-\frac{1}{2}} \cdot \sin (2 \cdot \theta+2 \cdot \varphi)\right]^{2} \\
& \left.+J_{r i}\right\} \dot{\theta}
\end{aligned}
$$


Derivando em relação ao tempo, obtém-se o primeiro termo da equação (3.35):

$$
\begin{aligned}
\frac{\partial}{\partial t}\left(\frac{\partial L}{\partial \dot{\theta}}\right)=\left\{m_{v}\right. & r_{v}^{2}\left[\sin \theta+\frac{\lambda_{v}}{2}\left(1-\lambda_{v}^{2} \cdot \sin ^{2} \theta\right)^{-\frac{1}{2}} \cdot \sin (2 \cdot \theta)\right]^{2} \\
& +m_{p} \cdot r_{p}^{2}\left[\sin (\theta+\varphi)+\frac{\lambda_{p}}{2}\left(1-\lambda_{p}^{2} \cdot \sin ^{2}(\theta+\varphi)\right)^{-\frac{1}{2}} \cdot \sin (2 \cdot \theta+2 \cdot \varphi)\right]^{2} \\
& \left.+J_{r i}\right\} \ddot{\theta} \\
& +2\left\{m_{v} \cdot r_{v}^{2}\left[\sin \theta+\frac{\lambda_{v}}{2}\left(1-\lambda_{v}^{2} \cdot \sin ^{2} \theta\right)^{-\frac{1}{2}} \cdot \sin (2 \cdot \theta)\right][\cos \theta\right. \\
& \left.+\frac{\lambda_{v}{ }^{3}}{4}\left(1-\lambda_{v}^{2} \cdot \sin ^{2} \theta\right)^{-\frac{3}{2}} \cdot \sin ^{2}(2 \cdot \theta)+\lambda_{v}\left(1-\lambda_{v}^{2} \cdot \sin ^{2} \theta\right)^{-\frac{1}{2}} \cdot \cos (2 \cdot \theta)\right] \\
& +m_{p} \cdot r_{p}^{2}\left[\sin ^{2}(\theta+\varphi)\right. \\
& \left.+\frac{\lambda_{p}}{2}\left(1-\lambda_{p}^{2} \cdot \sin ^{2}(\theta+\varphi)\right)^{-\frac{1}{2}} \cdot \sin (2 \cdot \theta+2 \cdot \varphi)\right][\cos (\theta+\varphi) \\
& +\frac{\lambda_{p}{ }^{3}}{4}\left(1-\lambda_{p}^{2} \cdot \sin ^{2}(\theta+\varphi)\right)^{-\frac{3}{2}} \cdot \sin { }^{2}(2 \cdot \theta+2 \cdot \varphi) \\
& \left.\left.+\lambda_{p}\left(1-\lambda_{p}^{2} \cdot \sin ^{2}(\theta+\varphi)\right)^{-\frac{1}{2}} \cdot \cos (2 \cdot \theta+2 \cdot \varphi)\right]\right\} \dot{\theta}^{2}
\end{aligned}
$$

Derivando a função Lagrangeana em relação à coordenada generalizada, obtém-se o segundo termo da equação (3.35):

$$
\begin{aligned}
\frac{\partial L}{\partial \theta}=\left\{m_{v} \cdot r_{v}^{2}[\right. & \left.\sin \theta+\frac{\lambda_{v}}{2}\left(1-\lambda_{v}^{2} \cdot \sin ^{2} \theta\right)^{-\frac{1}{2}} \cdot \sin (2 \cdot \theta)\right][\cos \theta \\
& \left.+\frac{\lambda_{v}{ }^{3}}{4}\left(1-\lambda_{v}^{2} \cdot \sin ^{2} \theta\right)^{-\frac{3}{2}} \cdot \sin ^{2}(2 \cdot \theta)+\lambda_{v}\left(1-\lambda_{v}^{2} \cdot \sin ^{2} \theta\right)^{-\frac{1}{2}} \cdot \cos (2 \cdot \theta)\right] \\
& +m_{p} \cdot r_{p}^{2}[\sin (\theta+\varphi) \\
& \left.+\frac{\lambda_{p}}{2}\left(1-\lambda_{p}^{2} \cdot \sin ^{2}(\theta+\varphi)\right)^{-\frac{1}{2}} \cdot \sin (2 \cdot \theta+2 \cdot \varphi)\right][\cos (\theta+\varphi) \\
& +\frac{\lambda_{p}{ }^{3}}{4}\left(1-\lambda_{p}^{2} \cdot \sin ^{2}(\theta+\varphi)\right)^{-\frac{3}{2}} \cdot \sin ^{2}(2 \cdot \theta+2 \cdot \varphi) \\
& \left.\left.+\lambda_{p}\left(1-\lambda_{p}^{2} \cdot \sin ^{2}(\theta+\varphi)\right)^{-\frac{1}{2}} \cdot \cos (2 \cdot \theta+2 \cdot \varphi)\right]\right\} \dot{\theta}^{2}
\end{aligned}
$$


Derivando a função Rayleigh em relação à derivada da coordenada generalizada, obtém-se o terceiro termo da equação (3.35):

$$
\frac{\partial R}{\partial \dot{\theta}}=c_{\theta} \cdot \dot{\theta}
$$

Portanto, a equação diferencial do sistema com o acréscimo de um torque resistivo é:

$$
\begin{aligned}
\left\{m_{v} \cdot r_{v}^{2}[\sin \theta+\right. & \left.\frac{\lambda_{v}}{2}\left(1-\lambda_{v}^{2} \cdot \sin ^{2} \theta\right)^{-\frac{1}{2}} \cdot \sin (2 \cdot \theta)\right]^{2} \\
& +m_{p} \cdot r_{p}^{2}\left[\sin (\theta+\varphi)+\frac{\lambda_{p}}{2}\left(1-\lambda_{p}^{2} \cdot \sin ^{2}(\theta+\varphi)\right)^{-\frac{1}{2}} \cdot \sin (2 \cdot \theta+2 \cdot \varphi)\right]^{2} \\
& \left.+J_{r i}\right\} \ddot{\theta} \\
& +\left\{m_{v} \cdot r_{v}^{2}\left[\sin \theta+\frac{\lambda_{v}}{2}\left(1-\lambda_{v}^{2} \cdot \sin ^{2} \theta\right)^{-\frac{1}{2}} \cdot \sin (2 \cdot \theta)\right][\cos \theta\right. \\
& \left.+\frac{\lambda_{v}{ }^{3}}{4}\left(1-\lambda_{v}^{2} \cdot \sin ^{2} \theta\right)^{-\frac{3}{2}} \cdot \sin ^{2}(2 \cdot \theta)+\lambda_{v}\left(1-\lambda_{v}^{2} \cdot \sin { }^{2} \theta\right)^{-\frac{1}{2}} \cdot \cos (2 \cdot \theta)\right] \\
& +m_{p} \cdot r_{p}^{2}[\sin (\theta+\varphi) \\
& \left.+\frac{\lambda_{p}}{2}\left(1-\lambda_{p}^{2} \cdot \sin ^{2}(\theta+\varphi)\right)^{-\frac{1}{2}} \cdot \sin (2 \cdot \theta+2 \cdot \varphi)\right][\cos (\theta+\varphi) \\
& +\frac{\lambda_{p}{ }^{3}}{4}\left(1-\lambda_{p}^{2} \cdot \sin ^{2}(\theta+\varphi)\right)^{-\frac{3}{2}} \cdot \sin { }^{2}(2 \cdot \theta+2 \cdot \varphi) \\
& \left.\left.+\lambda_{p}\left(1-\lambda_{p}^{2} \cdot \sin ^{2}(\theta+\varphi)\right)^{-\frac{1}{2}} \cdot \cos (2 \cdot \theta+2 \cdot \varphi)\right]\right\} \dot{\theta}^{2}+c_{\theta} \cdot \dot{\theta} \\
& =P\left(x_{p}\right) \cdot A_{p} \cdot r_{p}\left[\sin ^{2}(\theta+\varphi)\right. \\
& \left.+\frac{\lambda_{p}}{2}\left(1-\lambda_{p}^{2} \cdot \sin ^{2}(\theta+\varphi)\right)^{-\frac{1}{2}} \cdot \sin (2 \cdot \theta+2 \cdot \varphi)\right] \\
& P\left(x_{v} \cdot r_{v}\left[\sin ^{2} \theta+\frac{\lambda_{v}}{2}\left(1-\lambda_{v}^{2} \cdot \sin ^{2} \theta\right)^{-\frac{1}{2}} \cdot \sin (2 \cdot \theta)\right]-T_{r}\right. \\
& \\
& \\
&
\end{aligned}
$$




\subsubsection{Vibração do Pistão e Respectiva Haste}

O modelo da vibração do sistema pistão e respectiva haste possibilitará prever a amplitude e a frequência de oscilação do pistão, bem como qualificar se o sistema é flexível em relação às forças atuantes. Para simplificar o equacionamento, foi admitido que o conjunto pistão e haste seja representado por duas massas concentradas e uma mola, ilustrado na Figura 3.3:

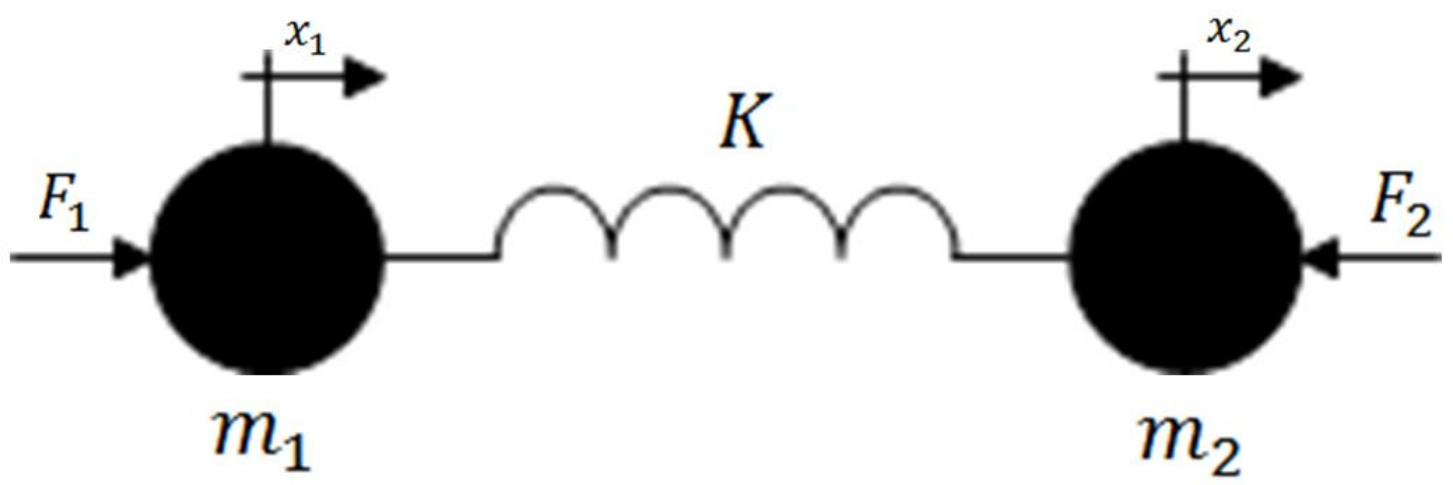

Figura 3.3 - Esquema físico da vibração do pistão.

Analisando o esquema acima, a massa concentrada 1 é equivalente à massa do pistão e metade da massa da haste. Por conseguinte, a massa concentrada 2 corresponde à metade da massa da haste, logo:

$$
\begin{gathered}
m_{1}=m_{p}+\frac{m_{h}}{2} \\
m_{2}=\frac{m_{h}}{2}
\end{gathered}
$$

Analogamente, a constante elástica da mola é igual a rigidez da haste:

$$
K=\frac{E \cdot A_{h}}{L_{h}}
$$


A força 1 é a resultante da força que o fluido exerce sobre o pistão e a força inercial da massa 1. Assim como a força 2 é a resultante da força que a biela exerce sobre a haste e a força inercial da massa 2, então:

$$
\begin{aligned}
& F_{1}=F_{f}-m_{1} a_{c r} \\
& F_{2}=F_{b}+m_{2} a_{c r}
\end{aligned}
$$

Portanto, as equações de movimento do esquema da Figura 3.3 são:

$$
\left\{\begin{array}{c}
m_{1} \ddot{x}_{1}=F_{1}-K\left(x_{1}-x_{2}\right) \\
m_{2} \ddot{x}_{2}=-F_{2}-K\left(x_{2}-x_{1}\right)
\end{array}\right.
$$

O diagrama de corpo livre do pistão é representado na Figura 3.4:

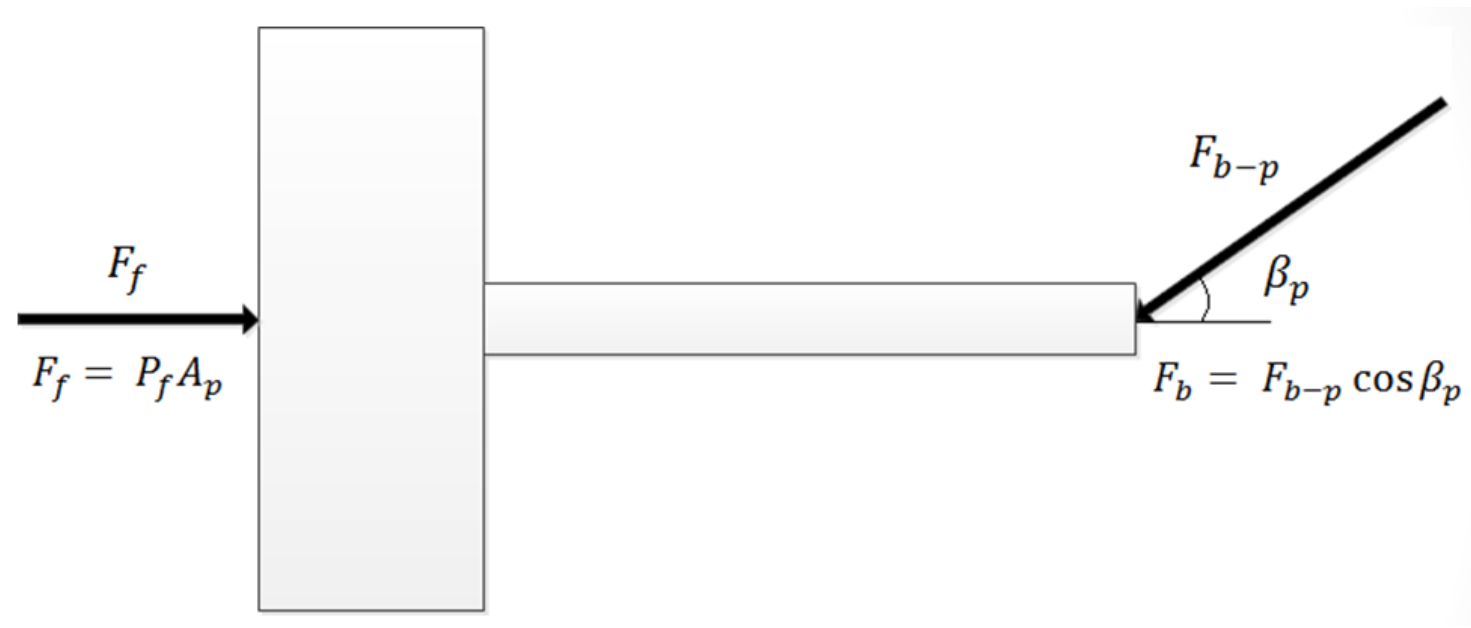

Figura 3.4 - Diagrama de corpo livre do pistão.

Logo,

$$
\left(m_{p}+m_{h}\right) a_{c r}=F_{f}-F_{b}
$$

Das equações (3.45) e (3.48), conclui-se:

$$
\therefore F_{1}=F_{2}=F_{R}=F_{f}-m_{1} a_{c r}
$$


Substituindo a equação (3.49) em (3.46) (3.47):

$$
\left\{\begin{array}{c}
m_{1} \ddot{x}_{1}+K\left(x_{1}-x_{2}\right)=F_{R} \\
m_{2} \ddot{x}_{2}+K\left(x_{2}-x_{1}\right)=-F_{R}
\end{array}\right.
$$

Portanto, a matriz de inércia e a matriz rigidez são:

$$
\begin{aligned}
\mathbb{M} & =\left[\begin{array}{cc}
m_{1} & 0 \\
0 & m_{2}
\end{array}\right] \\
\mathbb{K} & =\left[\begin{array}{cc}
K & -K \\
-K & K
\end{array}\right]
\end{aligned}
$$

A matriz dinâmica do sistema é:

$$
\mathbb{A}=\left[\begin{array}{cc}
K-\omega^{2} m_{1} & -K \\
-K & K-\omega^{2} m_{2}
\end{array}\right]
$$

Logo, o determinante da matriz anterior:

$$
\operatorname{det}(\mathbb{A})=m_{1} m_{2} \omega^{4}-K \omega^{2}\left(m_{1}+m_{2}\right)
$$

Igualando a equação (3.55) a zero, obtêm-se as frequências naturais:

$$
\begin{gathered}
\omega_{1}=0 \\
\omega_{2}=\omega_{n}=\sqrt{\frac{K\left(m_{1}+m_{2}\right)}{m_{1} \cdot m_{2}}}
\end{gathered}
$$

A primeira frequência natural é de corpo rígido. Já a segunda frequência natural pode ser excitada pelo termo forçante, a qual deve ser analisada.

Porém para calcular a resposta analítica da vibração do pistão é necessário aproximar as forças atuantes por uma série de Fourier, utilizando as equações (2.1) a (2.4). 


\subsection{Modelagem do Sistema Elétrico}

O modelo do sistema elétrico possibilitará prever a tensão gerada, a corrente e a frequência, bem como o impacto do gerador sobre a dinâmica da micromáquina a vapor, isto é, estimar o torque resistivo do gerador e seu efeito sobre a velocidade angular da máquina.

Para simplificar o modelo, foram desprezadas as dinâmicas dos transformadores de potência, dos retificadores e do amplificador rotativo. Assim como foi considerado que estão trabalhando dentro da sua faixa de operação e suas respostas são muito mais rápidas que a do gerador e da excitatriz.

Aplicando a lei das malhas de Kirchhoff ao circuito da excitatriz da Figura 2.5, obtemos:

$$
N \frac{d \phi_{F}}{d t}+R . i=v_{f d}+v_{R}
$$

Supondo que a velocidade angular do eixo seja constante, podemos afirmar que a tensão da armadura da excitatriz é proporcional ao fluxo magnético no entreferro da excitatriz:

$$
v_{f d}=k \cdot \phi_{e f}
$$

Denotando o fluxo de dispersão:

$$
\phi_{F}=\phi_{e f}+\phi_{\text {disp }}
$$

Considerando que o fluxo de dispersão pode ser determinado com uma fração constante do fluxo de campo:

$$
\phi_{F}=\sigma \cdot \phi_{e f}
$$


Substituindo a equação anterior na equação (3.59):

$$
\phi_{F}=\left(\frac{\sigma}{k}\right) \cdot v_{f d}
$$

Reescrevendo a equação (3.58):

$$
\left(\frac{N . \sigma}{k}\right) \cdot \frac{d v_{f d}}{d t}+R . i=v_{f d}+v_{R}
$$

A corrente pode ser calculada a partir da característica da saturação da excitatriz, sendo que $S_{E}^{\prime}\left(v_{f d}\right)$ é uma função não-linear que representa o acréscimo de corrente de campo exigido pela saturação:

$$
i=\frac{1}{R_{e f}} \cdot v_{f d}+S_{E}^{\prime}\left(v_{f d}\right) \cdot v_{f d}
$$

Considerando que a excitatriz não esteja saturada, pode-se desprezar termo não-linear da equação acima, logo:

$$
i=\frac{1}{R_{e f}} \cdot v_{f d}
$$

Finalmente, definindo-se:

$$
\begin{gathered}
T_{E} \triangleq \frac{N . \sigma}{k} \\
K_{E} \triangleq \frac{R}{R_{e f}}-1
\end{gathered}
$$

Pode-se escrever a equação diferencial que representa matematicamente o sistema da excitatriz:

$$
T_{E} \cdot \frac{d v_{f d}}{d t}+K_{E} \cdot v_{f d}=v_{R}
$$


A equação das tensões no circuito de campo do gerador fornece:

$$
v_{f d}=R_{f} \cdot i_{f}+L_{f} \cdot \frac{d i_{f}}{d t}
$$

A tensão terminal é dada por:

$$
v_{t}=\omega \cdot M_{f} \cdot i_{f}
$$

Definindo-se, também:

$$
\begin{gathered}
T_{G} \triangleq \frac{L_{f}}{R_{f}} \\
K_{G} \triangleq \frac{\omega \cdot M_{f}}{R_{f}}
\end{gathered}
$$

Pode-se escrever a equação diferencial que representa matematicamente o gerador:

$$
T_{G} \cdot \frac{d v_{t}}{d t}+v_{t}=K_{G} \cdot v_{f d}
$$

A partir dos parâmetros definidos anteriormente, pode-se calcular o fator de potência e o ângulo de defasagem entre a tensão e a corrente do gerador:

$$
\begin{gathered}
F P=\frac{1}{\sqrt{T_{G}^{2}+1}} \\
\Phi=\cos ^{-1}\left(\frac{1}{\sqrt{T_{G}^{2}+1}}\right)
\end{gathered}
$$

A frequência elétrica do gerador é definida por:

$$
f_{e}=\left(\frac{n_{p o ́} l o s}{2}\right) \cdot\left(\frac{\omega}{2 \cdot \pi}\right)
$$


O torque resistivo do gerador no eixo é dado por:

$$
T_{G}=\frac{v_{t}^{2}}{\omega^{2} \cdot M_{f}}
$$

Finalmente, pode-se definir outras grandezas importantes como a corrente, a potência útil e a eficiência do gerador:

$$
\begin{aligned}
i_{f} & =\frac{v_{t}}{\omega \cdot M_{f}} \\
P_{\text {útil }} & =F P \cdot v_{t} \cdot i_{f} \\
\eta_{\text {elétrica }} & =\frac{P_{\text {útil }}}{P_{\text {mecânica }}}
\end{aligned}
$$




\section{SIMULAÇÃO}

Com base nas equações desenvolvidas no capítulo anterior, são determinados os parâmetros de entrada do modelo. Os valores dos parâmetros de entrada são obtidos através de medições, cálculos ou são retirados da literatura. Com auxílio do software Matlab foi implementado um script para realizar as simulações, que se encontra no APÊNDICE B - ALGORITMO DAS SIMULAÇÕES EM MATLAB.

\subsection{Sistema Térmico}

Para realizar a simulação do diagrama indicado na Figura 2.4 são necessários os seguintes parâmetros:

- Ângulos dos pontos 1 a 6 do ciclo - foram medidos através do modelo 3D da máquina. Assume-se que o ângulo de abertura/fechamento da válvula corresponde à posição em que a válvula se encontra metade aberta e metade fechada.

Tabela 4.1 - Medidas do ângulos do ciclo da máquina.

\begin{tabular}{cc}
\hline Ponto & Ângulo Medido \\
\hline 1 & $0^{\circ}$ \\
2 & $66,6^{\circ}$ \\
3 & $114,2^{\circ}$ \\
4 & $180^{\circ}$ \\
5 & $244,2^{\circ}$ \\
6 & $293,8^{\circ}$ \\
\hline
\end{tabular}

- Pressão de admissão - pressão de admissão do sistema.

$$
P_{a d m}=3,0 \text { bar }
$$


- Pressão de escape - pressão de escape do sistema.

$$
P_{e s c}=1,0 \mathrm{bar}
$$

- Expoente do processo politrópico - a máquina será ensaiada com ar comprimido e, portanto, de acordo com Van Wylen et. al. (2003), tem-se que o expoente para processo isoentrópico é 1,4.

$$
k=1,4
$$

- Volume morto - para se obter o volume morto do sistema é necessário medir a distância entre o pistão posicionado no fim de curso e o fundo da câmara. Também é necessário mensurar o diâmetro do pistão. Para tais medidas foi utilizado o modelo 3D da máquina.

$$
\begin{gathered}
x_{m}=10 \mathrm{~mm} \\
d_{p}=30 \mathrm{~mm} \\
\therefore V_{m}=7,07 \cdot 10^{-6} \mathrm{~m}^{3}
\end{gathered}
$$

Os parâmetros e seus respectivos valores foram sumarizados no APÊNDICE

\section{C - PARÂMETROS DAS SIMULAÇÕES.}

O diagrama de blocos para as simulações do sistema térmico é mostrado na Figura 4.1:

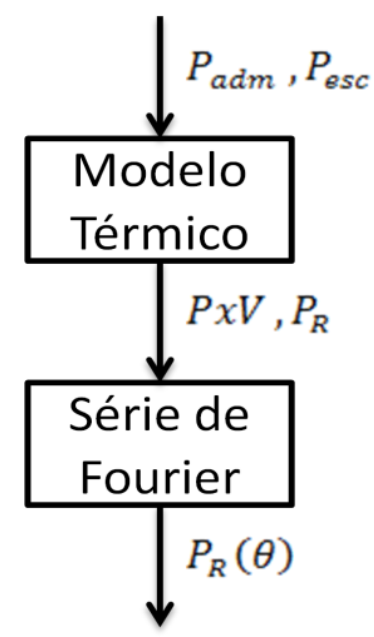

Figura 4.1 - Diagrama de blocos para as simulações do sistema térmico. 
Então, implementando as equações (3.1) a (3.6) com estes parâmetros, obtém-se a Figura 4.2:

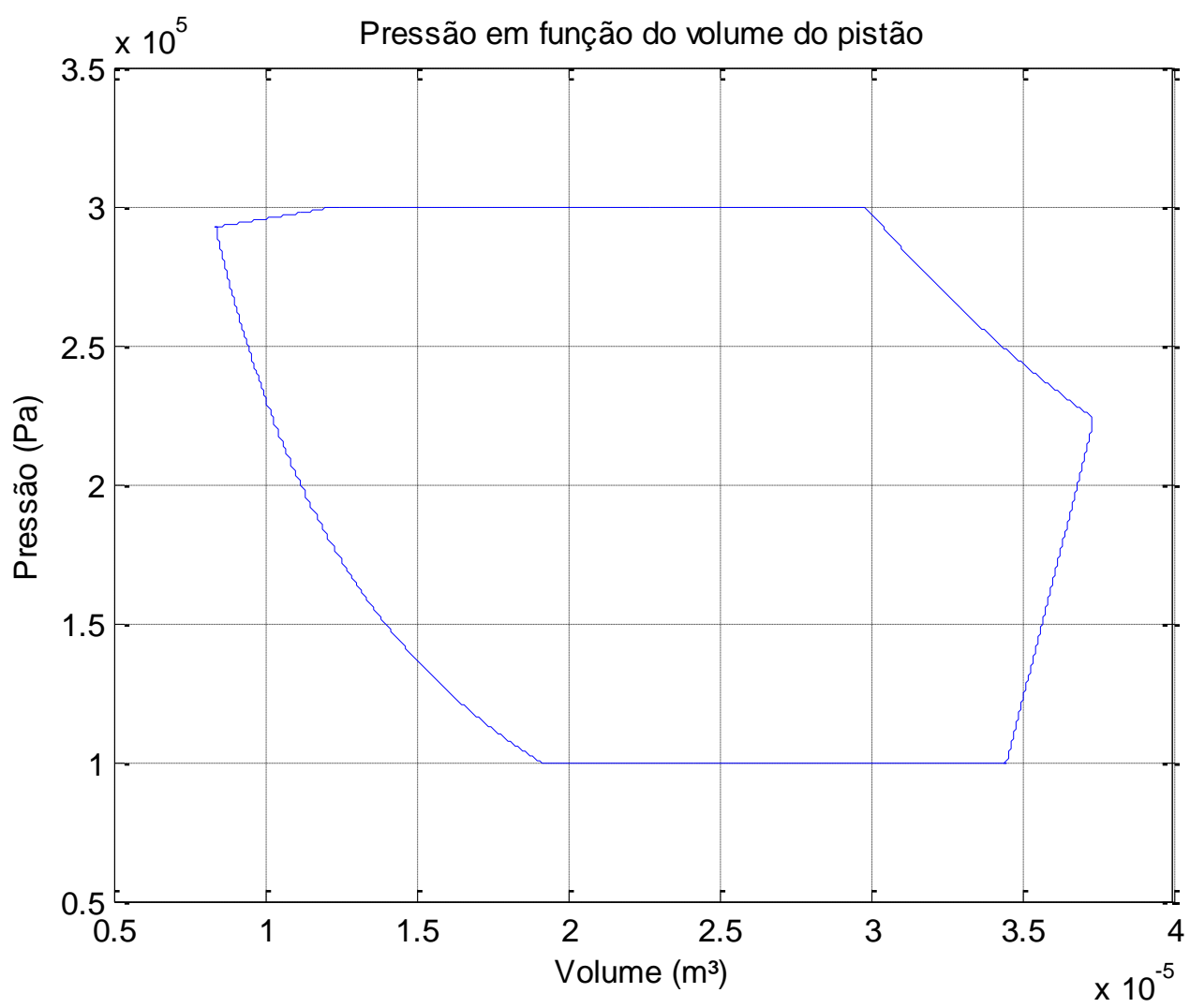

Figura 4.2 - Simulação do diagrama indicado da máquina a vapor.

Observa-se que os processos (3)-(4) e (6)-(1) do ciclo teórico (Figura 2.4) não são possíveis: como o pistão está sempre em movimento devido ao mecanismo da biela-manivela, não são possíveis processos a volume constante.

Analisando o diagrama indicado simulado, o volume de ar dentro do pistão nunca se anula. $O$ volume mínimo é de aproximadamente $0,7.10^{-5} \mathrm{~m}^{3}$ e corresponde ao volume morto do pistão. 
Porém a máquina a vapor estudada é pressurizada em ambos os lados do pistão e, portanto, é necessário simular a pressão do outro lado do pistão; o resultado da simulação é mostrado na Figura 4.3:

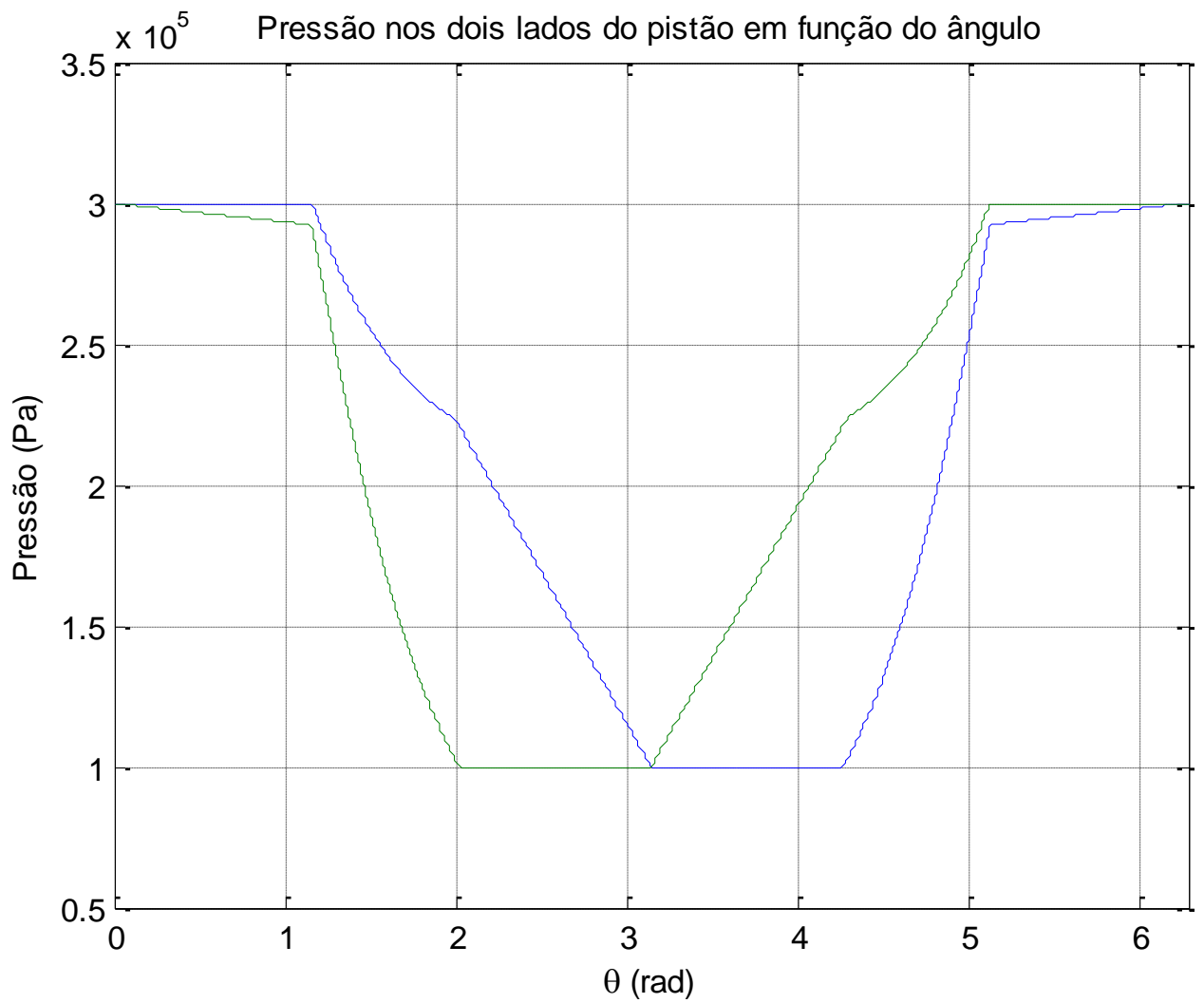

Figura 4.3 - Simulação da pressão em ambos os lados do pistão.

Observa-se na Figura 4.3 que o diagrama da pressão correspondente à outra face do pistão é simétrico em relação a $\theta=\pi$. Fisicamente, significa que enquanto em uma face do pistão o ar está sendo comprimido, na outra, o ar está sendo expandido. 
Finalmente, a pressão resultante no pistão corresponde a diferença entre o perfil de pressão de cada face do pistão, obtendo-se assim o gráfico da Figura 4.4:

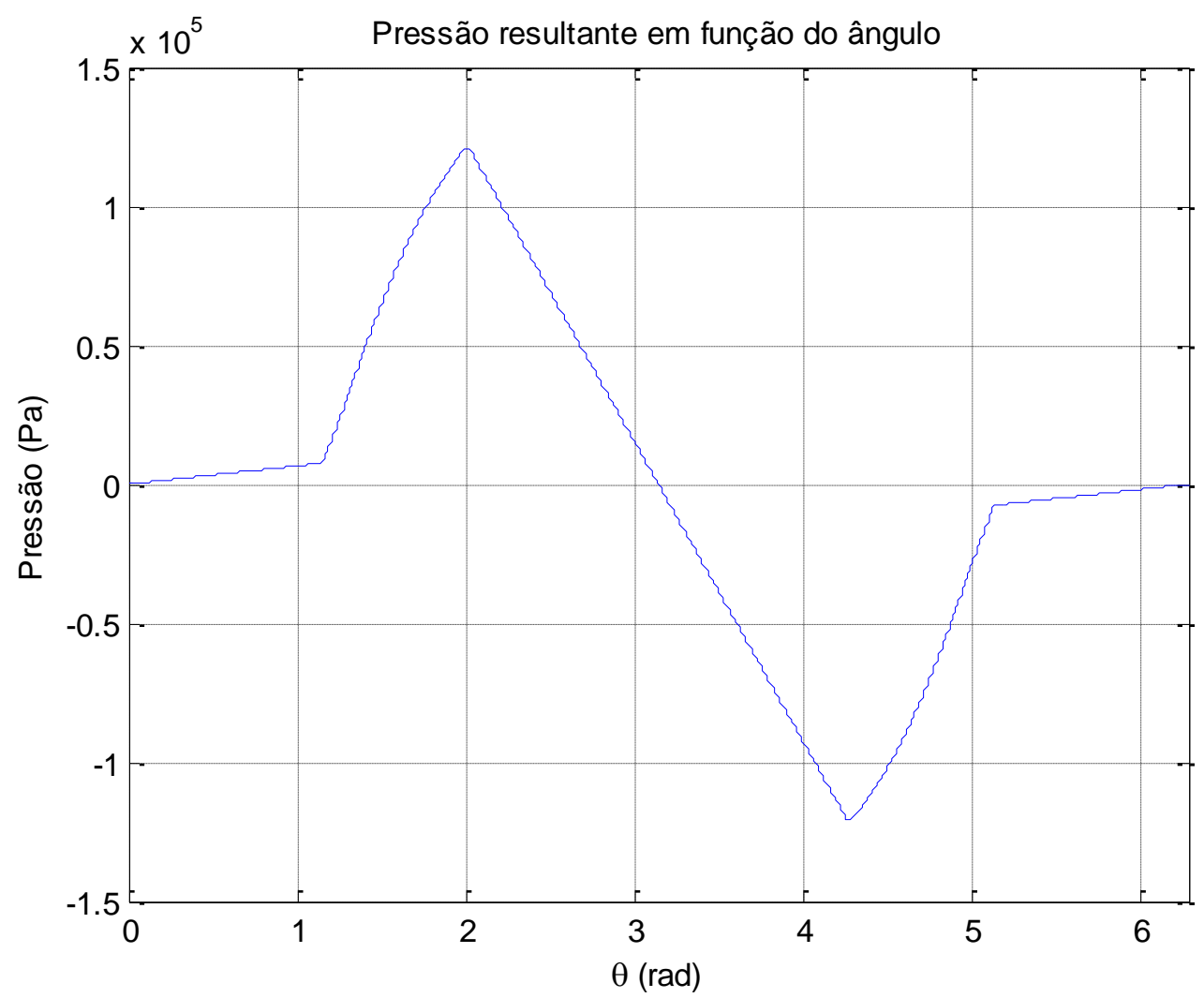

Figura 4.4 - Simulação da pressão resultante no pistão.

Observa-se que o perfil de pressão resultante é simétrico, conforme o esperado, e que há pressões negativas. Interpretando fisicamente, o pistão está sendo puxado, ao invés de empurrado, para o referencial adotado.

Logo, este é o perfil de pressão que rege o movimento do pistão, realizando trabalho. A pressão resultante fornecerá subsídios para o modelo mecânico. 
Como visto anteriormente, para a simulação do sistema mecânico é de grande interesse representar a pressão em uma função contínua, cuja variável seja a posição angular. Portanto, aproximando o ciclo por uma série de Fourier com $n=100$, tem-se:

Tabela 4.2 - Amplitude e fase dos 10 primeiros termos da série de Fourier da pressão resultante.

\begin{tabular}{c|cc}
\hline $\mathbf{i}$ & $\mathbf{A}(\mathbf{P a})$ & $\boldsymbol{\phi}(\mathbf{r a d})$ \\
\hline $\mathbf{1}$ & 69254 & $-7,05 \mathrm{E}-06$ \\
\hline $\mathbf{2}$ & 44847 & $-3,95 \mathrm{E}-06$ \\
\hline $\mathbf{3}$ & 4963 & $-1,08 \mathrm{E}-05$ \\
\hline $\mathbf{4}$ & 14949 & $-7,87 \mathrm{E}-06$ \\
\hline $\mathbf{5}$ & 591 & $9,31 \mathrm{E}-05$ \\
\hline $\mathbf{6}$ & 3937 & $-1,14 \mathrm{E}-05$ \\
\hline $\mathbf{7}$ & 44 & $1,72 \mathrm{E}-03$ \\
\hline $\mathbf{8}$ & 681 & $-2,08 \mathrm{E}-05$ \\
\hline $\mathbf{9}$ & 169 & $2,80 \mathrm{E}-04$ \\
\hline $\mathbf{1 0}$ & 1893 & $-2,23 \mathrm{E}-05$ \\
\hline
\end{tabular}

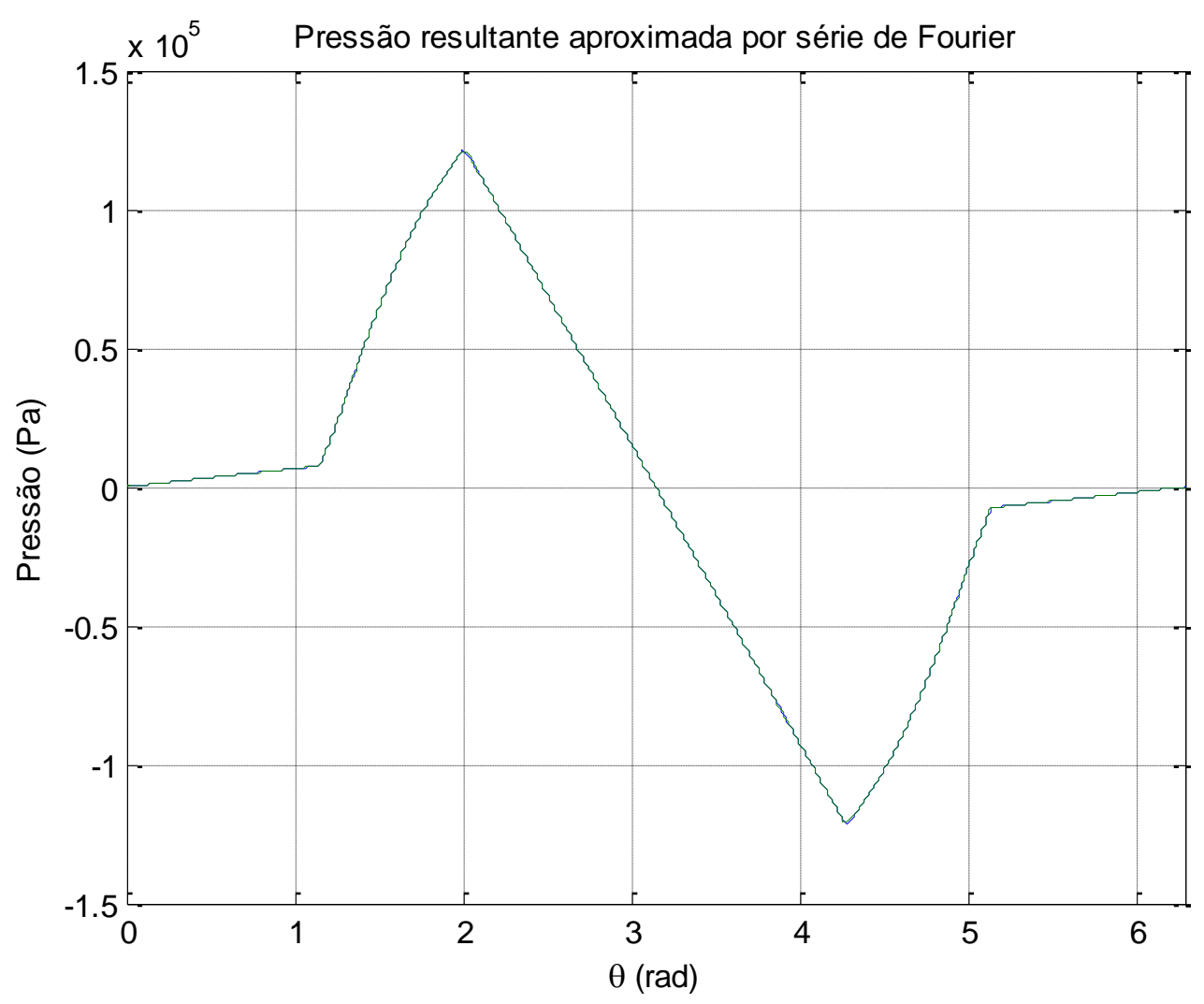

Figura 4.5 - Simulação da pressão aproximada por série de Fourier. 
Analisando o gráfico da Figura 4.5, observa-se que a pressão aproximada por série de Fourier (linha azul) se sobrepõe à função pressão calculada anteriormente (linha verde), concluindo-se que aproximação é satisfatória. Porém para realizar uma análise mais crítica, calcula-se a diferença entre a pressão calculada e a pressão aproximada por série de Fourier, obtendo-se o gráfico do erro na Figura 4.6:

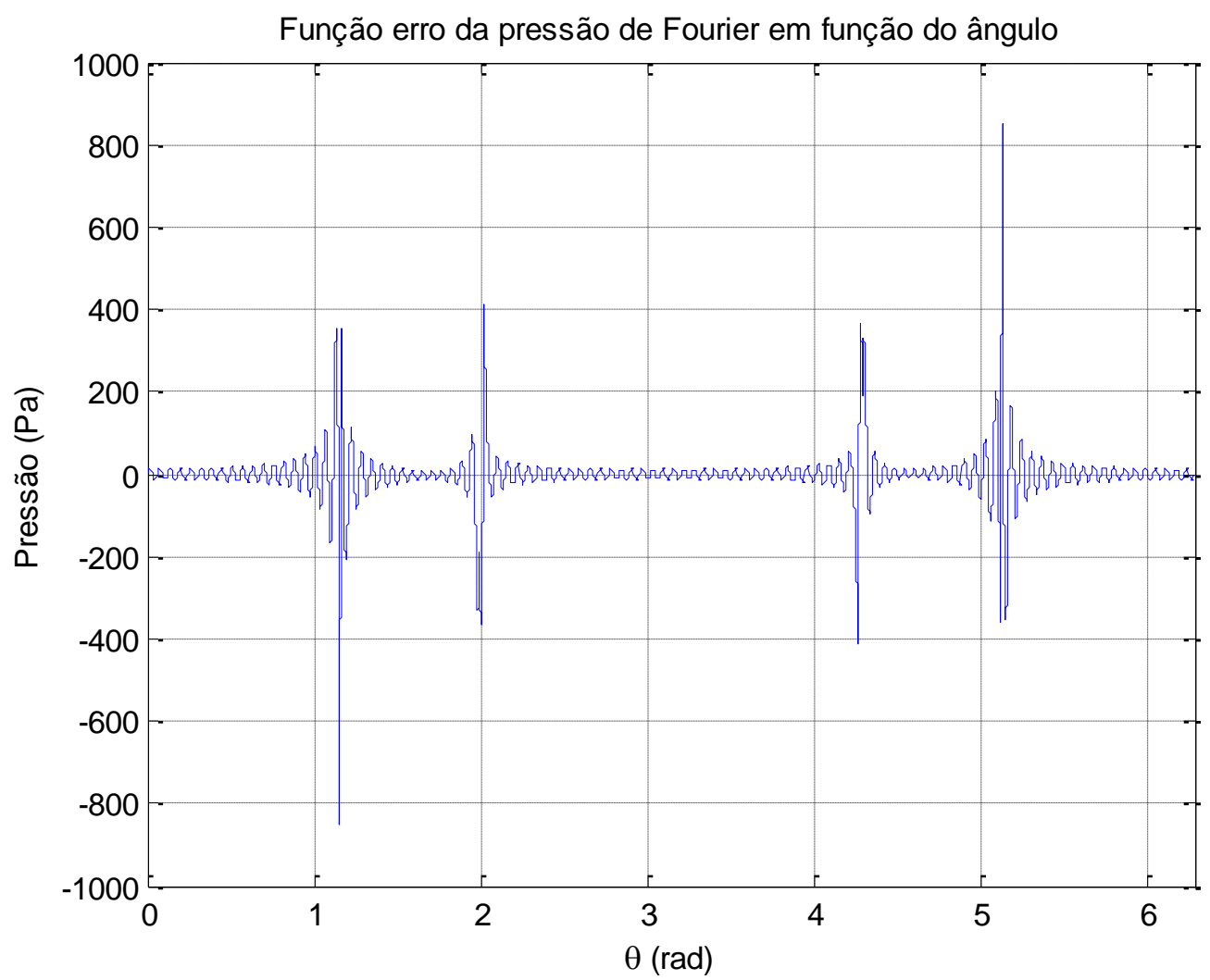

Figura 4.6 - Erro da série de Fourier.

Como visto no gráfico, os maiores erros ocorrem nas descontinuidades das pressões, isto é, onde a função da pressão se altera. Os maiores erros são da ordem de $800 \mathrm{~Pa}$, enquanto a pressão mínima no pistão é da ordem $1,0.10^{5} \mathrm{~Pa}$. Calculando o erro percentual na condição mais crítica, isto é, maior erro e menor medida, resulta em $0,8 \%$. Logo, pode-se afirmar que o erro em todo ciclo é menor ou igual a $0,8 \%$ da medida, sendo assim uma boa aproximação.

A série de Fourier da pressão resultante é de extrema importância, pois é a entrada do sistema mecânico que será simulado no item a seguir. 


\subsection{Sistema Mecânico}

\subsubsection{Propriedades para a Simulação Dinâmica}

Assim como no sistema térmico, inicialmente foi feito o levantamento dos parâmetros:

- Comprimento da manivela da válvula - medida retirada do modelo 3D.

$$
r_{v}=5,4 \mathrm{~mm}
$$

- Comprimento da biela da válvula - medida retirada do modelo 3D.

$$
L_{v}=110,6 \mathrm{~mm}
$$

- Área da válvula - a partir do diâmetro da válvula é possível calcular sua área. Porém um dos lados da válvula possui uma haste que reduz a área da válvula, mas como a haste é de pequeno diâmetro, o efeito se torna desprezível.

$$
\begin{gathered}
d_{v}=11,5 \mathrm{~mm} \\
\therefore A_{v}=104,5 \cdot 10^{-6} \mathrm{~m}^{2}
\end{gathered}
$$

- Massa da válvula - com auxílio do modelo 3D é possível medir o volume da válvula e da literatura é determinada a densidade do latão. Assim, pode-se calcular a massa.

$$
\begin{gathered}
V_{v}=4,235 \cdot 10^{-6} \mathrm{~m}^{3} \\
\rho_{\text {latão }}=8600 \mathrm{~kg} / \mathrm{m}^{3} \\
\therefore m_{v}=36,421 \cdot 10^{-3} \mathrm{~kg}
\end{gathered}
$$

- Comprimento da manivela do pistão - medida retirada do modelo 3D.

$$
r_{p}=22 \mathrm{~mm}
$$


- Comprimento da biela do pistão - medida retirada do modelo 3D.

$$
L_{p}=80 \mathrm{~mm}
$$

- Área do pistão - análogo à área da válvula.

$$
\begin{gathered}
d_{p}=30 \mathrm{~mm} \\
\therefore A_{p}=707,0.10^{-6} \mathrm{~m}^{2}
\end{gathered}
$$

- Massa do pistão - análogo a massa da válvula.

$$
\begin{gathered}
V_{p}=10,0.10^{-6} \mathrm{~m}^{3} \\
\rho_{\text {latão }}=8600 \mathrm{~kg} / \mathrm{m}^{3} \\
\therefore m_{p}=86,0.10^{-3} \mathrm{~kg}
\end{gathered}
$$

- Diferença de fase entre o pistão e a válvula - parâmetro geométrico do projeto da máquina, o qual, uma vez definido, permanece inalterado. Determina a abertura e o fechamento das válvulas, alterando diretamente o ciclo da máquina e sua dinâmica. Foi obtido através do modelo 3D.

$$
\varphi=45^{\circ}
$$

- Momento de inércia - com auxílio da ferramenta de cálculo do modelo 3D é possível calcular o momento de inércia geométrico. Da literatura temos a densidade do aço, assim é possível calcular o momento de inércia.

$$
\begin{gathered}
\rho_{a c ̧ o}=7860 \mathrm{~kg} / \mathrm{m}^{3} \\
\therefore J_{r i}=242,8 \cdot 10^{-6} \mathrm{~kg} \cdot \mathrm{m}^{2}
\end{gathered}
$$

Os parâmetros e seus respectivos valores foram condensados no APÊNDICE C - PARÂMETROS DAS SIMULAÇÕES.

O diagrama de blocos para as simulações do sistema mecânico é mostrado Figura 4.7. 


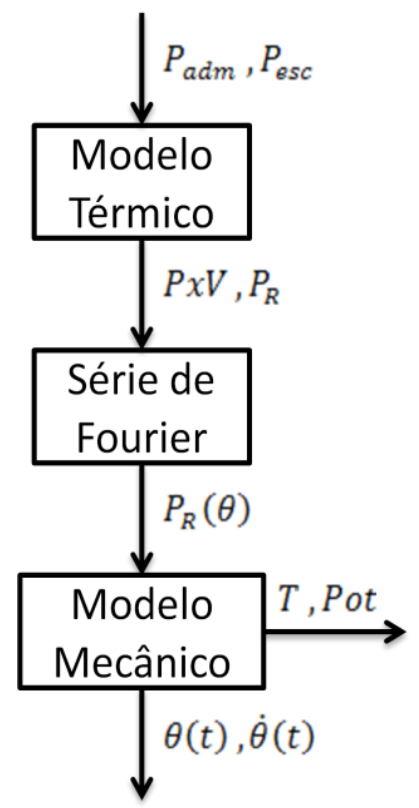

Figura 4.7 - Diagrama de blocos para as simulações do sistema mecânico.

Simulando a equação (3.40), obtêm-se os seguintes gráficos apresentados na Figura 4.8 e na Figura 4.9:

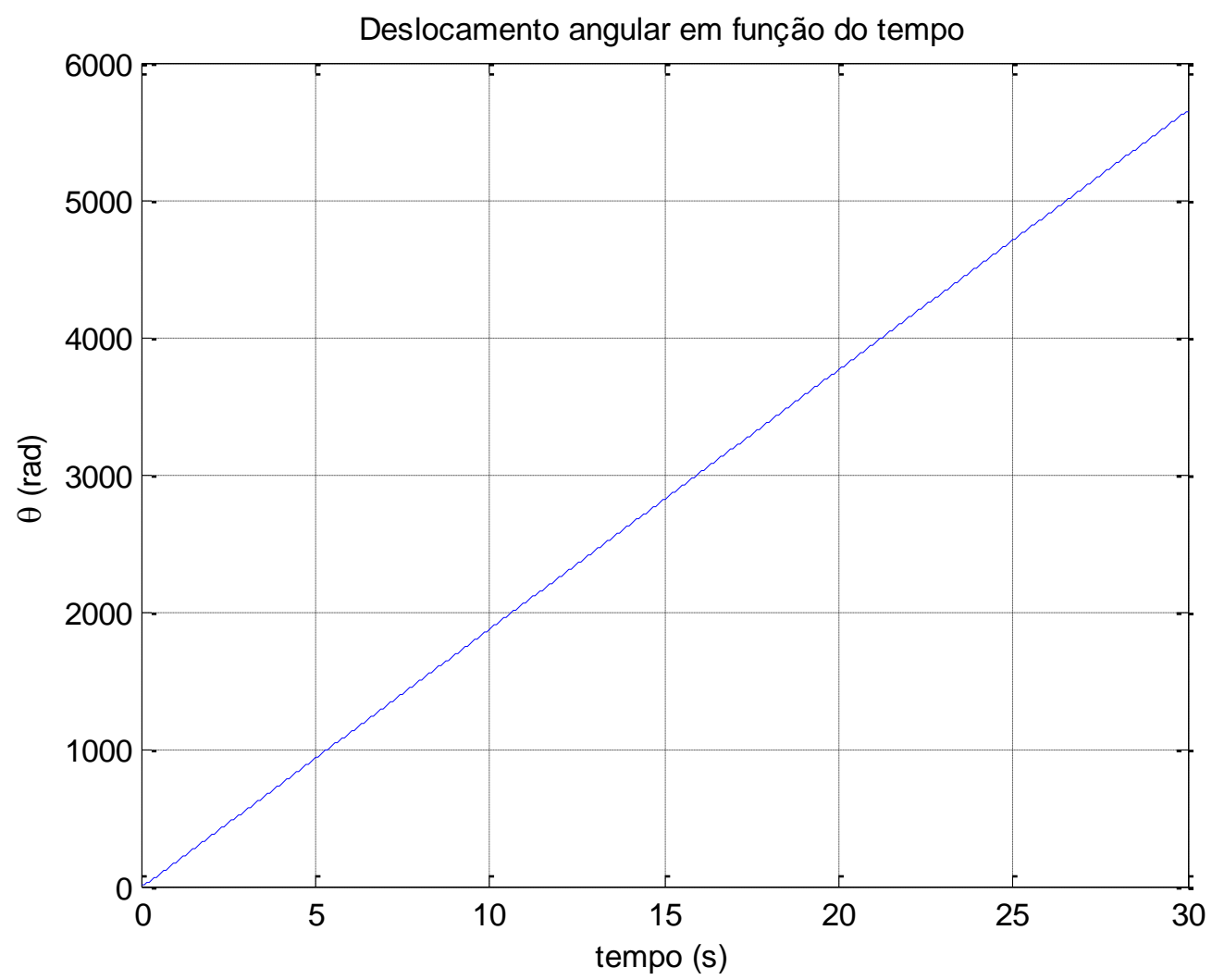

Figura 4.8 - Simulação do deslocamento angular. 
Observa-se que o gráfico da Figura 4.8 apresenta o comportamento de acordo com o esperado, pois a variação angular da biela-manivela é sempre crescente, isto é, a roda de inércia permanece girando continuamente em um mesmo sentido.

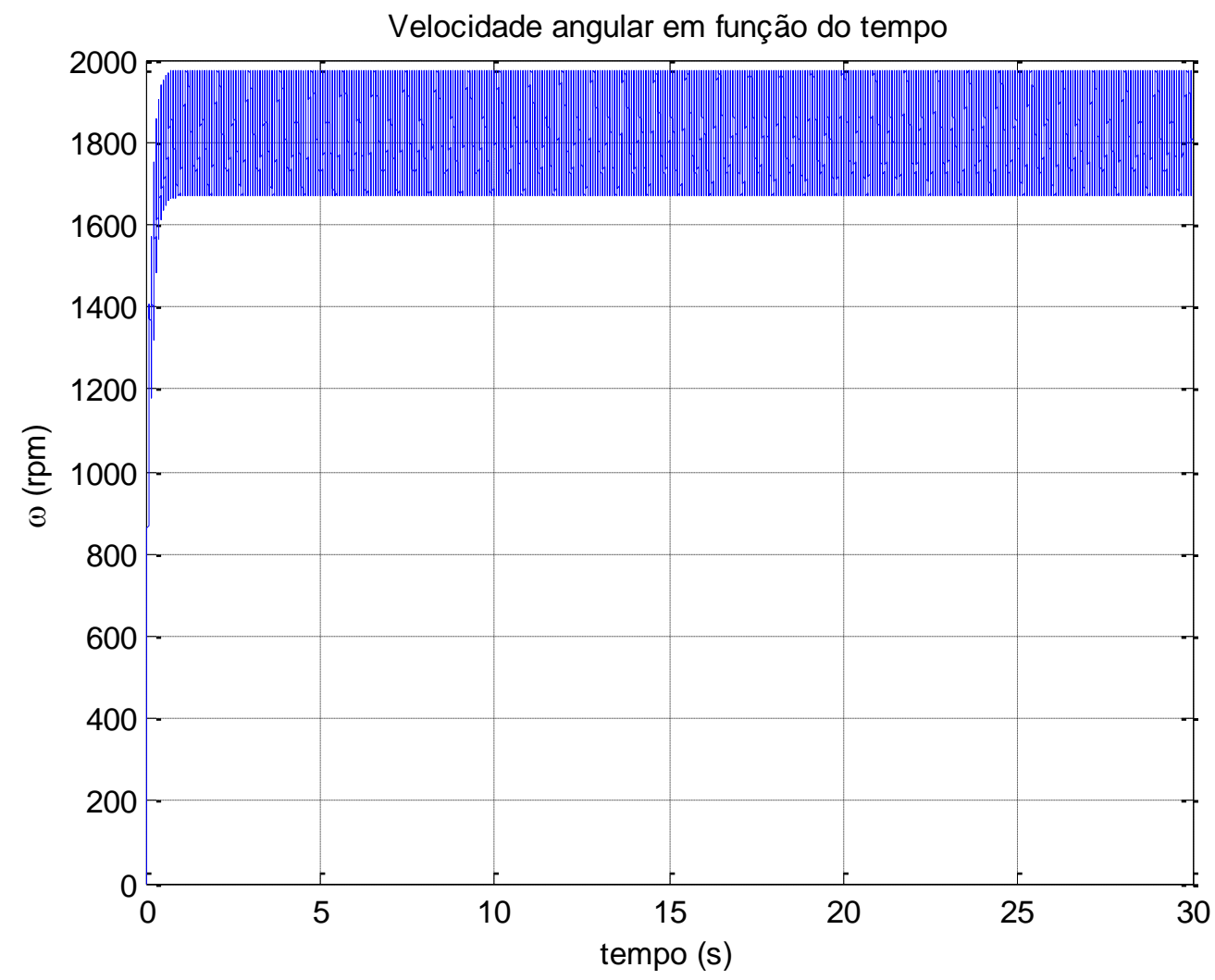

Figura 4.9 - Simulação da velocidade angular.

A velocidade angular se estabiliza em cerca de $1800 \mathrm{rpm}(190,7 \mathrm{rad} / \mathrm{s})$, para $P_{\text {adm }}=3,0$ bar e um $c_{\theta}=0,002$ N.m.s $/$ rad. Porém este coeficiente de atrito viscoso foi adotado como aproximação do comportamento real da máquina e será estimado posteriormente. 


\subsubsection{Curvas Características}

Para se obter as curvas características simuladas foi utilizada a mesma metodologia do levantamento experimental, que consiste em se aplicar um torque resistivo de valor conhecido ao eixo da máquina e realizar a medida da rotação, repetindo este processo para diversos valores de torque.

Portanto, foram realizadas diversas simulações variando o torque resistivo e a partir da resposta calcula-se a velocidade angular média e a potência. Os respectivos gráficos são apresentados na Figura 4.10 e na Figura 4.11.

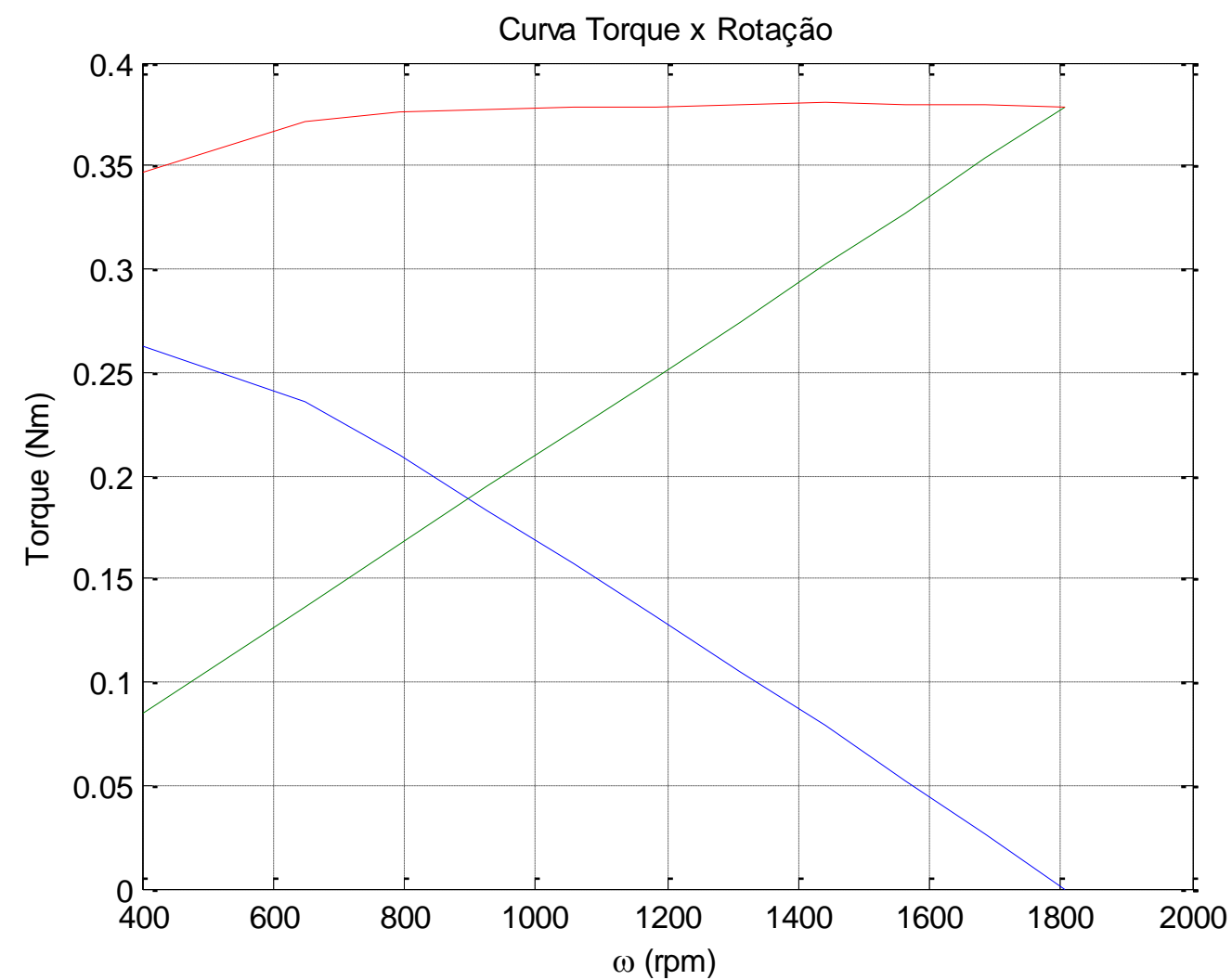

Figura 4.10 - Simulação do torque em função da velocidade angular.

A curva azul corresponde ao torque resistivo, isto é, o torque útil, que será utilizado para gerar energia. Assim como em um motor de combustão interna, em rotações mais baixas apresenta maior torque útil. 
A curva verde corresponde ao torque referente às perdas, as quais são relativas ao atrito viscoso como foi proposto no modelo e, portanto, as perdas são diretamente proporcionais à velocidade angular.

A curva vermelha corresponde à soma da curva azul com a verde, isto é, corresponde ao torque total da máquina.

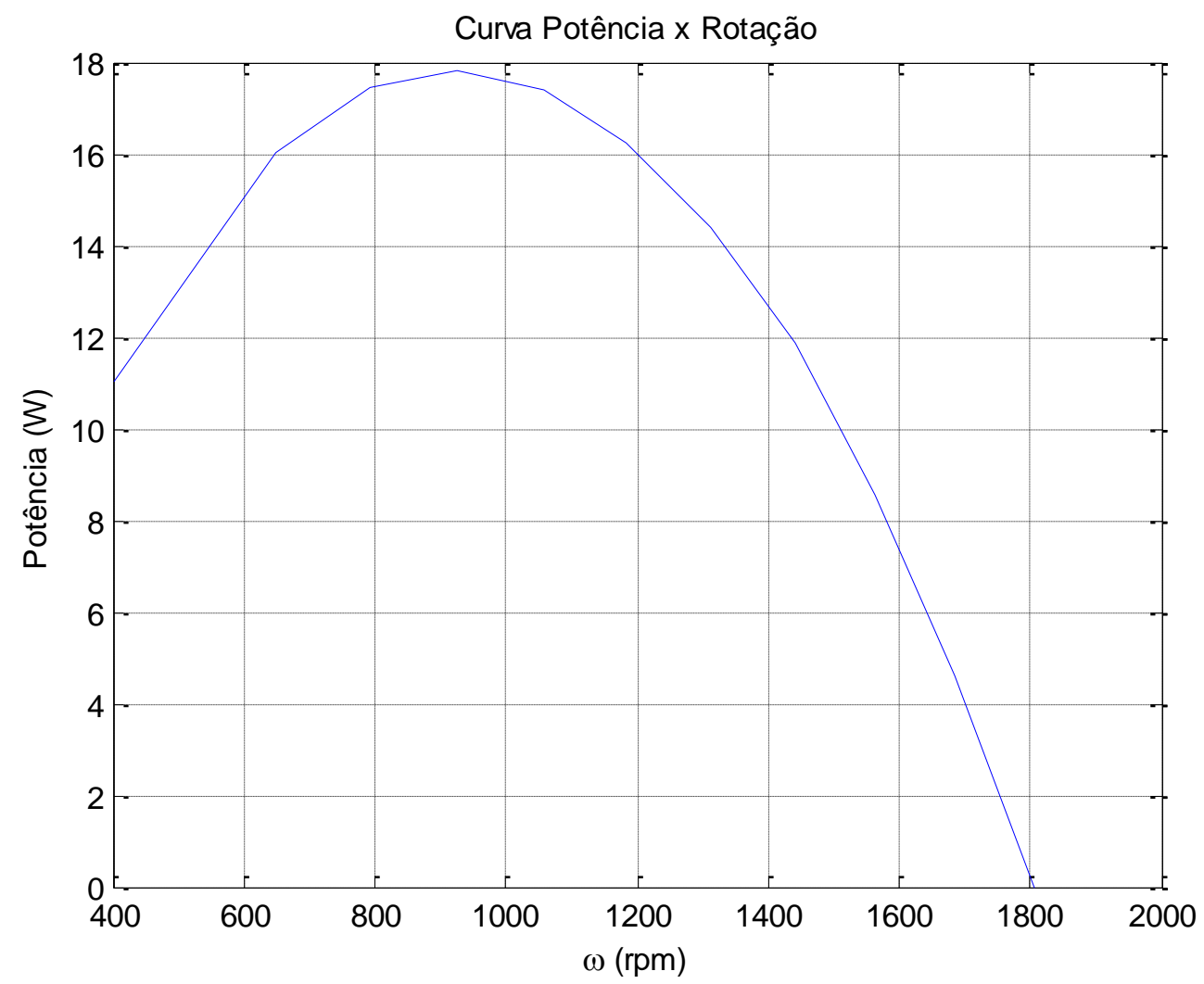

Figura 4.11 - Simulação da potência em função da velocidade angular.

Observa-se no gráfico da Figura 4.11 que para a pressão de 3,0 bar, a máxima potência é de cerca de $18 \mathrm{~W}$ e ocorre a aproximadamente $900 \mathrm{rpm}$. Esta potência é suficiente para acender três lâmpadas led por exemplo. Porém este valor ainda é muito baixo, logo uma solução para aumentar a potência mecânica do eixo é aumentar a pressão de entrada; esta solução será abordada na análise de sensibilidade. 


\subsubsection{Vibração do Pistão}

Inicialmente foi feito o levantamento dos parâmetros.

- Comprimento da haste do pistão:

$$
L_{h}=155 \mathrm{~mm}
$$

- Área da seção transversal da haste:

$$
A_{h}=12,57 \mathrm{~mm}^{2}
$$

- As massas são calculadas a partir da massa do pistão e da haste:

$$
\begin{aligned}
& m_{1}=69,2 \mathrm{~g} \\
& m_{2}=8,4 \mathrm{~g}
\end{aligned}
$$

- Da literatura temos o módulo de elasticidade do latão:

$$
E=64 G P a
$$

- A partir dos parâmetros é possível calcular a rigidez da haste (equação (3.43)) e a frequência natural do pistão (equação (3.57)):

$$
\begin{gathered}
K=5,19 \cdot 10^{6} \mathrm{~N} / \mathrm{m} \\
\omega_{n}=2,63 \cdot 10^{4} \mathrm{rad} / \mathrm{s} \\
r=\frac{\omega}{\omega_{n}}=0,0072
\end{gathered}
$$

Os parâmetros e seus respectivos valores foram compilados no APÊNDICE C - PARÂMETROS DAS SIMULAÇÕES.

O diagrama de blocos para as simulações da vibração do pistão é mostrado na Figura 4.12. 


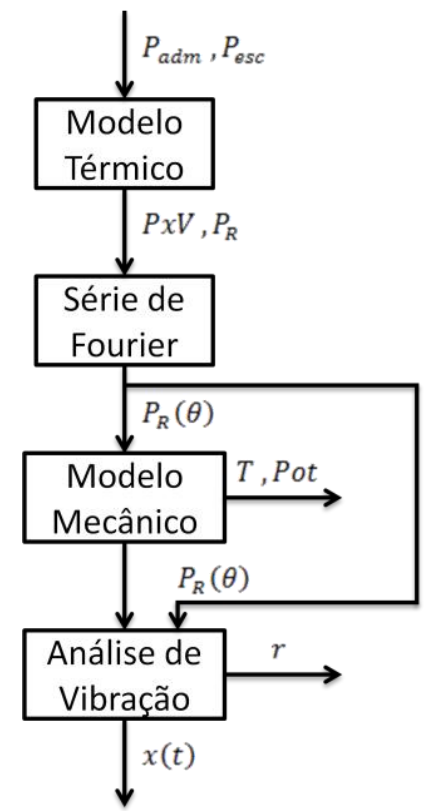

Figura 4.12 - Diagrama de blocos para as simulações da vibração do pistão.

A Figura 4.13 mostra a força do fluido (ar) exercida no pistão $\left(P_{a d m}=\right.$ 3,0 bar) :

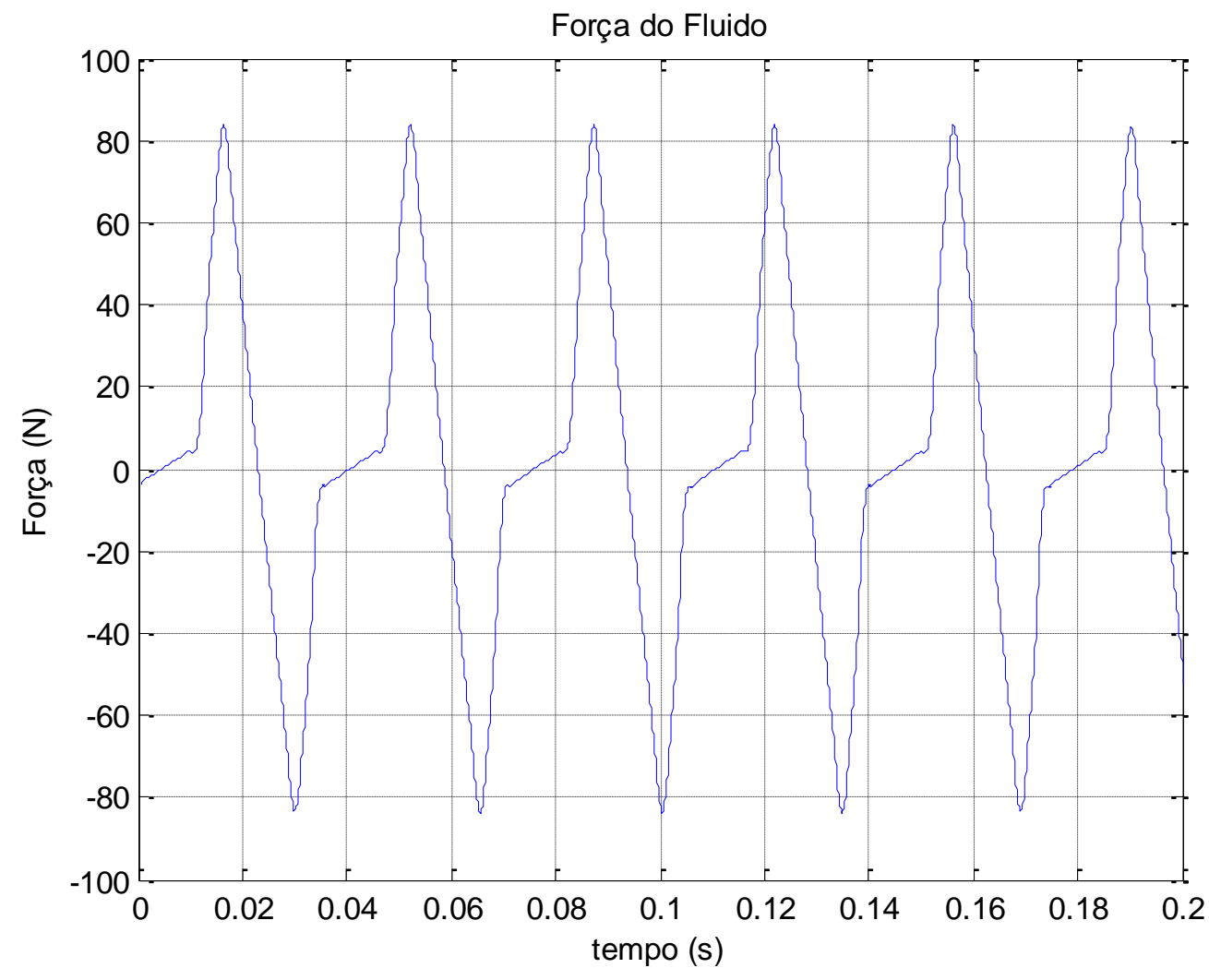

Figura 4.13 - Simulação da força do fluido em função do tempo. 
Como visto anteriormente, para calcular a resposta analítica da vibração do pistão é necessário aproximar as forças atuantes por uma série de Fourier. Os coeficientes da série de Fourier são mostrados no gráfico da Figura 4.14.

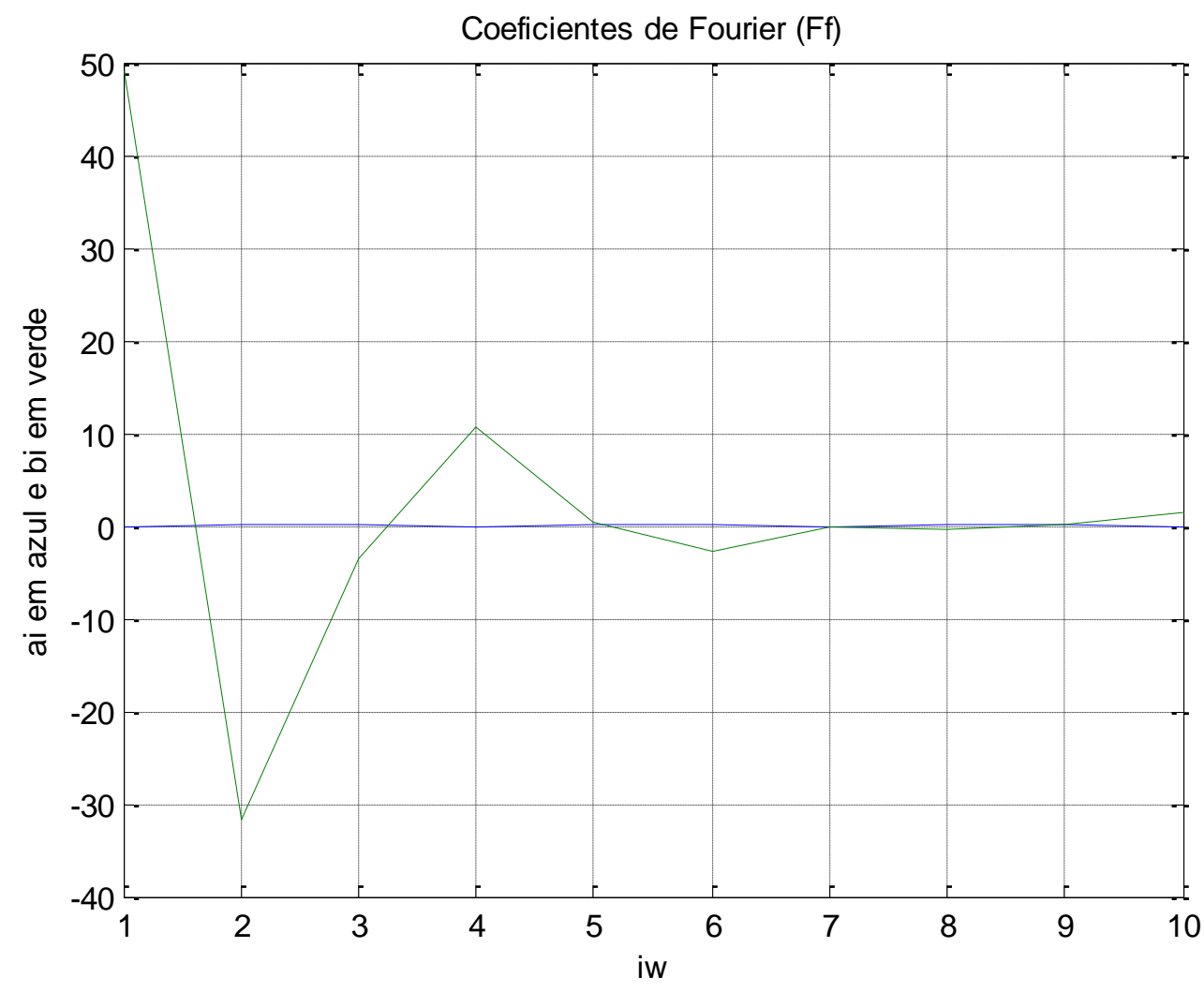

Figura 4.14 - Coeficientes da série de Fourier da força do fluido.

Utilizando a forma de amplitude e fase:

Tabela 4.3 - Amplitude e fase da série de Fourier da força do fluido.

\begin{tabular}{c|ccc}
\hline $\mathbf{i}$ & $\mathbf{A}(\mathbf{N})$ & $\boldsymbol{\phi}(\mathbf{r a d})$ & $\mathbf{A i} / \mathbf{A 1}(\%)$ \\
\hline $\mathbf{1}$ & 48,96 & $-7,05 \mathrm{E}-06$ & - \\
\hline $\mathbf{2}$ & 31,71 & $-3,95 \mathrm{E}-06$ & 64,8 \\
\hline $\mathbf{3}$ & 3,51 & $-1,08 \mathrm{E}-05$ & 7,2 \\
\hline $\mathbf{4}$ & 10,57 & $-7,87 \mathrm{E}-06$ & 21,6 \\
\hline $\mathbf{5}$ & 0,42 & $9,31 \mathrm{E}-05$ & 0,9 \\
\hline $\mathbf{6}$ & 2,78 & $-1,14 \mathrm{E}-05$ & 5,7 \\
\hline $\mathbf{7}$ & 0,03 & $1,72 \mathrm{E}-03$ & 0,1 \\
\hline $\mathbf{8}$ & 0,48 & $-2,08 \mathrm{E}-05$ & 1,0 \\
\hline $\mathbf{9}$ & 0,12 & $2,80 \mathrm{E}-04$ & 0,2 \\
\hline $\mathbf{1 0}$ & 1,34 & $-2,23 \mathrm{E}-05$ & 2,7 \\
\hline
\end{tabular}


Portanto, o $1^{\circ}$, $2^{\circ}$ e $4^{\circ}$ harmônicos são relevantes para força do fluido.

A Figura 4.15 mostra a força inercial do pistão $(\omega=190,7 \mathrm{rad} / \mathrm{s})$ :

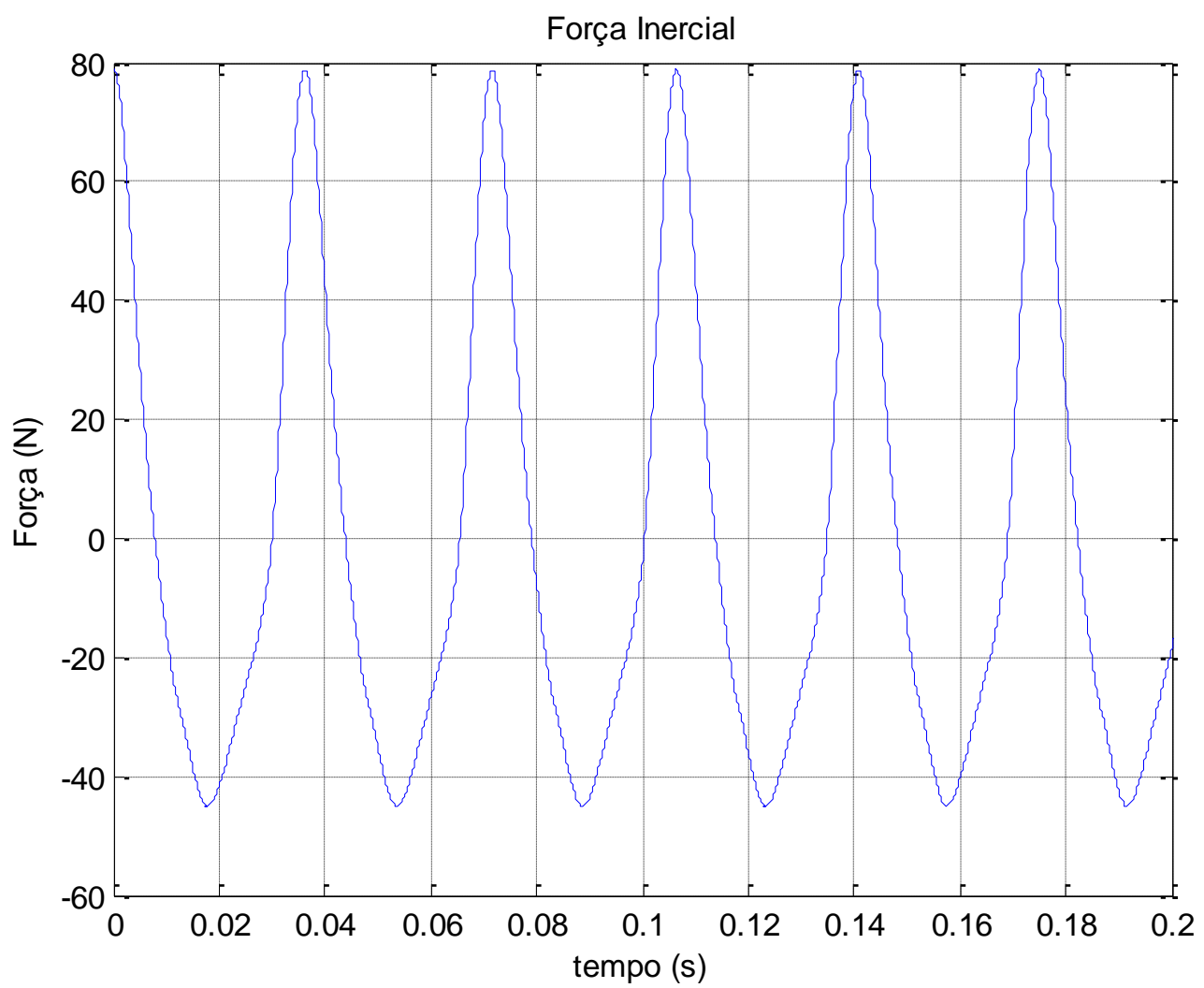

Figura 4.15 - Simulação da força inercial em função do tempo.

Analogamente, os coeficientes da série de Fourier são mostrados no gráfico da Figura 4.16. 


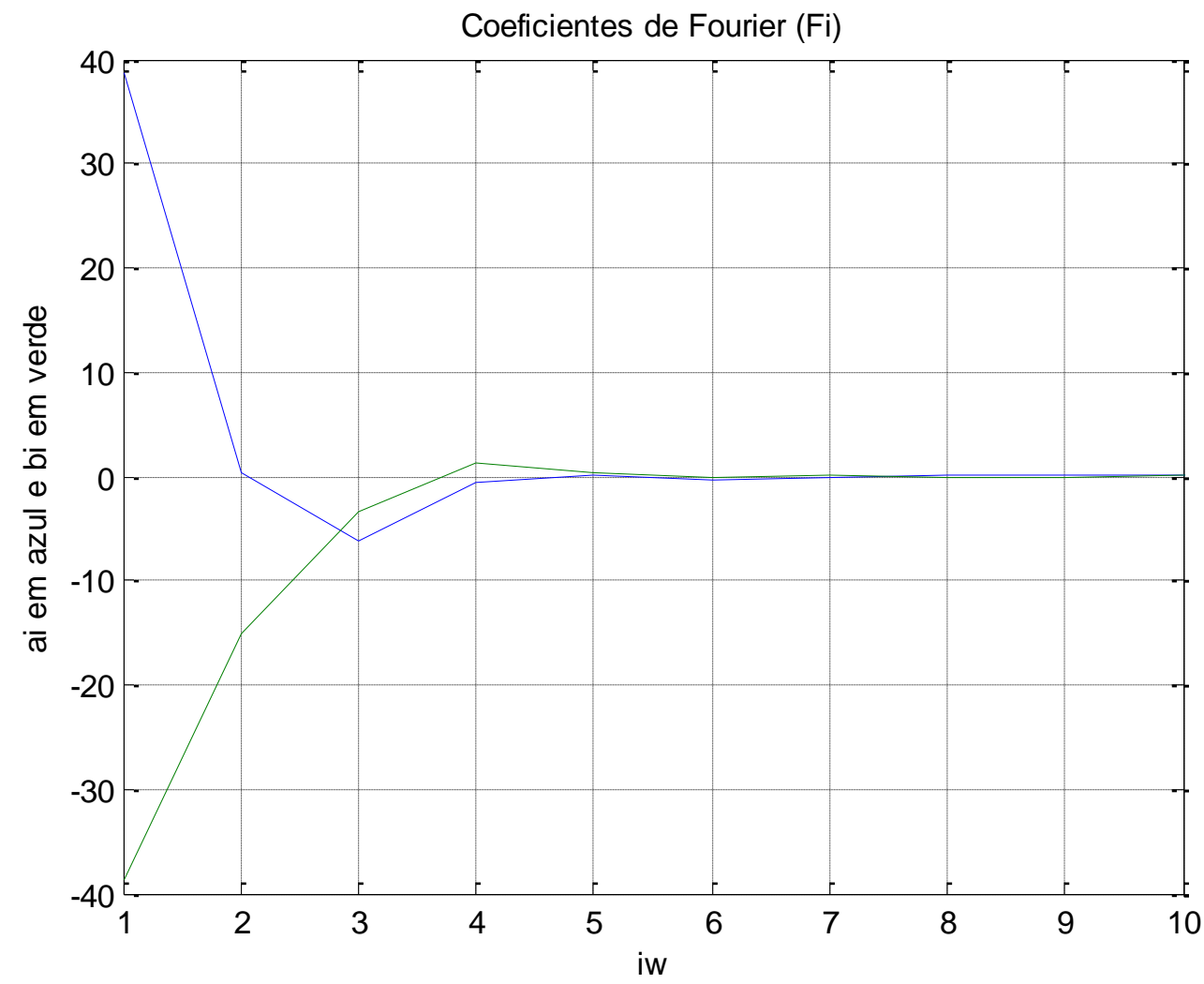

Figura 4.16 - Coeficientes da série de Fourier da força inercial.

Utilizando a forma de amplitude e fase:

Tabela 4.4 - Amplitude e fase da série de Fourier da força inercial.

\begin{tabular}{c|ccc}
\hline $\mathbf{i}$ & $\mathbf{A}(\mathbf{N})$ & $\mathbf{\Phi}(\mathbf{r a d})$ & $\mathbf{A i} / \mathbf{A} \mathbf{1}(\%)$ \\
\hline $\mathbf{1}$ & 48,12 & $-0,78$ & - \\
\hline $\mathbf{2}$ & 13,22 & $-0,03$ & 27,5 \\
\hline $\mathbf{3}$ & 6,23 & 1,08 & 13,0 \\
\hline $\mathbf{4}$ & 1,24 & $-0,47$ & 2,6 \\
\hline $\mathbf{5}$ & 0,35 & 0,48 & 0,7 \\
\hline $\mathbf{6}$ & 0,35 & 1,26 & 0,7 \\
\hline $\mathbf{7}$ & 0,08 & $-1,00$ & 0,2 \\
\hline $\mathbf{8}$ & 0,13 & $-1,47$ & 0,3 \\
\hline $\mathbf{9}$ & 0,01 & $-0,54$ & 0,0 \\
\hline $\mathbf{1 0}$ & 0,08 & 0,01 & 0,2 \\
\hline
\end{tabular}

Portanto, $01^{\circ}$ e $2^{\circ}$ harmônicos são relevantes para força inercial. 
Finalmente, calculando a força resultante, obtém-se o gráfico da Figura 4.17:

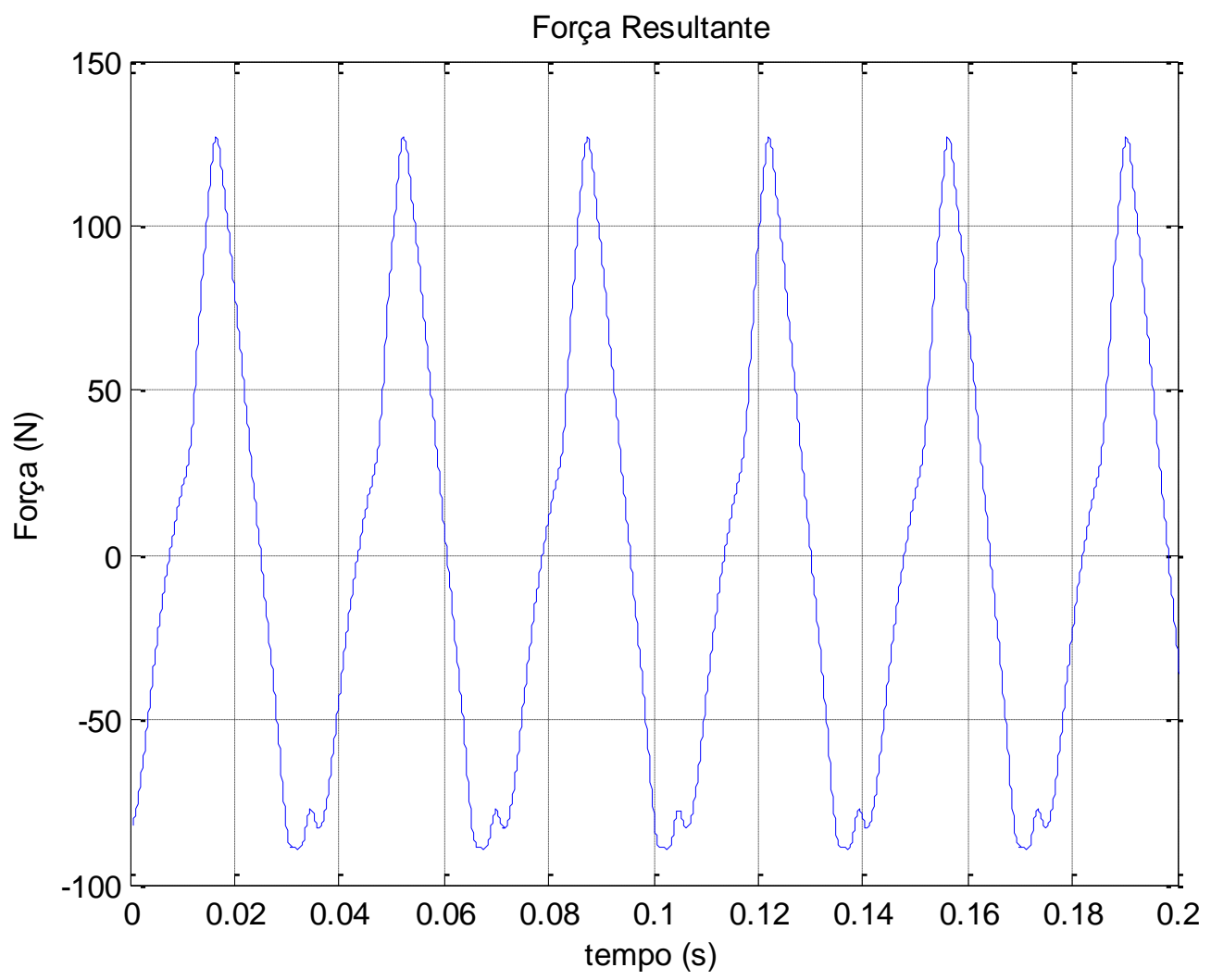

Figura 4.17 - Simulação da força resultante em função do tempo.

Analogamente, os coeficientes da série de Fourier são mostrados no gráfico na Figura 4.18. 


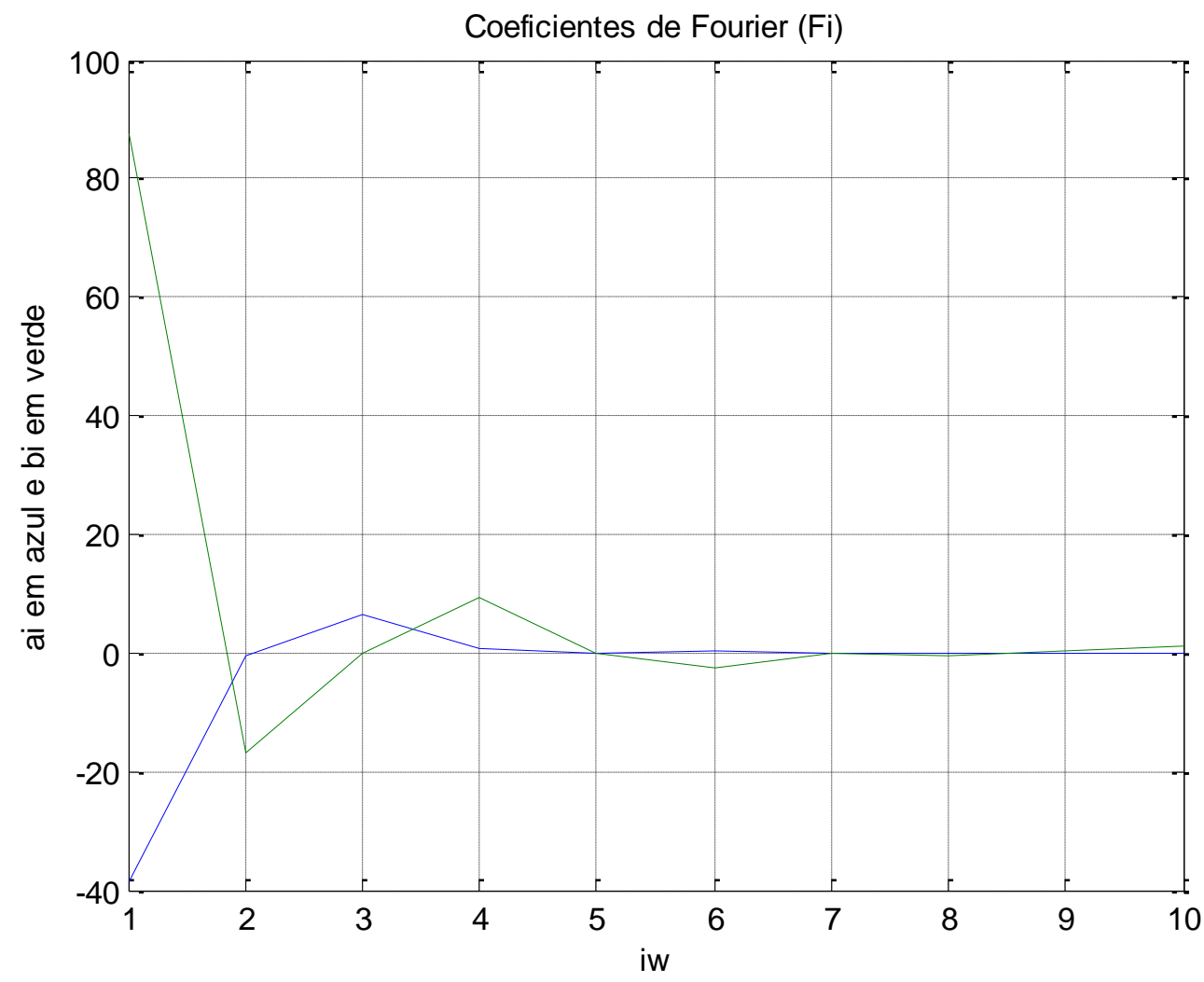

Figura 4.18 - Coeficientes da série de Fourier da força resultante.

Utilizando a forma de amplitude e fase:

Tabela 4.5 - Amplitude e fase da série de Fourier da força resultante.

\begin{tabular}{c|ccc}
\hline $\mathbf{i}$ & $\mathbf{A ~ ( N )}$ & $\mathbf{\phi}(\mathbf{r a d})$ & $\mathbf{A i} / \mathbf{A} \mathbf{1}(\%)$ \\
\hline $\mathbf{1}$ & 89,70 & $-0,39$ & - \\
\hline $\mathbf{2}$ & 18,50 & 0,02 & 20,6 \\
\hline $\mathbf{3}$ & 5,53 & $-1,47$ & 6,2 \\
\hline $\mathbf{4}$ & 9,48 & 0,06 & 10,6 \\
\hline $\mathbf{5}$ & 0,19 & $-0,99$ & 0,2 \\
\hline $\mathbf{6}$ & 2,70 & $-0,12$ & 3,0 \\
\hline $\mathbf{7}$ & 0,10 & $-0,73$ & 0,1 \\
\hline $\mathbf{8}$ & 0,49 & 0,26 & 0,5 \\
\hline $\mathbf{9}$ & 0,13 & $-0,04$ & 0,1 \\
\hline $\mathbf{1 0}$ & 1,26 & 0,00 & 1,4 \\
\hline
\end{tabular}

Portanto, $01^{\circ}$ e $2^{\circ}$ harmônicos são relevantes para força inercial. 


$$
\therefore F_{R}=A_{1} \sin \left(\omega t+\varphi_{1}\right)+A_{2} \sin \left(2 \omega t+\varphi_{2}\right)
$$

Calculando a resposta analítica para a força resultante encontrada:

$$
\begin{aligned}
& x_{1}=\frac{A_{1} / K}{\frac{m_{1}+m_{2}}{m_{2}}\left(1-r^{2}\right)} \cdot \sin \left(\omega t+\varphi_{1}\right)+\frac{A_{2} / K}{\frac{m_{1}+m_{2}}{m_{2}}\left(1-4 r^{2}\right)} \cdot \sin \left(2 \omega t+\varphi_{2}\right) \\
& x_{2}=\frac{-A_{1} / K}{\frac{m_{1}+m_{2}}{m_{1}}\left(1-r^{2}\right)} \cdot \sin \left(\omega t+\varphi_{1}\right)+\frac{-A_{2} / K}{\frac{m_{1}+m_{2}}{m_{1}}\left(1-4 r^{2}\right)} \cdot \sin \left(2 \omega t+\varphi_{2}\right)
\end{aligned}
$$

Utilizando valores numéricos nas equações (4.2) e (4.3), obtém-se o gráfico da Figura 4.19:

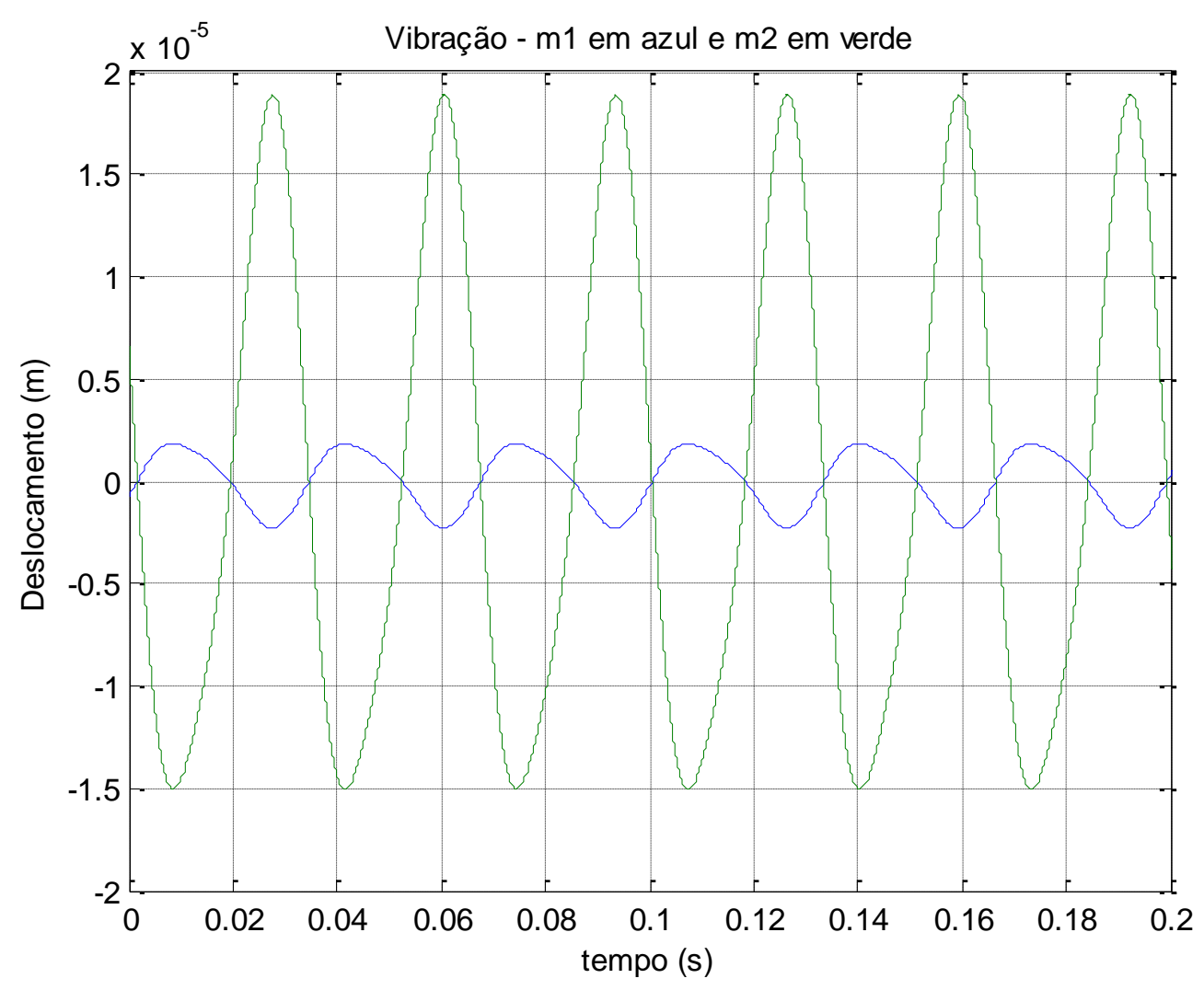

Figura 4.19 - Resposta analítica da vibração do pistão.

Observa-se que as duas massas oscilam em oposição de fase, a massa $m_{2}$, por haver menos inércia que a massa $m_{1}$, oscila com maior amplitude. $O$ primeiro harmônico rege o movimento. 
Simulando numericamente as equações (3.50) (3.51), obtém-se o gráfico da Figura 4.20:

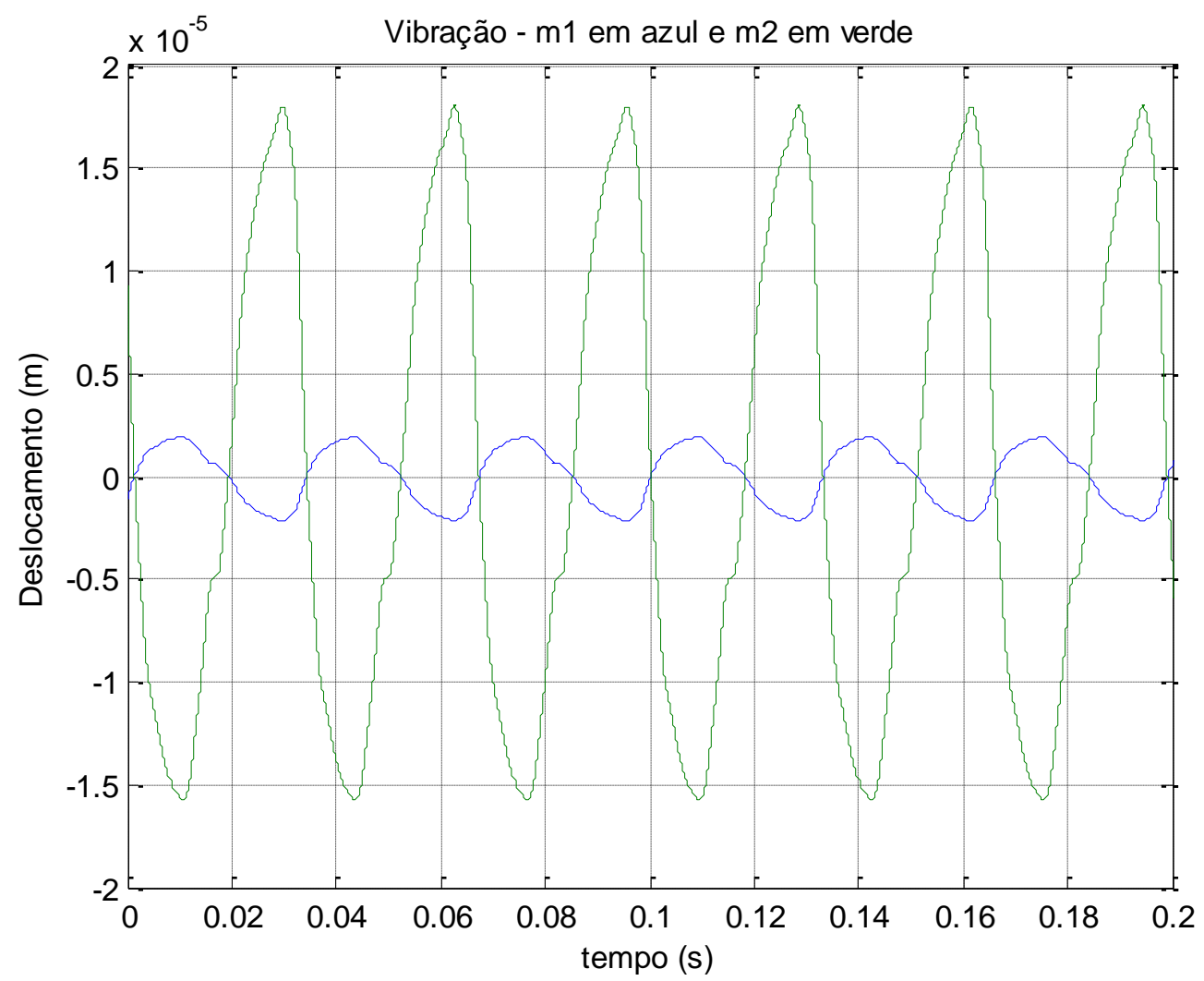

Figura 4.20 - Simulação numérica da vibração do pistão.

Comparando a Figura 4.19 com a Figura 4.20, a reposta analítica para os dois primeiros harmônicos da série de Fourier da força resultante apresenta o mesmo comportamento que a simulação numérica, com valores semelhantes tanto de amplitude quanto de fase. Portanto, a aproximação da força resultante adotada é válida. 
Utilizando a solução analítica é possível calcular a amplitude de oscilação de cada massa em função da velocidade de operação da máquina, que é mostrado no gráfico da Figura 4.21:

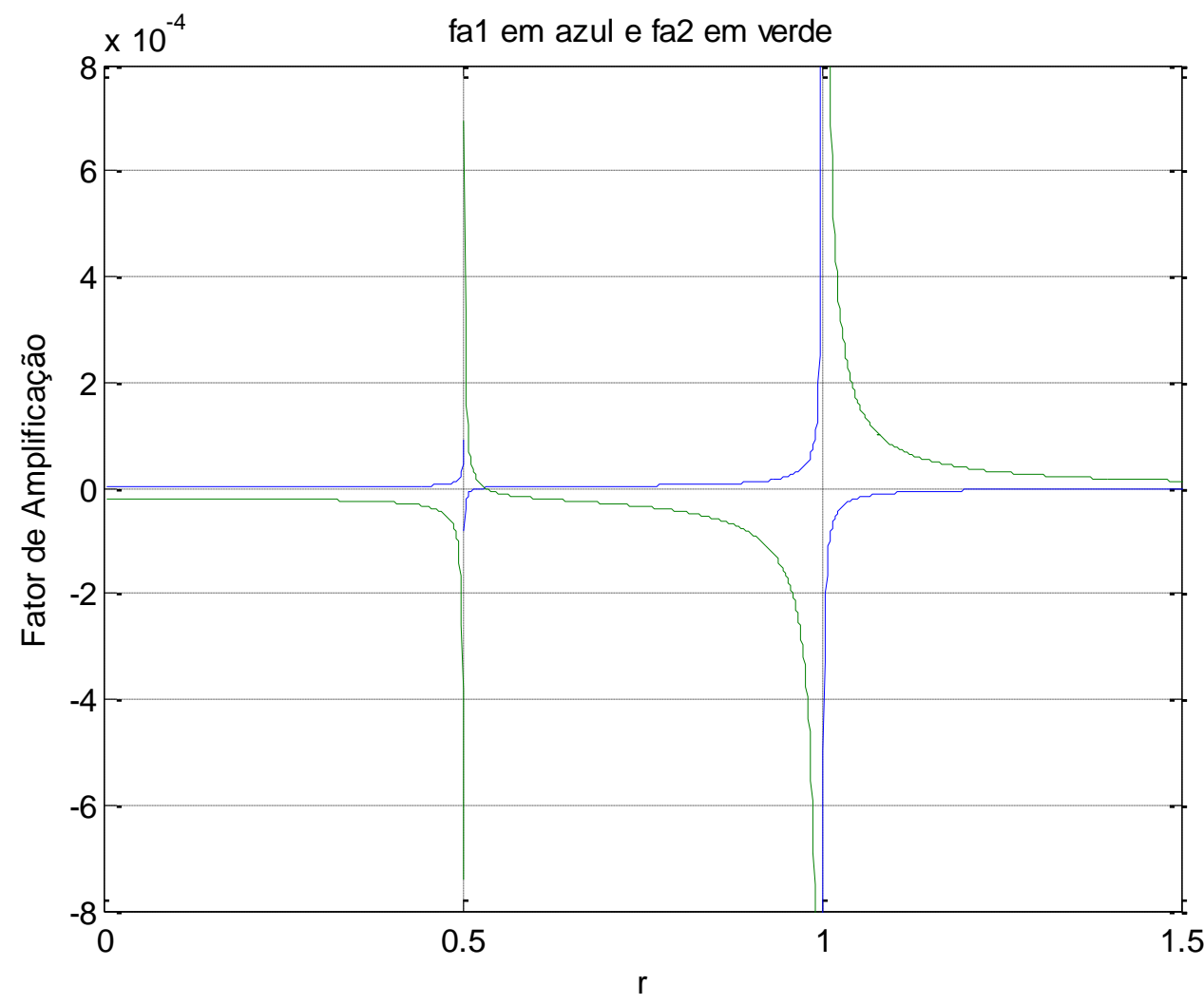

Figura 4.21 - Fator de amplificação em função da velocidade angular.

Analisando a Figura 4.21, a ressonância ocorre para $r=0,5$ (segundo harmônico da excitação) e $r=1,0$ (primeiro harmônico da excitação).

As frequências da excitação são muito menores que a frequência natural $(r<0,01)$ e, portanto, o pistão pode ser considerado como corpo rígido para as forças atuantes.

Um estudo análogo permitiu verificar que as frequências naturais de vibração do eixo que conecta a manivela da válvula e a roda de inércia são muito superiores a qualquer possível frequência de excitação. 


\subsection{Sistema Elétrico}

Com base na literatura e em catálogo de geradores, foram adotados os seguintes valores:

- Excitatriz:

$$
\begin{gathered}
T_{E}=0,5 \\
K_{E}=0,05 \\
v_{R}=5,5 \mathrm{~V}
\end{gathered}
$$

- Gerador:

$$
\begin{aligned}
T_{G} & =0,6 \\
K_{G} & =1,0
\end{aligned}
$$

Os parâmetros e seus respectivos valores foram reunidos no APÊNDICE C PARÂMETROS DAS SIMULAÇÕES.

O diagrama de blocos para as simulações do sistema elétrico é mostrado na Figura 4.22 .

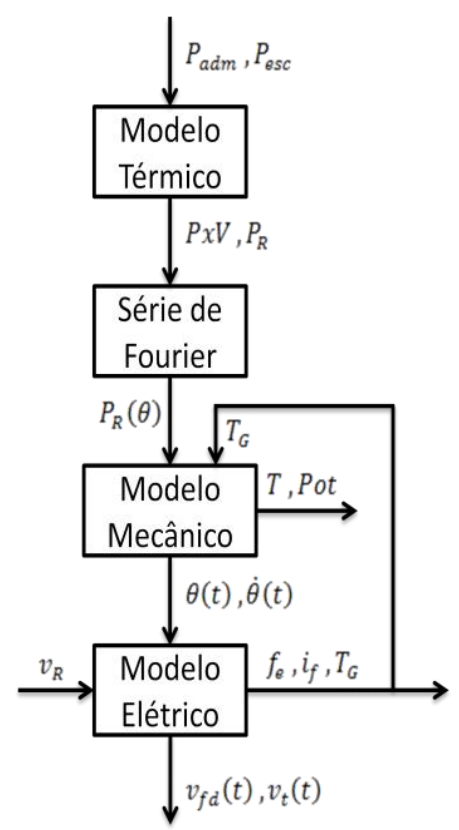

Figura 4.22 - Diagrama de blocos para as simulações do sistema elétrico. 
Nas simulações, foi adotado que o gerador é acionado após 10 segundos de operação da máquina, pois a mesma já opera em regime permanente.

Implementando as equações (3.68) e (3.73) com os parâmetros apresentados anteriormente, tem-se como resultado o gráfico da Figura 4.23:

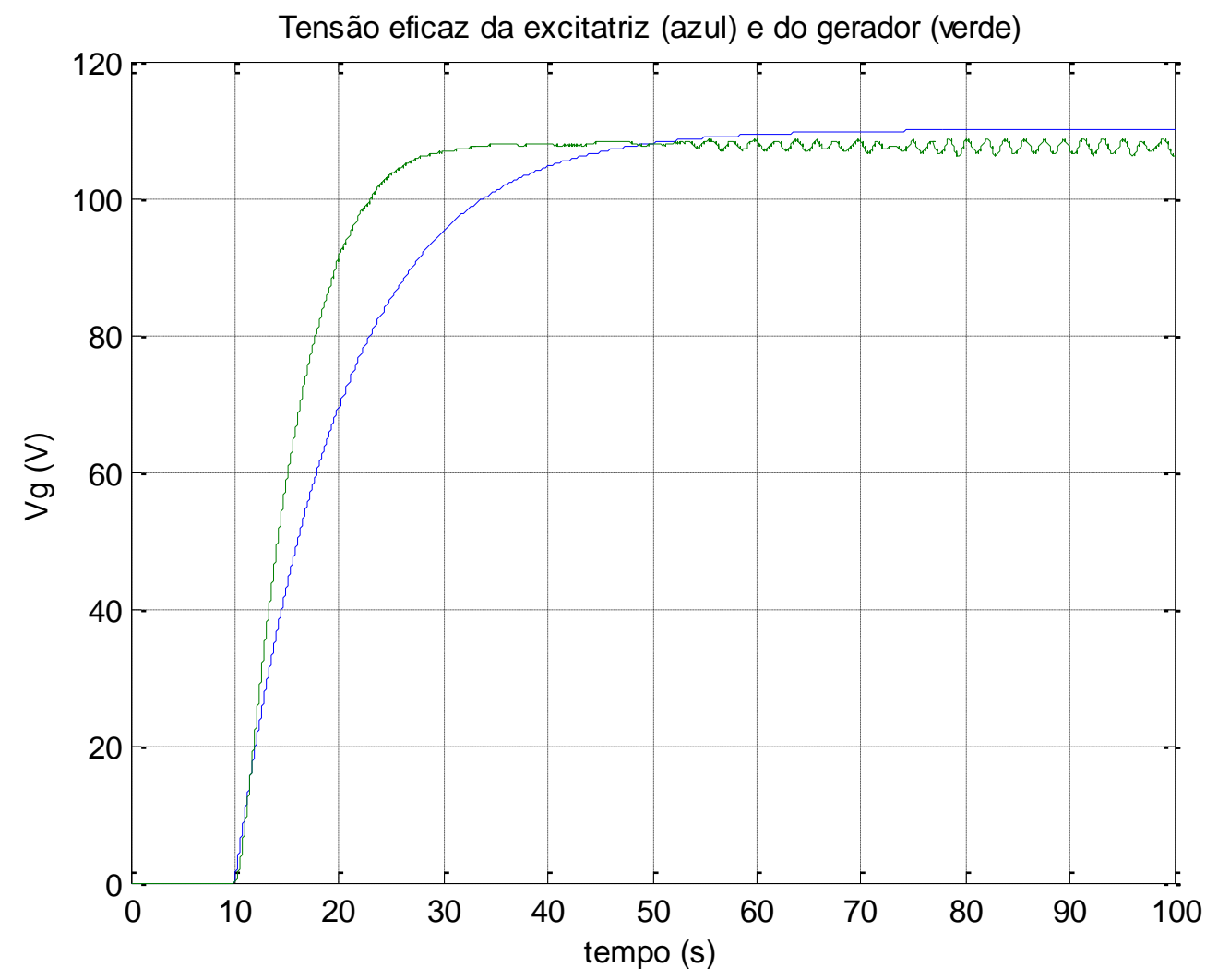

Figura 4.23 - Simulação da tensão eficaz em função do tempo.

Observa-se no gráfico (Figura 4.23) que a tensão eficaz tanto da excitatriz quanto do gerador se estabilizam por volta de $110 \mathrm{~V}$ para uma tensão de armadura da excitatriz de 5,5V. Tanto a tensão da excitatriz quanto a do gerador levam cerca de 45 segundos para entrar em regime permanente. A tensão do gerador sofre pequenas oscilações devido à variação da velocidade angular. 
A partir da resposta das tensões, é possível calcular a corrente no circuito do gerador, resultando no gráfico da Figura 4.24:

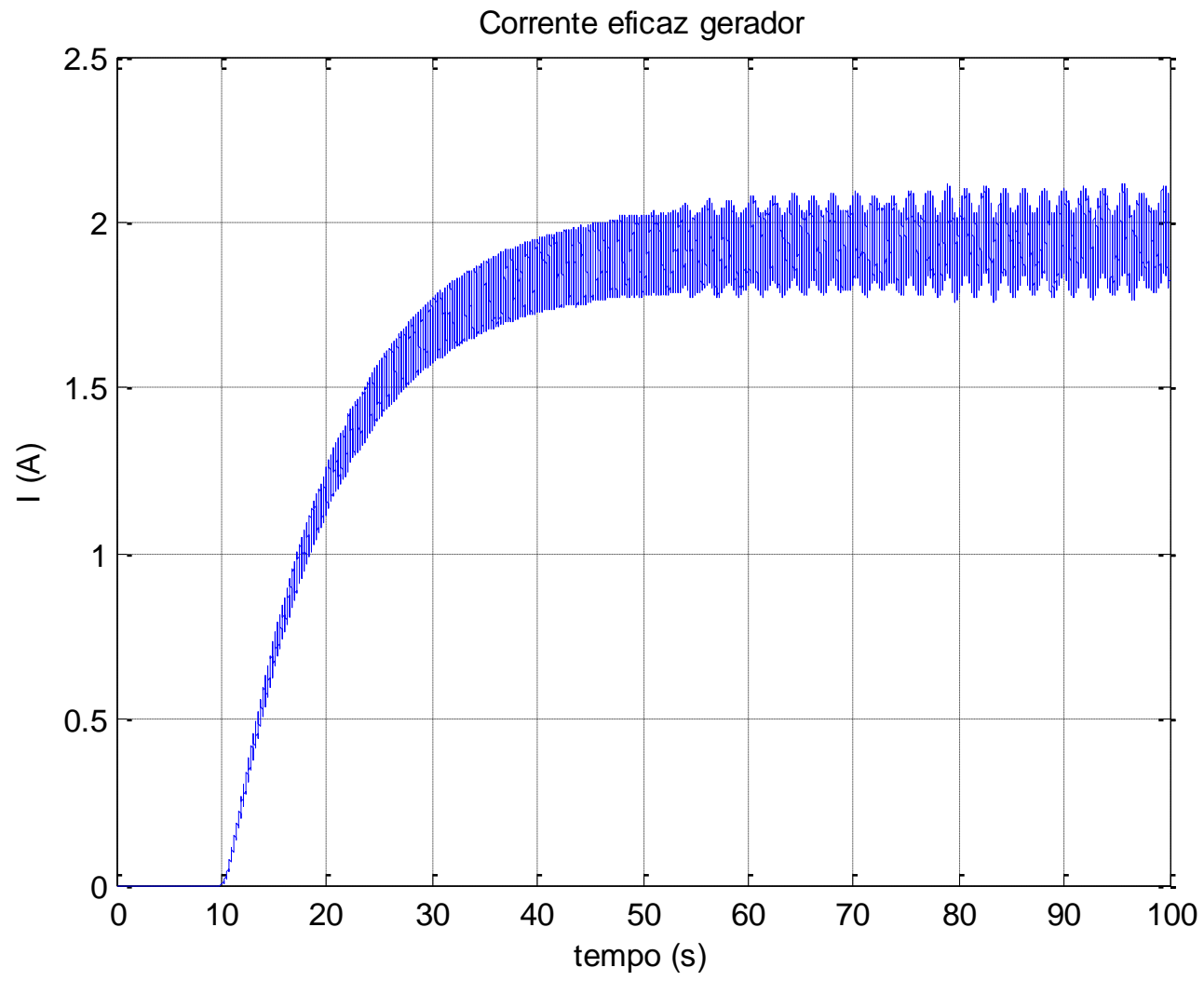

Figura 4.24 - Simulação da corrente eficaz em função do tempo.

Observa-se no gráfico da Figura 4.24, que a corrente se estabiliza após 45 segundos e oscila com valor próximo a 2 A. 
A frequência elétrica é diretamente proporcional a velocidade angular da máquina. Portanto, simulando a velocidade angular para a pressão de entrada de 5,0 bar e acionando o gerador após de 10 segundos de operação, obtém-se o gráfico da Figura 4.25:

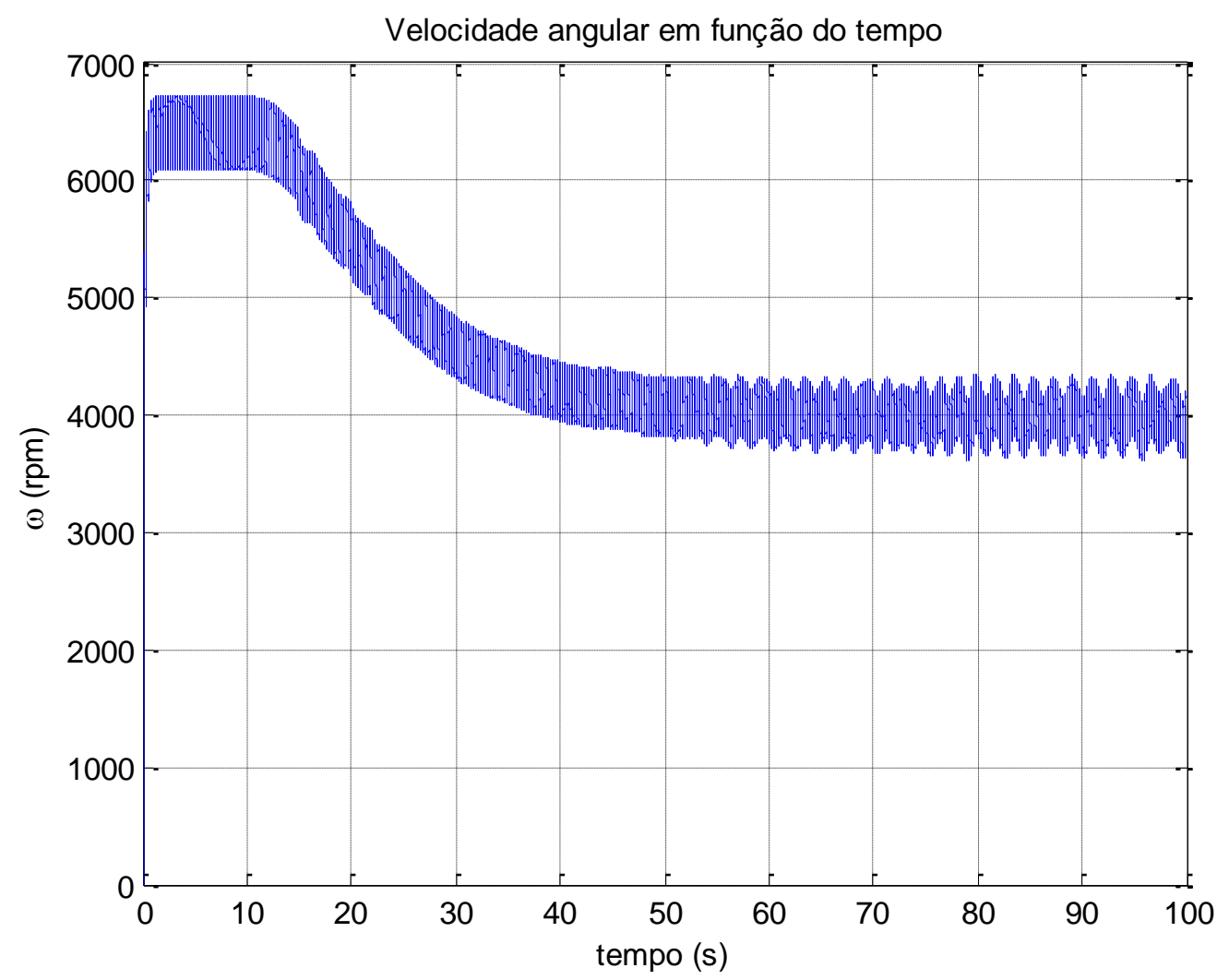

Figura 4.25 - Simulação da velocidade angular em função do tempo.

Analisando o gráfico da Figura 4.25, observa-se que a máquina opera em vazio durante os 10 segundos iniciais e possui velocidade angular de aproximadamente $6500 \mathrm{rpm}$. Porém, após o acionamento do gerador, a máquina leva 45 segundos para entrar em equilíbrio com o torque resistivo imposto pelo gerador e opera a cerca de $4000 \mathrm{rpm}$. 
Portanto, a partir deste resultado é possível obter o gráfico da frequência (Figura 4.26):

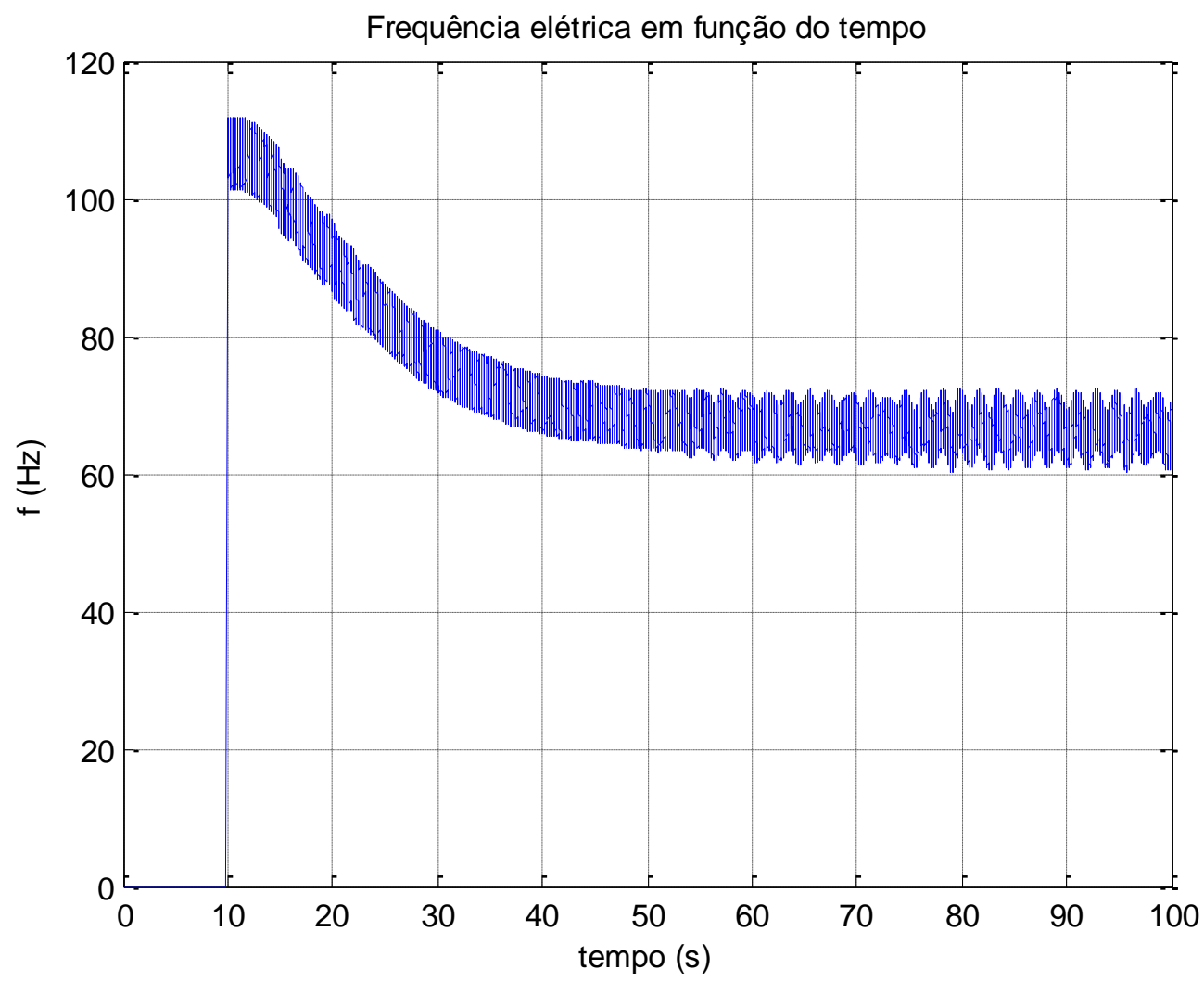

Figura 4.26 - Simulação da frequência elétrica em função do tempo.

Durante os 10 segundos iniciais, o gerador está desacoplado do eixo da máquina, logo este período é desconsiderado. Após 45 segundos do acionamento do gerador, a frequência oscila um pouco acima de $60 \mathrm{~Hz}$ e, portanto, é necessário um sistema de controle que estabilize a frequência elétrica em $60 \mathrm{~Hz}$. 
Outros resultados obtidos através da simulação da modelagem são apresentados na tabela seguir:

Tabela 4.6 - Resultados da simulação elétrica.

\begin{tabular}{cc}
\hline Variável & Valor \\
\hline$F P$ & 0,8575 \\
$\Phi$ & $31,0^{\circ}$ \\
$P_{\text {útil }}$ & $178,9 \mathrm{~W}$ \\
$\eta_{\text {elétrica }}$ & $86,65 \%$ \\
\hline
\end{tabular}

O Fator de Potência se encontra na faixa entre 0,8 e 0,9 , adequado para geradores elétricos. Como visto anteriormente, a defasagem entre a corrente e a tensão é de $31,0^{\circ}$.

A potência gerada é próxima de $180 \mathrm{~W}$, suficiente para acionar de dois a três laptops, a iluminação de uma residência ou um pequeno motor elétrico. Segundo Souza et. al. (2005), a eficiência de um gerador é proporcional ao seu tamanho e geradores elétricos de grande porte podem atingir eficiências de 98\% a 99\%. Logo, comparando com o gerador em questão, a eficiência é baixa $(86,65 \%)$; isto se deve ao fato de ser um gerador de pequeno porte. 


\subsection{Análise de Sensibilidade}

Utilizando os modelos matemáticos obtidos anteriormente, pode-se variar os parâmetros e verificar seus efeitos sobre o funcionamento da máquina. Portanto, mantendo os demais parâmetros com os valores de referência do protótipo, os seguintes parâmetros foram analisados: momento de inércia, coeficiente de atrito viscoso, pressão de entrada e tensão de entrada.

\subsubsection{Momento de Inércia}

Para analisar os efeitos da variação do momento de inércia sobre a máquina, foram executadas cinco simulações (Figura 4.27). Em azul, foi utilizado o valor de referência, isto é, o momento de inércia do protótipo $\left(242,8 \cdot 10^{-6} \mathrm{~kg} \cdot \mathrm{m}^{2}\right)$. Em vermelho foi adotado o dobro do valor de referência; já em azul claro, dez vezes maior. Em verde foi arbitrado a metade do valor de referência; já em roxo, um quarto.

Observando a Figura 4.27, conclui-se que o momento de inércia não influencia na velocidade média de operação, que é por volta de 1800 rpm (190,7 $\mathrm{rad} / \mathrm{s}$ ). Contudo, quanto maior o momento de inércia, menor será a amplitude de oscilação da velocidade angular. Portanto, este efeito pode ser utilizado para reduzir a vibração da máquina, bastando apenas aumentar a roda de inércia da mesma. 


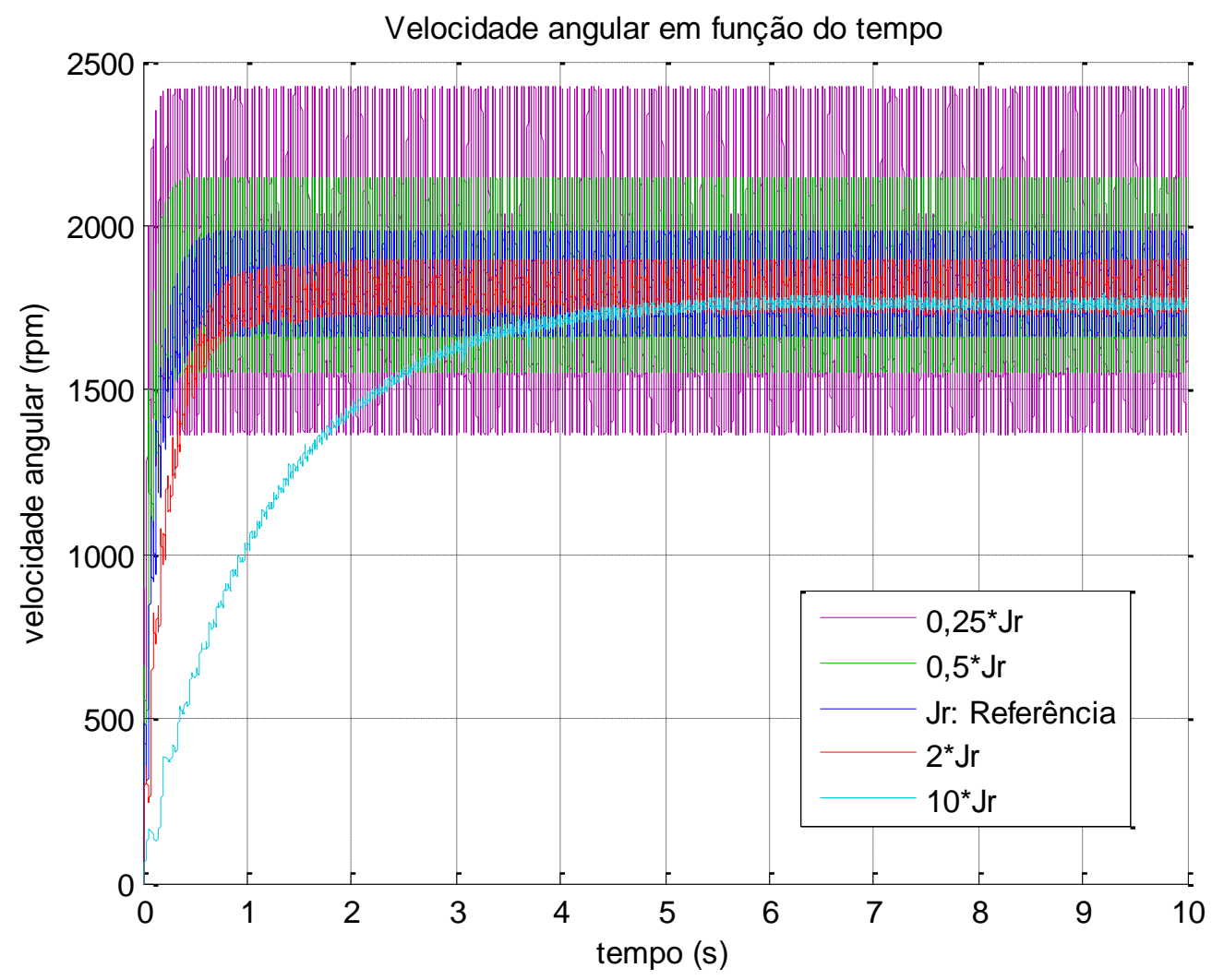

Figura 4.27 - Simulação da velocidade angular variando o momento de inércia.

\subsubsection{Coeficiente de Atrito Viscoso}

Da mesma forma que o momento de inércia, foram realizadas cinco simulações para verificar o efeito da variação do coeficiente de atrito viscoso (Figura 4.28). Tal como foi proposto, as perdas por atrito da máquina são modeladas como decorrentes de um esforço de amortecimento viscoso equivalente. Em azul, foi utilizado o valor de referência $(0,002 \mathrm{~N} . \mathrm{m} . \mathrm{s} / \mathrm{rad})$. Em vermelho foi adotado um acréscimo de $15 \%$ ao valor de referência, e em azul claro, 30\%. Em verde foi arbitrado uma redução de $15 \%$ ao valor de referência, e em roxo, 30\%. 


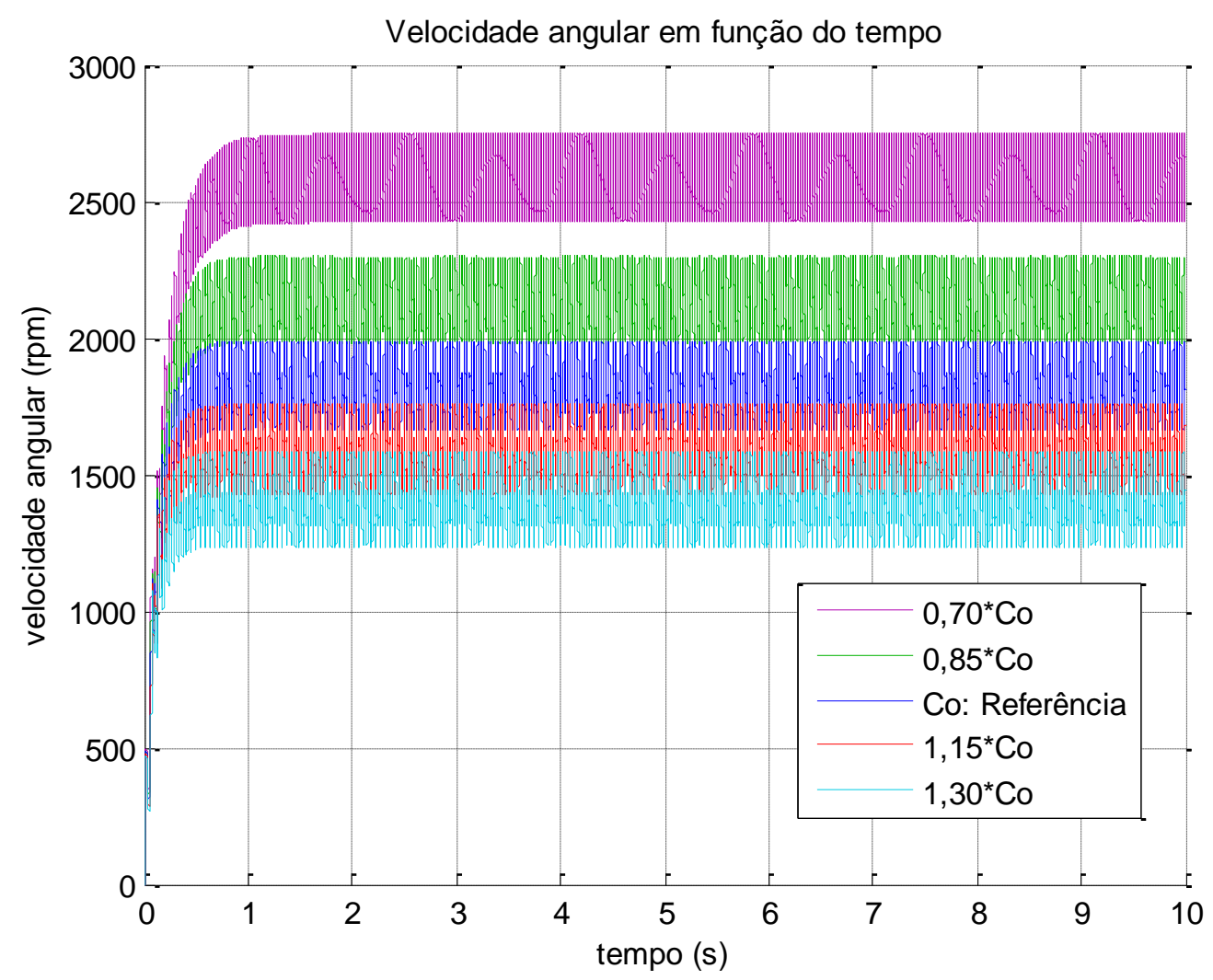

Figura 4.28 - Simulação da velocidade angular variando o coeficiente de atrito viscoso.

A partir do gráfico da Figura 4.28, é possível afirmar que a variação do coeficiente de atrito viscoso modifica tanto a velocidade média de operação quanto a frequência de oscilação da velocidade angular.

Logo, quanto menor o coeficiente de atrito viscoso, menores serão as perdas, e consequentemente, maior será a velocidade de rotação. Já a frequência de oscilação está diretamente ligada à velocidade de operação, portanto, quanto maior a velocidade angular, maior será a frequência de oscilação. 


\subsubsection{Pressão de Entrada}

A pressão de entrada é um dos parâmetros mais importantes pois é de fácil ajuste, isto é, a partir de uma válvula reguladora de pressão é possível alterar a pressão de entrada da máquina. Assim foram feitas simulações do diagrama indicado para as seguintes pressões de entrada de 3,0 bar, 3,5 bar, 4,0 bar, 4,5 bar e 5,0 bar na Figura 4.29.

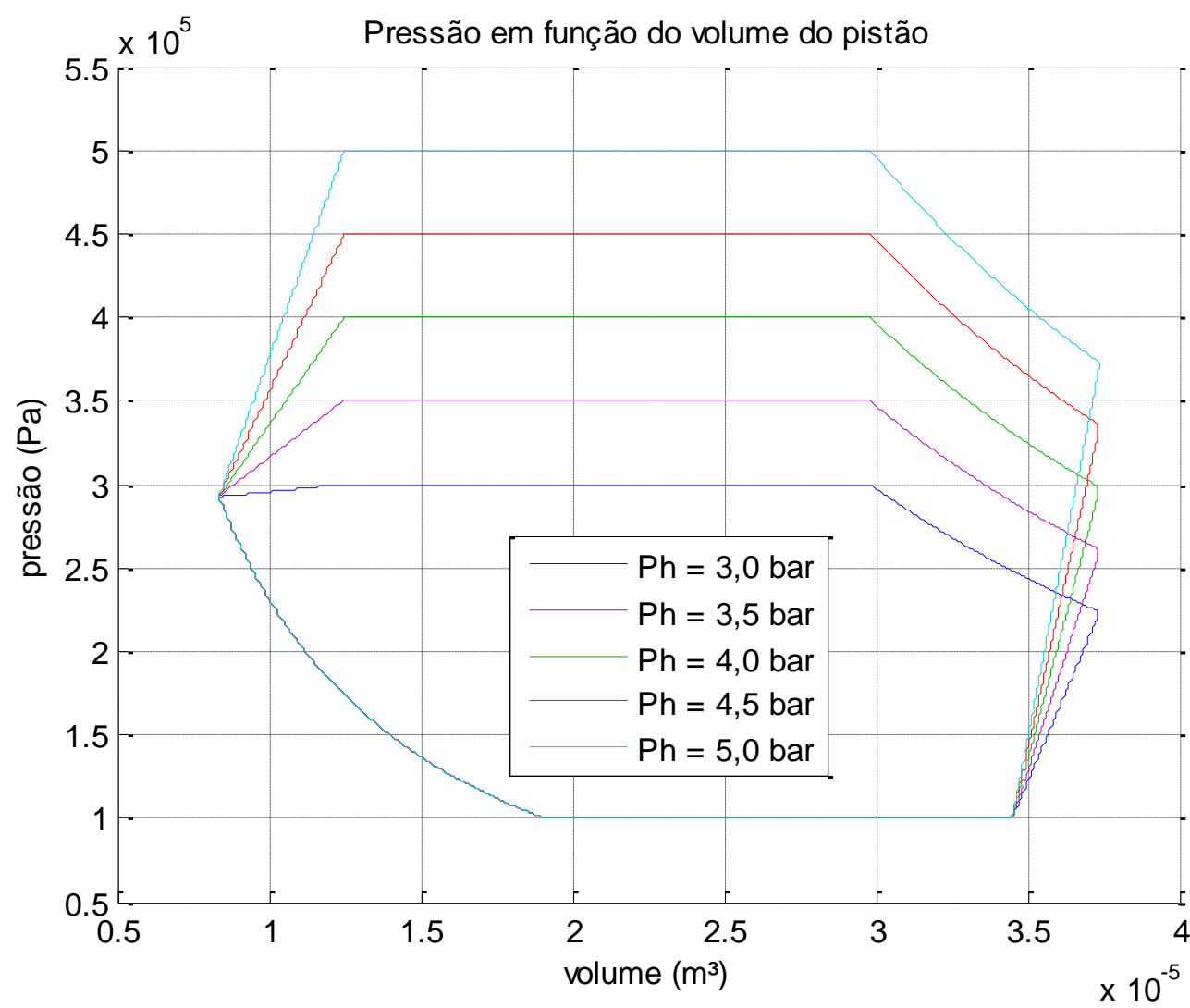

Figura 4.29 - Simulação do diagrama indicado da máquina variando a pressão de entrada.

A partir da Figura 4.29, observa-se que os pontos de abertura e fechamento das válvulas se mantêm. Constata-se que quanto maior a pressão de entrada, maior será a área interna do gráfico, logo maior é o trabalho realizado pelo fluido. 
A partir do ciclo de pressão é possível calcular a pressão resultante sobre o pistão, o resultado da simulação é mostrado na Figura 4.30:

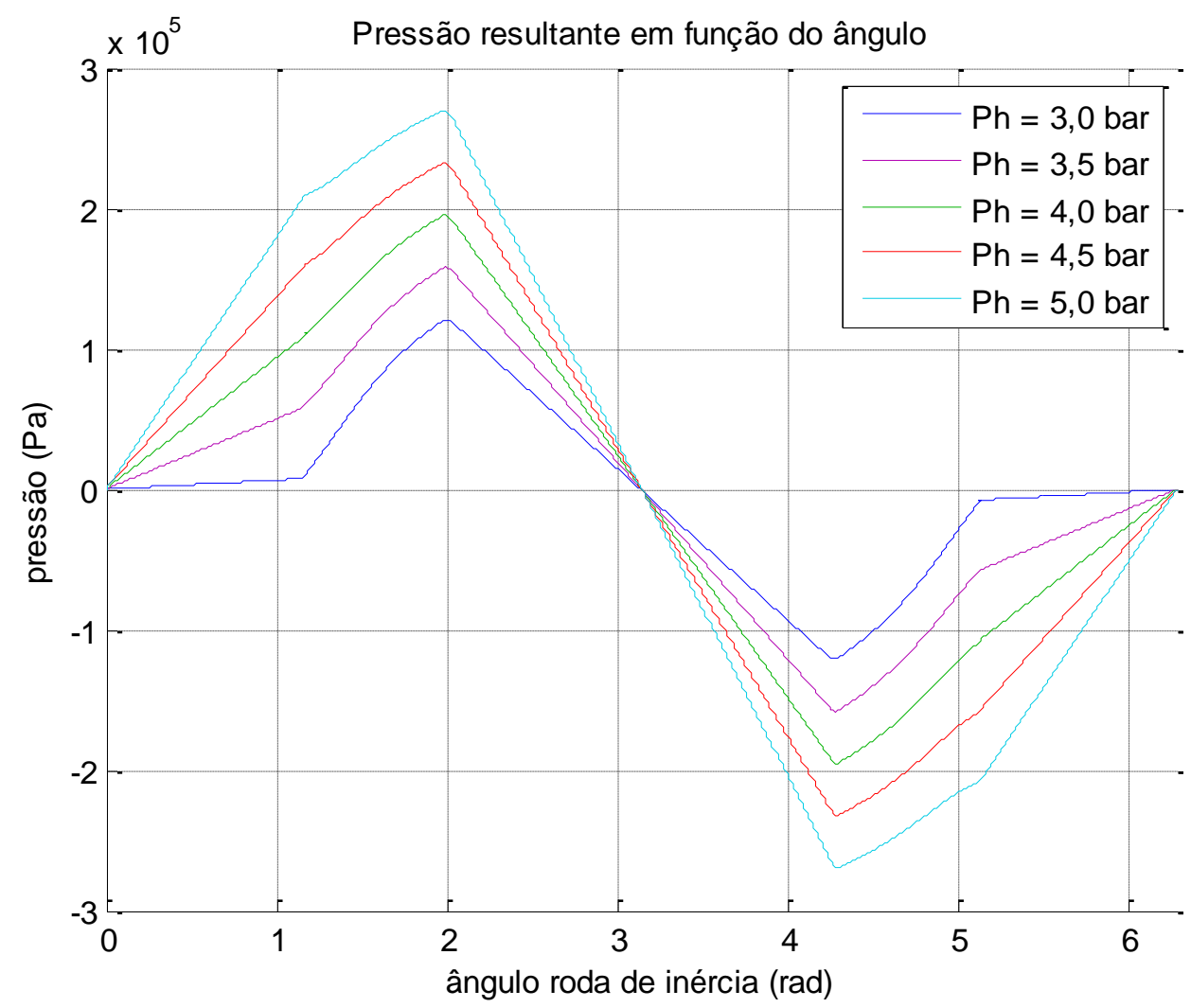

Figura 4.30 - Simulação da pressão resultante variando a pressão de entrada.

Analisando o gráfico da Figura 4.30, observa-se que quanto maior a pressão de entrada, maior será a área da pressão resultante em relação à abscissa. A pressão resultante influencia diretamente a velocidade de operação e o torque do eixo, e consequentemente, a potência. 
Simulando a velocidade angular para cada um dos perfis de pressão, obtém-se a Figura 4.31:

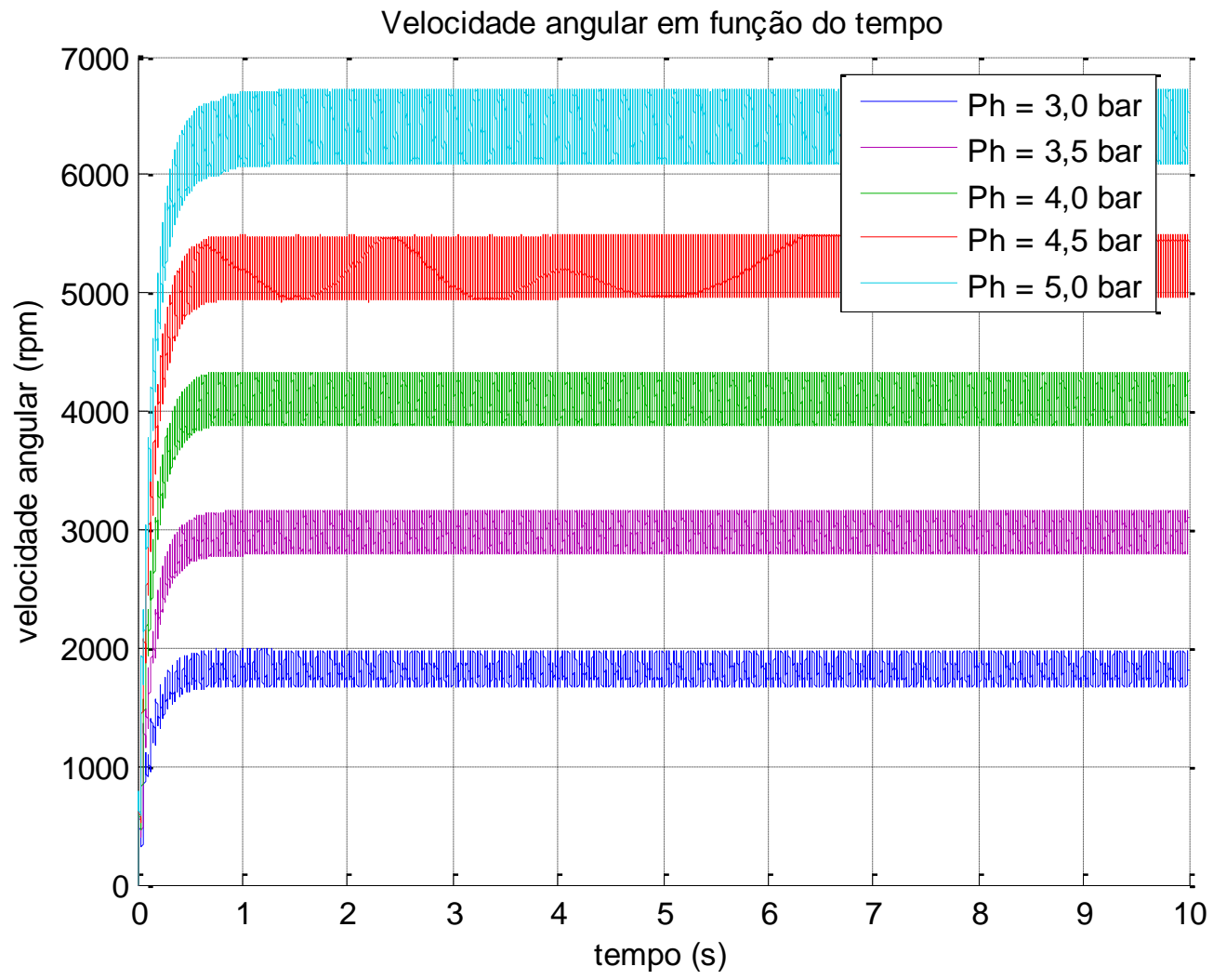

Figura 4.31 - Simulação da velocidade angular variando a pressão de entrada.

Observa-se no gráfico da Figura 4.31, que quanto maior a pressão de entrada, maior será a velocidade média de operação. Comparando a resposta para 3,0 bar com a de 5,0 bar, verifica-se que quanto maior a velocidade angular, maior será frequência de oscilação, tal como já comentado. 
Utilizando a mesma metodologia proposta anteriormente, que consiste em se aplicar um torque resistivo de valor conhecido ao eixo da máquina e realizar a medida da rotação, repetindo este processo para diversos valores de torque é possível se obter as curvas características da máquina.

Portanto, para cada pressão de entrada, foram executadas diversas simulações variando o torque resistivo e a partir da resposta dinâmica calcula-se a velocidade média de operação (Figura 4.32).

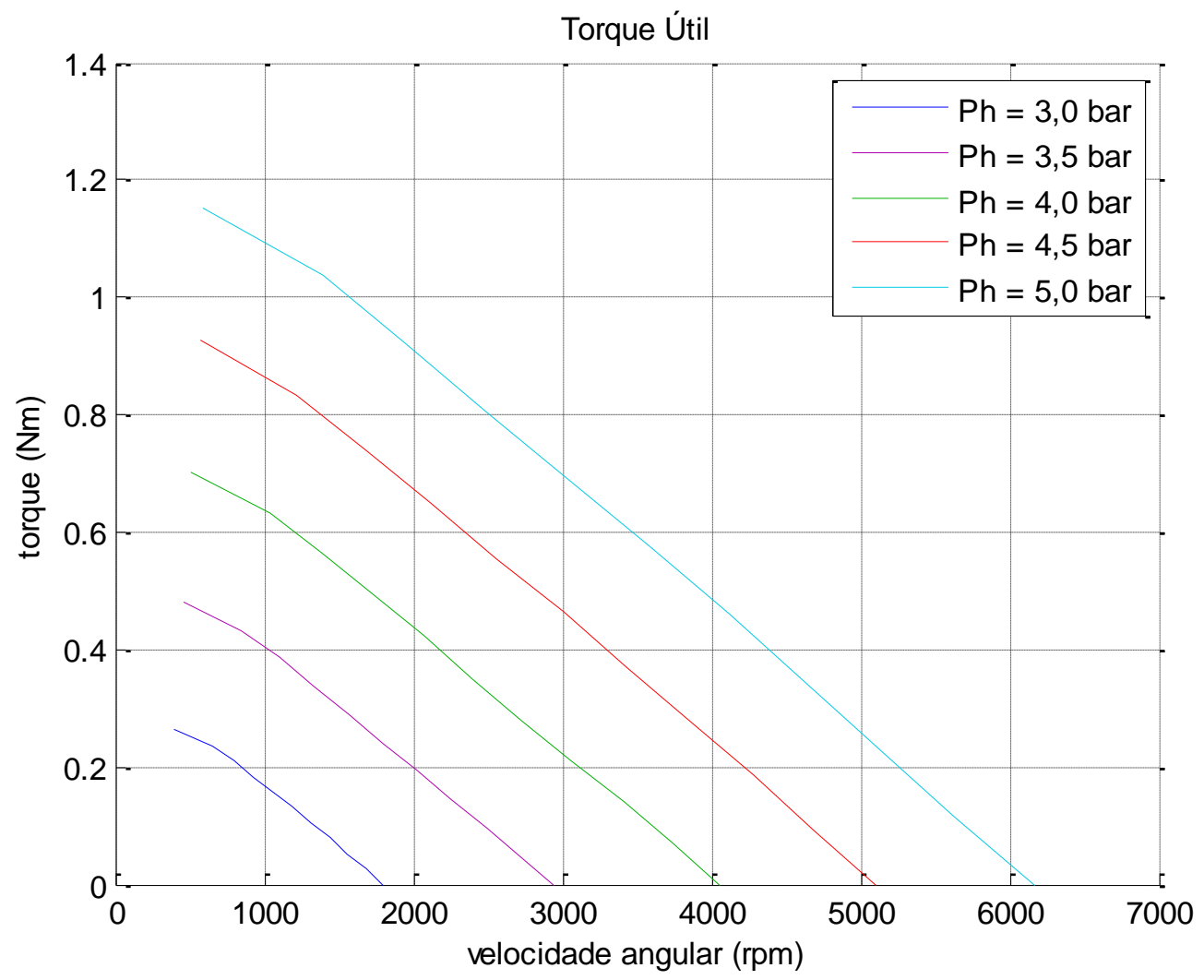

Figura 4.32 - Simulação do torque útil variando a pressão de entrada.

A curva de torque útil corresponde ao torque resistivo, isto é, o que será utilizado para gerar energia. Assim como em um motor, em rotações mais baixas apresenta maior torque útil.

Analisando o gráfico da Figura 4.32, o perfil do torque útil é semelhante para diferentes pressões. Para maiores pressões, maior será o torque útil do eixo da máquina. 
A partir das curvas de torque, obtêm-se as curvas de potência apresentadas na Figura 4.33.

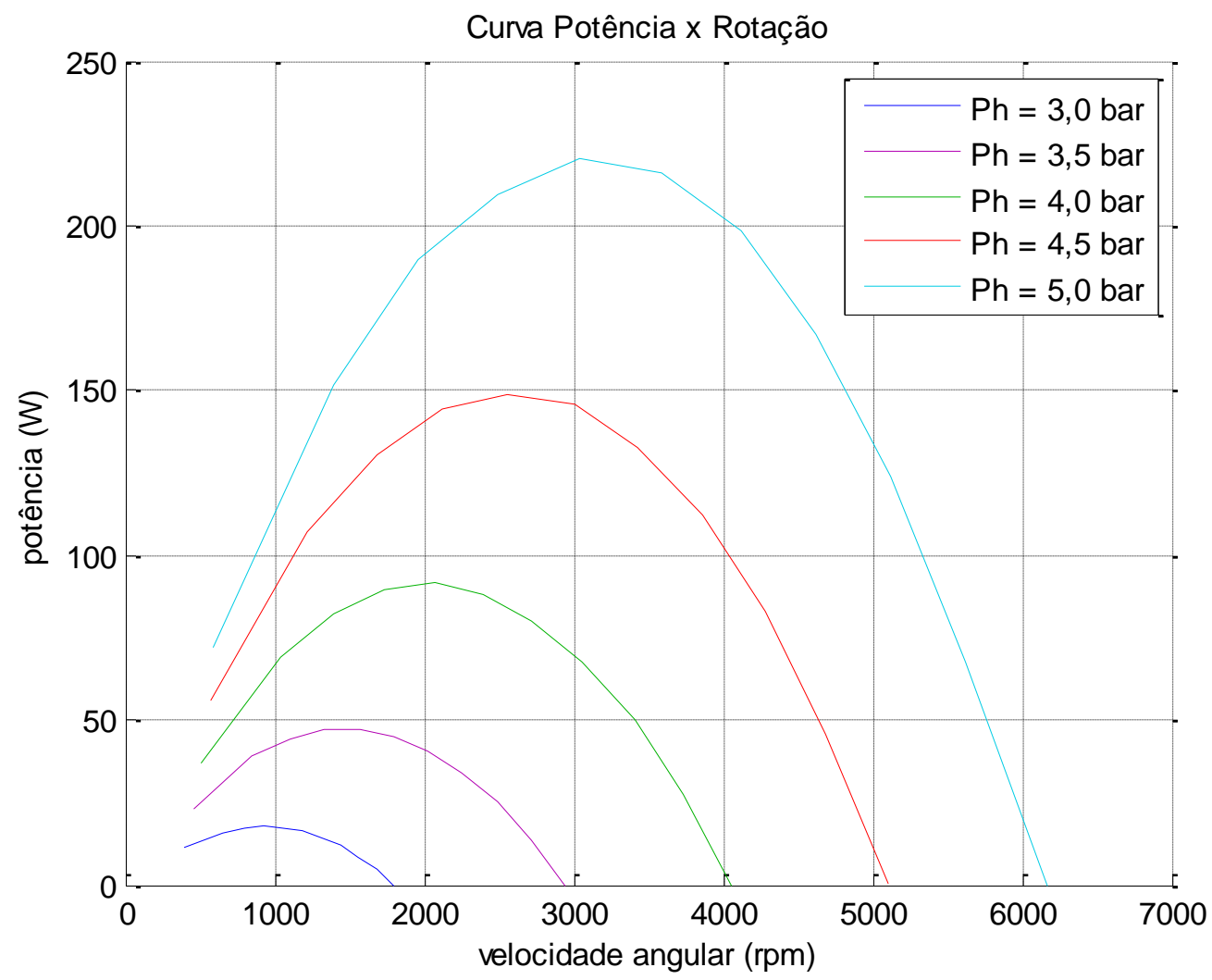

Figura 4.33 - Simulação da potência variando a pressão de entrada.

Observa-se no gráfico da Figura 4.33, que ao se aumentar a pressão de entrada, a potência aumenta. O perfil da curva de potência se torna mais côncavo para pressões de entrada mais altas. Conforme se aumenta a pressão de entrada, maior será a potência máxima e sua respectiva velocidade angular. 
Registrando os pontos de máximo torque (Figura 4.32) e máxima potência (Figura 4.33) com a pressão de entrada correspondente, obtêm-se os resultados mostrados na Tabela 4.7:

Tabela 4.7 - Principais resultados da variação da pressão de entrada.

\begin{tabular}{c|cc}
\hline Pressão de Entrada (bar) & Torque Máximo (N.m) & Potência Máxima (W) \\
\hline $\mathbf{3 , 0}$ & 0,262 & 17,8 \\
\hline $\mathbf{3 , 5}$ & 0,481 & 47,3 \\
\hline $\mathbf{4 , 0}$ & 0,703 & 91,5 \\
\hline $\mathbf{4 , 5}$ & 0,926 & 149,0 \\
\hline $\mathbf{5 , 0}$ & 1,151 & 220,4 \\
\hline
\end{tabular}

Através dos dados da Tabela 4.7 é possível traçar o gráfico da Figura 4.34:

Torque e potência máximos em função da presssão de admisssão

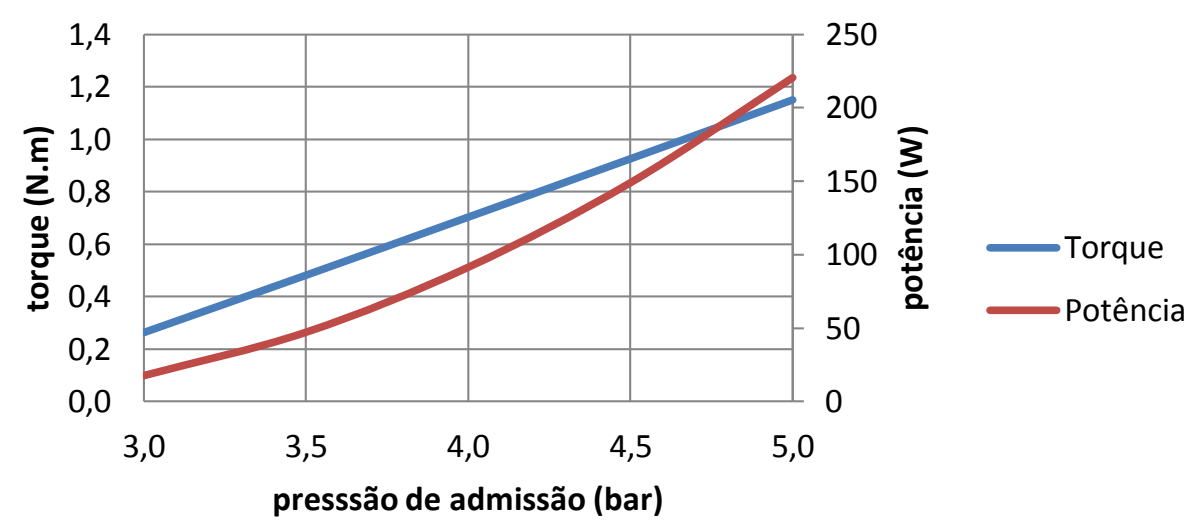

Figura 4.34 - Potência e torque máximos em função da pressão de entrada.

Examinando o gráfico da Figura 4.34 é possível afirmar que o torque máximo apresenta um crescimento linear com a pressão de entrada e a potência máxima possui um crescimento quadrático com a pressão de entrada. Portanto, a máquina deve operar a alta pressão para melhorar sua performance. 


\subsubsection{Tensão de Entrada}

Tal como a pressão, a tensão de entrada é um dos parâmetros mais importantes, pois também é de fácil ajuste, isto é, a partir de um amplificador de tensão é possível alterar a tensão de entrada da excitatriz. Para verificar os efeitos da tensão de entrada, foram realizadas cinco simulações (Figura 4.35). Em azul, foi utilizado o valor de referência (5,5 V). Em roxo, verde, vermelho e azul claro, foram adotadas reduções de 15\%, 30\%, 45\% e $60 \%$ ao valor de referência, respectivamente.

Foi adotado que o gerador é acionado após 10 segundos de operação da máquina, pois a mesma já opera em regime permanente.

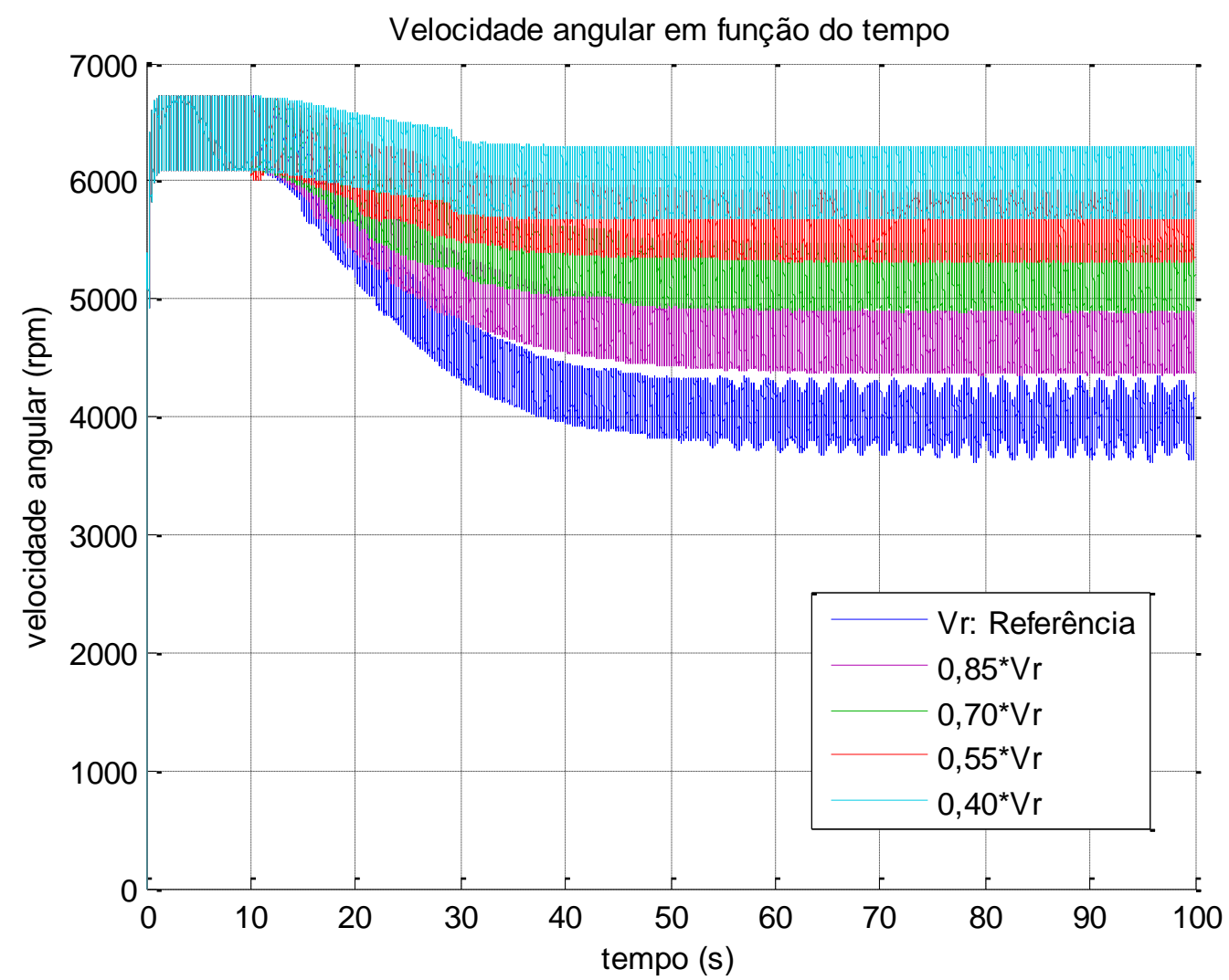

Figura 4.35 - Simulação da velocidade angular variando a tensão de entrada. 
Observa-se na Figura 4.35, que até os 10 segundos, enquanto o gerador ainda está desacionado, as cinco curvas são iguais. Após seu acionamento, o gerador impõe um torque resistivo ao eixo da máquina, e consequentemente, há uma queda na sua velocidade angular. Portanto, quanto maior a tensão de entrada, maior será o torque resistivo do gerador e, por conseguinte, menor será a velocidade final da máquina.

Simulando a tensão da excitatriz para cada tensão de entrada, obtém-se os resultados mostrados na Figura 4.36:

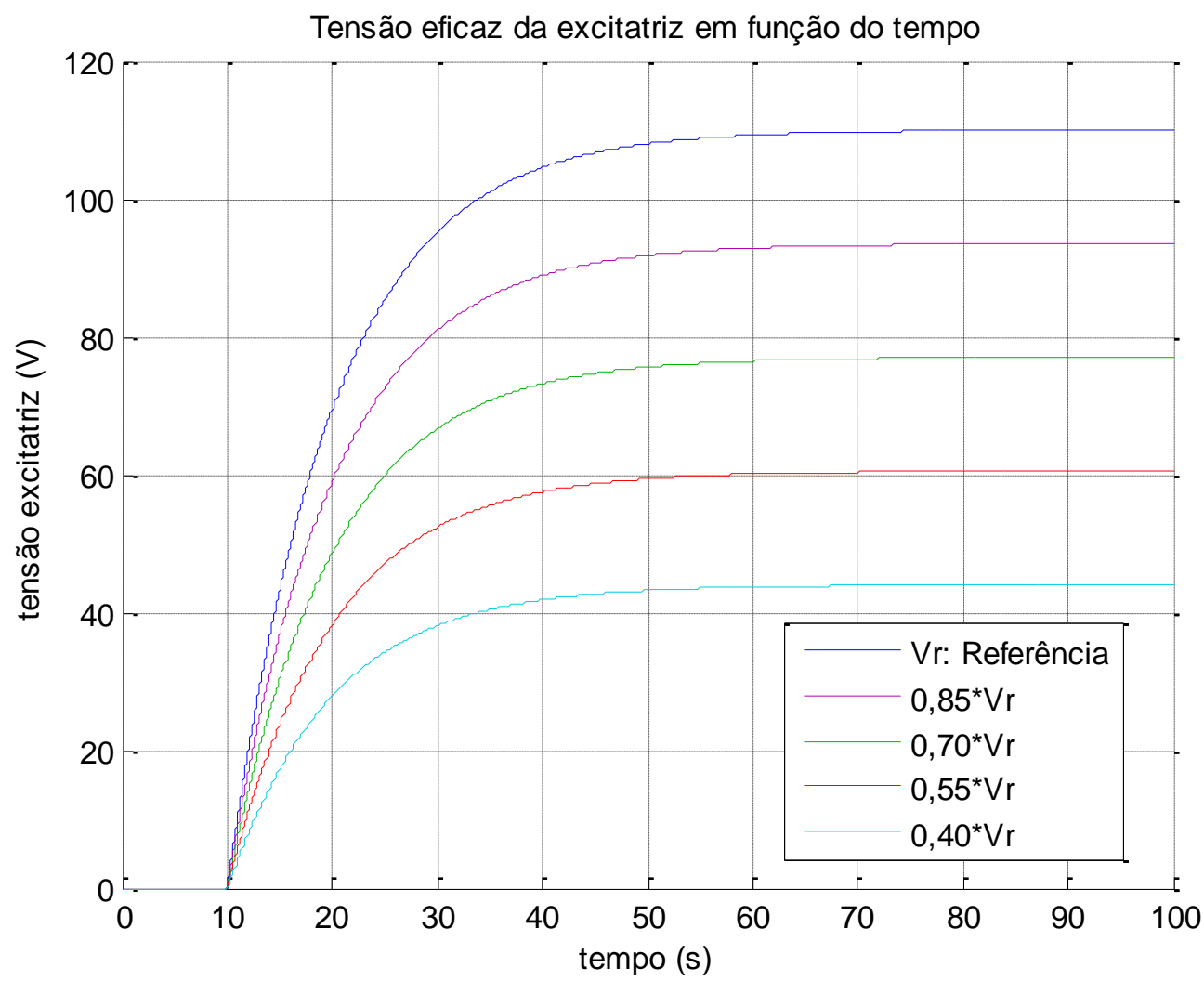

Figura 4.36 - Simulação da tensão excitatriz variando a tensão de entrada.

Analisando o gráfico da Figura 4.36, verifica-se que a tensão da excitatriz é diretamente proporcional à tensão de entrada, de acordo com o esperado ao se examinar o circuito da excitatriz. 
Através da tensão da excitatriz, é possível simular a tensão do gerador para cada tensão de entrada, o resultado da simulação é mostrado na Figura 4.37:

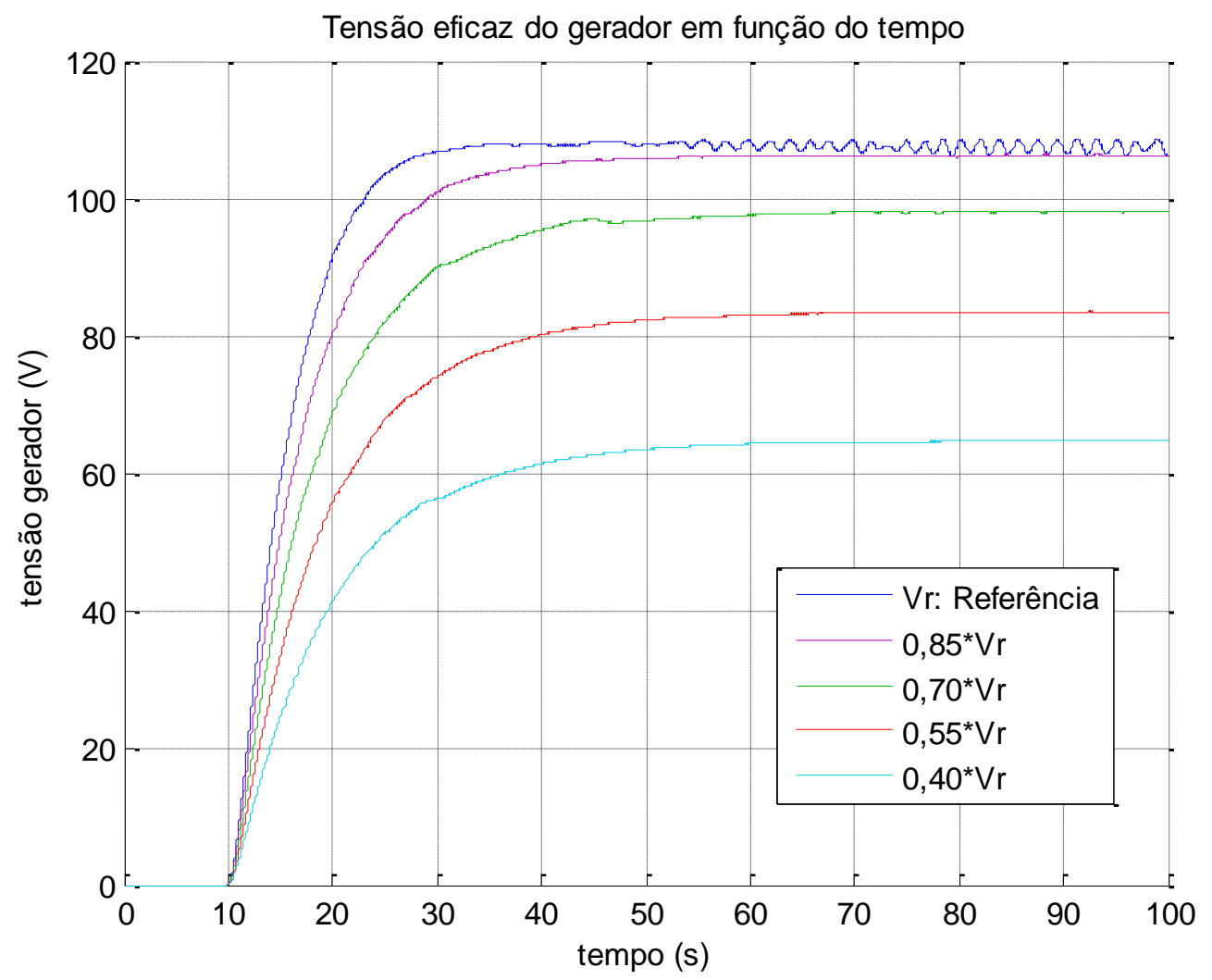

Figura 4.37 - Simulação da tensão gerador variando a tensão de entrada.

Verifica-se na Figura 4.37, que a tensão do gerador aumenta conforme a tensão de entrada é amplificada, porém o incremento da tensão do gerador vai se reduzindo para tensões de entrada mais altas. 
A frequência elétrica é diretamente proporcional à velocidade angular. Através da Figura 4.35 é obtido o gráfico da Figura 4.38:

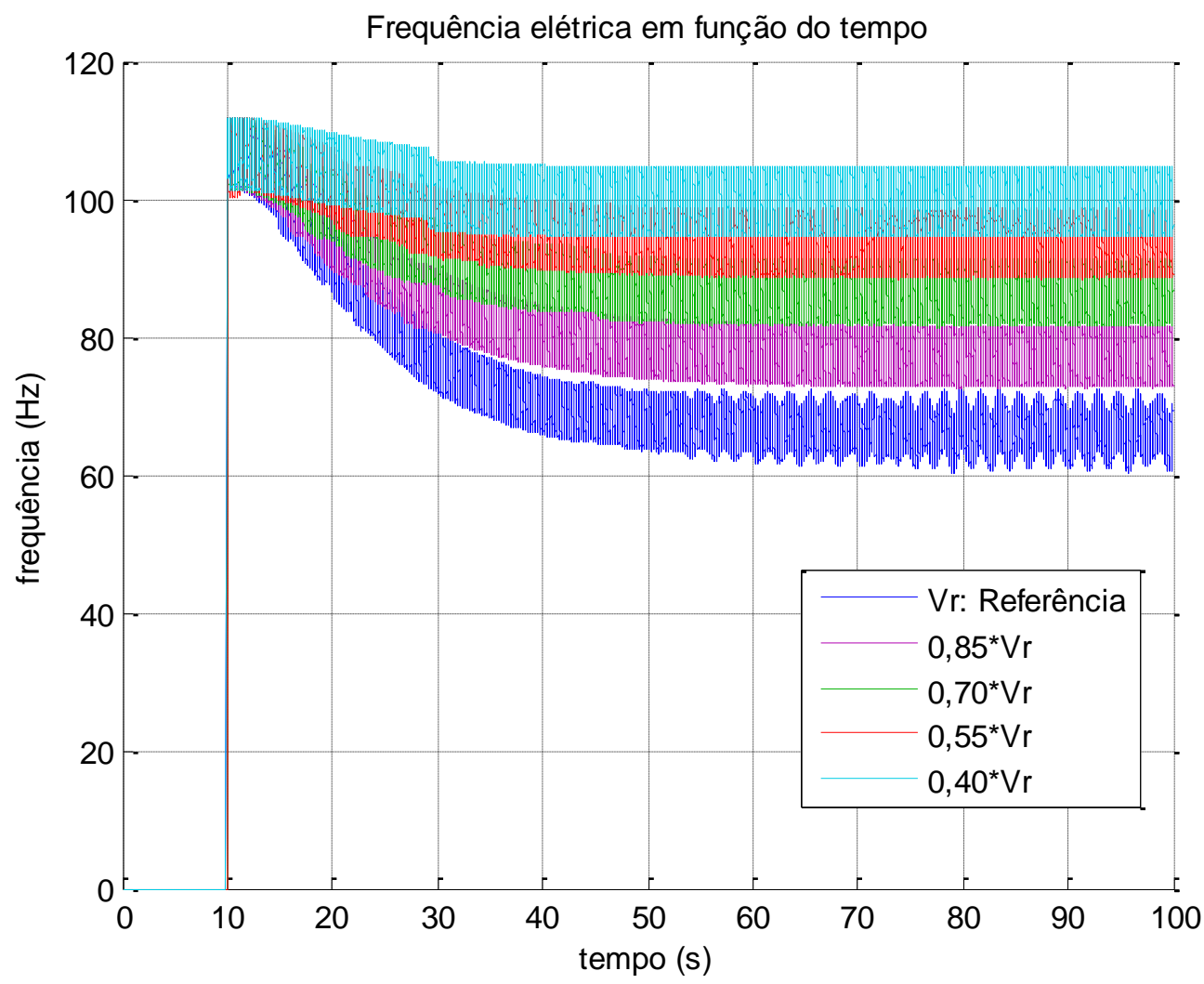

Figura 4.38 - Simulação da frequência elétrica variando a tensão de entrada.

Analogamente à velocidade angular, quanto maior a tensão de entrada, menor será a frequência elétrica. Entretanto, o decréscimo da frequência elétrica aumenta para tensões de entrada mais altas. 
Simulando a corrente do gerador para cada tensão de entrada, obtém-se a Figura 4.39:

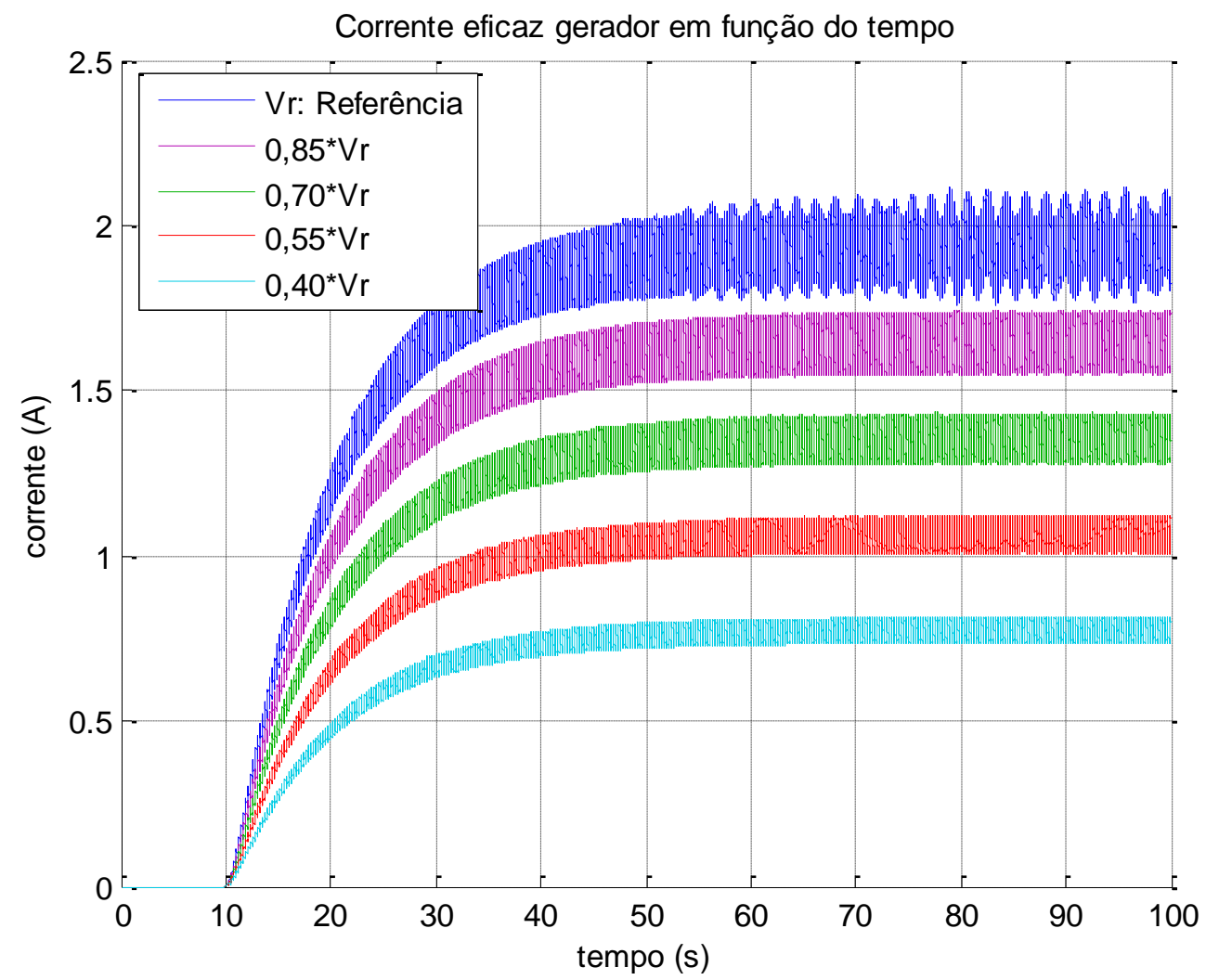

Figura 4.39 - Simulação da corrente eficaz variando a tensão de entrada.

Constata-se que quanto maior a tensão de entrada, maior será a corrente eficaz do gerador, segundo o gráfico da Figura 4.39. Levando em consideração que a tensão do gerador também aumenta com a tensão de entrada, como visto anteriormente, pode-se concluir que a potência gerada também será maior. Todavia, deve-se lembrar que parte da energia gerada é utilizada para alimentar a excitatriz.

Registrando a média da tensão da excitatriz (Figura 4.36), da tensão do gerador (Figura 4.37), da frequência elétrica (Figura 4.38) e da corrente do gerador (Figura 4.39) para cada tensão de entrada, obtêm-se os resultados da Tabela 4.8. 
Tabela 4.8 - Principais resultados da variação da tensão de entrada.

\begin{tabular}{c|cccc}
\hline $\begin{array}{c}\text { Tensão de } \\
\text { Entrada (V) }\end{array}$ & $\begin{array}{c}\text { Tensão da } \\
\text { Excitatriz (V) }\end{array}$ & $\begin{array}{c}\text { Tensão do } \\
\text { Gerador (V) }\end{array}$ & Frequência (Hz) & Corrente (A) \\
\hline $\mathbf{2 , 2 0}$ & 44 & 65 & 100 & 0,77 \\
\hline $\mathbf{3 , 0 3}$ & 60 & 83 & 94 & 1,06 \\
\hline $\mathbf{3 , 8 5}$ & 77 & 98 & 86 & 1,35 \\
\hline $\mathbf{4 , 6 8}$ & 93 & 106 & 77 & 1,64 \\
\hline $\mathbf{5 , 5 0}$ & 110 & 108 & 67 & 1,94 \\
\hline
\end{tabular}

Através dos dados da Tabela 4.8 é possível traçar os gráficos da Figura 4.40:

\section{Principais resultados do sistema elétrico}

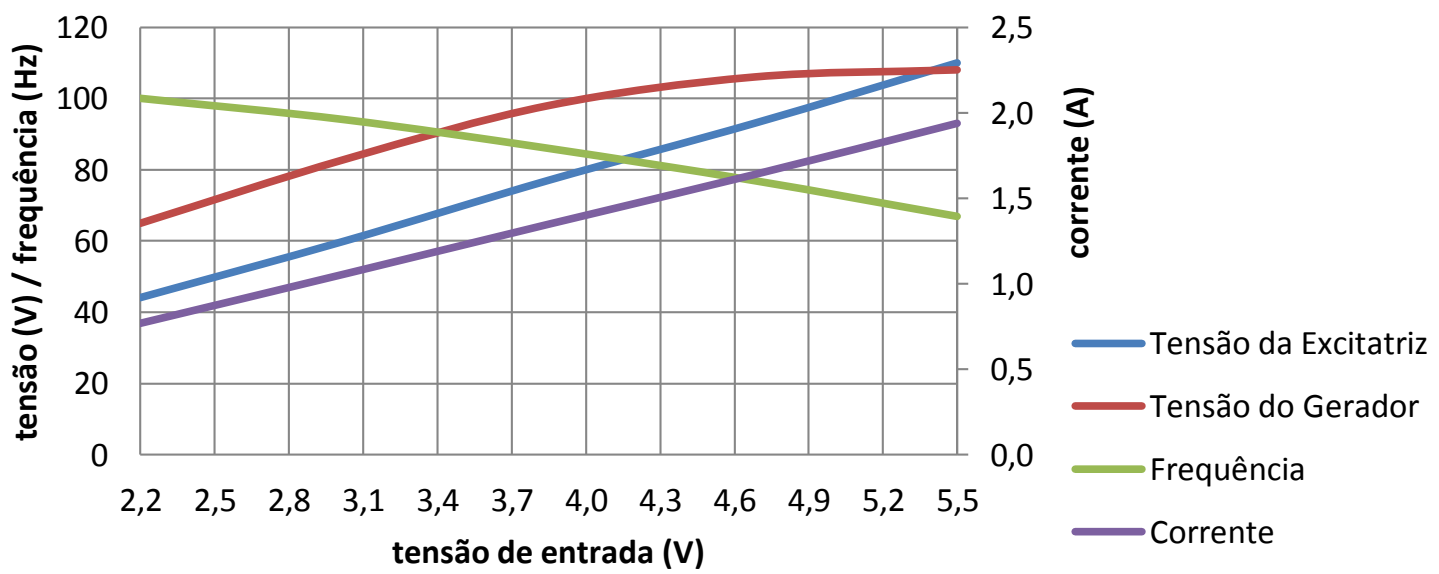

Figura 4.40 - Tensão do gerador, tensão da excitatriz, frequência elétrica e corrente do gerador em função da tensão de entrada.

Examinando o gráfico da Figura 4.40 é possível afirmar que a tensão da excitatriz e a corrente apresentam um crescimento linear com a tensão de entrada. A tensão do gerador possui um crescimento quadrático, e a frequência tem um decrescimento quadrático em relação à tensão de entrada. 


\subsubsection{Resultados}

Compilando os principais resultados da análise de sensibilidade, obtém-se a Tabela 4.9:

Tabela 4.9 - Principais resultados da análise de sensibilidade.

\begin{tabular}{c|cc}
\hline Variável & Efeito & Tendência \\
\hline Momento de inércia $(\uparrow)$ & Amplitude de oscilação $(\downarrow)$ & - \\
\hline \multirow{2}{*}{$\begin{array}{c}\text { Coeficiente de atrito } \\
\text { viscoso equivalente }(\uparrow)\end{array}$} & Velocidade angular $(\downarrow)$ & - \\
\hline \multirow{4}{*}{$\begin{array}{c}\text { Pressão de } \\
\text { admissão }(\uparrow)\end{array}$} & Pressão resultante $(\uparrow)$ & - \\
\cline { 2 - 3 } & Velocidade angular $(\uparrow)$ & Crescimento linear \\
\cline { 2 - 3 } & Torque $(\uparrow)$ & Crescimento quadrático \\
\cline { 2 - 3 } & Potência $(\uparrow)$ & Crescimento linear \\
\cline { 2 - 3 } & Telocidade angular $(\downarrow)$ & Crescimento com queda quadrática \\
\cline { 2 - 3 } entrada $(\uparrow)$ & Tensão da excitatriz $(\uparrow)$ & Decrescimento quadrático \\
\cline { 2 - 3 } & Frequência elétrica $(\downarrow)$ & Crescimento linear \\
\cline { 2 - 3 } & Corrente do gerador $(\uparrow)$ &
\end{tabular}




\section{ESTUDO EXPERIMENTAL}

O projeto inicial da máquina foi resultado do trabalho de Bassi e Machado (2011). No inicio deste estudo a máquina estava avariada e inoperante. Após a sua completa desmontagem, verificou-se a necessidade de refazer o projeto e introduzir diversas modificações visando torná-la mais robusta, melhorar sua vedação e reduzir as perdas por atrito. A vista em perspectiva da nova máquina é mostrada na Figura 5.1:

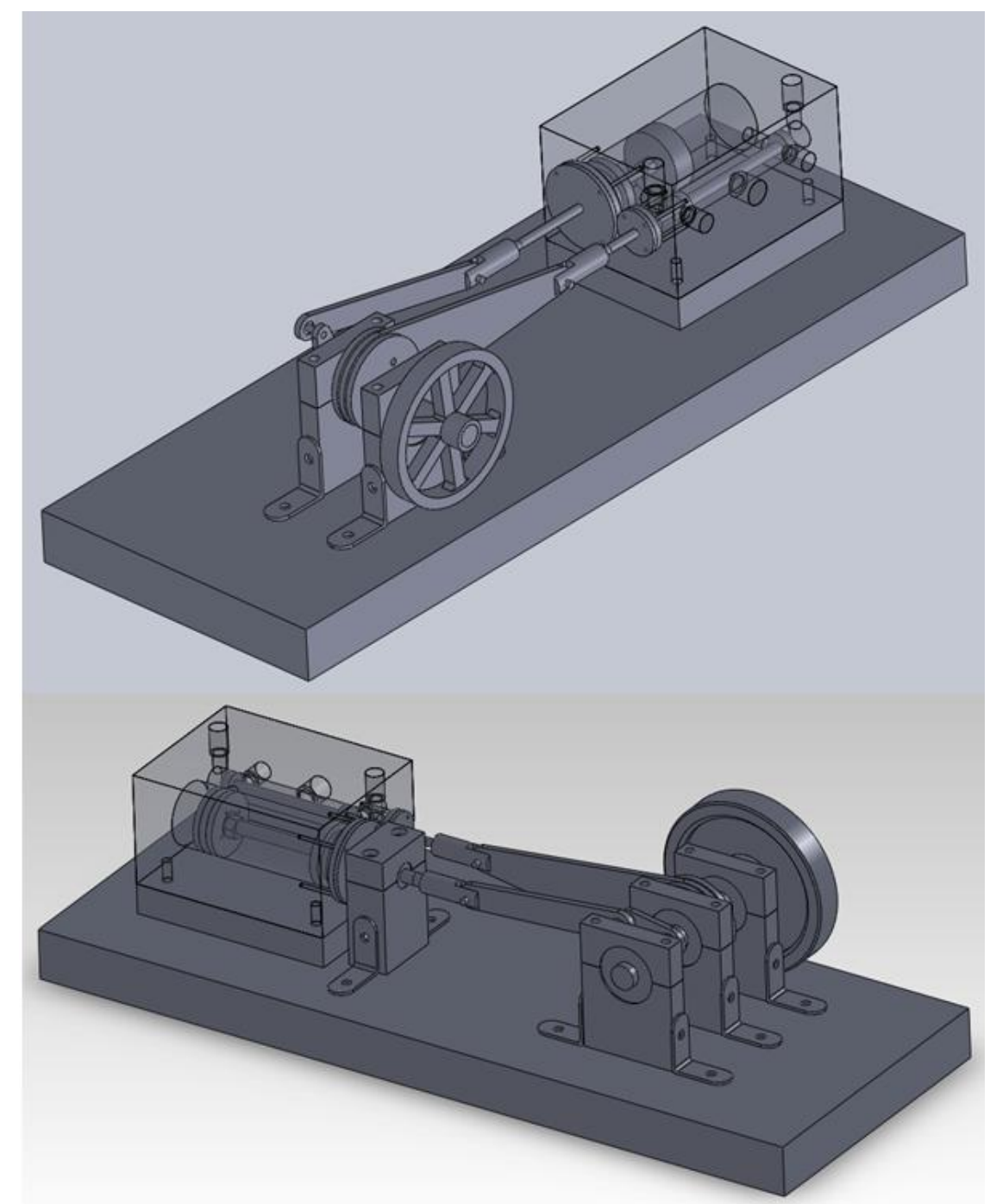

Figura 5.1 - Projeto da micromáquina a vapor : (a) original e (b) modificado.

Os desenhos, fotos e mais detalhes de cada uma das modificações são apresentados no APÊNDICE A - PROJETO DA MÁQUINA. 
O estudo experimental tem como finalidade conhecer:

- Pressão de admissão;

- Rotação;

- Torque;

- Potência;

- Vazão mássica;

- Eficiência isoentrópica;

- Curvas características da máquina a vapor.

Para se obter tais resultados, é necessário medir os seguintes parâmetros:

- Pressão do fluido na entrada da máquina;

- Torque na roda de inércia;

- Rotação no eixo da roda de inércia;

- Temperatura do fluido na entrada da máquina;

- Temperatura do fluido na saída da máquina;

- Temperatura do fluido na entrada do bocal;

- Pressão do fluido na entrada do bocal.

O objetivo do estudo experimental é compreender o funcionamento da micromáquina a vapor e analisar a influência da pressão de admissão nas suas curvas características. Desta forma, foi utilizado ar comprimido como fluido de trabalho para os experimentos, devido à sua fácil obtenção e por poder ser liberado para a atmosfera. 


\subsection{Arranjo Experimental}

O esquema do arranjo experimental é ilustrado na Figura 5.2:

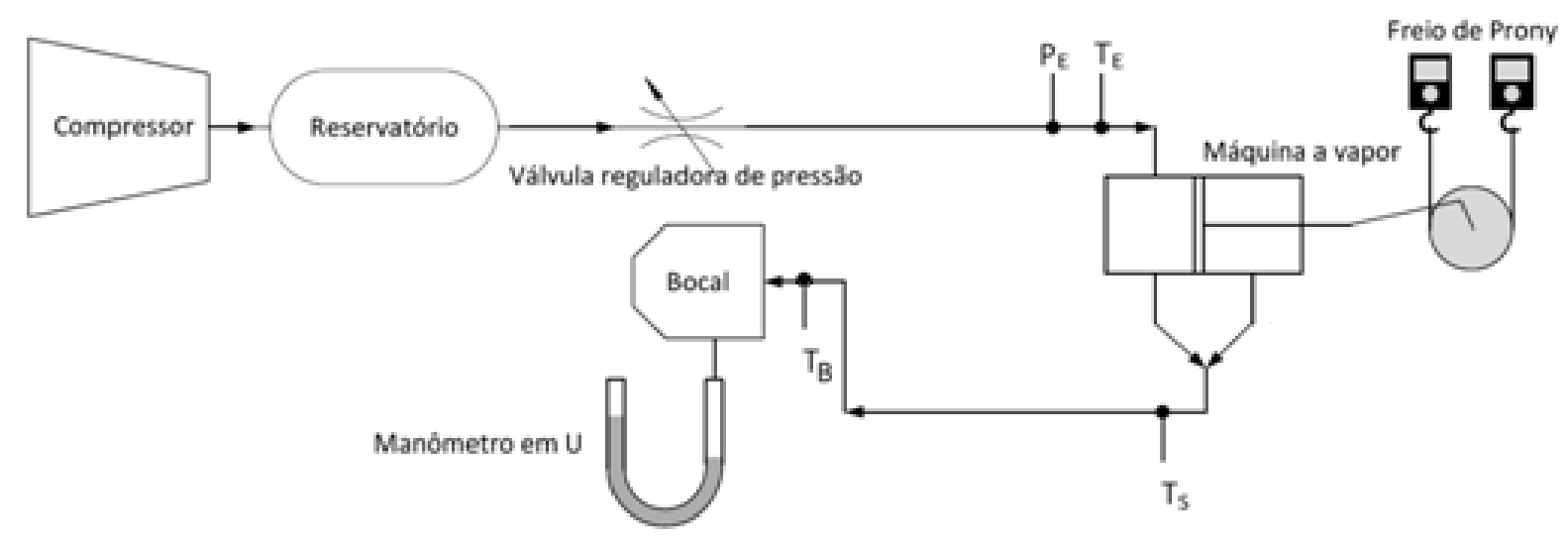

Figura 5.2 - Esquema do arranjo experimental.

Observa-se que o compressor fornece ar comprimido a um reservatório. Após o reservatório há uma válvula reguladora de pressão, a qual regula a pressão de admissão da máquina. Na tubulação de admissão (Figura 5.3) são medidas a pressão e a temperatura do ar comprimido antes de entrar na máquina.

Na máquina a vapor são obtidos os valores de torque e de rotação, utilizando o freio de Prony e o tacômetro. Na tubulação de escape (Figura 5.3) é medida a temperatura do ar comprimido após sair da máquina. E por fim, no bocal convergente é medida a temperatura de entrada do ar comprimido na seção (1) (Figura 5.13) e a pressão através do manômetro em U.

As tubulações de admissão e de escape, onde os termopares e o manômetro serão instalados, são mostradas na foto da Figura 5.3:

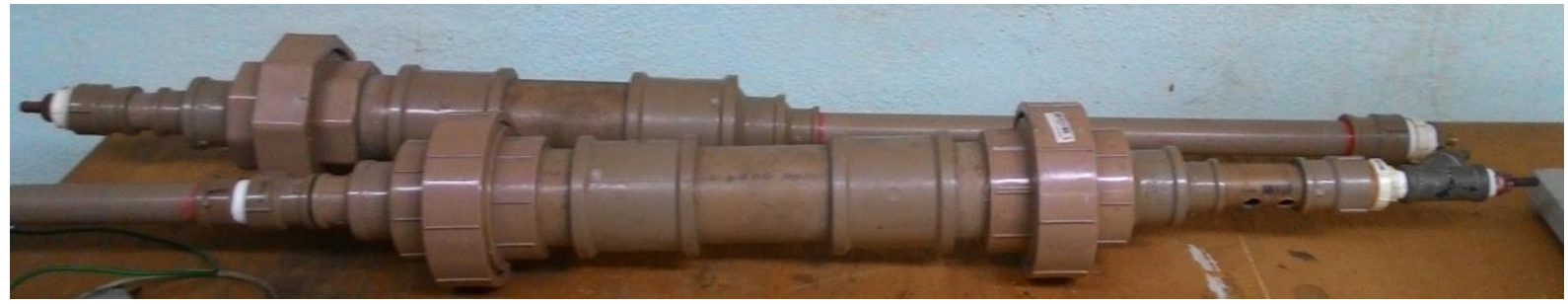

Figura 5.3 - Tubulações de admissão e de escape. 


\subsection{Instrumentação}

Este item aborda a seleção dos instrumentos utilizados para medir a pressão de admissão, o torque, a rotação, as temperaturas e a vazão mássica.

\subsubsection{Manômetro}

Para indicar a pressão de admissão da máquina, foi selecionado o manômetro ilustrado na foto da Figura 5.4:

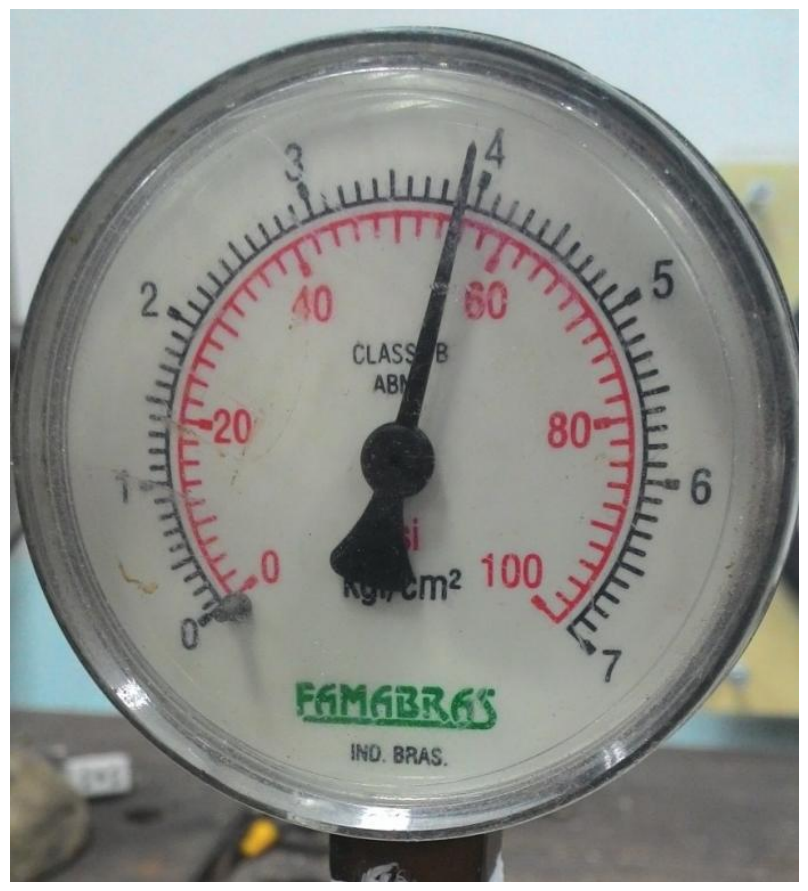

Figura 5.4 - Manômetro utilizado nos testes.

Este manômetro é fabricado pela Famabras e é Classe B de acordo com a ABNT. Mede pressões de 0 a $7 \mathrm{kgf} / \mathrm{cm}^{2}$ com um fundo de escala de $0,1 \mathrm{kgf} / \mathrm{cm}^{2}$. É indicado em aplicações que utilizem gás GLP, gás natural ou ar comprimido como fluido de trabalho. Possui diâmetro de 62mm e entrada do tipo 1/4 NPT. 


\subsubsection{Freio de Prony}

Os valores do torque da máquina foram mensurados de forma indireta, através do mecanismo chamado freio de Prony, cujo o esquema é ilustrado na Figura 5.5:

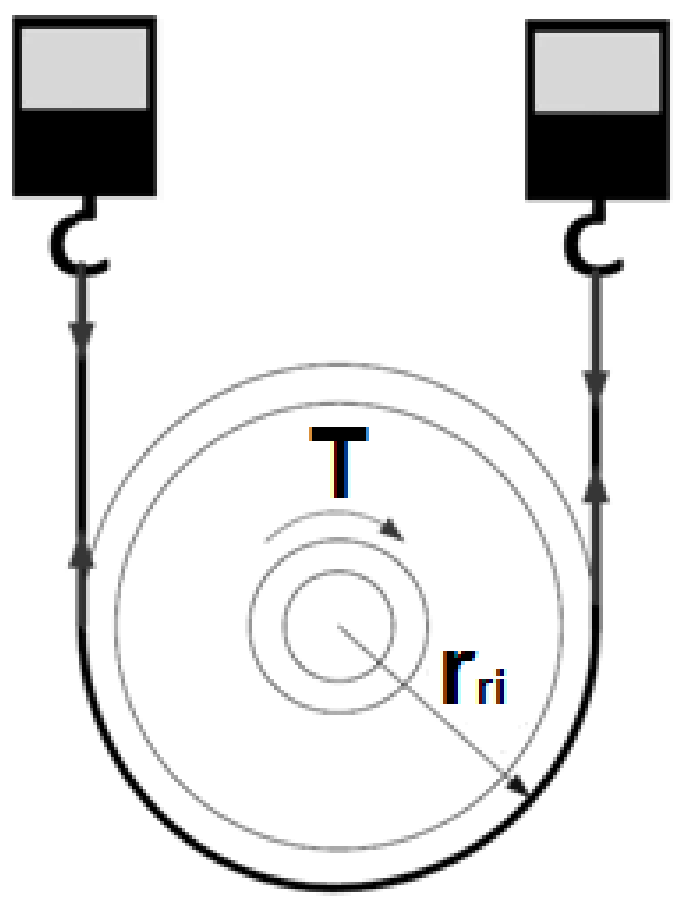

Figura 5.5 - Esquema do freio de Prony.

O freio de Prony consiste em dois dinamômetros e uma tira de couro. Os dinamômetros registram as forças exercidas em cada uma das extremidades da tira de couro, a qual é utilizada para atritar com a roda de inércia, freando a máquina.

O torque resistivo exercido pela tira de couro sobre a roda de inércia faz com que as forças nas suas extremidades sejam diferentes. Desta forma é possível calcular o torque através da seguinte equação:

$$
T=\Delta F_{\text {dinamômetros }} \cdot r_{r i}
$$


Porém devido à facilidade e ao menor custo de aquisição, ao invés dos dinamômetros, foram utilizadas balanças de gancho que são mostradas na foto da Figura 5.6:

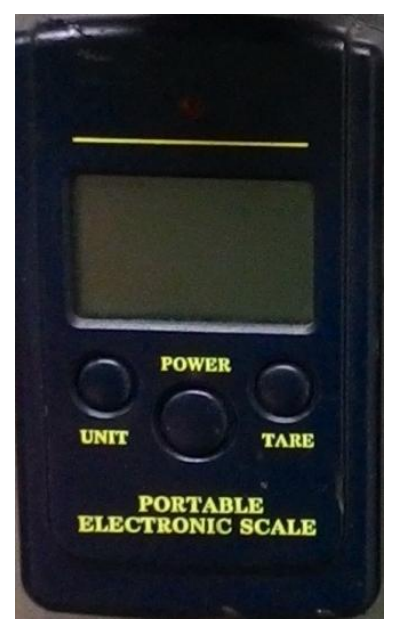

Figura 5.6 - Balanças de gancho utilizadas nos testes.

As balanças de gancho utilizadas medem de 0 a $40 \mathrm{~kg}$, com fundo de escala de $0,01 \mathrm{~kg}$.

Entretanto, devido ao uso das balanças de gancho, o cálculo do torque sofre uma pequena alteração, apresentada abaixo:

$$
T=\Delta m_{\text {balanças }} \cdot g \cdot r_{r i}
$$

O freio de Prony utilizado nos testes é ilustrado na Figura 5.7.

É possível observar que foi utilizada uma chapa de metal com dois rasgos como base para o freio de Prony. A chapa foi fixada verticalmente através de três mãos francesas. Os rasgos da chapa permitem o deslocamento vertical das balanças de gancho, e a régua foi utilizada como referência para tal deslocamento. 


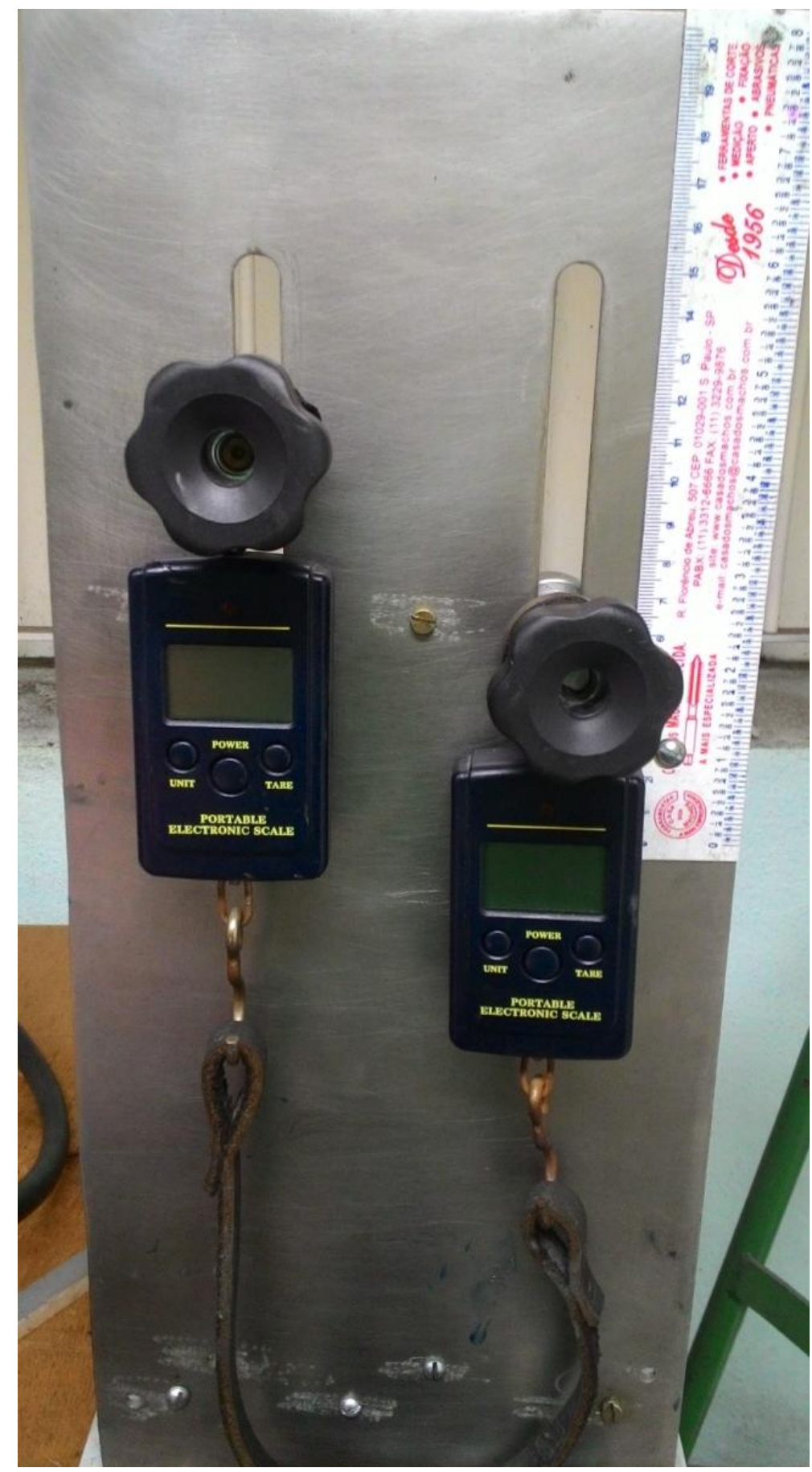

Figura 5.7 - Freio de Prony utilizado nos testes.

Portanto, ao se movimentar uma das balanças para cima ou para baixo, o atrito entre a tira de couro e a roda de inércia se altera, variando os valores medidos pelas balanças e, consequentemente, o torque calculado. 


\subsubsection{Tacômetro}

Para medir a velocidade angular da máquina, foi utilizado o tacômetro mostrado na Figura 5.8:

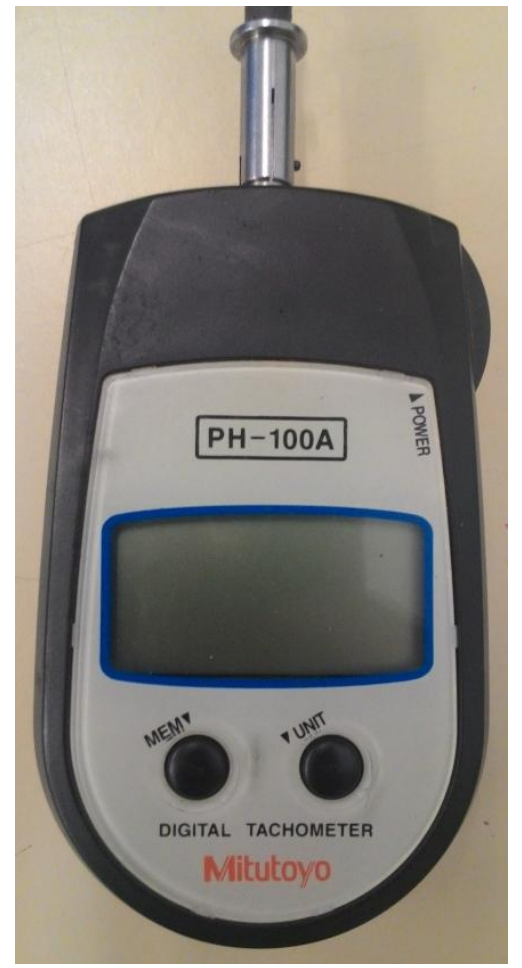

Figura 5.8 - Tacômetro utilizado nos testes.

O tacômetro é fabricado pela Mitutoyo e seu modelo é PH-100A. Mede de 1,0 a 25.000 rpm. Possui a seguinte precisão:

- De 1,0 a 599,5 rpm: \pm 1 rpm;

- De 600,0 a 25.000 rpm: $\pm 0.006 \%$.

Este tacômetro realiza a medida a partir do contato direto com o centro do eixo. Portanto, as medidas foram realizadas na extremidade livre do eixo da roda de inércia. 


\subsubsection{Termopares}

Para as medidas de temperaturas, foram utilizados termopares do tipo $\mathrm{K}$, pois as suas características são adequadas para a aplicação e devido à sua disponibilidade. A foto de um dos termopares é mostrada na Figura 5.9:

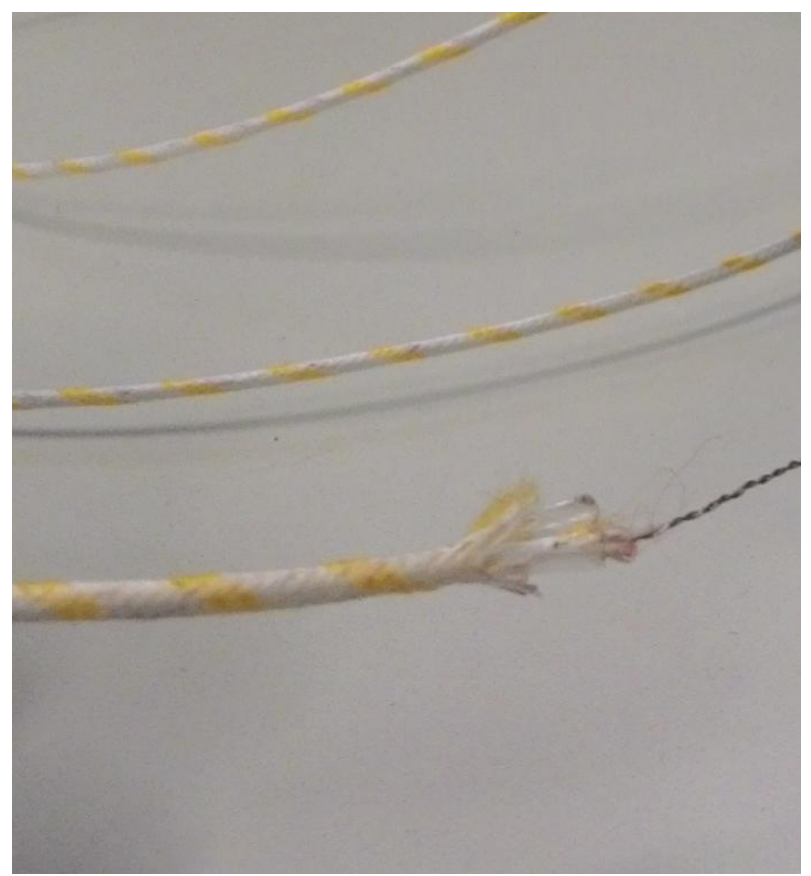

Figura 5.9 - Termopar do tipo K utilizado nos testes.

As informações técnicas dos termopares do tipo K utilizados são:

- Fio amarelo: chromel, positivo (+);

- Fio vermelho: alumel, negativo (-);

- Medidas de 0 a $1260^{\circ} \mathrm{C}$;

- Indicado para atmosfera oxidante;

- Vulnerável em atmosferas redutoras. 
Para realizar a leitura das medidas de temperatura feitas pelo termopar, foi utilizado o módulo controlador de temperatura N1040, o qual é ilustrado na foto da Figura 5.10:

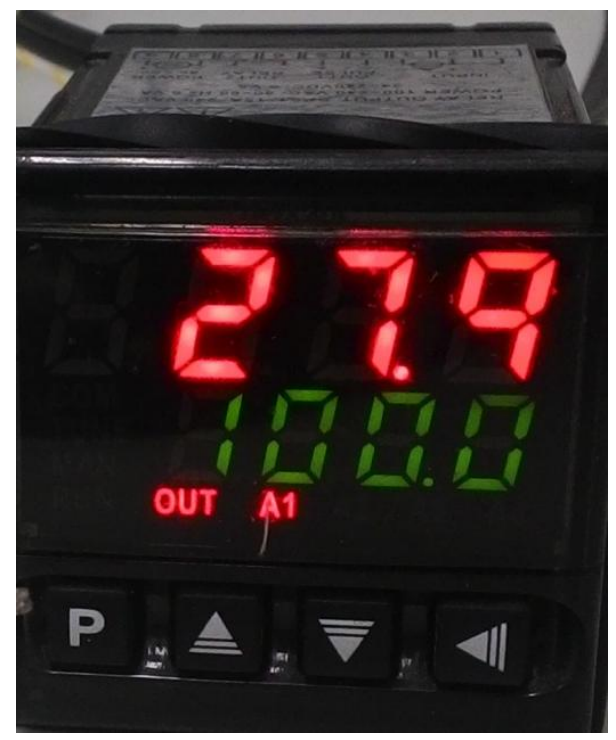

Figura 5.10 - Módulo controlador de temperatura N1040.

Devido à disponibilidade, à fácil instalação e operação, foram utilizados três módulos para as medidas de temperatura.

As informações técnicas dos módulos controladores de temperatura N1040 são:

- Aceita termopares do tipo J, K, T e termorresistência Pt100;

- Alimentação: corrente alternada: de 100 a 240 Vca ( $\pm 10 \%), 50 / 60 \mathrm{~Hz}$ e corrente contínua: de 48 a 240 Vcc $( \pm 10 \%)$;

- Taxa de leitura da entrada: até 55 por segundo;

- Precisão: Termopares J, K, T: 0,25\% do span $\pm 1{ }^{\circ} \mathrm{C}$ e Pt100: 0,2 \% do span. 


\subsubsection{Bocal com Manômetro em U}

A vazão mássica foi mensurada de forma indireta através de um bocal convergente conectado a um manômetro em $\mathrm{U}$. O bocal convergente foi projetado de acordo com a norma NBR ISO 5167-1 (1994) e seu desenho técnico é mostrado na Figura 5.11:

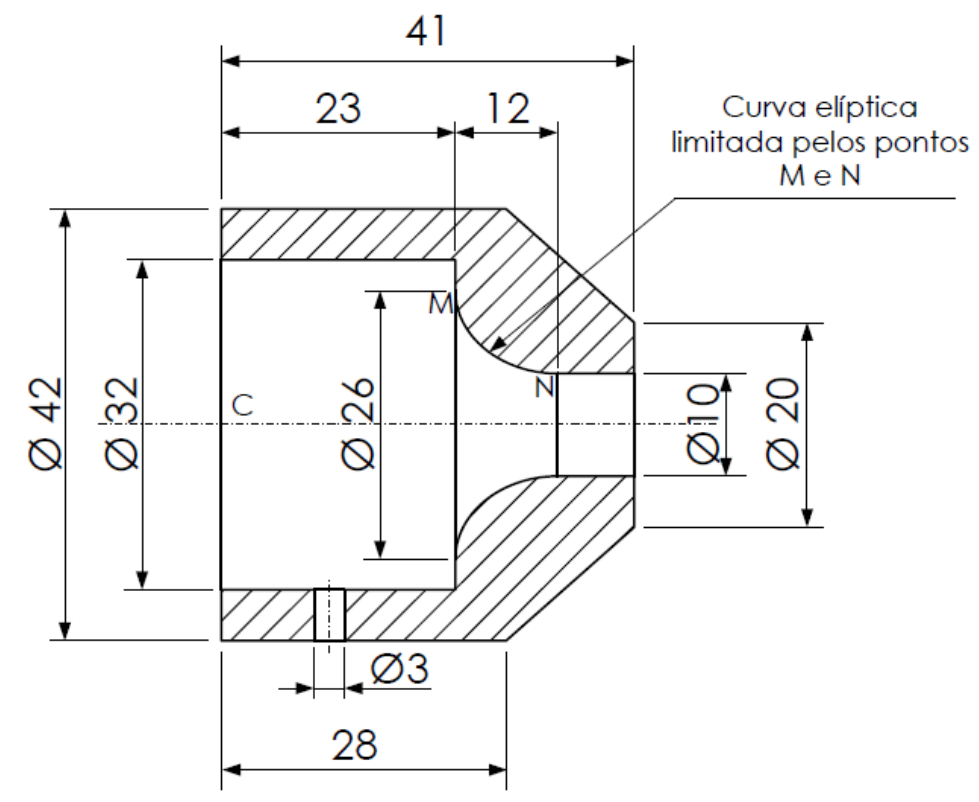

Figura 5.11 - Projeto do bocal convergente para medição da vazão conforme a norma NBR ISO 5167-1 (1994).

Tomando o ponto $\mathrm{C}$ da Figura 5.11 como origem do sistema de coordenadas, a curvatura do bocal (curva $\mathrm{M}-\mathrm{N}$ ) é uma elipse, representada pela seguinte equação matemática:

$$
y=13-8 \cdot \sqrt{1-\frac{(35-x)^{2}}{12^{2}}}[\mathrm{~mm}]
$$


O bocal foi usinado por uma máquina de comando numérico computadorizado (CNC) e o mesmo é ilustrado na foto da Figura 5.12:

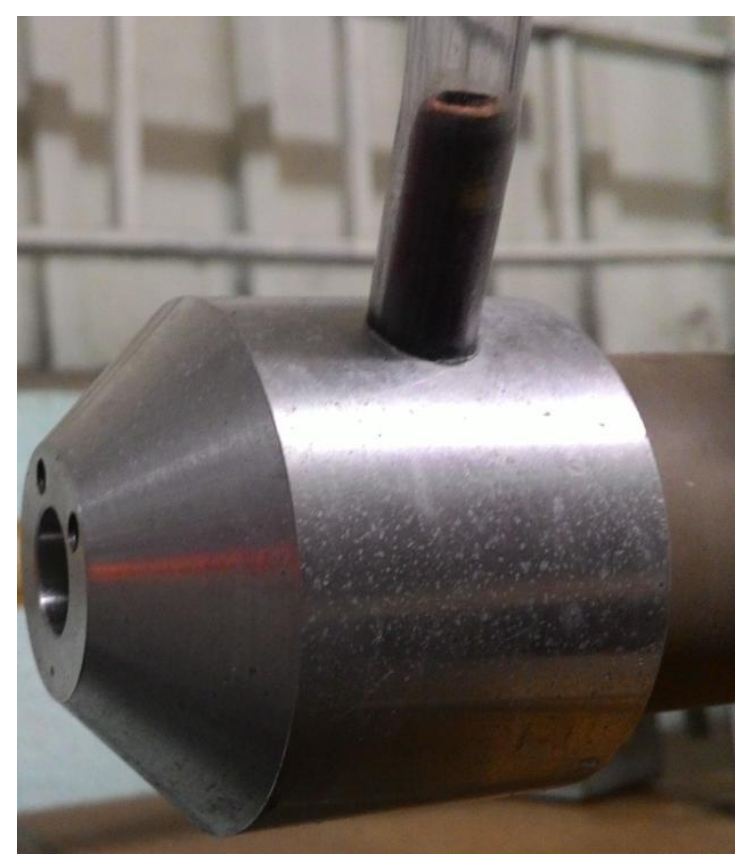

Figura 5.12 - Bocal convergente para medição da vazão utilizado nos testes.

Na seção (1) (escoamento do fluido na entrada do bocal) é conectado o manômetro em U; a seção (2) (escoamento do fluido na saída do bocal) é livre para a atmosfera. Ambas as seções são ilustradas no esquema da Figura 5.13:

(1)

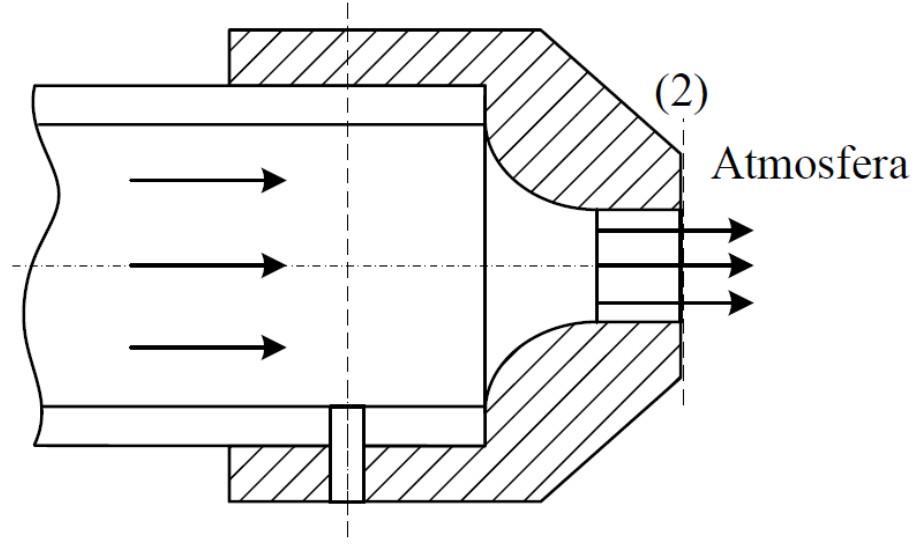

Figura 5.13 - Esquema do bocal convergente para medição de vazão acoplado à extremidade da tubulação de escape. 
O manômetro em U utilizado nos testes é ilustrado na foto da Figura 5.14:

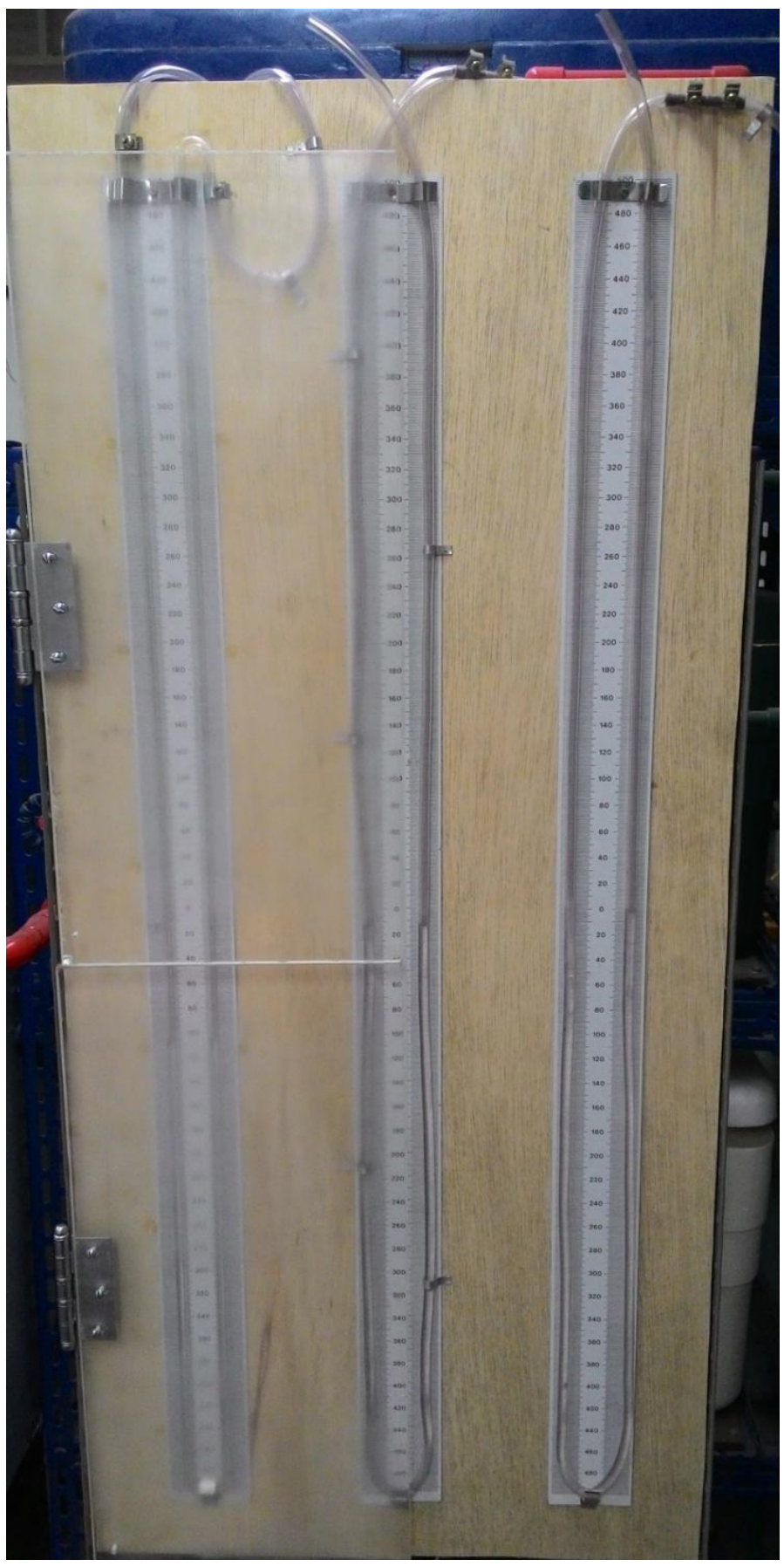

Figura 5.14 - Manômetro em U utilizado nos testes.

Observa-se que se utilizou água como fluido manométrico, e a graduação da régua é de $1 \mathrm{~mm}$. Apenas o manômetro da direita foi usado nos testes. 
Considerando o escoamento compressível, a equação da velocidade do escoamento na seção (1) é dada por:

$$
v_{1}=\sqrt{\frac{2 \cdot c_{p} \cdot T_{1} \cdot\left(1-\left(\frac{P_{a t m}}{P_{1}}\right)^{\left(\frac{k-1}{k}\right)}\right)}{\left(\frac{A_{1}}{A_{2}}\right)^{2} \cdot\left(\frac{P_{1}}{P_{a t m}}\right)^{\frac{2}{k}}-1}}
$$

A diferença de pressão entre a seção (1) e a seção (2) é medida pelo manômetro em $\mathrm{U}$ e é dada pela densidade do fluido manométrico, a gravidade e a diferença de altura do fluido. Como a seção (2) é livre para atmosfera, sua pressão é igual à atmosférica. Portanto, pode-se determinar a pressão na seção (1) da seguinte forma:

$$
P_{1}=P_{a t m}+\rho_{\text {água }} \cdot g \cdot \Delta z_{\text {manômetro }}
$$

Finalmente, o valor da vazão mássica é calculado através da equação a seguir:

$$
\dot{m}=A_{1} \cdot \frac{P_{1}}{R \cdot T_{1}} \cdot v_{1}
$$




\subsection{Calibração}

Este item aborda a calibração dos instrumentos utilizados no estudo experimental: manômetro, termopares e tacômetro.

\subsubsection{Manômetro}

Para a calibração do manômetro foi utilizado como referência um manômetro de pressão absoluta, o qual é exposto na Figura 5.15:

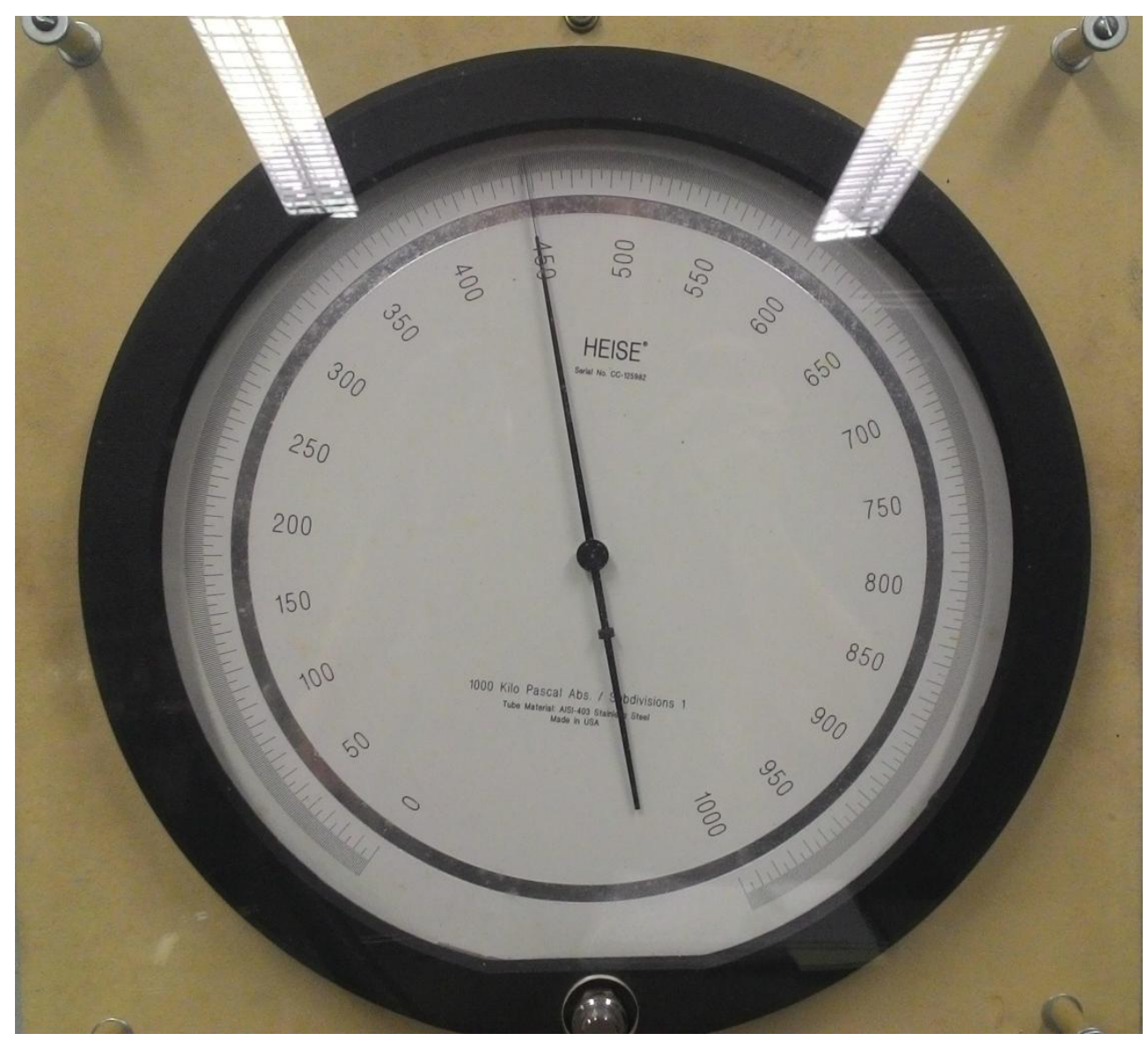

Figura 5.15 - Manômetro de pressão absoluta utilizado como referência para a calibração. 
O esquema do sistema de calibração utilizando o manômetro de pressão absoluta como referência é exibido na Figura 5.16:

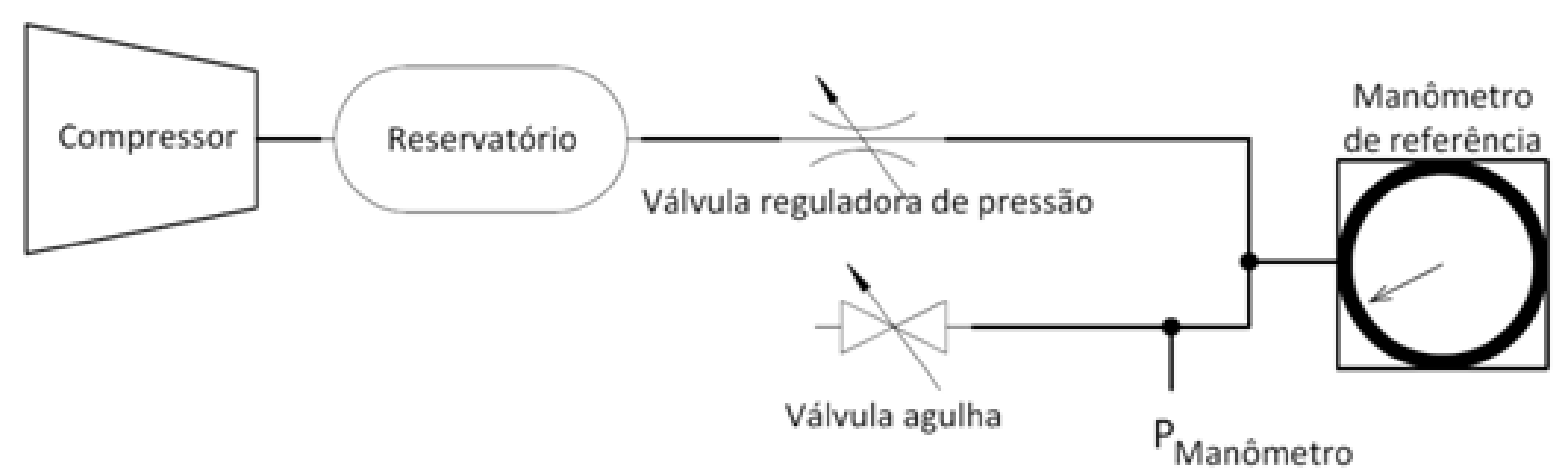

Figura 5.16 - Esquema do sistema de calibração do manômetro.

O compressor fornece ar comprimido ao sistema. Após atingir a pressão máxima tanto a válvula reguladora de pressão quanto a válvula agulha são fechadas, mantendo os manômetros pressurizados. Após cada valor medido, a válvula agulha é aberta, liberando parte do ar comprimido e reduzindo a pressão do sistema. Este processo é repetido para cada uma das medidas.

Para validar a calibração foram feitas três sequências de onze medidas. As três sequências de medidas se encontram no APÊNDICE D - TABELAS DE CALIBRAÇÃo.

Para ajustar a pressão absoluta do manômetro de referência, foi utilizado um barômetro de mercúrio para medir a pressão atmosférica.

Após se subtrair a pressão atmosférica da pressão absoluta, aplica-se o método dos mínimos quadrados para se obter os coeficientes que corrigirão a medida do manômetro para a calibrada. Tais coeficientes, bem como a correlação, são apresentados na Tabela 5.1. 
Tabela 5.1 - Coeficientes de calibração do manômetro.

\begin{tabular}{c|ccc}
\hline \multicolumn{4}{|c}{$\mathbf{P}_{\text {calibrada }}=\mathbf{a} \cdot \mathbf{P}_{\text {manometro }}+\mathbf{b}$} \\
\hline Medida & $\mathbf{a}$ & $\mathbf{b}$ & $\mathbf{R}^{\mathbf{2}}$ \\
\hline $\mathbf{1}$ & 0,957582 & $-0,235913$ & 0,999770 \\
$\mathbf{2}$ & 0,967898 & $-0,249374$ & 0,999834 \\
$\mathbf{3}$ & 0,955770 & $-0,203062$ & 0,998922 \\
\hline
\end{tabular}

Para se obter a medida calibrada, basta multiplicar a medida obtida pelo coeficiente a e somar o coeficiente $b$.

\subsubsection{Termopares}

Inicialmente, os termopares foram conectados aos módulos controladores de temperatura e fixados a uma base, como se observa na Figura 5.17:

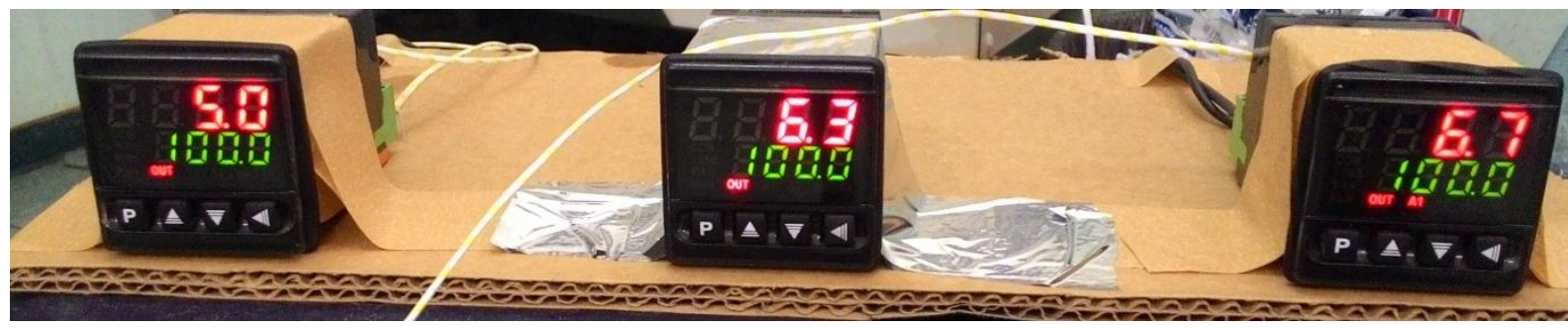

Figura 5.17 - Termopares conectados aos módulos controladores de temperatura.

Para a calibração dos termopares foram utilizados como referência dois termômetros de mercúrio, os quais são vistos na foto da Figura 5.18:

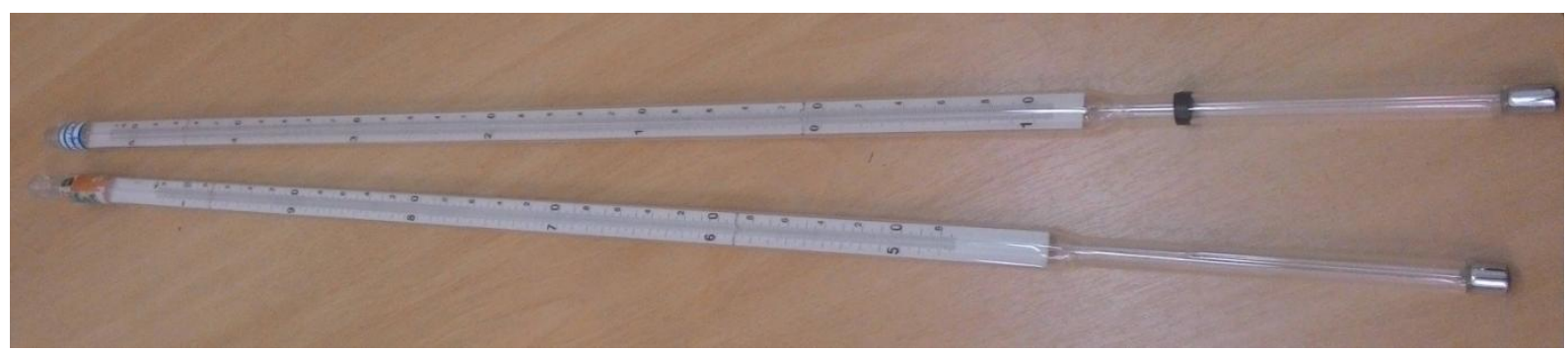

Figura 5.18 - Termômetro de mercúrio utilizado como referência para a calibração. 
Para controlar o aquecimento da água foi utilizado um banho-maria, o qual é ilustrado na Figura 5.19:

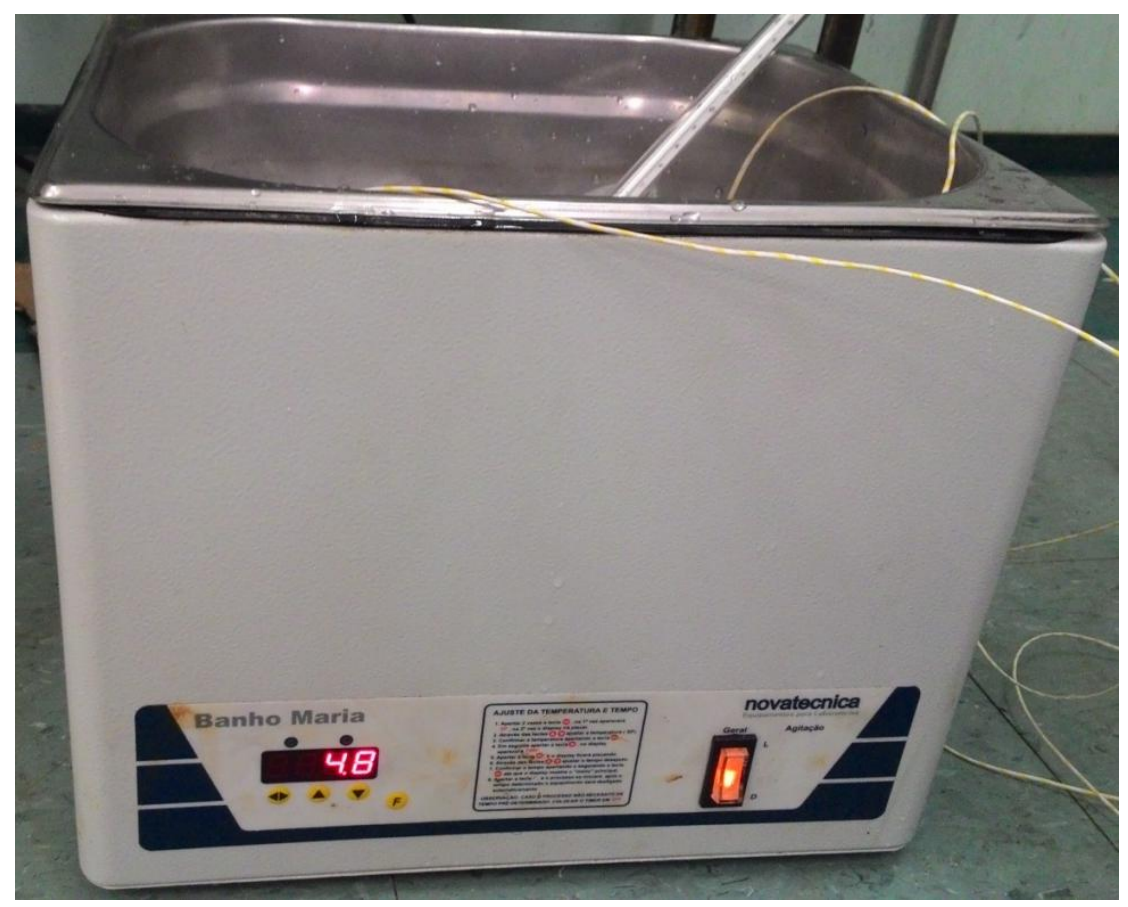

Figura 5.19 - Banho-maria NT245 utilizado para a calibração.

O banho-maria NT245 possui controlador microprocessado digital com resolução de $0,1^{\circ} \mathrm{C}$, com sistema PID. Utiliza o sensor de temperatura tipo PT 100. O sistema de aquecimento da água ocorre através de uma resistência tubular de $1000 \mathrm{~W}$, blindada em aço inox. Seu volume nominal é de 9 litros.

Inicialmente, foi utilizado gelo para se obter temperaturas próximas a $0^{\circ} \mathrm{C}$. Após a fusão do gelo, as medidas foram feitas a cada $5^{\circ} \mathrm{C}$ até atingir o ponto de ebulição.

Para validar a calibração foram feitas três sequências de medidas. As três sequências de medidas se encontram no APÊNDICE D - TABELAS DE CALIBRAÇÃo.

Analogamente à calibração do manômetro, aplica-se o método dos mínimos quadrados para se obter os coeficientes e a correlação. 
Os coeficientes de calibração do termopar 1, para cada uma das sequências de medidas, são apresentados na Tabela 5.2:

Tabela 5.2 - Coeficientes de calibração do termopar 1.

\begin{tabular}{c|ccc}
\hline \multicolumn{4}{|c}{$\mathbf{T 1}_{\text {calibrada }}=\mathbf{a} \cdot \mathbf{T} 1_{\text {termopar }}+\mathbf{b}$} \\
\hline Medida & $\mathbf{a}$ & $\mathbf{b}$ & $\mathbf{R}^{\mathbf{2}}$ \\
\hline $\mathbf{1}$ & 1,001947 & 0,321889 & 0,999658 \\
$\mathbf{2}$ & 1,000183 & 0,400484 & 0,999955 \\
$\mathbf{3}$ & 1,000446 & 0,139825 & 0,999982 \\
\hline
\end{tabular}

Analogamente, os coeficientes de calibração do termopar 2 são exibidos na Tabela 5.3:

Tabela 5.3 - Coeficientes de calibração do termopar 2.

\begin{tabular}{c|ccc}
\hline \multicolumn{4}{|c}{$\mathbf{T 2}_{\text {calibrada }}=\mathbf{a} \cdot \mathbf{T} 2_{\text {termopar }}+\mathbf{b}$} \\
\hline Medida & $\mathbf{a}$ & $\mathbf{b}$ & $\mathbf{R}^{\mathbf{2}}$ \\
\hline $\mathbf{1}$ & 1,016095 & $-1,114642$ & 0,999465 \\
$\mathbf{2}$ & 1,011210 & $-0,880788$ & 0,999948 \\
$\mathbf{3}$ & 1,010403 & $-1,026494$ & 0,999905 \\
\hline
\end{tabular}

Finalmente, os coeficientes de calibração do termopar 3, bem como a correlação, podem ser vistos na Tabela 5.4:

Tabela 5.4 - Coeficientes de calibração do termopar 3.

\begin{tabular}{c|ccc}
\hline \multicolumn{4}{|c}{ T3 $_{\text {calibrada }}=\mathbf{a} \cdot \mathbf{T} 3_{\text {termopar }}+\mathbf{b}$} \\
\hline Medida & $\mathbf{a}$ & $\mathbf{b}$ & $\mathbf{R}^{\mathbf{2}}$ \\
\hline $\mathbf{1}$ & 1,005014 & $-0,692579$ & 0,999225 \\
$\mathbf{2}$ & 1,009248 & $-1,027575$ & 0,999977 \\
$\mathbf{3}$ & 1,011072 & $-1,122629$ & 0,999831 \\
\hline
\end{tabular}

Para se obter a medida calibrada, basta multiplicar a medida obtida pelo coeficiente $a$ e somar o coeficiente $b$. 


\subsubsection{Tacômetro}

Para a calibração do tacômetro foram utilizados tornos como referência. Dentre os tornos disponíveis, as rotações variam entre 100 rpm e 2500 rpm.

Para validar a calibração foram feitas três sequências de nove medidas. As três sequências de medidas se encontram no APÊNDICE D - TABELAS DE CALIBRAÇÃo.

Analogamente à calibração do manômetro, aplica-se o método dos mínimos quadrados. Portanto, os coeficientes de calibração do tacômetro, bem como a correlação, podem ser vistos na Tabela 5.5:

Tabela 5.5 - Curva de calibração do tacômetro.

\begin{tabular}{c|ccc}
\hline \multicolumn{4}{|c}{$\boldsymbol{\omega}_{\text {calibrada }}=\mathbf{a} \cdot \boldsymbol{\omega}_{\text {tacômetro }}+\mathbf{b}$} \\
\hline Medida & $\mathbf{a}$ & $\mathbf{b}$ & $\mathbf{R}^{\mathbf{2}}$ \\
\hline $\mathbf{1}$ & 0,977317 & $-13,6519$ & 0,997980 \\
$\mathbf{2}$ & 0,981891 & $-16,6642$ & 0,998124 \\
$\mathbf{3}$ & 0,978035 & $-13,7508$ & 0,997928 \\
\hline
\end{tabular}

Para se obter a medida calibrada, basta multiplicar a medida obtida pelo coeficiente a e somar o coeficiente $b$. 


\subsection{Medições}

\subsubsection{Medidas}

Foram realizadas três sequências de teste para cada pressão de admissão. Inicialmente foram feitas 8 medidas variando o torque a 0,5 bar, posteriormente a 1,0 bar, e finalmente, a 1,5 bar. Os resultados de cada uma das sequências de teste foram agrupados na Tabela 5.6, na Tabela 5.7 e na Tabela 5.8.

Tabela 5.6 - Medidas obtidas para a primeira sequência de teste.

\begin{tabular}{|c|c|c|c|c|c|c|c|c|}
\hline $\begin{array}{l}\mathbf{P}_{\text {ref }} \\
\text { (bar) }\end{array}$ & Medida & $\begin{array}{c}\text { Manômetro } \\
\left(\mathbf{k g f} / \mathrm{cm}^{2}\right)\end{array}$ & $\begin{array}{l}\Delta \mathrm{m} \\
(\mathrm{kg})\end{array}$ & $\begin{array}{c}\text { Tacômetro } \\
\text { (rpm) }\end{array}$ & $\begin{array}{l}\text { Termopar } \\
2\left({ }^{\circ} \mathrm{C}\right)\end{array}$ & $\begin{array}{l}\text { Termopar } \\
3\left({ }^{\circ} \mathrm{C}\right)\end{array}$ & $\begin{array}{c}\text { Termopar } \\
1\left({ }^{\circ} \mathrm{C}\right)\end{array}$ & $\begin{array}{c}\text { Coluna } \\
\mathrm{H}_{2} \mathrm{O} \\
(\mathrm{mm})\end{array}$ \\
\hline \multirow{8}{*}{0,5} & 1 & 0,70 & 0,00 & 1099 & 22,3 & 19,5 & 19,4 & 44 \\
\hline & 2 & 0,70 & 0,11 & 1026 & 22,3 & 18,5 & 18,6 & 44 \\
\hline & 3 & 0,70 & 0,17 & 980 & 22,2 & 18,1 & 18,7 & 44 \\
\hline & 4 & 0,70 & 0,30 & 926 & 22,4 & 18,3 & 18,8 & 44 \\
\hline & 5 & 0,70 & 0,39 & 868 & 22,3 & 18,2 & 18,7 & 44 \\
\hline & 6 & 0,70 & 0,56 & 730 & 22,3 & 16,9 & 18,8 & 40 \\
\hline & 7 & 0,70 & 0,64 & 669 & 22,2 & 17,1 & 18,7 & 39 \\
\hline & 8 & 0,75 & 0,71 & 601 & 22,3 & 18,0 & 18,7 & 36 \\
\hline \multirow{8}{*}{1,0} & 1 & 1,25 & 0,00 & 1350 & 22,3 & 19,1 & 19,4 & 101 \\
\hline & 2 & 1,20 & 0,25 & 1167 & 22,8 & 17,4 & 18,0 & 99 \\
\hline & 3 & 1,20 & 0,36 & 1125 & 23,2 & 17,6 & 17,9 & 95 \\
\hline & 4 & 1,20 & 0,56 & 1037 & 22,9 & 16,6 & 17,8 & 92 \\
\hline & 5 & 1,25 & 0,82 & 987 & 23,3 & 15,9 & 17,4 & 89 \\
\hline & 6 & 1,30 & 0,93 & 848 & 23,2 & 15,7 & 17,3 & 83 \\
\hline & 7 & 1,30 & 1,19 & 738 & 22,3 & 15,2 & 17,6 & 77 \\
\hline & 8 & 1,30 & 1,51 & 612 & 22,4 & 15,1 & 17,5 & 70 \\
\hline \multirow{8}{*}{1,5} & 1 & 1,90 & 0,00 & 1519 & 23,9 & 19,0 & 19,3 & 199 \\
\hline & 2 & 1,85 & 0,17 & 1454 & 24,5 & 17,4 & 17,9 & 194 \\
\hline & 3 & 1,85 & 0,38 & 1370 & 24,8 & 17,4 & 17,9 & 192 \\
\hline & 4 & 1,85 & 0,61 & 1254 & 24,9 & 16,0 & 16,9 & 184 \\
\hline & 5 & 1,90 & 1,10 & 1111 & 24,9 & 14,0 & 16,3 & 166 \\
\hline & 6 & 1,90 & 1,32 & 990 & 24,9 & 14,0 & 16,3 & 164 \\
\hline & 7 & 1,95 & 1,84 & 902 & 24,7 & 13,9 & 16,8 & 150 \\
\hline & 8 & 2,05 & 2,00 & 866 & 24,2 & 14,8 & 17,2 & 153 \\
\hline
\end{tabular}


Tabela 5.7 - Medidas obtidas para a segunda sequência de teste.

\begin{tabular}{|c|c|c|c|c|c|c|c|c|}
\hline $\begin{array}{l}\mathbf{P}_{\text {ref }} \\
\text { (bar) }\end{array}$ & Medida & $\begin{array}{c}\text { Manômetro } \\
\left(\mathrm{kgf} / \mathrm{cm}^{2}\right)\end{array}$ & $\begin{array}{l}\Delta \mathrm{m} \\
(\mathrm{kg})\end{array}$ & $\begin{array}{l}\text { Tacômetro } \\
\text { (rpm) }\end{array}$ & $\begin{array}{c}\text { Termopar } \\
2\left({ }^{\circ} \mathrm{C}\right)\end{array}$ & $\begin{array}{c}\text { Termopar } \\
\mathbf{3}\left({ }^{\circ} \mathrm{C}\right)\end{array}$ & $\begin{array}{c}\text { Termopar } \\
1\left({ }^{\circ} \mathrm{C}\right)\end{array}$ & $\begin{array}{c}\text { Coluna } \\
\mathrm{H}_{2} \mathrm{O} \\
(\mathrm{mm})\end{array}$ \\
\hline \multirow{8}{*}{0,5} & 1 & 0,70 & 0,00 & 1031 & 21,5 & 20,3 & 20,0 & 40 \\
\hline & 2 & 0,70 & 0,11 & 962 & 21,7 & 18,5 & 19,1 & 41 \\
\hline & 3 & 0,70 & 0,21 & 932 & 21,8 & 18,4 & 19,1 & 40 \\
\hline & 4 & 0,70 & 0,31 & 854 & 21,6 & 18,0 & 18,8 & 39 \\
\hline & 5 & 0,70 & 0,41 & 692 & 21,7 & 17,3 & 18,2 & 37 \\
\hline & 6 & 0,70 & 0,49 & 721 & 21,7 & 17,4 & 18,4 & 33 \\
\hline & 7 & 0,70 & 0,58 & 633 & 21,6 & 17,2 & 18,2 & 30 \\
\hline & 8 & 0,75 & 0,79 & 531 & 21,7 & 17,8 & 19,5 & 29 \\
\hline \multirow{8}{*}{1,0} & 1 & 1,20 & 0,00 & 1279 & 22,7 & 18,3 & 18,1 & 99 \\
\hline & 2 & 1,20 & 0,22 & 1190 & 23,0 & 18,1 & 18,1 & 97 \\
\hline & 3 & 1,20 & 0,36 & 1127 & 23,1 & 16,9 & 17,8 & 94 \\
\hline & 4 & 1,20 & 0,54 & 1032 & 23,1 & 16,9 & 17,5 & 91 \\
\hline & 5 & 1,25 & 0,78 & 898 & 23,1 & 15,1 & 17,2 & 83 \\
\hline & 6 & 1,25 & 0,96 & 803 & 23,5 & 15,2 & 17,2 & 79 \\
\hline & 7 & 1,30 & 1,13 & 737 & 23,1 & 14,7 & 16,8 & 75 \\
\hline & 8 & 1,30 & 1,36 & 689 & 23,2 & 14,9 & 17,1 & 70 \\
\hline
\end{tabular}

Tabela 5.8 - Medidas obtidas para a terceira sequência de teste.

\begin{tabular}{|c|c|c|c|c|c|c|c|c|}
\hline $\begin{array}{l}\mathbf{P}_{\text {ref }} \\
\text { (bar) }\end{array}$ & Medida & $\begin{array}{c}\text { Manômetro } \\
\left(\mathrm{kgf} / \mathrm{cm}^{2}\right)\end{array}$ & $\begin{array}{l}\Delta \mathrm{m} \\
(\mathrm{kg})\end{array}$ & $\begin{array}{l}\text { Tacômetro } \\
\text { (rpm) }\end{array}$ & $\begin{array}{c}\text { Termopar } \\
2\left({ }^{\circ} \mathrm{C}\right)\end{array}$ & $\begin{array}{c}\text { Termopar } \\
\mathbf{3}\left({ }^{\circ} \mathrm{C}\right)\end{array}$ & $\begin{array}{c}\text { Termopar } \\
1\left({ }^{\circ} \mathrm{C}\right)\end{array}$ & $\begin{array}{c}\text { Coluna } \\
\mathrm{H}_{2} \mathrm{O} \\
(\mathrm{mm})\end{array}$ \\
\hline \multirow{8}{*}{0,5} & 1 & 0,75 & 0,00 & 1067 & 22,2 & 21,3 & 21,3 & 46 \\
\hline & 2 & 0,70 & 0,09 & 1020 & 22,4 & 18,4 & 19,8 & 45 \\
\hline & 3 & 0,70 & 0,17 & 988 & 22,3 & 18,6 & 19,6 & 45 \\
\hline & 4 & 0,70 & 0,29 & 910 & 22,1 & 19,1 & 20,2 & 44 \\
\hline & 5 & 0,70 & 0,38 & 859 & 22,2 & 18,4 & 18,7 & 43 \\
\hline & 6 & 0,70 & 0,43 & 829 & 22,2 & 17,1 & 18,7 & 42 \\
\hline & 7 & 0,75 & 0,55 & 753 & 22,3 & 17,8 & 19,5 & 39 \\
\hline & 8 & 0,75 & 0,70 & 642 & 21,9 & 18,7 & 20,5 & 36 \\
\hline \multirow{8}{*}{1,0} & 1 & 1,25 & 0,00 & 1386 & 21,9 & 19,9 & 19,8 & 104 \\
\hline & 2 & 1,20 & 0,24 & 1267 & 22,5 & 18,0 & 18,4 & 99 \\
\hline & 3 & 1,20 & 0,39 & 1206 & 22,3 & 17,0 & 18,0 & 98 \\
\hline & 4 & 1,20 & 0,55 & 1108 & 22,9 & 16,8 & 17,9 & 93 \\
\hline & 5 & 1,25 & 0,87 & 935 & 23,3 & 16,0 & 17,7 & 88 \\
\hline & 6 & 1,30 & 1,01 & 910 & 22,5 & 16,1 & 17,5 & 86 \\
\hline & 7 & 1,35 & 1,22 & 760 & 21,9 & 15,0 & 17,3 & 76 \\
\hline & 8 & 1,35 & 1,45 & 676 & 21,2 & 14,7 & 17,1 & 73 \\
\hline
\end{tabular}


Observa-se nas tabelas (Tabela 5.6, Tabela 5.7 e Tabela 5.8) que para cada pressão de admissão foram medidas: a pressão do manômetro, a diferença de massa entre as balanças, a rotação através do tacômetro, as temperaturas dos termopares e a altura da coluna de água do manômetro em $\mathrm{U}$.

Durante a execução da segunda sequência de teste para a 1,5 bar, ocorreu a ruptura da biela do excêntrico da máquina, impossibilitando o prosseguimento dos experimentos. Devido a este problema, a Tabela 5.7 e a Tabela 5.8 não possuem medidas para a pressão de referência de 1,5 bar.

\subsubsection{Calibração das Medidas}

Utilizando os coeficientes de calibração obtidos anteriormente, as medidas foram corrigidas. Ao invés de se utilizar o nome do instrumento utilizado, foi substituído pela grandeza física medida de acordo com o arranjo experimental, como visto abaixo:

- Manômetro: pressão de entrada;

- Tacômetro: rotação;

- Termopar 2: temperatura de entrada;

- Termopar 3: temperatura de saída;

- Termopar 1: temperatura do bocal.

Os coeficientes de calibração utilizados foram aqueles com a maior correlação dentre as três sequências de medidas. E deve-se tomar o devido cuidado, pois os termopares não foram colocados em sequência, por causa da posição física dos mesmos.

Também vale ressaltar que a pressão de entrada foi colocada em forma de pressão absoluta, para permitir a comparação com os resultados simulados obtidos anteriormente. 
Portanto, a calibração da Tabela 5.6, da Tabela 5.7 e da Tabela 5.8 é mostrada na Tabela 5.9, na Tabela 5.10 e na Tabela 5.11, respectivamente.

Tabela 5.9 - Valores calibrados da Tabela 5.6.

\begin{tabular}{|c|c|c|c|c|c|c|}
\hline $\begin{array}{l}P_{\text {ref }} \\
\text { (bar) }\end{array}$ & Medida & $\begin{array}{l}\text { Pressão de } \\
\text { entrada (bar) }\end{array}$ & $\begin{array}{c}\text { Rotação } \\
\text { (rpm) }\end{array}$ & $\begin{array}{c}\text { Temperatura } \\
\text { de entrada }\left({ }^{\circ} \mathrm{C}\right)\end{array}$ & $\begin{array}{l}\text { Temperatura } \\
\text { de saída }\left({ }^{\circ} \mathrm{C}\right)\end{array}$ & $\begin{array}{l}\text { Temperatura } \\
\text { no bocal }\left({ }^{\circ} \mathrm{C}\right)\end{array}$ \\
\hline \multirow{8}{*}{0,5} & 1 & 1,36 & 1062 & 21,7 & 18,7 & 19,5 \\
\hline & 2 & 1,36 & 991 & 21,7 & 17,6 & 18,7 \\
\hline & 3 & 1,36 & 946 & 21,6 & 17,2 & 18,8 \\
\hline & 4 & 1,36 & 893 & 21,8 & 17,4 & 18,9 \\
\hline & 5 & 1,36 & 836 & 21,7 & 17,3 & 18,8 \\
\hline & 6 & 1,36 & 700 & 21,7 & 16,0 & 18,9 \\
\hline & 7 & 1,36 & 640 & 21,6 & 16,2 & 18,8 \\
\hline & 8 & 1,41 & 573 & 21,7 & 17,1 & 18,8 \\
\hline \multirow{8}{*}{1,0} & 1 & 1,89 & 1309 & 21,7 & 18,2 & 19,5 \\
\hline & 2 & 1,84 & 1129 & 22,2 & 16,5 & 18,1 \\
\hline & 3 & 1,84 & 1088 & 22,6 & 16,7 & 18,0 \\
\hline & 4 & 1,84 & 1002 & 22,3 & 15,7 & 17,9 \\
\hline & 5 & 1,89 & 952 & 22,7 & 15,0 & 17,5 \\
\hline & 6 & 1,94 & 816 & 22,6 & 14,8 & 17,4 \\
\hline & 7 & 1,94 & 708 & 21,7 & 14,3 & 17,7 \\
\hline & 8 & 1,94 & 584 & 21,8 & 14,2 & 17,6 \\
\hline \multirow{8}{*}{1,5} & 1 & 2,52 & 1475 & 23,3 & 18,1 & 19,4 \\
\hline & 2 & 2,47 & 1411 & 23,9 & 16,5 & 18,0 \\
\hline & 3 & 2,47 & 1329 & 24,2 & 16,5 & 18,0 \\
\hline & 4 & 2,47 & 1215 & 24,3 & 15,1 & 17,0 \\
\hline & 5 & 2,52 & 1074 & 24,3 & 13,1 & 16,4 \\
\hline & 6 & 2,52 & 955 & 24,3 & 13,1 & 16,4 \\
\hline & 7 & 2,57 & 869 & 24,1 & 13,0 & 16,9 \\
\hline & 8 & 2,67 & 834 & 23,6 & 13,9 & 17,3 \\
\hline
\end{tabular}


Tabela 5.10 - Valores calibrados da Tabela 5.7.

\begin{tabular}{c|c|ccccc}
\hline $\begin{array}{c}\mathbf{P}_{\text {ref }} \\
\text { (bar) }\end{array}$ & Medida & $\begin{array}{c}\text { Pressão de } \\
\text { entrada (bar) }\end{array}$ & $\begin{array}{c}\text { Rotação } \\
(\mathbf{r p m})\end{array}$ & $\begin{array}{c}\text { Temperatura } \\
\text { de entrada }\left({ }^{\circ} \mathbf{C}\right)\end{array}$ & $\begin{array}{c}\text { Temperatura } \\
\text { de saída }\left({ }^{\circ} \mathbf{C}\right)\end{array}$ & $\begin{array}{c}\text { Temperatura } \\
\text { no bocal }\left({ }^{\circ} \mathbf{C}\right)\end{array}$ \\
\hline \multirow{5}{*}{$\mathbf{0}$} & 1 & 1,36 & 996 & 20,9 & 19,5 & 20,1 \\
\cline { 2 - 7 } & 2 & 1,36 & 928 & 21,1 & 17,6 & 19,2 \\
\cline { 2 - 7 } & 3 & 1,36 & 898 & 21,2 & 17,5 & 19,2 \\
\cline { 2 - 7 } & 4 & 1,36 & 822 & 21,0 & 17,1 & 18,9 \\
\cline { 2 - 7 } & 5 & 1,36 & 663 & 21,1 & 16,4 & 18,3 \\
\cline { 2 - 7 } & 6 & 1,36 & 691 & 21,1 & 16,5 & 18,5 \\
\cline { 2 - 7 } & 7 & 1,36 & 605 & 21,0 & 16,3 & 18,3 \\
\cline { 2 - 7 } & 8 & 1,41 & 505 & 21,1 & 16,9 & 19,6 \\
\hline \multirow{4}{*}{$\mathbf{1 , 0}$} & 1 & 1,84 & 1239 & 22,1 & 17,4 & 18,2 \\
\cline { 2 - 7 } & 2 & 1,84 & 1152 & 22,4 & 17,2 & 18,2 \\
\cline { 2 - 7 } & 3 & 1,84 & 1090 & 22,5 & 16,0 & 17,9 \\
\cline { 2 - 7 } & 4 & 1,84 & 997 & 22,5 & 16,0 & 17,6 \\
\cline { 2 - 7 } & 5 & 1,89 & 865 & 22,5 & 14,2 & 17,3 \\
\cline { 2 - 7 } & 6 & 1,89 & 772 & 22,9 & 14,0 & 17,3 \\
\hline
\end{tabular}

Tabela 5.11 - Valores calibrados da Tabela 5.8.

\begin{tabular}{|c|c|c|c|c|c|c|}
\hline $\begin{array}{l}\mathbf{P}_{\text {ref }} \\
\text { (bar) }\end{array}$ & Medida & $\begin{array}{l}\text { Pressão de } \\
\text { entrada (bar) }\end{array}$ & $\begin{array}{c}\text { Rotação } \\
\text { (rpm) }\end{array}$ & $\begin{array}{c}\text { Temperatura } \\
\text { de entrada }\left({ }^{\circ} \mathrm{C}\right)\end{array}$ & $\begin{array}{l}\text { Temperatura } \\
\text { de saída }\left({ }^{\circ} \mathrm{C}\right)\end{array}$ & $\begin{array}{l}\text { Temperatura } \\
\text { no bocal }\left({ }^{\circ} \mathrm{C}\right)\end{array}$ \\
\hline \multirow{8}{*}{0,5} & 1 & 1,41 & 1031 & 21,6 & 20,5 & 21,4 \\
\hline & 2 & 1,36 & 985 & 21,8 & 17,5 & 19,9 \\
\hline & 3 & 1,36 & 953 & 21,7 & 17,7 & 19,7 \\
\hline & 4 & 1,36 & 877 & 21,5 & 18,2 & 20,3 \\
\hline & 5 & 1,36 & 827 & 21,6 & 17,5 & 18,8 \\
\hline & 6 & 1,36 & 797 & 21,6 & 16,2 & 18,8 \\
\hline & 7 & 1,41 & 723 & 21,7 & 16,9 & 19,6 \\
\hline & 8 & 1,41 & 614 & 21,3 & 17,8 & 20,6 \\
\hline \multirow{8}{*}{1,0} & 1 & 1,89 & 1344 & 21,3 & 19,1 & 19,9 \\
\hline & 2 & 1,84 & 1227 & 21,9 & 17,1 & 18,5 \\
\hline & 3 & 1,84 & 1167 & 21,7 & 16,1 & 18,1 \\
\hline & 4 & 1,84 & 1071 & 22,3 & 15,9 & 18,0 \\
\hline & 5 & 1,89 & 901 & 22,7 & 15,1 & 17,8 \\
\hline & 6 & 1,94 & 877 & 21,9 & 15,2 & 17,6 \\
\hline & 7 & 1,99 & 730 & 21,3 & 14,1 & 17,4 \\
\hline & 8 & 1,99 & 647 & 20,6 & 13,8 & 17,2 \\
\hline
\end{tabular}




\subsection{Resultados}

Utilizando as medidas calibradas da Tabela 5.9, obtêm-se os resultados apresentados na Tabela 5.12:

Tabela 5.12 - Resultados obtidos a partir da Tabela 5.9.

\begin{tabular}{|c|c|c|c|c|c|c|}
\hline $\begin{array}{l}\text { Pref } \\
\text { (bar) }\end{array}$ & Medida & $\begin{array}{l}\text { Torque } \\
\text { (N.m) }\end{array}$ & $\begin{array}{l}\text { Potência } \\
\text { (W) }\end{array}$ & $\begin{array}{l}\text { Velocidade do ar } \\
\text { no bocal }(\mathrm{m} / \mathrm{s})\end{array}$ & $\begin{array}{c}\text { Vazão } \\
\text { mássica (g/s) }\end{array}$ & $\begin{array}{c}\text { Eficiência } \\
\text { Isoentrópica (\%) }\end{array}$ \\
\hline \multirow{8}{*}{0,5} & 1 & 0,000 & 0,00 & 4,15 & 2,45 & 0,00 \\
\hline & 2 & 0,043 & 4,47 & 4,14 & 2,45 & 4,92 \\
\hline & 3 & 0,067 & 6,59 & 4,14 & 2,45 & 7,26 \\
\hline & 4 & 0,117 & 10,98 & 4,14 & 2,45 & 12,09 \\
\hline & 5 & 0,153 & 13,36 & 4,14 & 2,45 & 14,72 \\
\hline & 6 & 0,219 & 16,08 & 3,95 & 2,34 & 18,39 \\
\hline & 7 & 0,251 & 16,80 & 3,90 & 2,31 & 19,42 \\
\hline & 8 & 0,278 & 16,69 & 3,75 & 2,22 & 18,65 \\
\hline \multirow{8}{*}{1,0} & 1 & 0,000 & 0,00 & 6,24 & 3,71 & 0,00 \\
\hline & 2 & 0,098 & 11,57 & 6,17 & 3,68 & 6,67 \\
\hline & 3 & 0,141 & 16,06 & 6,04 & 3,61 & 9,36 \\
\hline & 4 & 0,219 & 23,00 & 5,95 & 3,55 & 13,57 \\
\hline & 5 & 0,321 & 32,02 & 5,85 & 3,50 & 18,38 \\
\hline & 6 & 0,364 & 31,11 & 5,65 & 3,38 & 17,70 \\
\hline & 7 & 0,466 & 34,54 & 5,45 & 3,25 & 20,29 \\
\hline & 8 & 0,591 & 36,17 & 5,20 & 3,10 & 22,04 \\
\hline \multirow{8}{*}{1,5} & 1 & 0,000 & 0,00 & 8,67 & 5,21 & 0,00 \\
\hline & 2 & 0,067 & 9,84 & 8,54 & 5,15 & 3,39 \\
\hline & 3 & 0,149 & 20,70 & 8,50 & 5,13 & 7,14 \\
\hline & 4 & 0,239 & 30,38 & 8,32 & 5,03 & 10,59 \\
\hline & 5 & 0,431 & 48,45 & 7,91 & 4,78 & 17,02 \\
\hline & 6 & 0,517 & 51,71 & 7,86 & 4,75 & 18,23 \\
\hline & 7 & 0,720 & 65,56 & 7,53 & 4,54 & 23,35 \\
\hline & 8 & 0,783 & 68,36 & 7,61 & 4,58 & 23,30 \\
\hline
\end{tabular}


O torque é calculado através da equação (5.2). Conhecidos os valores de torque e de rotação, é possível calcular a potência da máquina pela equação matemática abaixo:

$$
P o t=T \cdot \omega \cdot \frac{\pi}{30}
$$

A velocidade do escoamento na seção (1) e a vazão mássica são determinadas pelas equações (5.4) e (5.6), respectivamente.

E por fim, calculando-se o trabalho específico isoentrópico através da equação (3.11), é possível determinar a eficiência isoentrópica pela expressão a seguir:

$$
\eta_{i s o}=\frac{P o t / \dot{m}}{w_{i s o}}
$$

Utilizando as medidas de rotação (Tabela 5.9) e os valores de torque (Tabela 5.12), obtém-se a curva característica de torque correspondente, cujo gráfico é mostrado na Figura 5.20:

\section{Curva característica - Torque}

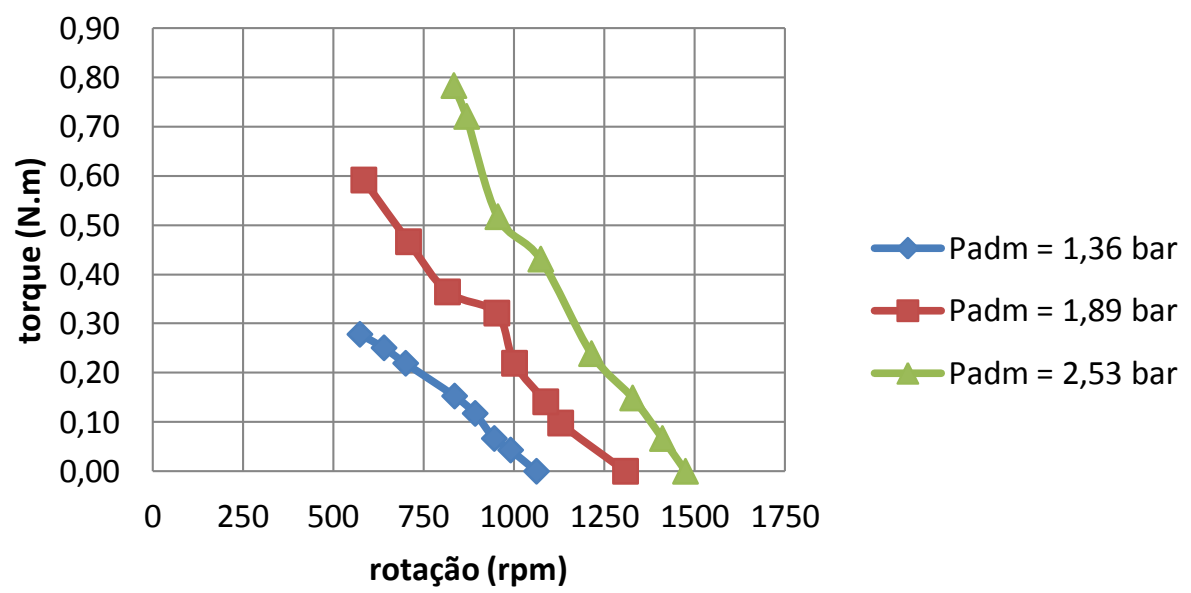

Figura 5.20 - Curva de torque (Tabela 5.12). 
Analogamente ao torque, a partir dos valores de potência, obtém-se a curva característica de potência, a qual é apresentada na Figura 5.21:

\section{Curva característica - Potência}

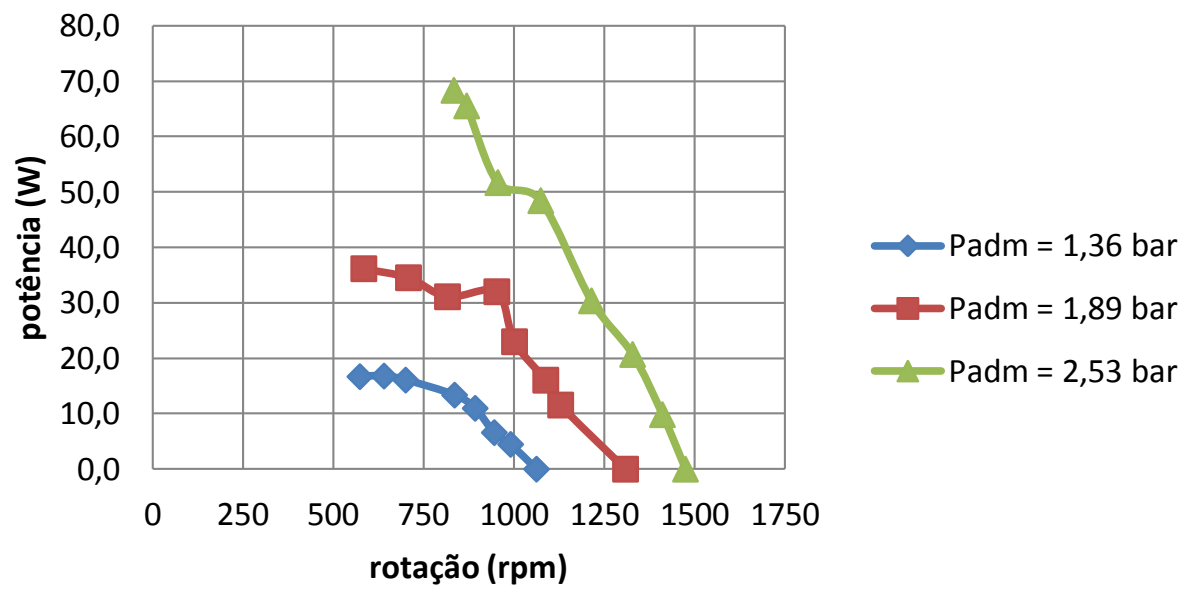

Figura 5.21 - Curva de potência (Tabela 5.12).

E por fim, utilizando os valores de eficiência isoentrópica calculados, obtémse a curva característica de eficiência, mostrada na Figura 5.22:

\section{Curva característica - Eficiência}

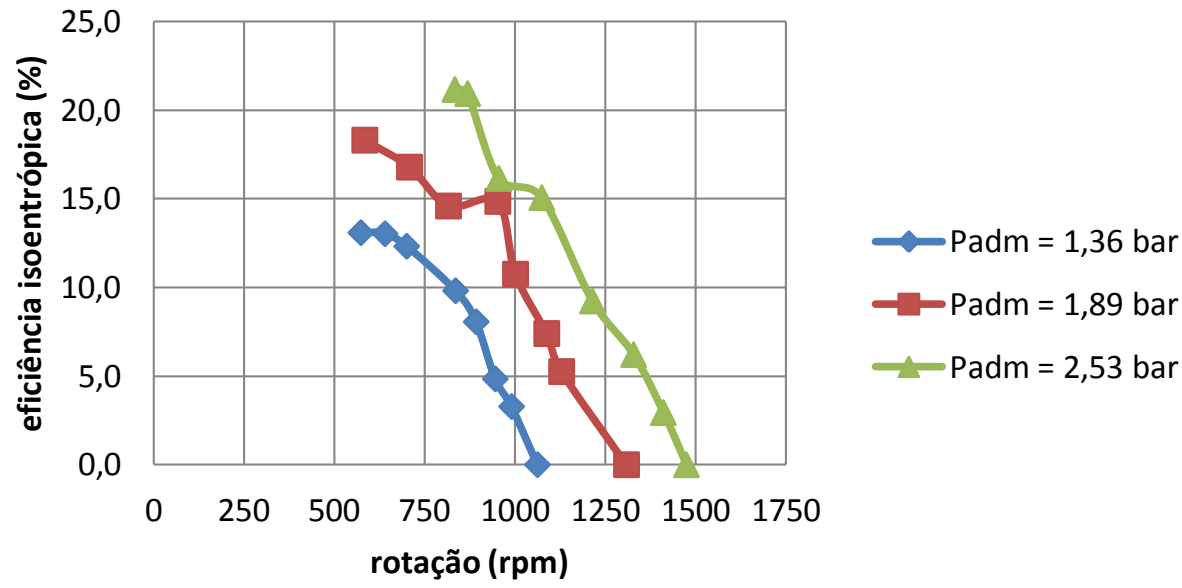

Figura 5.22 - Curva de eficiência isoentrópica (Tabela 5.12). 
Analogamente à Tabela 5.12, obtêm-se os resultados da Tabela 5.13 a partir da Tabela 5.10.

Tabela 5.13 - Resultados obtidos a partir da Tabela 5.10.

\begin{tabular}{|c|c|c|c|c|c|c|}
\hline $\begin{array}{l}\text { Pref } \\
\text { (bar) }\end{array}$ & Medida & $\begin{array}{l}\text { Torque } \\
\text { (N.m) }\end{array}$ & $\begin{array}{l}\text { Potência } \\
\text { (W) }\end{array}$ & $\begin{array}{l}\text { Velocidade do ar } \\
\text { no bocal }(\mathrm{m} / \mathrm{s})\end{array}$ & $\begin{array}{c}\text { Vazão } \\
\text { mássica }(g / s)\end{array}$ & $\begin{array}{c}\text { Eficiência } \\
\text { Isoentrópica (\%) }\end{array}$ \\
\hline \multirow{8}{*}{0,5} & 1 & 0,000 & 0,00 & 3,96 & 2,33 & 0,00 \\
\hline & 2 & 0,043 & 4,19 & 4,00 & 2,37 & 4,82 \\
\hline & 3 & 0,082 & 7,74 & 3,95 & 2,34 & 9,00 \\
\hline & 4 & 0,121 & 10,45 & 3,90 & 2,31 & 12,28 \\
\hline & 5 & 0,161 & 11,14 & 3,80 & 2,25 & 13,36 \\
\hline & 6 & 0,192 & 13,89 & 3,59 & 2,13 & 17,46 \\
\hline & 7 & 0,227 & 14,38 & 3,42 & 2,03 & 18,82 \\
\hline & 8 & 0,309 & 16,35 & 3,37 & 1,99 & 20,36 \\
\hline \multirow{8}{*}{1,0} & 1 & 0,000 & 0,00 & 6,17 & 3,68 & 0,00 \\
\hline & 2 & 0,086 & 10,39 & 6,11 & 3,64 & 6,01 \\
\hline & 3 & 0,141 & 16,09 & 6,01 & 3,59 & 9,40 \\
\hline & 4 & 0,211 & 22,07 & 5,91 & 3,53 & 13,04 \\
\hline & 5 & 0,305 & 27,67 & 5,65 & 3,38 & 16,27 \\
\hline & 6 & 0,376 & 30,38 & 5,51 & 3,29 & 18,18 \\
\hline & 7 & 0,442 & 32,76 & 5,37 & 3,21 & 19,33 \\
\hline & 8 & 0,532 & 36,80 & 5,20 & 3,10 & 22,32 \\
\hline
\end{tabular}

Utilizando os valores de torque, de potência e de eficiência isoentrópica (Tabela 5.13), em conjunto com as medidas de rotação (Tabela 5.10), obtém-se as seguintes curvas características:

- Curva de torque: Figura 5.23;

- Curva de potência: Figura 5.24;

- Curva de eficiência isoentrópica: Figura 5.25. 
Curva característica - Torque

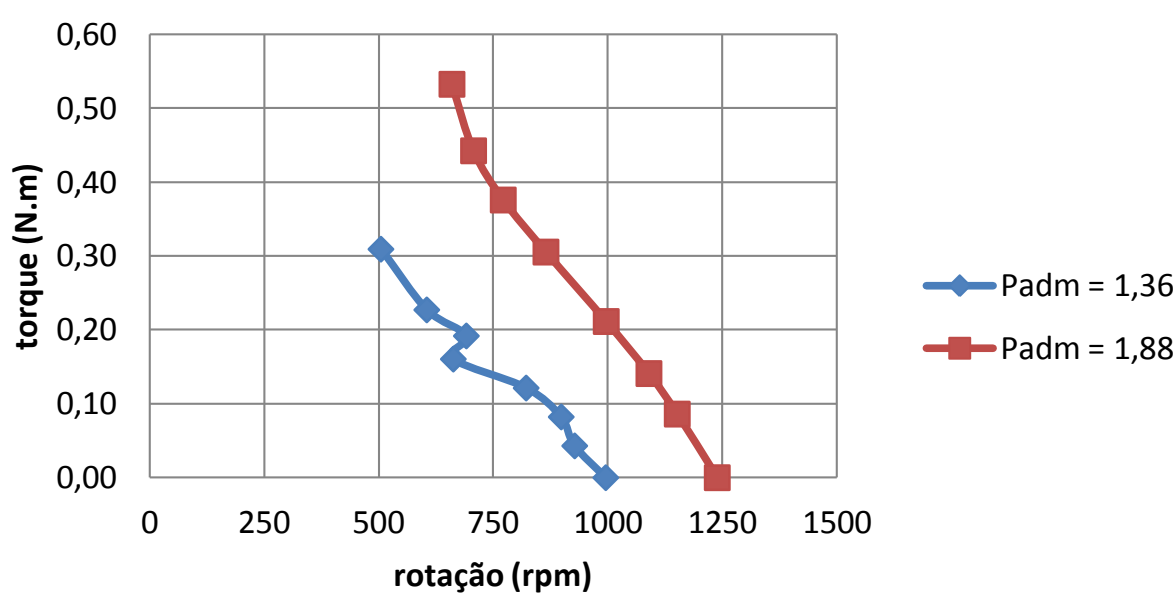

Figura 5.23 - Curva de torque (Tabela 5.13).

\section{Curva característica - Potência}

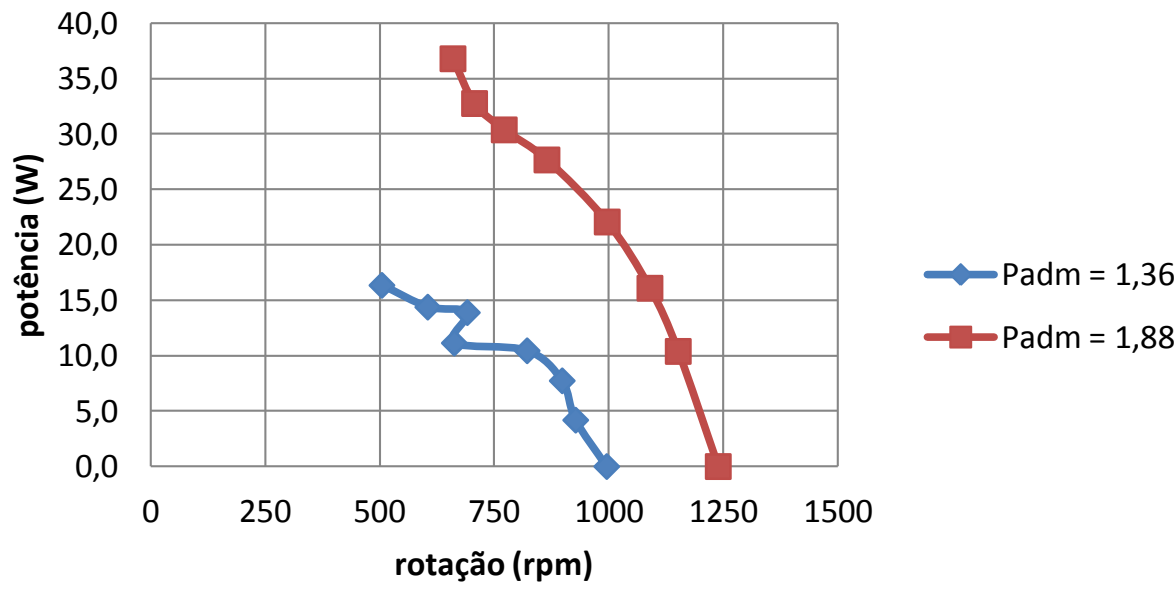

Figura 5.24 - Curva de potência (Tabela 5.13). 


\section{Curva característica - Eficiência}

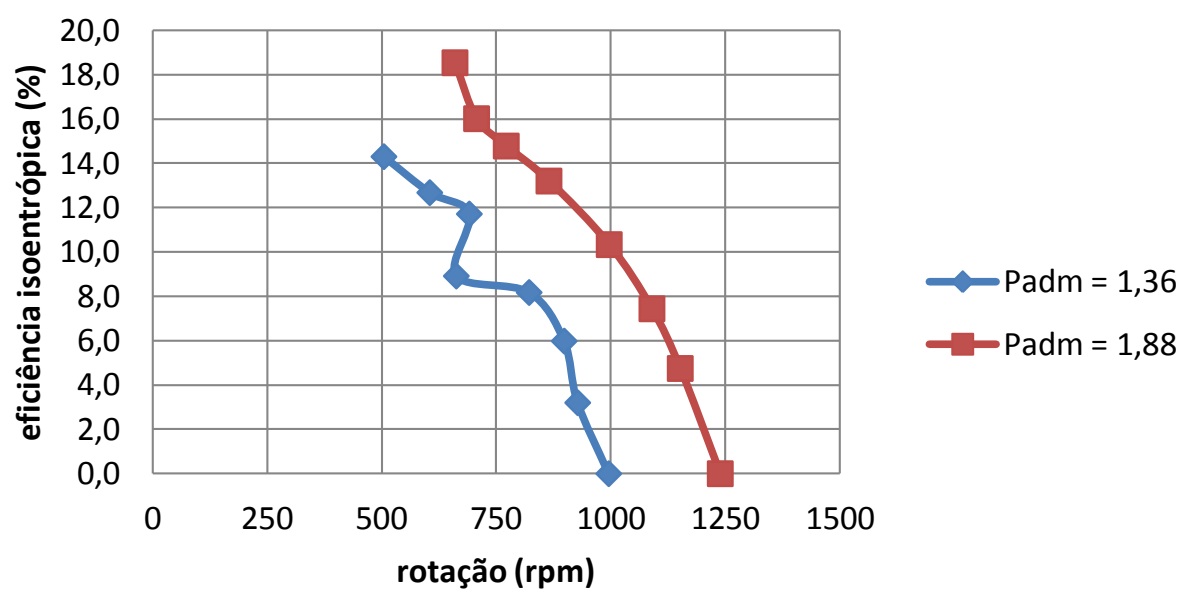

Figura 5.25 - Curva de eficiência isoentrópica (Tabela 5.13).

Finalmente, os resultados da Tabela 5.14 são obtidos a partir da Tabela 5.11:

Tabela 5.14 - Resultados obtidos a partir da Tabela 5.11.

\begin{tabular}{|c|c|c|c|c|c|c|}
\hline $\begin{array}{l}\text { Pref } \\
\text { (bar) }\end{array}$ & Medida & $\begin{array}{l}\text { Torque } \\
\text { (N.m) }\end{array}$ & $\begin{array}{l}\text { Potência } \\
\text { (W) }\end{array}$ & $\begin{array}{l}\text { Velocidade do ar } \\
\text { no bocal (m/s) }\end{array}$ & $\begin{array}{c}\text { Vazão } \\
\text { mássica (g/s) }\end{array}$ & $\begin{array}{c}\text { Eficiência } \\
\text { Isoentrópica (\%) }\end{array}$ \\
\hline \multirow{8}{*}{0,5} & 1 & 0,000 & 0,00 & 4,25 & 2,50 & 0,00 \\
\hline & 2 & 0,035 & 3,63 & 4,20 & 2,48 & 4,00 \\
\hline & 3 & 0,067 & 6,65 & 4,19 & 2,48 & 7,32 \\
\hline & 4 & 0,114 & 10,43 & 4,15 & 2,45 & 11,60 \\
\hline & 5 & 0,149 & 12,88 & 4,10 & 2,42 & 14,41 \\
\hline & 6 & 0,168 & 14,06 & 4,05 & 2,40 & 15,87 \\
\hline & 7 & 0,215 & 16,30 & 3,91 & 2,31 & 17,75 \\
\hline & 8 & 0,274 & 17,61 & 3,76 & 2,21 & 19,88 \\
\hline \multirow{8}{*}{1,0} & 1 & 0,000 & 0,00 & 6,34 & 3,76 & 0,00 \\
\hline & 2 & 0,094 & 12,08 & 6,17 & 3,68 & 6,99 \\
\hline & 3 & 0,153 & 18,67 & 6,14 & 3,66 & 10,84 \\
\hline & 4 & 0,215 & 24,16 & 5,98 & 3,57 & 14,24 \\
\hline & 5 & 0,341 & 32,15 & 5,82 & 3,47 & 18,59 \\
\hline & 6 & 0,395 & 36,31 & 5,75 & 3,44 & 20,49 \\
\hline & 7 & 0,478 & 36,49 & 5,41 & 3,23 & 20,93 \\
\hline & 8 & 0,568 & 38,47 & 5,30 & 3,17 & 22,46 \\
\hline
\end{tabular}


Curva característica - Torque

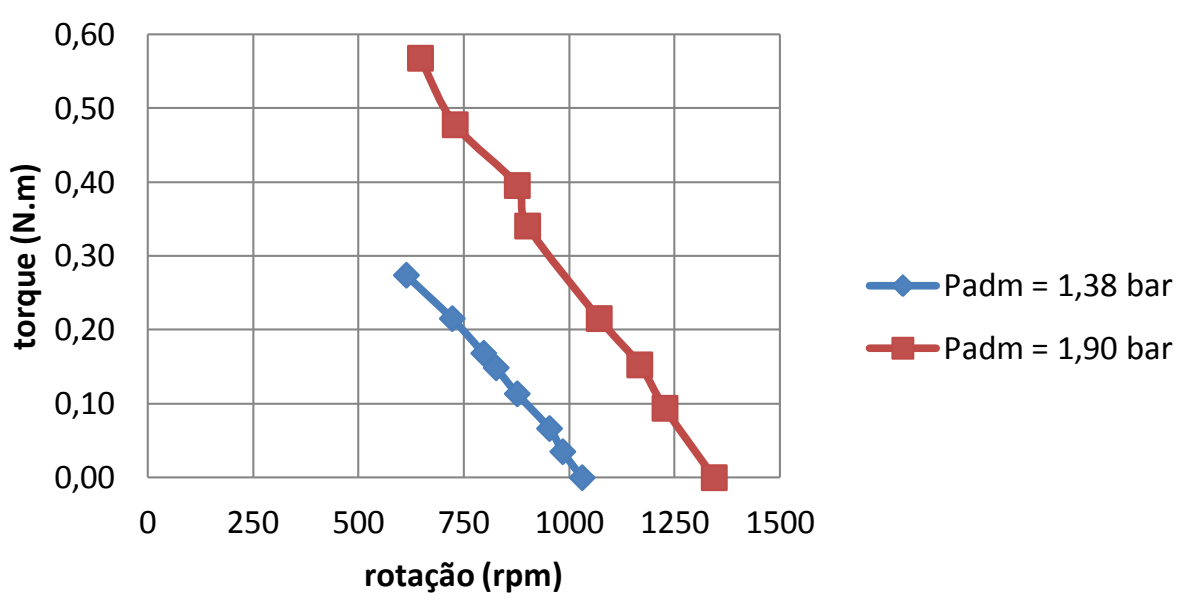

Figura 5.26 - Curva de torque (Tabela 5.14).

\section{Curva característica - Potência}

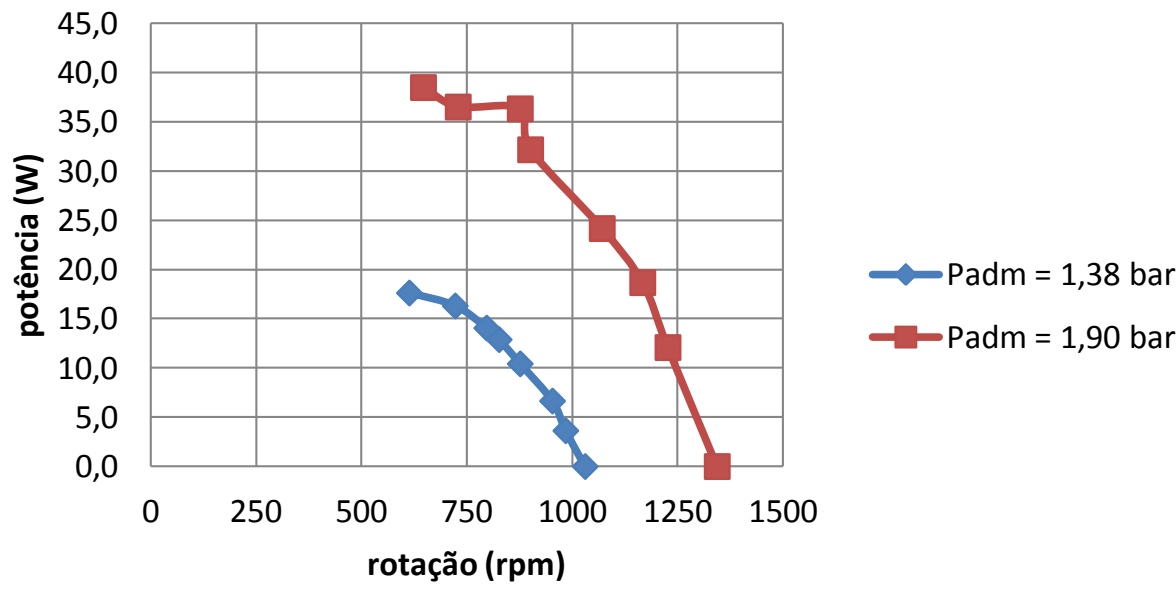

Figura 5.27 - Curva de potência (Tabela 5.14). 


\section{Curva característica - Eficiência}

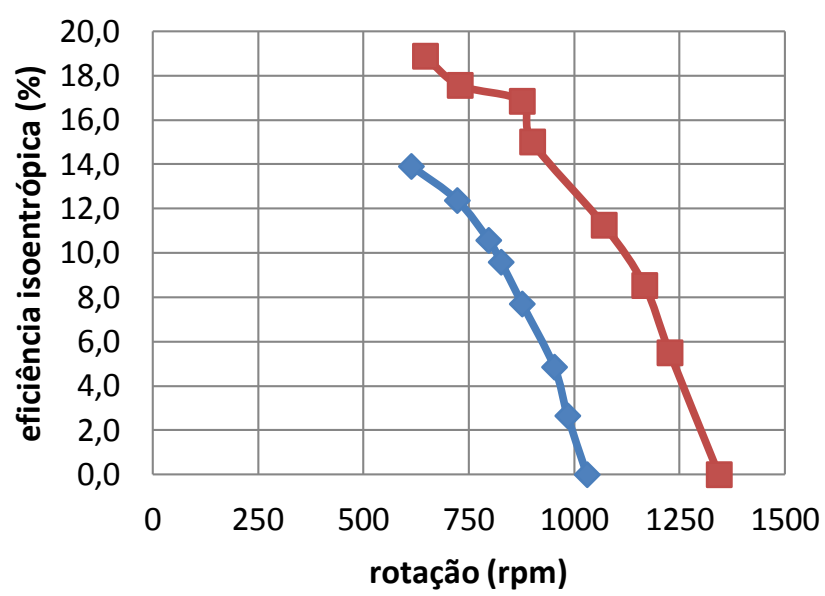

$\longrightarrow$ Padm $=1,38$ bar

$-P a d m=1,90$ bar

Figura 5.28 - Curva de eficiência isoentrópica (Tabela 5.14).

Examinando os gráficos da Figura 5.20 à Figura 5.28, observa-se que alguns pontos estão fora da tendência da curva. Tal comportamento é causado pelo freio de Prony, pois o torque exercido pela tira de couro sobre a roda de inércia não é constante. Portanto, durante o processo de tomar nota das medidas, pode ocorrer a variação do torque, obtendo-se tais pontos.

Analisando os gráficos de torque (Figura 5.20, Figura 5.23 e Figura 5.26), o perfil da curva de torque é semelhante para diferentes pressões, porém quanto maior a pressão de admissão, maior será o torque do eixo da máquina. Assim como em um motor de combustão interna, em rotações mais baixas apresenta maior torque.

Examinando a Figura 5.21, a Figura 5.24 e a Figura 5.27, observa-se que não foi possível obter a curva de potência completa. Devido ao mecanismo do freio Prony, o torque imposto é determinado pelo deslocamento das balanças, entretanto tal deslocamento não é preciso. Portanto, para valores de torque elevados, o movimento da máquina é cessado pelo freio de Prony. E consequentemente, a medição da parte da curva de potência à esquerda do ponto de máximo é comprometida. 
Analisando as curvas de potência, conforme se aumenta a pressão de entrada, maior será a potência máxima e sua respectiva velocidade angular. Para a pressão de 2,53 bar, a máxima potência é de cerca de $68 \mathrm{~W}$ e ocorre a aproximadamente $830 \mathrm{rpm}$.

Com base na Figura 5.22, na Figura 5.25 e na Figura 5.28, pode-se afirmar que a curva de eficiência, assim como a curva de potência, não foi obtida completamente, faltando a parte à esquerda do ponto de máximo. A máxima eficiência é de cerca de $21,2 \%$ e ocorre a aproximadamente $830 \mathrm{rpm}$ para a pressão de entrada de 2,53 bar. O perfil da curva de eficiência é semelhante para diferentes pressões, mas se nota que os valores de eficiência maiores ocorrem para a pressão de admissão mais elevada.

Utilizando os gráficos da Figura 5.20 à Figura 5.28, registram-se os pontos de máximos: rotação, torque, potência e eficiência isoentrópica. Este processo foi realizado para cada umas das pressões de entrada e sua respectiva sequência de testes, obtendo-se os resultados mostrados na Tabela 5.15:

Tabela 5.15 - Principais resultados da variação da pressão de entrada.

\begin{tabular}{c|c|cccc}
\hline $\begin{array}{c}\text { Sequência } \\
\text { de teste }\end{array}$ & $\begin{array}{c}\text { Pressão de } \\
\text { entrada (bar) }\end{array}$ & $\begin{array}{c}\text { Rotação } \\
\text { (rpm) }\end{array}$ & $\begin{array}{c}\text { Torque } \\
\text { (N.m) }\end{array}$ & $\begin{array}{c}\text { Potência } \\
\text { (W) }\end{array}$ & $\begin{array}{c}\text { Eficiência } \\
\text { Isoentrópica (\%) }\end{array}$ \\
\hline \multirow{3}{*}{$\mathbf{1}$} & 1,36 & 1062 & 0,278 & 16,80 & 13,08 \\
\cline { 2 - 6 } & 1,89 & 1309 & 0,591 & 36,17 & 18,30 \\
\cline { 2 - 6 } & 2,53 & 1475 & 0,783 & 68,36 & 21,16 \\
\hline \multirow{2}{*}{2} & 1,36 & 996 & 0,309 & 16,35 & 14,30 \\
\cline { 2 - 6 } & 1,88 & 1239 & 0,532 & 36,80 & 18,54 \\
\hline \multirow{2}{*}{3} & 1,38 & 1031 & 0,274 & 17,61 & 13,91 \\
\cline { 2 - 6 } & 1,90 & 1344 & 0,568 & 38,47 & 18,88 \\
\hline
\end{tabular}

A partir dos resultados da Tabela 5.15, é possível analisar o efeito da variação da pressão de admissão sobre o torque máximo da máquina, obtendo-se o gráfico da Figura 5.29: 


\section{Torque máximo em função da pressão de admissão}

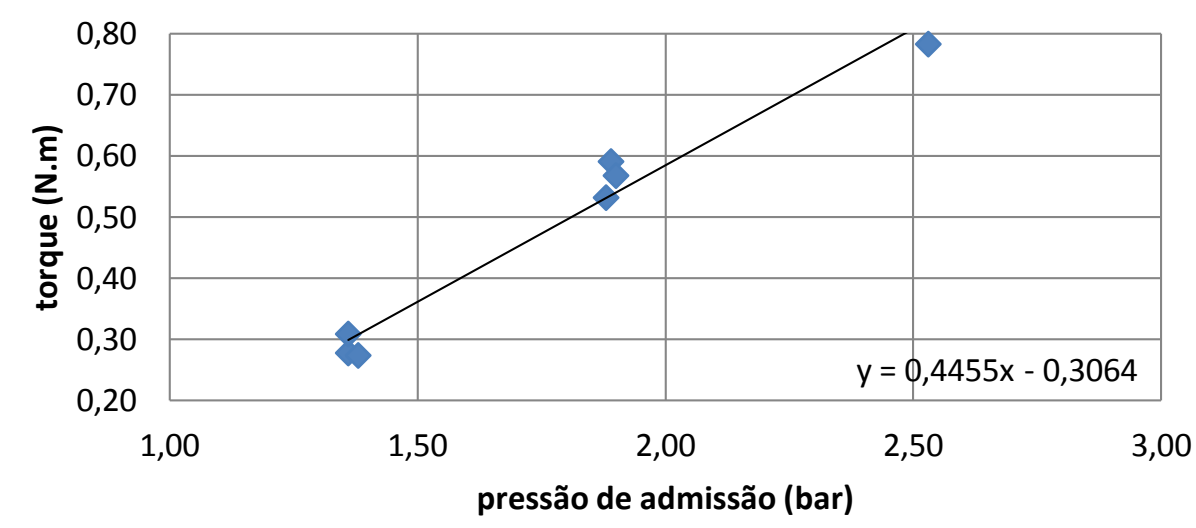

Figura 5.29 - Torque máximo em função da pressão de admissão com linha de tendência.

Examinando o gráfico acima, é possível afirmar que o torque máximo apresenta um crescimento linear em relação à pressão de entrada.

A partir dos valores da Tabela 5.15, pode-se analisar o efeito da variação da pressão de admissão sobre a potência máxima da máquina, obtendo-se o gráfico da Figura 5.30:

\section{Potência máxima em função da pressão de admissão}

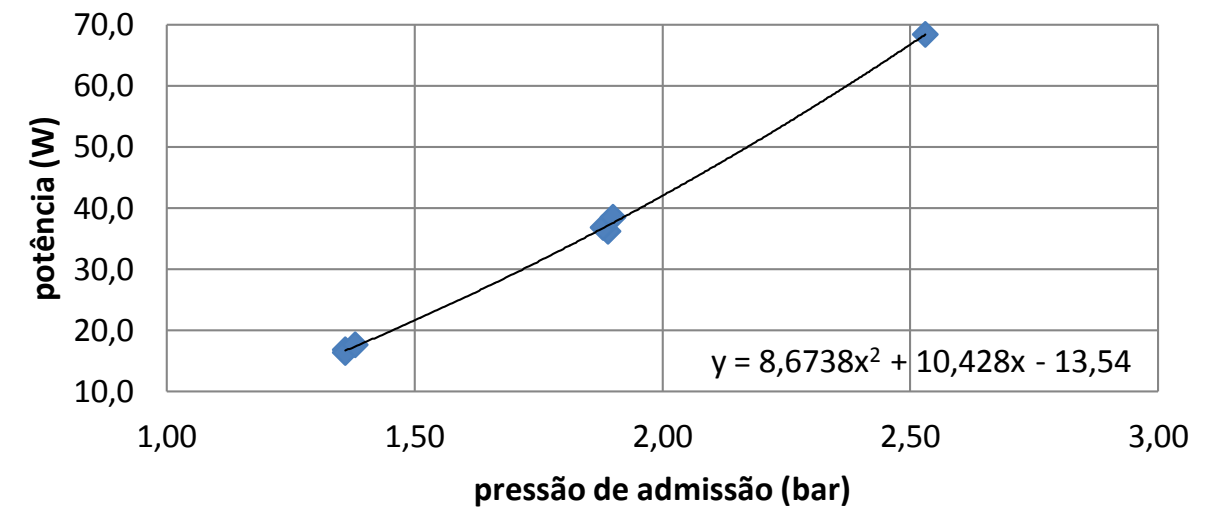

Figura 5.30 - Potência máxima em função da pressão de admissão com linha de tendência. 
Observando o gráfico da Figura 5.30, conclui-se que a potência máxima da máquina demonstra ter um crescimento quadrático em função da pressão de admissão.

Finalmente, da mesma forma que o torque e a potência, é possível analisar a eficiência isoentrópica máxima em função da pressão de entrada, exposta no gráfico da Figura 5.31:

\section{Eficiência isoentrópica máxima em função da pressão de admissão}

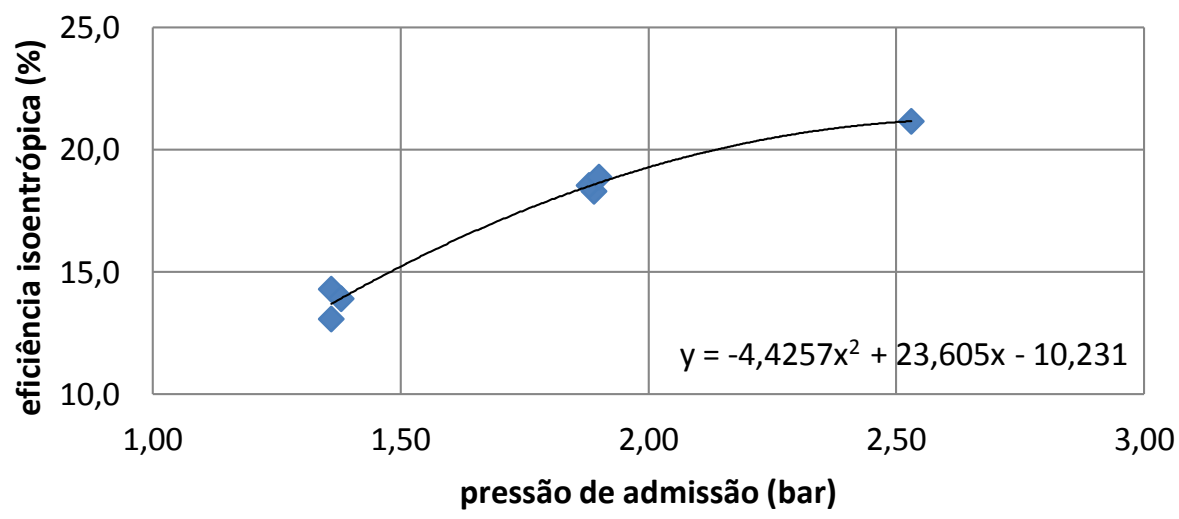

Figura 5.31 - Eficiência isoentrópica máxima em função da pressão de admissão com linha de tendência.

Analisando a linha de tendência da eficiência isoentrópica, nota-se que há uma queda em seu crescimento, indicando que possivelmente existe uma pressão ideal de operação. De acordo com a extrapolação dos resultados obtidos, a máxima eficiência isoentrópica seria entre $20 \%$ e $25 \%$, e ocorreria para uma pressão de entrada entre 2,5 bar e 3,0 bar.

A partir dos resultados experimentais de Unzueta (2012), é possível comparar os valores da rotação sem carga, do torque máximo, da potência máxima e da eficiência isoentrópica máxima com os valores da Tabela 5.15, deste modo, obtendo-se a Tabela 5.16. 
Tabela 5.16 - Comparação dos principais resultados entre a máquina original e a máquina modificada.

\begin{tabular}{c|c|cc}
\hline $\begin{array}{c}\text { Pref } \\
\text { [bar] }\end{array}$ & Parâmetro & $\begin{array}{c}\text { Máquina } \\
\text { Original }\end{array}$ & $\begin{array}{c}\text { Máquina } \\
\text { Modificada }\end{array}$ \\
\hline \multirow{4}{*}{$\mathbf{0} 5$} & Rotação sem carga [rpm] & 793 & 1030 \\
\cline { 2 - 4 } & Torque máximo [N.m] & 0,141 & 0,287 \\
\cline { 2 - 4 } & Potência máxima [W] & 5,72 & 16,92 \\
\cline { 2 - 4 } & Eficiência isoentrópica [\%] & 6,97 & 13,76 \\
\hline \multirow{4}{*}{$\mathbf{1 0}$} & Rotação sem carga [rpm] & 897 & 1297 \\
\cline { 2 - 4 } & Torque máximo [N.m] & 0,224 & 0,564 \\
\cline { 2 - 4 } & Potência máxima [W] & 13,85 & 37,15 \\
\cline { 2 - 4 } & Eficiência isoentrópica [\%] & 10,14 & 18,57 \\
\hline \multirow{4}{*}{$\mathbf{1 , 5}$} & Rotação sem carga [rpm] & 1359 & 1475 \\
\cline { 2 - 4 } & Torque máximo [N.m] & 0,290 & 0,783 \\
\cline { 2 - 4 } & Potência máxima [W] & 20,57 & 68,36 \\
\cline { 2 - 4 } & Eficiência isoentrópica [\%] & 9,84 & 21,16 \\
\hline
\end{tabular}

Através da Tabela 5.16, compara-se os valores da rotação sem carga no gráfico da Figura 5.32:

\section{Comparativo da rotação sem carga}

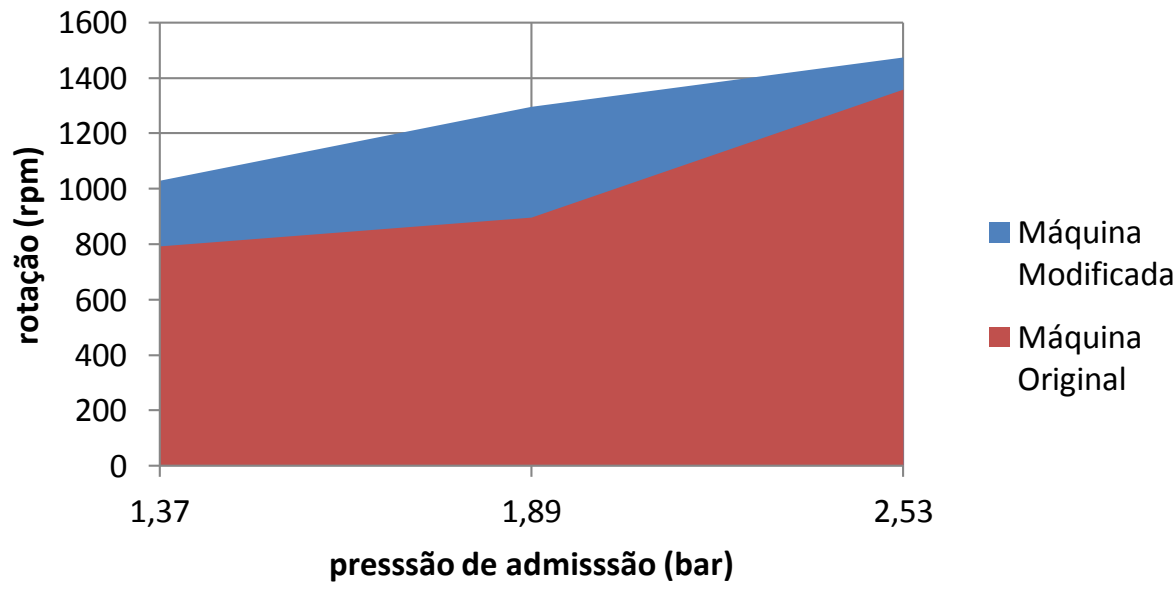

Figura 5.32 - Comparativo da rotação sem carga entre a máquina original e a modificada.

Analisando o gráfico, observa-se que após as modificações a velocidade angular aumentou para todas as pressões de admissão, indicando que as perdas por atrito são menores. 
Da mesma forma, obtém-se o gráfico comparativo do torque máximo na Figura 5.33:

\section{Comparativo do torque máximo}

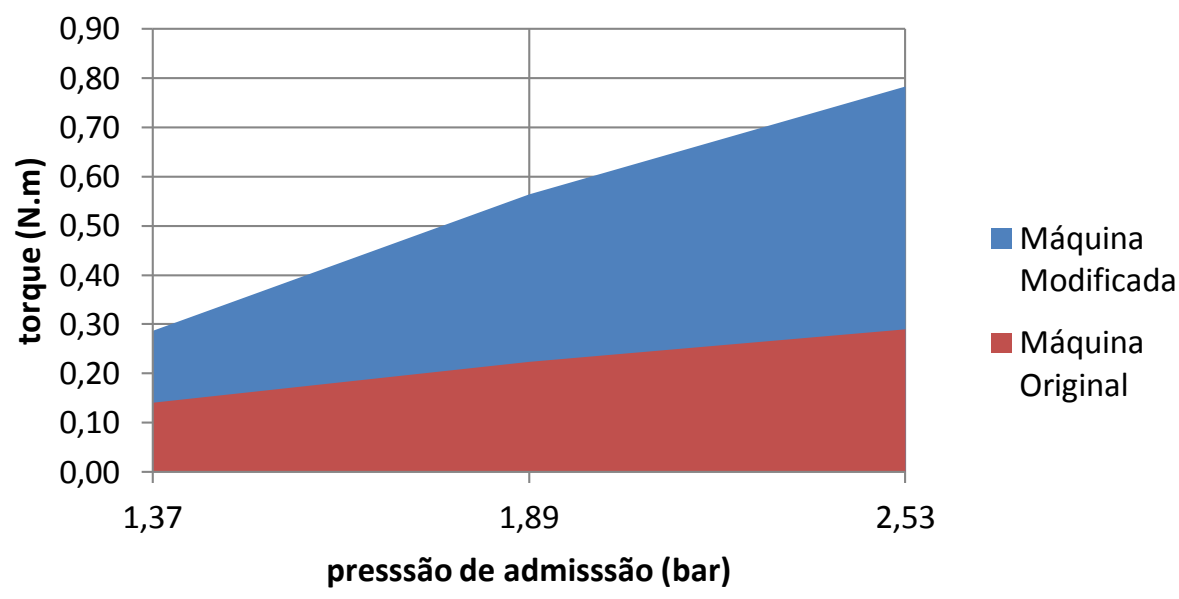

Figura 5.33 - Comparativo do torque máximo entre a máquina original e a modificada.

Observa-se na Figura 5.33, que em ambos os casos o torque possui um crescimento linear com a pressão de admissão. Porém, após a modificação da máquina, os valores de torque são superiores, e o coeficiente da curva é maior.

Analogamente, o gráfico comparativo da potência máxima é apresentado na Figura 5.34.

Analisando o gráfico, os valores de potência máxima se mostraram significativamente superiores após as modificações, além de apresentarem crescimento quadrático em relação à pressão de admissão. 


\section{Comparativo da potência máxima}

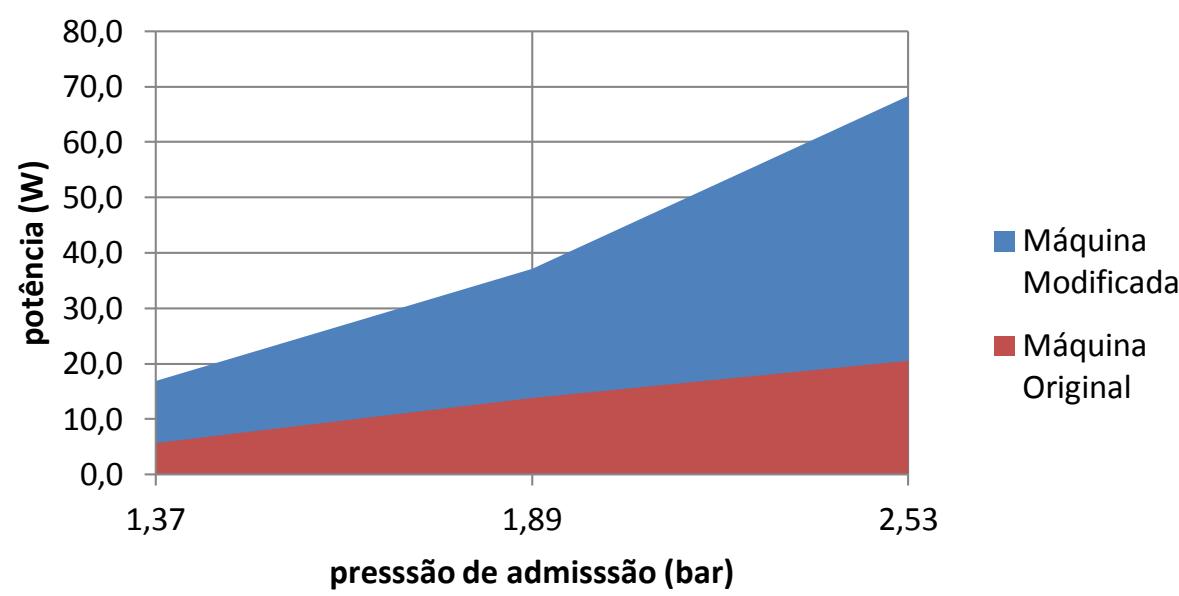

Figura 5.34 - Comparativo da potência máxima entre a máquina original e a modificada.

Finalmente, na Figura 5.35 tem-se o comparativo da eficiência isoentrópica máxima:

\section{Comparativo da eficiência isoentrópica}

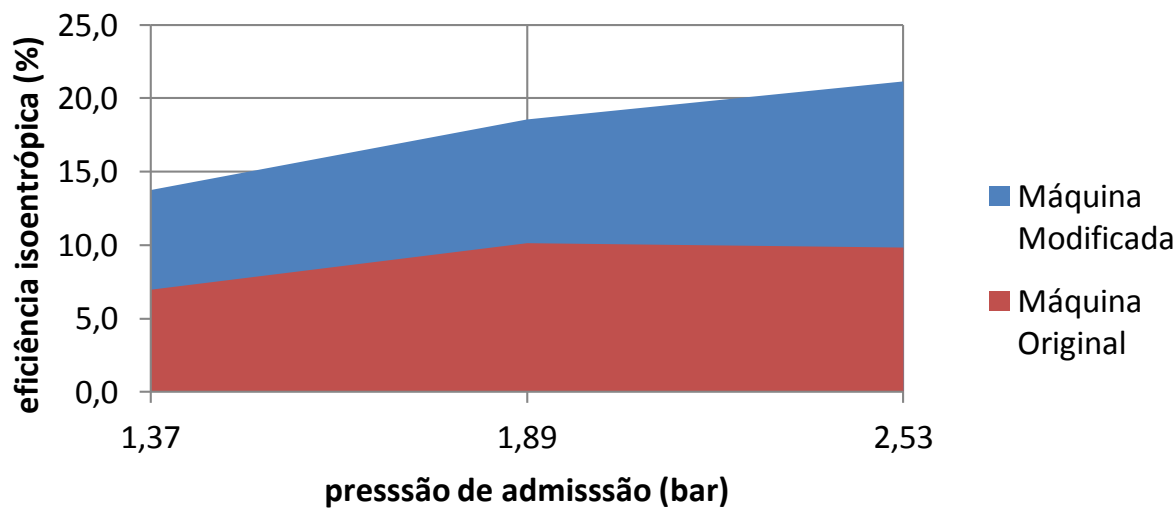

Figura 5.35 - Comparativo da eficiência isoentrópica entre a máquina original e a modificada.

Através da Figura 5.35, conclui-se que em ambos os casos a eficiência isoentrópica máxima possui curvas semelhantes. Porém, após as modificações os valores de eficiência isoentrópica aumentaram, indicando que as perdas reduziram. 


\section{COMPARAÇÃo ENTRE RESULTADOS TEÓRICOS E EXPERIMENTAIS}

Este capítulo destina-se à comparação entre os resultados obtidos nas simulações e no estudo experimental. Também aborda a estimativa do coeficiente de atrito viscoso equivalente global, bem como o seu cálculo.

As curvas de torque obtidas no estudo experimental e nas simulações da análise de sensibilidade são confrontadas na Figura 6.1:
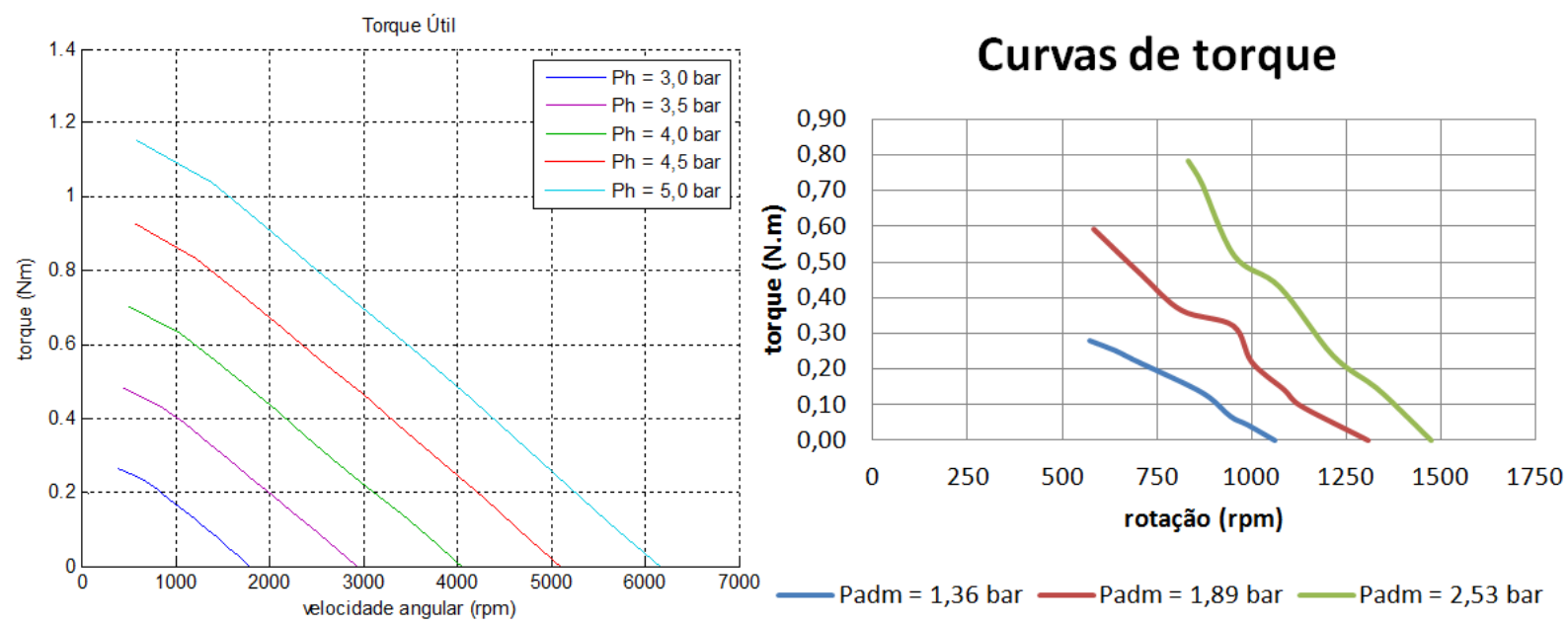

Figura 6.1 - Curvas de torque: (a) simulado e (b) experimental.

Analisando os gráficos da Figura 6.1, o perfil das curvas simuladas de torque para diversas pressões de admissão é semelhante ao perfil obtido no estudo experimental, salvo os pontos que estão fora da tendência da curva, causados pelo freio de Prony, como visto anteriormente.

Nota-se que, em ambos os casos, quanto maior a pressão de entrada, maior será o torque da máquina. E como em um motor de combustão interna, em rotações mais baixas apresenta maior torque.

Analogamente ao torque, confrontando as curvas de potência simuladas e experimentais, obtém-se a Figura 6.2: 

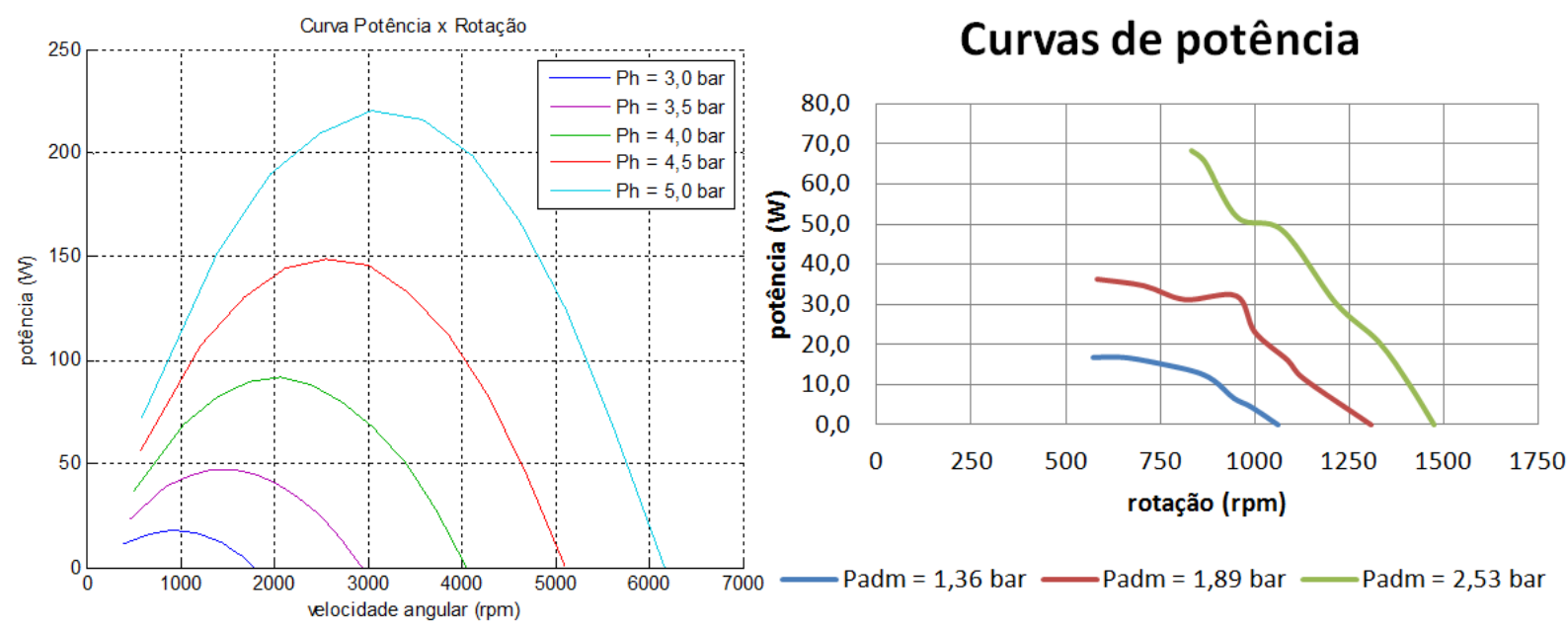

Figura 6.2 - Curvas de potência: (a) simulado e (b) experimental.

Examinando a Figura 6.2, exceto pela parte da curva de potência à esquerda do ponto de máximo, comprometida pelo freio de Prony, o perfil das curvas experimentais de potência para diversas pressões de admissão é semelhante ao perfil obtido nas simulações.

Nota-se que, em ambos os casos, o perfil da curva de potência se torna mais côncavo para pressões de entrada mais altas. E conforme se aumenta a pressão de admissão, maior será a potência máxima e sua respectiva velocidade angular.

Comparando os resultados obtidos nas simulações e no estudo experimental, pode-se analisar a variação do torque e da potência máximos em função da pressão de admissão, obtendo os gráficos da Figura 6.3:

\section{Torque e potência máximos em} função da presssão de admisssão

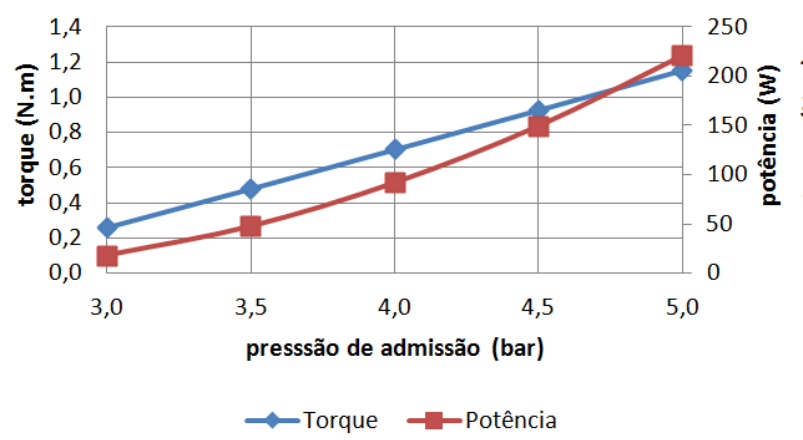

Torque e potência máximos em função da pressão de admissão

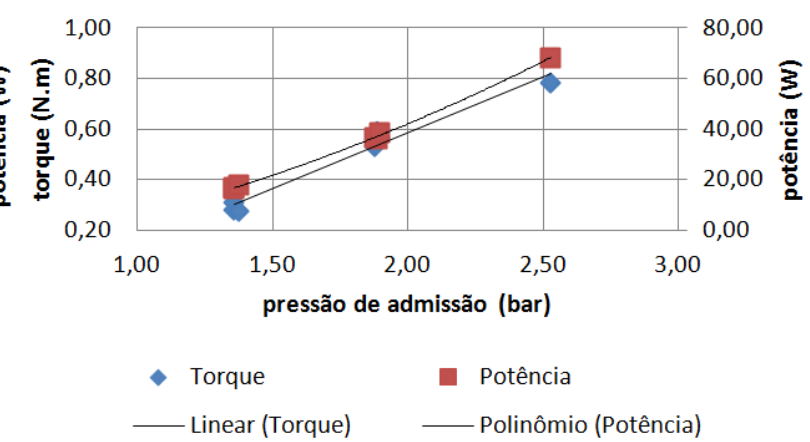

Figura 6.3 - Potência e torque máximos em função da pressão de entrada: (a) simulado e (b) experimental. 
Observando os gráficos da Figura 6.3, é possível afirmar que o torque máximo, tanto experimental quanto simulado, apresenta um crescimento linear em relação à pressão de admissão. $E$ as potências máximas da máquina, simulada e experimental, demonstram ter um crescimento quadrático em função da pressão de entrada. Portanto, os efeitos da variação da pressão de admissão nas simulações são equivalentes aos experimentais.

Com base na pressão de admissão de 2,53; é possível comparar diretamente os valores obtidos nas simulações e nos testes. A velocidade angular da máquina operando em vazio, isto é, sem carga, é de $1475 \mathrm{rpm}$. Simulando nas mesmas condições, obtém-se o gráfico da Figura 6.4:

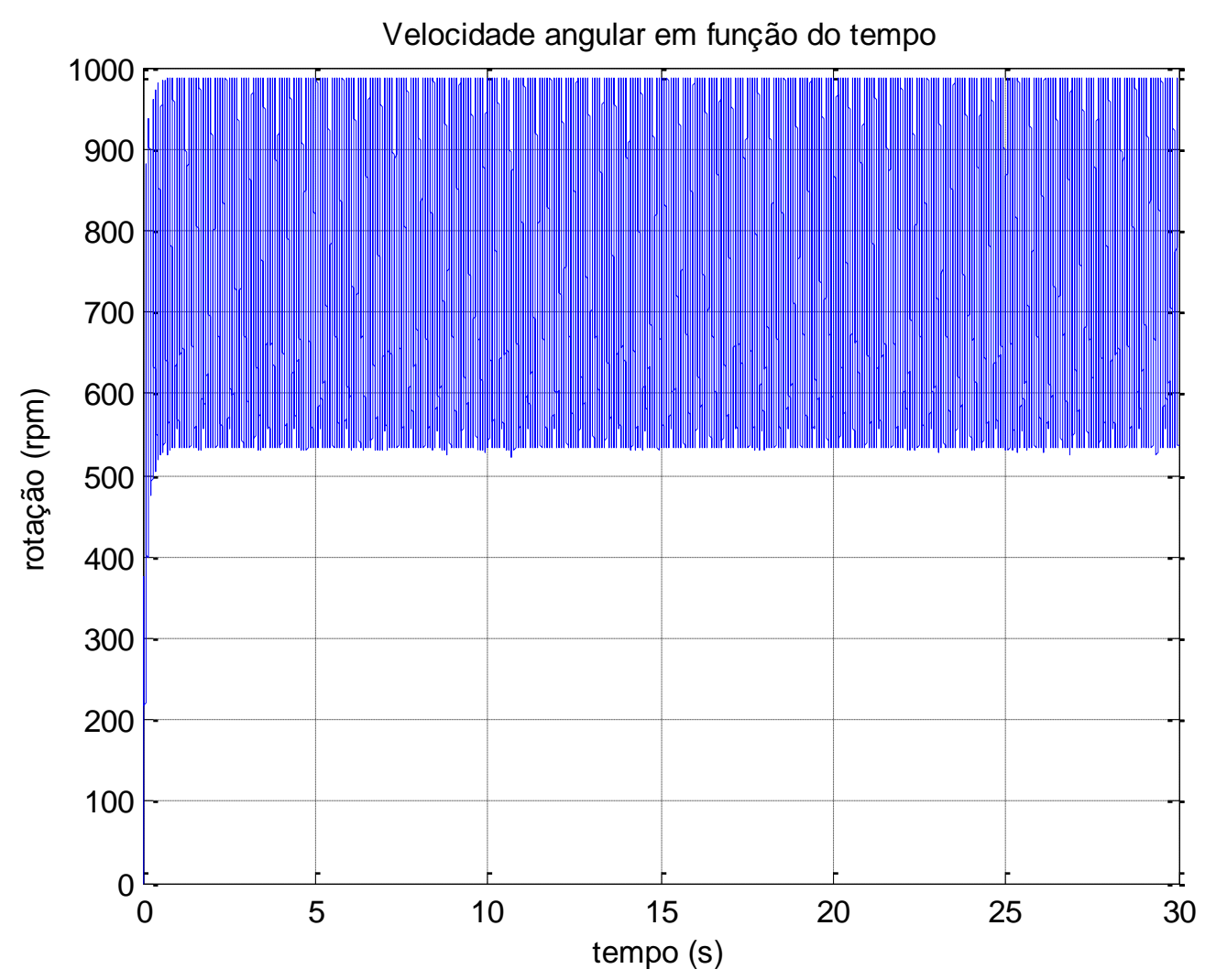

Figura 6.4 - Velocidade angular simulada para a pressão de admissão de 2,53 bar.

Examinando a simulação (Figura 6.4), a velocidade angular média é por volta de $750 \mathrm{rpm}$. Conclui-se que os valores obtidos durante os testes são superiores aos simulados, sugerindo que o coeficiente de atrito viscoso estipulado anteriormente foi superestimado. 
A comparação entre as curvas de torque, experimental e simulada, é apresentada na Figura 6.5:
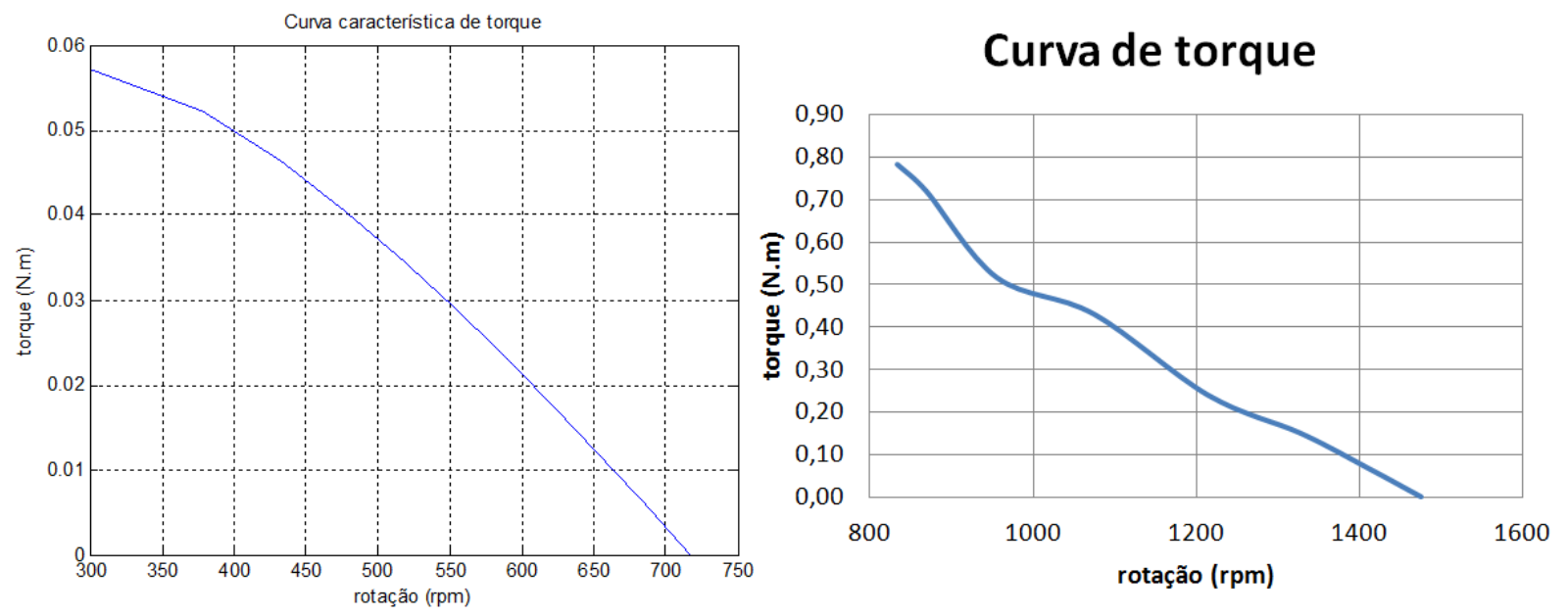

Figura 6.5 - Curva de torque para a pressão de admissão de 2,53 bar (a) simulado e (b) experimental.

$\mathrm{Na}$ Figura 6.5, observa-se que o torque máximo simulado é de aproximadamente 0,055 N.m, já o torque máximo medido é de quase 0,80 N.m. Desta forma, os valores de torque simulados são inferiores aos reais, sugerindo que a maior parcela do torque da máquina é referente às perdas na simulação.

Confrontando a curva de potência simulada com a experimental, obtém-se a Figura 6.6:
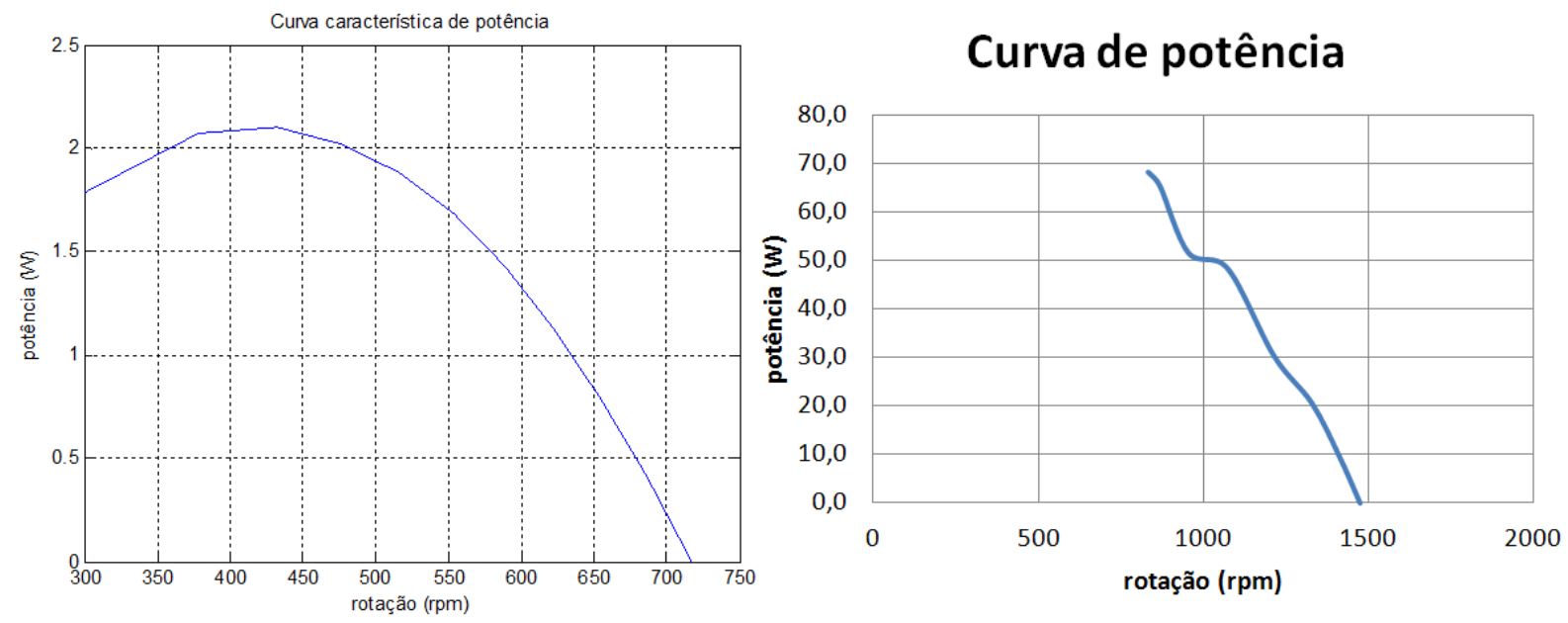

Figura 6.6 - Curva de potência para a pressão de admissão de 2,53 bar (a) simulado e (b) experimental. 
Analisando a Figura 6.6, a máxima potência simulada é de cerca de 2,2 W e ocorre a aproximadamente $430 \mathrm{rpm}$. Enquanto que nos testes a máxima potência medida é de cerca de $68 \mathrm{~W}$ e ocorre a aproximadamente $830 \mathrm{rpm}$. Logo, os valores de potência simulados são muito inferiores aos reais.

Vale ressaltar que as perdas na simulação devido ao ciclo da máquina são mínimas, pois nas simulações realizadas foi utilizado o diagrama PxV teórico e foi considerado que a abertura e o fechamento da válvula é instantâneo. Contudo as perdas mecânicas foram modeladas como um coeficiente de atrito viscoso e são responsáveis pela maior parte das perdas da máquina na simulação.

Durante o estudo experimental, foi constatado que na máquina real, devido às alterações feitas, as perdas por atrito são baixíssimas. Entretanto, como a válvula da máquina é do tipo carretel, há uma grande perda de trabalho no ciclo da máquina, sendo a maior parcela das perdas da máquina real.

De extrema relevância foi a constatação, possibilitada pela análise de sensibilidade, de que o diagrama PxV teórico adotado para representar o ciclo da máquina não é válido para simular a operação do sistema quando a pressão de entrada for inferior a aproximadamente 2,5 bar, como mostrado no diagrama da Figura 6.7 abaixo:

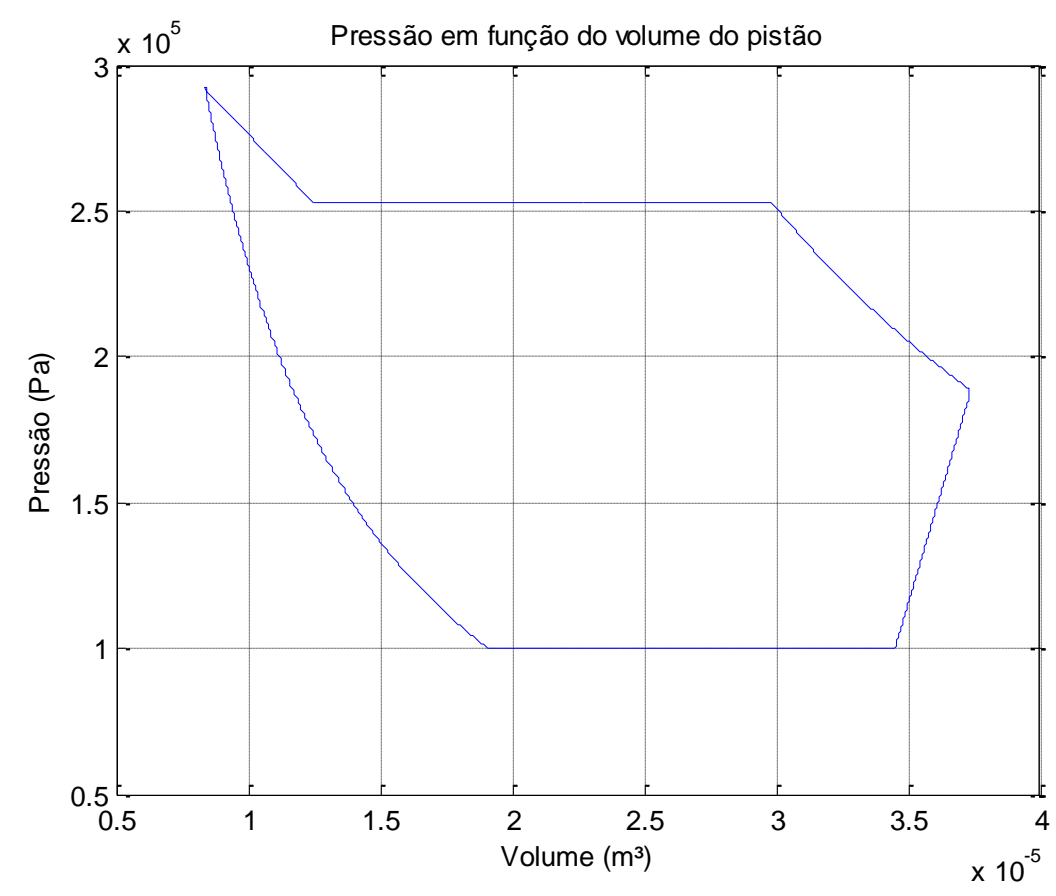

Figura 6.7 - Diagrama PxV distorcido entre o fim da compressão e o início da expansão. 
Conforme mostrado no diagrama, há perda de trabalho devido à sobrecompressão; para pressões de admissão inferiores a perda de trabalho se acentua, chegando-se ao extremo de impossibilitar a simulação. Verificou-se que quanto maior a pressão, menor o erro, sendo que para valores de pressão de entrada superiores a 3,0 bar não ocorrem mais distorções do diagrama.

Como há esta diferença entre as perdas globais das simulações e do estudo experimental, para corrigir este viés seria necessário modelar o ciclo da máquina de forma satisfatória e determinar as perdas por atrito.

Contudo não faz parte do escopo deste trabalho modelar o diagrama PxV real da máquina, sendo tal estudo proposto para trabalhos futuros.

Salvo a diferença entre as perdas reais e simuladas, e com base na análise da Figura 6.4, da Figura 6.5 e da Figura 6.6, tem-se a Tabela 6.1:

Tabela 6.1 - Comparação entre a simulação e o estudo experimental.

\begin{tabular}{c|cc}
\hline Parâmetro & Simulação & Experimental \\
\hline $\begin{array}{c}\text { Velocida angular } \\
\text { sem carga (rpm) }\end{array}$ & 752 & 1475 \\
\hline Torque máximo (N.m) & 0,055 & 0,783 \\
\hline Potência máxima (W) & 2,2 & 68,4 \\
\hline
\end{tabular}

A partir da Tabela 6.1, conclui-se que as perdas nas simulações estão acima dos valores reais e, portanto, deve-se estimar o coeficiente de atrito viscoso equivalente. 


\subsection{Estimativa do Coeficiente de Atrito Viscoso}

Para estimar o coeficiente de atrito viscoso, é proposto utilizar a velocidade angular da máquina operando em vazio (sem carga) como referência. Portanto, para uma dada pressão de admissão, simula-se a velocidade angular para cinco valores de coeficiente de atrito viscoso e determina-se a velocidade angular média para cada um dos valores. Através destes resultados, obtém-se uma linha de tendência, a qual correlaciona o coeficiente de atrito viscoso à velocidade angular. E por fim, utiliza-se o valor experimental da velocidade angular para calcular o coeficiente de atrito viscoso.

As variações do coeficiente de atrito viscoso foram feitas com base no valor de referência que é de 0,002 N.m.s/rad.

Para a pressão de admissão de 2,53 bar, a velocidade angular é simulada para diferentes coeficientes de atrito viscoso, obtendo-se a Figura 6.8:

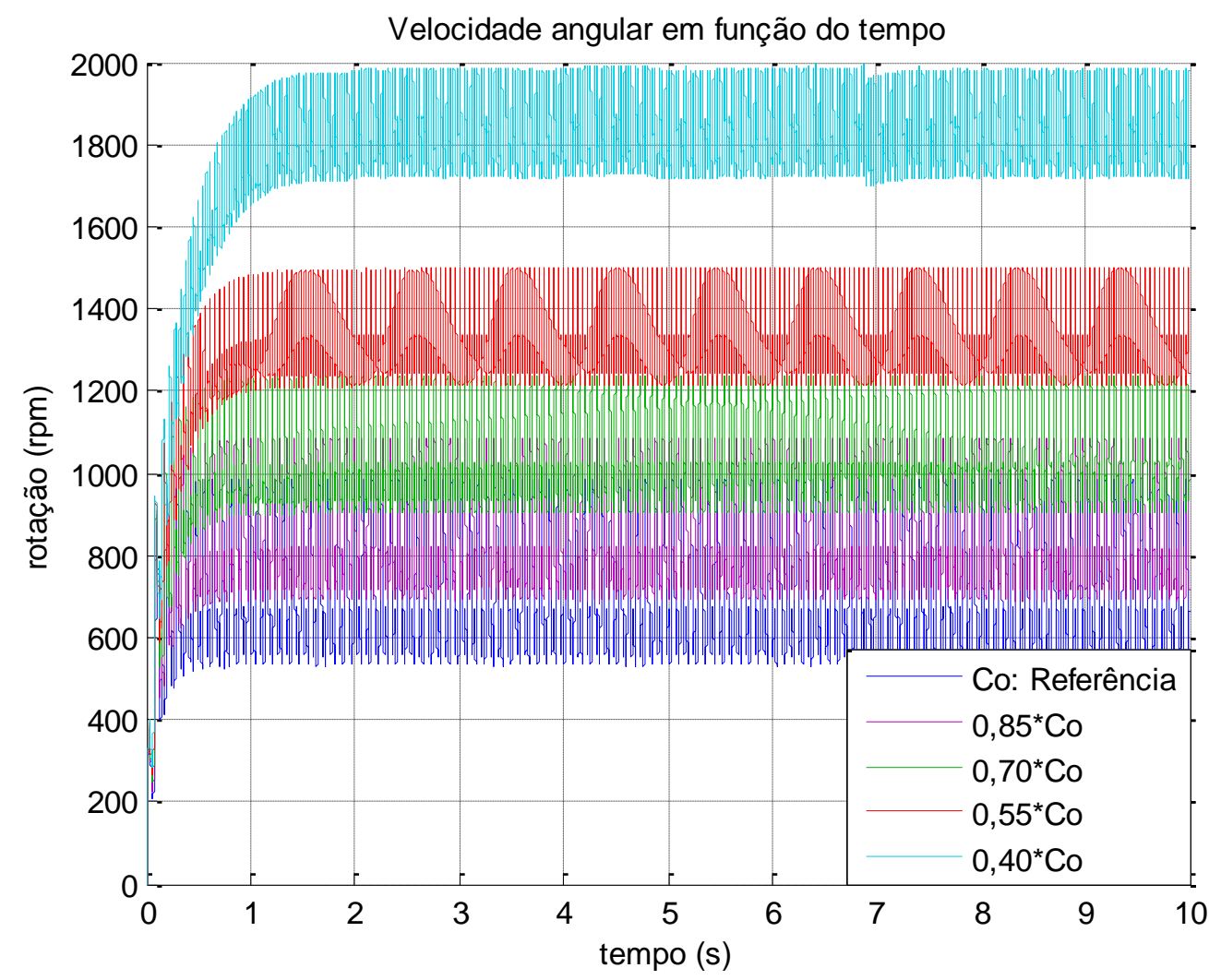

Figura 6.8 - Velocidade angular em função do coeficiente de atrito viscoso para a pressão de admissão de 2,53 bar. 
A partir do gráfico anterior, determina-se a velocidade angular média para cada um dos coeficientes de atrito viscoso, que são apresentados na Tabela 6.2 abaixo:

Tabela 6.2 - Resultados obtidos para a pressão de admissão de 2,53 bar.

\begin{tabular}{cc}
\hline $\begin{array}{c}\text { Coeficiente de } \\
\text { atrito viscoso } \\
\text { (N.m.s/rad) }\end{array}$ & $\begin{array}{c}\text { Velocidade } \\
\text { Angular (rpm) }\end{array}$ \\
\hline 0,0020 & 702 \\
0,0017 & 840 \\
0,0014 & 1026 \\
0,0011 & 1308 \\
0,0008 & 1780 \\
\hline
\end{tabular}

Utilizando os resultados da Tabela 6.2, obtém-se o gráfico da Figura 6.9:

Coeficiente de atrito viscoso

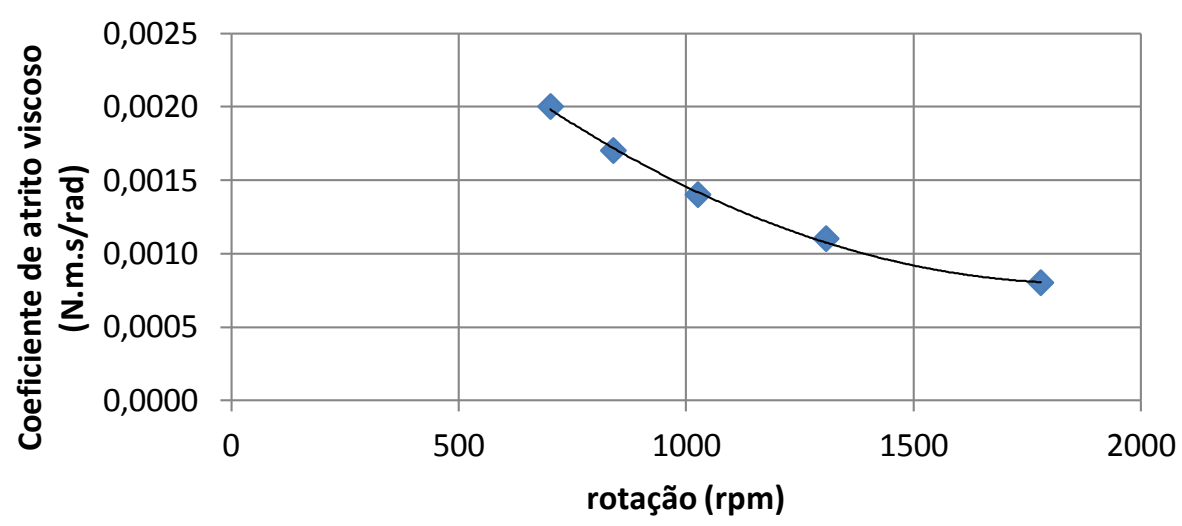

Figura 6.9 - Coeficiente de atrito viscoso em função da velocidade angular para a pressão de admissão de 2,53 bar.

Através dos pontos, é possível determinar a linha de tendência, cuja equação é expressa a seguir:

$$
c_{\theta}=8,563 \cdot 10^{-10} \cdot \omega^{2}-3,215 \cdot 10^{-6} \cdot \omega+3,816 \cdot 10^{-3}
$$


Da Tabela 5.15, tem-se que a velocidade angular para pressão de 2,53 bar:

$$
\omega=1475 \mathrm{rpm}
$$

Portanto, substituindo o valor da velocidade angular na equação (6.1), determina-se o coeficiente de atrito viscoso para a pressão de admissão de 2,53 bar:

$$
c_{\theta}=0,00094 \text { N.m.s/rad }
$$

Como a pressão de admissão mínima aceita pela simulação é de 2,5 bar (Figura 6.7) e os testes foram interrompidos a uma pressão de entrada de 2,53 bar, é proposto extrapolar os resultados da Tabela 5.15, obtendo-se o gráfico da Figura 6.10:

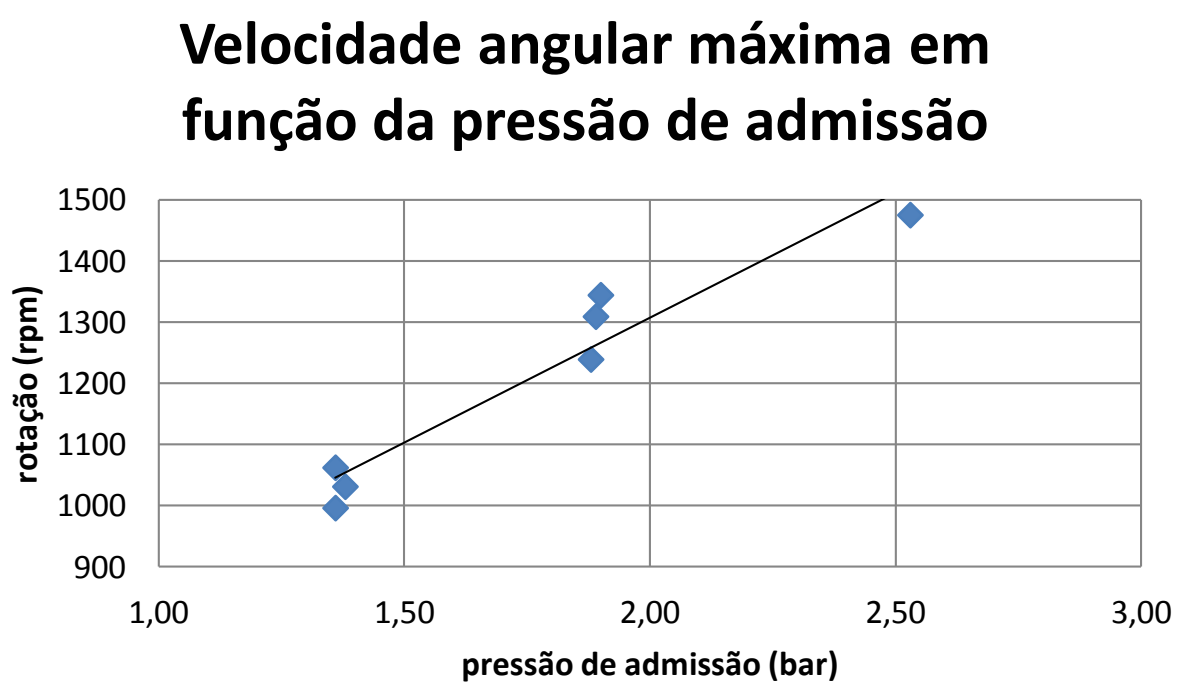

Figura 6.10 - Velocidade angular máxima em função da pressão de admissão com linha de tendência.

Observando o gráfico da Figura 6.10, conclui-se que a velocidade angular máxima da máquina demonstra ter um crescimento linear em função da pressão de admissão, e pode ser expressa pela seguinte equação matemática:

$$
\omega=407,84 \cdot P_{a d m}+491,37
$$


Com base na equação (6.2), é possível extrapolar os resultados experimentais para as seguintes pressões de admissão: 3,0 bar, 3,5 bar, 4,0 bar, 4,5 bar e 5,0 bar. Os resultados desta extrapolação são apresentados na Tabela 6.3:

Tabela 6.3 - Extrapolação dos resultados experimentais.

\begin{tabular}{cc}
\hline $\begin{array}{c}\text { Pressão de } \\
\text { admissão (bar) }\end{array}$ & $\begin{array}{c}\text { Velocidade } \\
\text { angular (rpm) }\end{array}$ \\
\hline 3,0 & 1715 \\
3,5 & 1919 \\
4,0 & 2123 \\
4,5 & 2327 \\
5,0 & 2531 \\
\hline
\end{tabular}

A partir dos resultados da Tabela 6.3, é possível repetir a metodologia para estimar o coeficiente de atrito viscoso para diferentes pressões de admissão.

Para a pressão de admissão de 3,0 bar, simula-se a velocidade angular para diferentes coeficientes de atrito viscoso, obtendo a Figura 6.11:

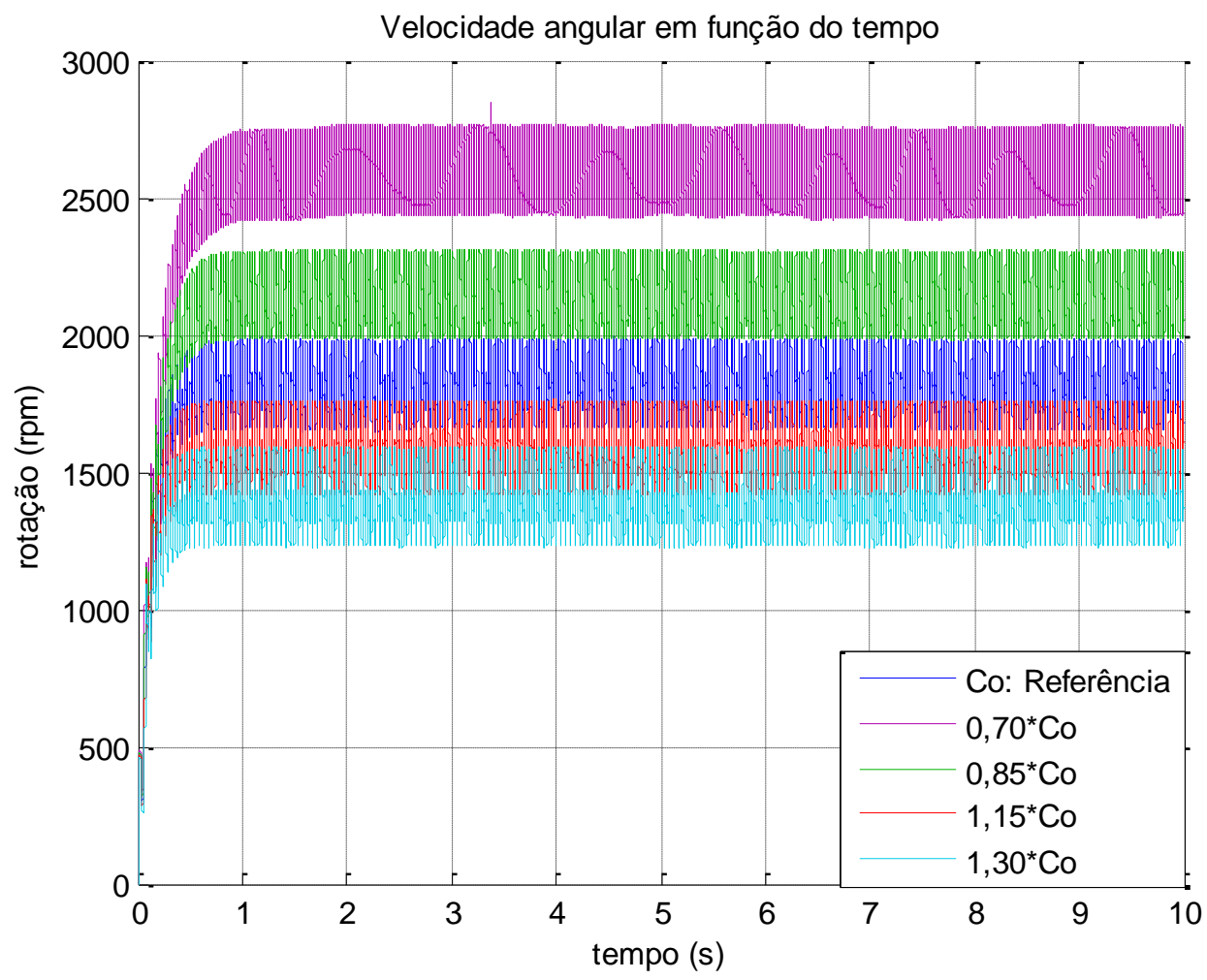

Figura 6.11 - Velocidade angular em função do coeficiente de atrito viscoso para a pressão de admissão de 3,0 bar. 
Com base na Figura 6.11, a velocidade angular média é determinada para cada um dos coeficientes de atrito viscoso, que são apresentados na Tabela 6.4 abaixo:

Tabela 6.4 - Resultados obtidos para a pressão de admissão de 3,0 bar.

\begin{tabular}{cc}
\hline $\begin{array}{c}\text { Coeficiente de } \\
\text { atrito viscoso } \\
\text { (N.m.s/rad) }\end{array}$ & $\begin{array}{c}\text { Velocidade } \\
\text { Angular (rpm) }\end{array}$ \\
\hline 0,0026 & 1374 \\
0,0023 & 1549 \\
0,0020 & 1778 \\
0,0017 & 2094 \\
0,0014 & 2528 \\
\hline
\end{tabular}

A partir dos resultados da Tabela 6.4, obtém-se o gráfico da Figura 6.12:

Coeficiente de atrito viscoso

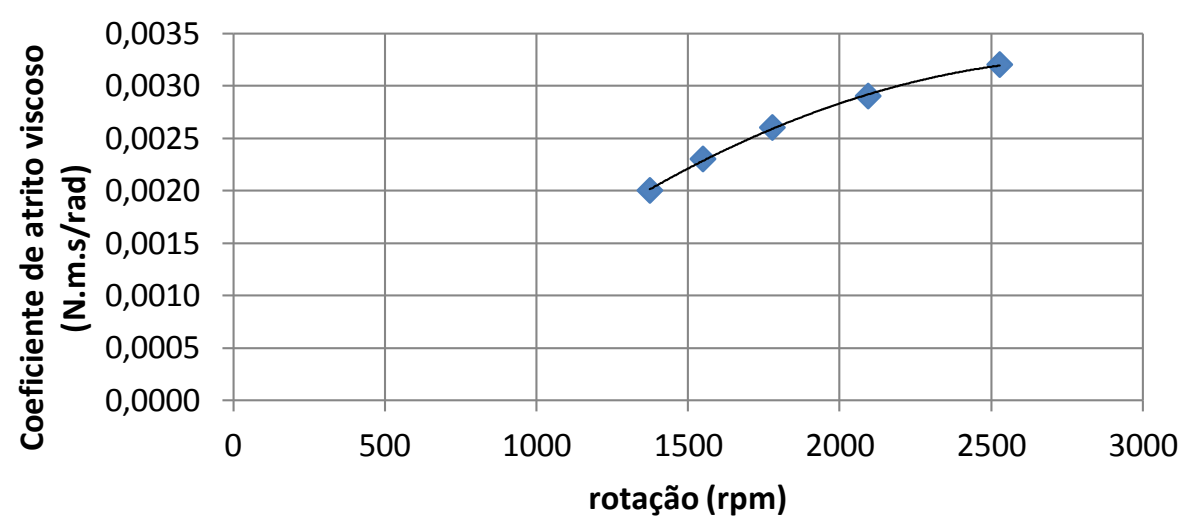

Figura 6.12 - Coeficiente de atrito viscoso em função da velocidade angular para a pressão de admissão de 3,0 bar.

Através do gráfico da Figura 6.12, determina-se a linha de tendência e sua respectiva equação, que é expressa a seguir:

$$
c_{\theta}=5,388 \cdot 10^{-10} \cdot \omega^{2}-3,126 \cdot 10^{-6} \cdot \omega+5,865 \cdot 10^{-3}
$$


Para pressão de 3,0 bar, determina-se a velocidade angular através da Tabela 6.3:

$$
\omega=1715 \mathrm{rpm}
$$

Logo, utilizando o valor da velocidade angular na equação (6.3), determina-se o coeficiente de atrito viscoso para a pressão de admissão de 3,0 bar:

$$
c_{\theta}=0,00209 \text { N.m.s } / \mathrm{rad}
$$

Para a pressão de admissão de 3,5 bar, a velocidade angular é simulada para diferentes coeficientes de atrito viscoso, obtendo-se a Figura 6.13:

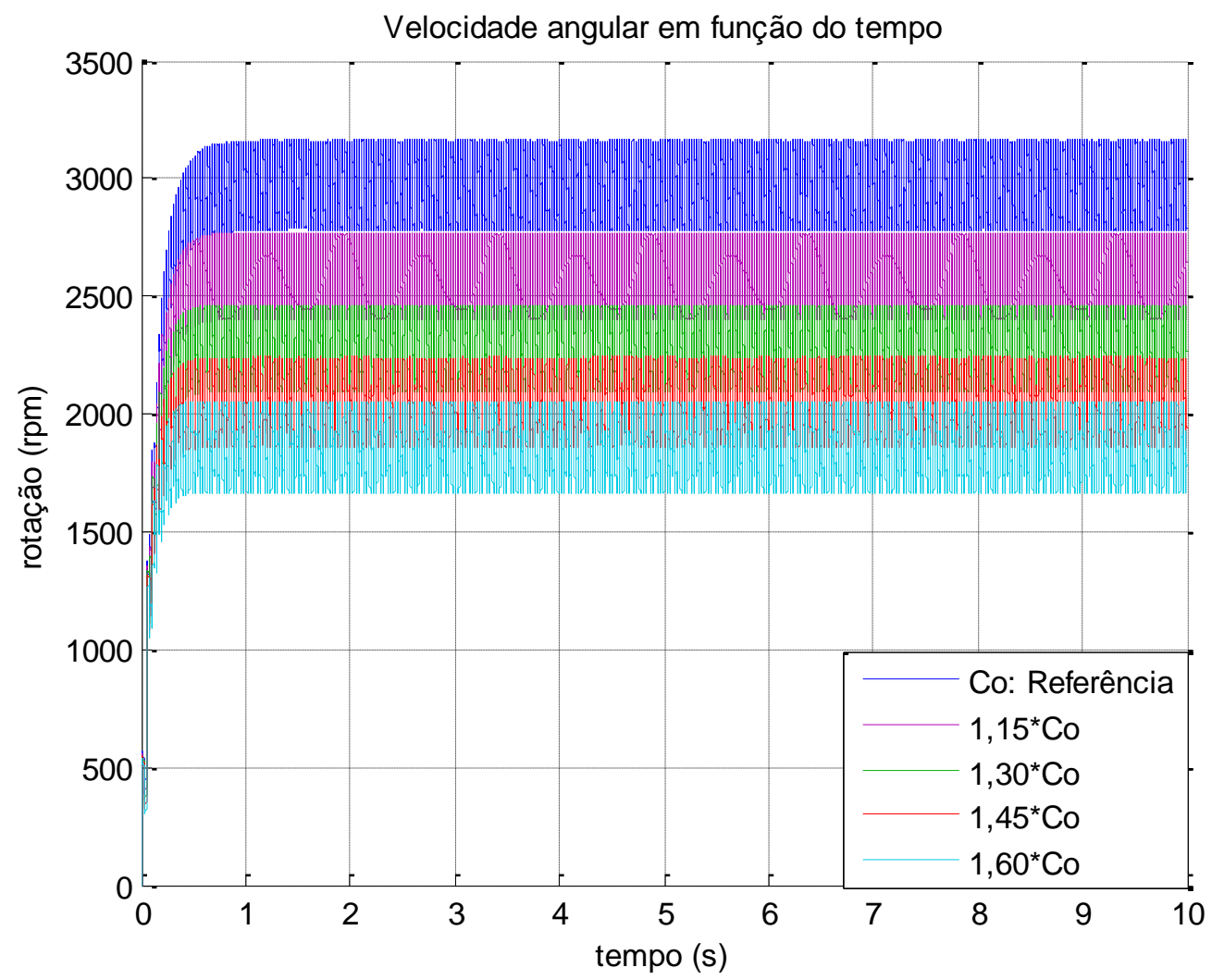

Figura 6.13 - Velocidade angular em função do coeficiente de atrito viscoso para a pressão de admissão de 3,5 bar. 
A partir do gráfico anterior, determina-se a velocidade angular média para cada um dos coeficientes de atrito viscoso, que são apresentados na Tabela 6.5 abaixo:

Tabela 6.5 - Resultados obtidos para a pressão de admissão de 3,5 bar.

\begin{tabular}{cc}
\hline $\begin{array}{c}\text { Coeficiente de } \\
\text { atrito viscoso } \\
\text { (N.m.s/rad) }\end{array}$ & $\begin{array}{c}\text { Velocidade } \\
\text { Angular (rpm) }\end{array}$ \\
\hline 0,0020 & 2912 \\
0,0023 & 2533 \\
0,0026 & 2233 \\
0,0029 & 2009 \\
0,0032 & 1821 \\
\hline
\end{tabular}

Utilizando os resultados da Tabela 6.5, obtém-se o gráfico da Figura 6.14:

\section{Coeficiente de atrito viscoso}

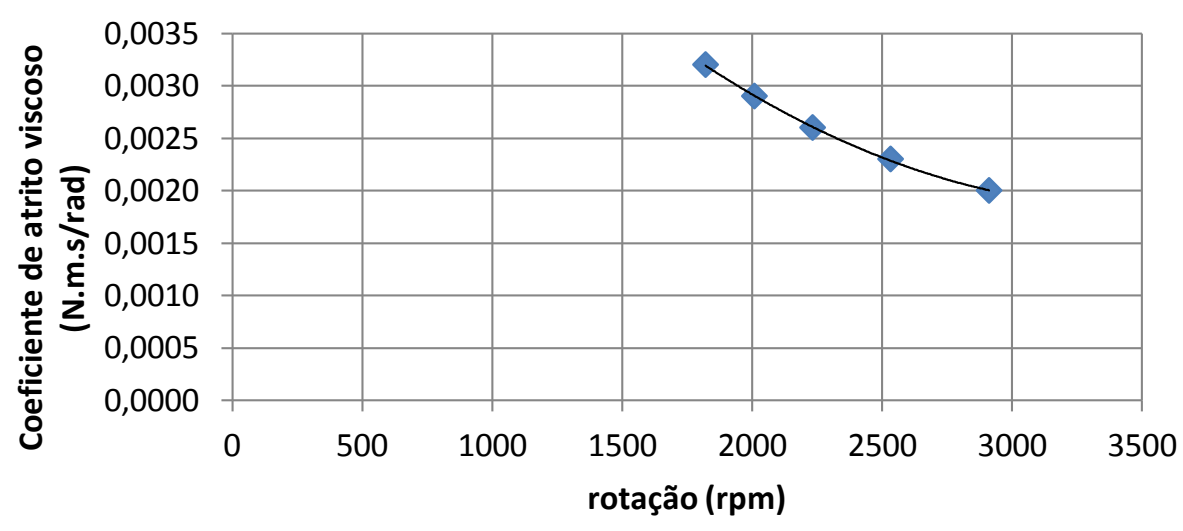

Figura 6.14 - Coeficiente de atrito viscoso em função da velocidade angular para a pressão de admissão de 3,5 bar.

Através dos pontos, é possível determinar a linha de tendência, cuja equação é expressa a seguir:

$$
c_{\theta}=4,846 \cdot 10^{-10} \cdot \omega^{2}-3,384 \cdot 10^{-6} \cdot \omega+7,749 \cdot 10^{-3}
$$


Da Tabela 6.3, tem-se que a velocidade angular para pressão de 3,5 bar:

$$
\omega=1919 \mathrm{rpm}
$$

Portanto, substituindo o valor da velocidade angular na equação (6.4), determina-se o coeficiente de atrito viscoso para a pressão de admissão de 3,5 bar:

$$
c_{\theta}=0,00304 N \cdot \mathrm{m} \cdot \mathrm{s} / \mathrm{rad}
$$

Para a pressão de admissão de 4,0 bar, simula-se a velocidade angular para diferentes coeficientes de atrito viscoso, obtendo a Figura 6.15:

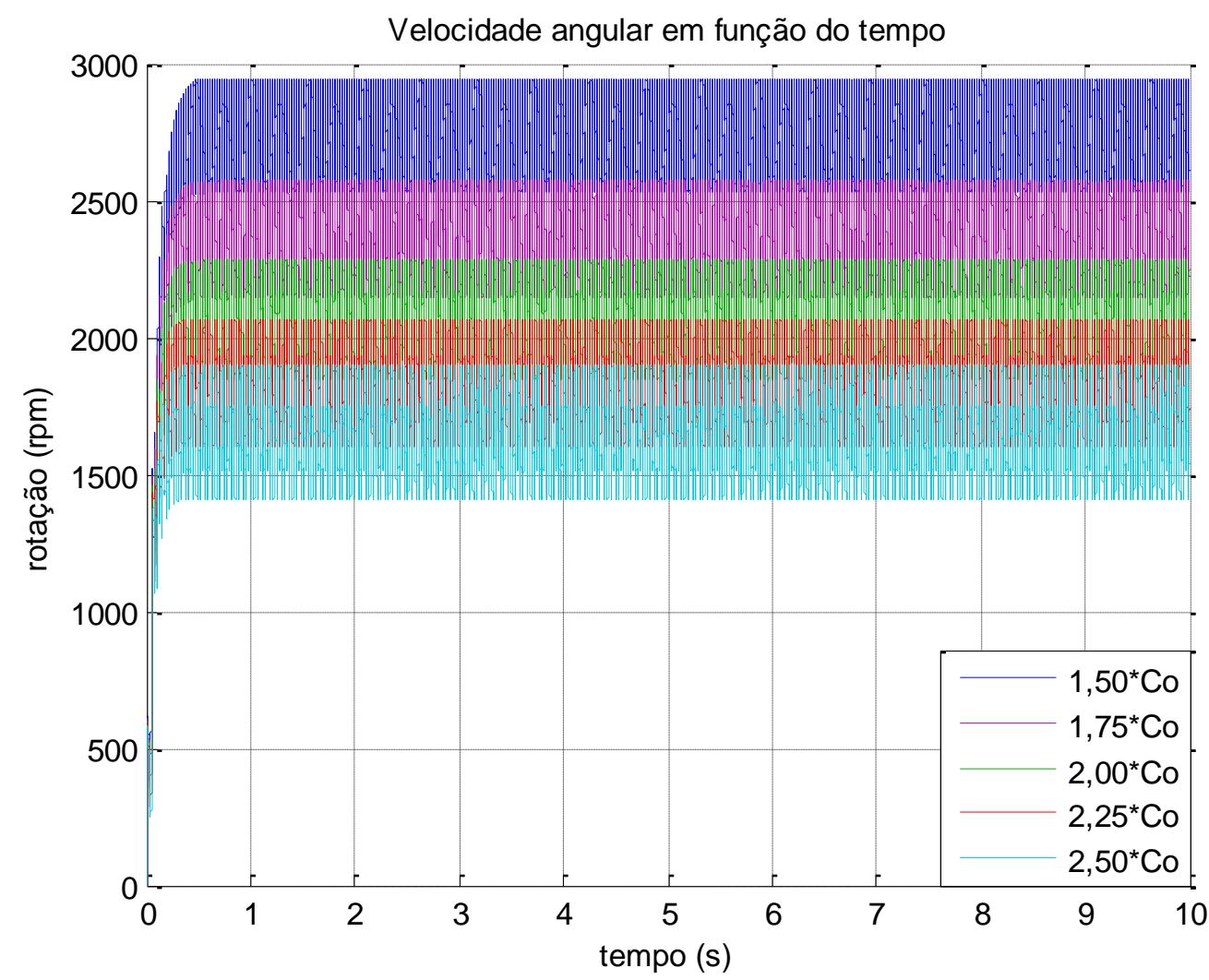

Figura 6.15 - Velocidade angular em função do coeficiente de atrito viscoso para a pressão de admissão de 4,0 bar. 
Com base na Figura 6.15, a velocidade angular média é determinada para cada um dos coeficientes de atrito viscoso, que são apresentados na Tabela 6.6 abaixo:

Tabela 6.6 - Resultados obtidos para a pressão de admissão de 4,0 bar.

\begin{tabular}{cc}
\hline $\begin{array}{c}\text { Coeficiente de } \\
\text { atrito viscoso } \\
\text { (N.m.s/rad) }\end{array}$ & $\begin{array}{c}\text { Velocidade } \\
\text { Angular (rpm) }\end{array}$ \\
\hline 0,0030 & 2690 \\
0,0035 & 2318 \\
0,0040 & 2025 \\
0,0045 & 1799 \\
0,0050 & 1619 \\
\hline
\end{tabular}

A partir dos resultados da Tabela 6.6, obtém-se o gráfico da Figura 6.16:

Coeficiente de atrito viscoso

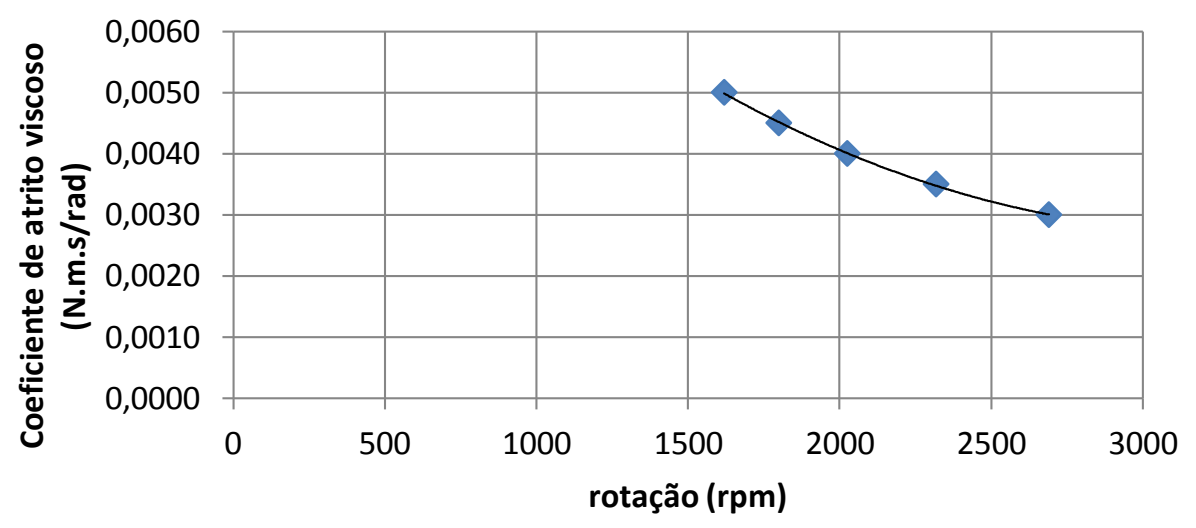

Figura 6.16 - Coeficiente de atrito viscoso em função da velocidade angular para a pressão de admissão de 4,0 bar.

Através do gráfico da Figura 6.16, determina-se a linha de tendência e sua respectiva equação, que é expressa a seguir:

$$
c_{\theta}=8,348 \cdot 10^{-10} \cdot \omega^{2}-5,444 \cdot 10^{-6} \cdot \omega+11,61 \cdot 10^{-3}
$$


Para pressão de 4,0 bar, determina-se a velocidade angular através da Tabela 6.3:

$$
\omega=2123 \mathrm{rpm}
$$

Logo, utilizando o valor da velocidade angular na equação (6.5), determina-se o coeficiente de atrito viscoso para a pressão de admissão de 4,0 bar:

$$
c_{\theta}=0,00381 \mathrm{~N} \cdot \mathrm{m} \cdot \mathrm{s} / \mathrm{rad}
$$

Para a pressão de admissão de 4,5 bar, a velocidade angular é simulada para diferentes coeficientes de atrito viscoso, obtendo-se a Figura 6.17:

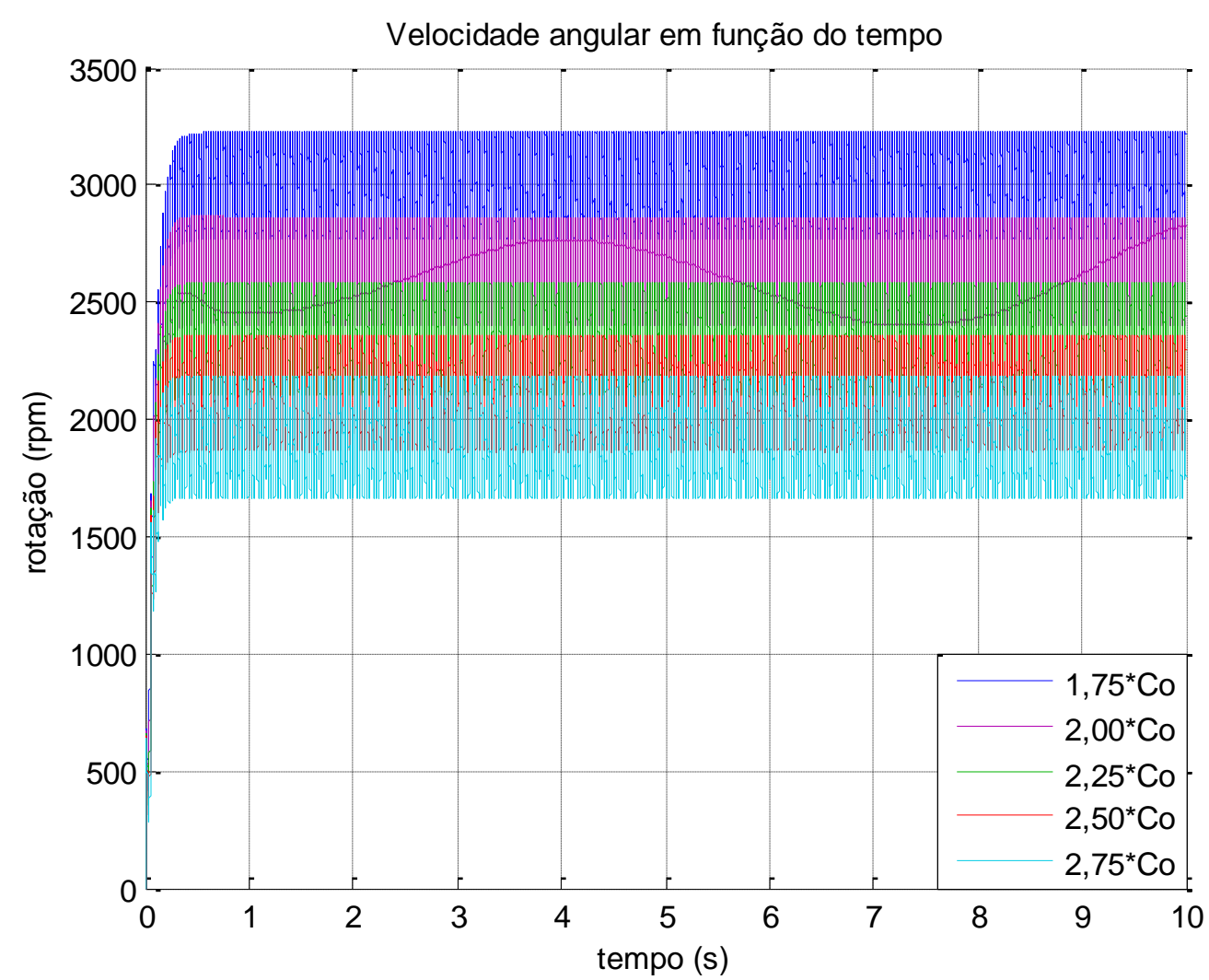

Figura 6.17 - Velocidade angular em função do coeficiente de atrito viscoso para a pressão de admissão de 4,5 bar. 
A partir do gráfico anterior, determina-se a velocidade angular média para cada um dos coeficientes de atrito viscoso, que são apresentados na Tabela 6.7 abaixo:

Tabela 6.7 - Resultados obtidos para a pressão de admissão de 4,5 bar.

\begin{tabular}{cc}
\hline $\begin{array}{c}\text { Coeficiente de } \\
\text { atrito viscoso } \\
\text { (N.m.s/rad) }\end{array}$ & $\begin{array}{c}\text { Velocidade } \\
\text { Angular (rpm) }\end{array}$ \\
\hline 0,0035 & 2950 \\
0,0040 & 2589 \\
0,0045 & 2304 \\
0,0050 & 2074 \\
0,0055 & 1885 \\
\hline
\end{tabular}

Utilizando os resultados da Tabela 6.7, obtém-se o gráfico da Figura 6.18:

\section{Coeficiente de atrito viscoso}

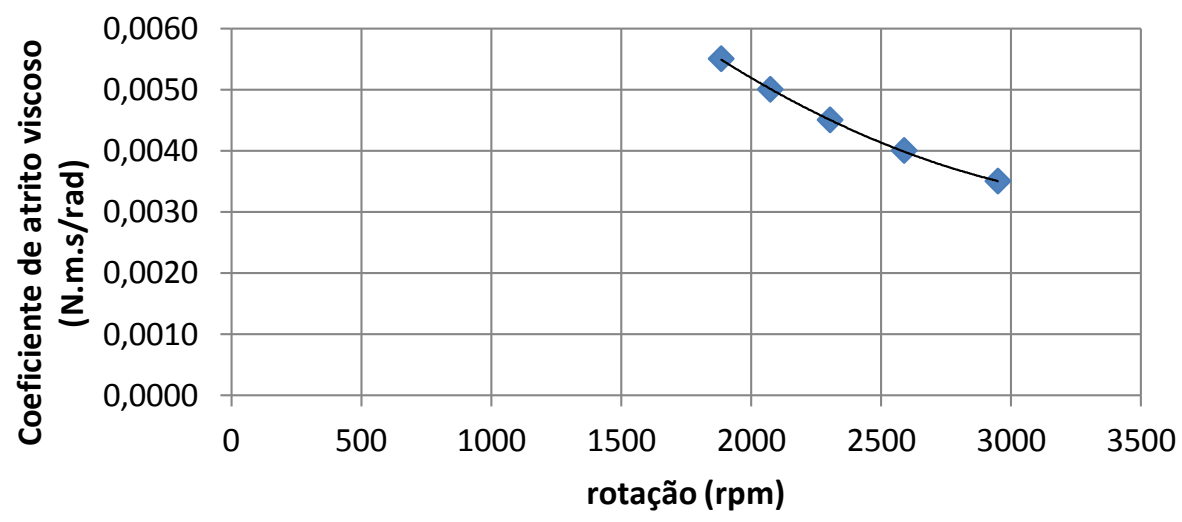

Figura 6.18 - Coeficiente de atrito viscoso em função da velocidade angular para a pressão de admissão de 4,5 bar.

Através dos pontos, é possível determinar a linha de tendência, cuja equação é expressa a seguir:

$$
c_{\theta}=7,555 \cdot 10^{-10} \cdot \omega^{2}-5,518 \cdot 10^{-6} \cdot \omega+13,21 \cdot 10^{-3}
$$


Da Tabela 6.3, tem-se que a velocidade angular para pressão de 4,5 bar:

$$
\omega=2327 \mathrm{rpm}
$$

Portanto, substituindo o valor da velocidade angular na equação (6.6), determina-se o coeficiente de atrito viscoso para a pressão de admissão de 4,5 bar:

$$
c_{\theta}=0,00446 \text { N.m.s } / \mathrm{rad}
$$

Para a pressão de admissão de 5,0 bar, simula-se a velocidade angular para diferentes coeficientes de atrito viscoso, obtendo a Figura 6.19:

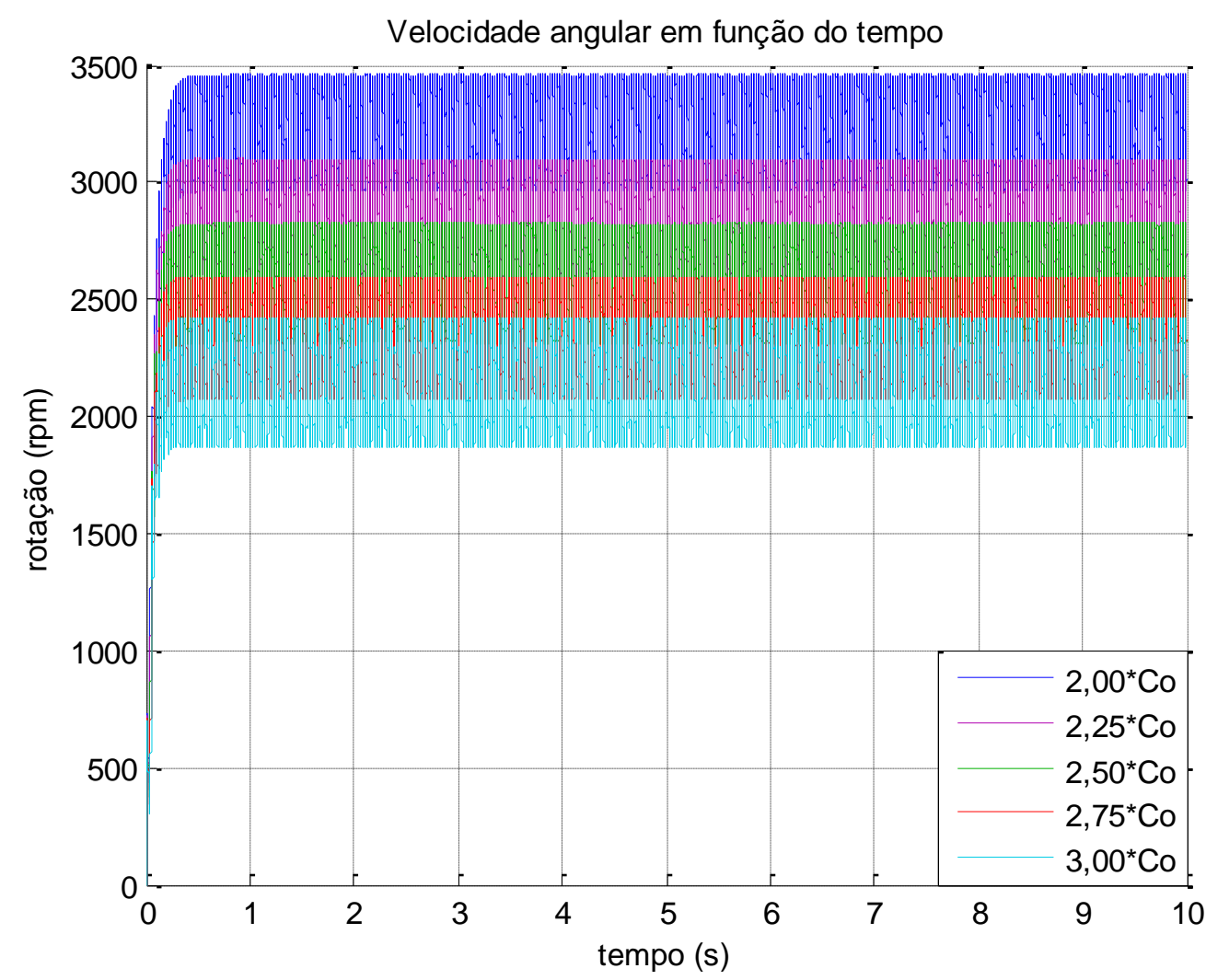

Figura 6.19 - Velocidade angular em função do coeficiente de atrito viscoso para a pressão de admissão de 5,0 bar. 
Com base na Figura 6.19, a velocidade angular média é determinada para cada um dos coeficientes de atrito viscoso, que são apresentados na Tabela 6.8 abaixo:

Tabela 6.8 - Resultados obtidos para a pressão de admissão de 5,0 bar.

\begin{tabular}{cc}
\hline $\begin{array}{c}\text { Coeficiente de } \\
\text { atrito viscoso } \\
\text { (N.m.s/rad) }\end{array}$ & $\begin{array}{c}\text { Velocidade } \\
\text { Angular (rpm) }\end{array}$ \\
\hline 0,0040 & 3164 \\
0,0045 & 2805 \\
0,0050 & 2528 \\
0,0055 & 2295 \\
0,0060 & 2106 \\
\hline
\end{tabular}

A partir dos resultados da Tabela 6.8, obtém-se o gráfico da Figura 6.20:

\section{Coeficiente de atrito viscoso}

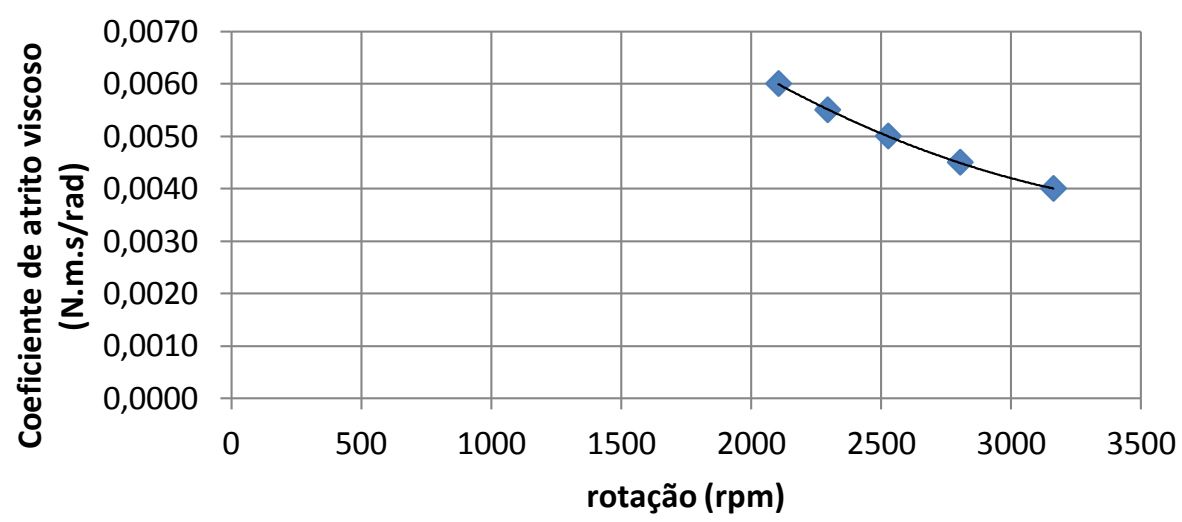

Figura 6.20 - Coeficiente de atrito viscoso em função da velocidade angular para a pressão de admissão de 5,0 bar.

Através do gráfico da Figura 6.20, determina-se a linha de tendência e sua respectiva equação, que é expressa a seguir:

$$
c_{\theta}=7,431 \cdot 10^{-10} \cdot \omega^{2}-5,795 \cdot 10^{-6} \cdot \omega+14,90 \cdot 10^{-3}
$$


Para pressão de 5,0 bar, determina-se a velocidade angular através da Tabela 6.3:

$$
\omega=2531 \mathrm{rpm}
$$

Logo, utilizando o valor da velocidade angular na equação (6.7), determina-se o coeficiente de atrito viscoso para a pressão de admissão de 5,0 bar:

$$
c_{\theta}=0,00499 \text { N.m.s } / \mathrm{rad}
$$

Compilando as estimativas de atrito viscoso para cada uma das pressões de entrada, obtém-se Tabela 6.9 abaixo:

Tabela 6.9 - Resultados obtidos para a estimativa do coeficiente de atrito viscoso.

\begin{tabular}{ccc}
\hline $\begin{array}{c}\text { Pressão de } \\
\text { admissão (bar) }\end{array}$ & $\begin{array}{c}\text { Velocidade } \\
\text { angular (rpm) }\end{array}$ & $\begin{array}{c}\text { Coeficiente de } \\
\text { atrito viscoso } \\
\text { (N.m.s/rad) }\end{array}$ \\
\hline 2,53 & 1475 & 0,00094 \\
3,00 & 1715 & 0,00209 \\
3,50 & 1919 & 0,00304 \\
4,00 & 2123 & 0,00381 \\
4,50 & 2327 & 0,00446 \\
5,00 & 2531 & 0,00499 \\
\hline
\end{tabular}

Utilizando os resultados da Tabela 6.9, obtém-se o gráfico da Figura 6.21:
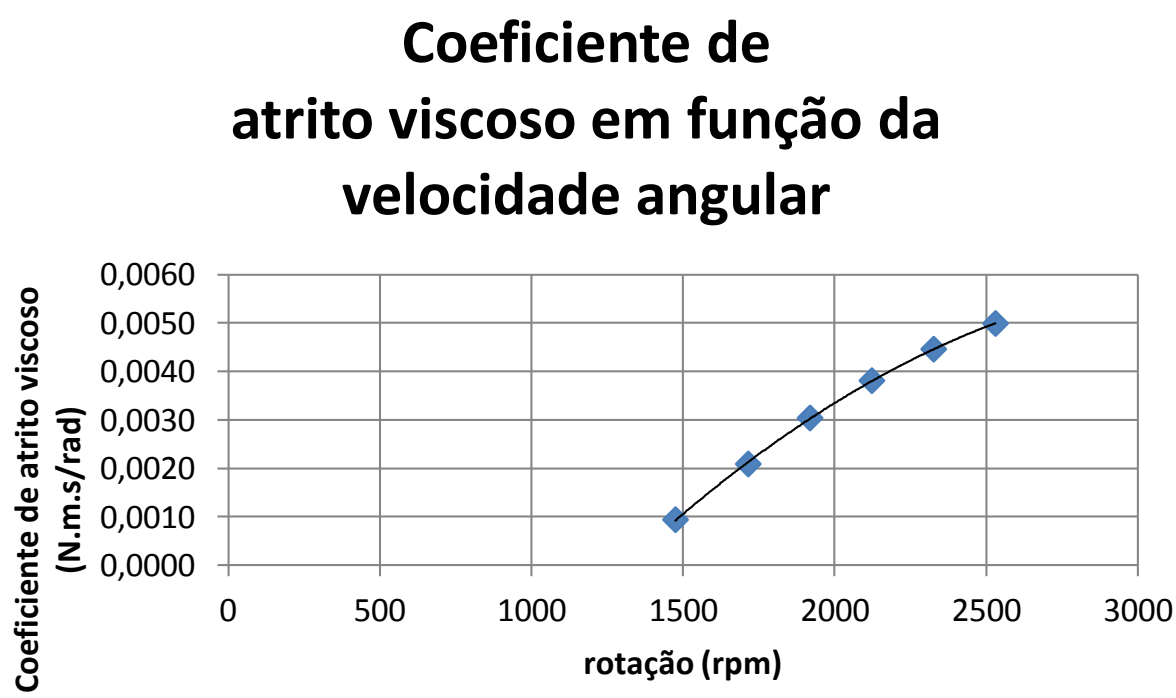

Figura 6.21 - Coeficiente de atrito viscoso em função da velocidade angular. 
Através dos pontos do gráfico anterior, é possível determinar a linha de tendência, cuja a equação é expressa a seguir:

$$
c_{\theta}=-1,427 \cdot 10^{-9} \cdot \omega^{2}+9,573 \cdot 10^{-6} \cdot \omega-1,009 \cdot 10^{-2}
$$

Como a velocidade angular da máquina operando sem carga é determinada pela pressão de admissão, é possível correlacionar o coeficiente de atrito viscoso com a pressão de entrada. Portanto, a partir dos resultados da Tabela 6.9, obtém-se o gráfico da Figura 6.22:

\section{Coeficiente de atrito viscoso em função da pressão de admissão}

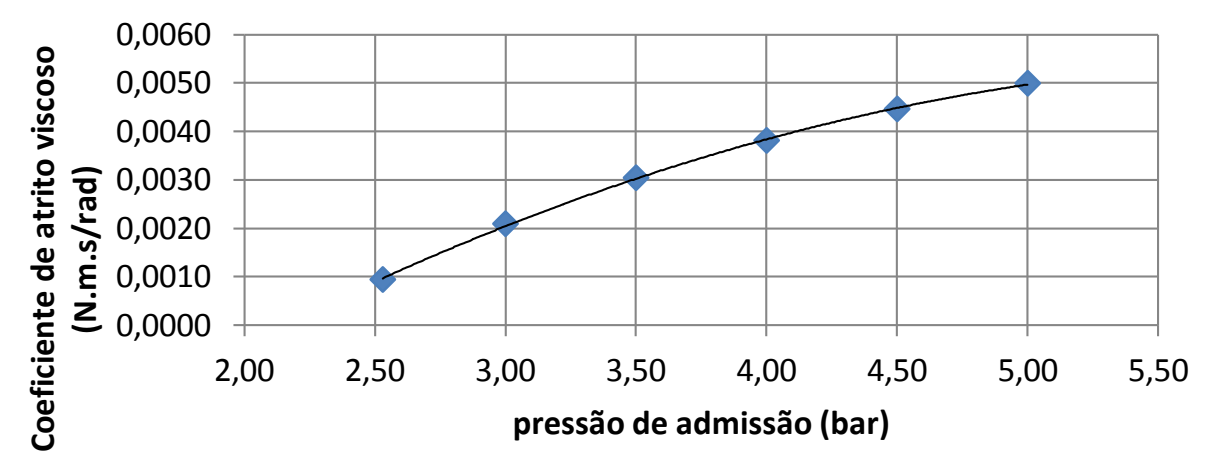

Figura 6.22 - Coeficiente de atrito viscoso em função da pressão de admissão.

Através do gráfico da Figura 6.22, determina-se a linha de tendência e sua respectiva equação, que é expressa a seguir:

$$
c_{\theta}=-3,324 \cdot 10^{-4} \cdot P_{a d m}{ }^{2}+4,121 \cdot 10^{-3} \cdot P_{a d m}-7,329 \cdot 10^{-3}
$$

Portanto, conhecendo a pressão de admissão ou a velocidade angular da máquina operando em vazio, estima-se o coeficiente de atrito viscoso através da equação (6.8) ou da equação (6.9), respectivamente. Observa-se que em ambos os casos, o coeficiente de atrito viscoso é estimado por função quadrática. 


\section{CONTROLE}

Segundo a norma internacional IEC 60034-1:2004, geradores elétricos devem fornecer energia elétrica com variações menores que $5 \%$ para a tensão e $2 \%$ para a frequência.

Para a rede elétrica brasileira, a tensão final para o consumidor é de $110 \mathrm{~V}$, variando de acordo com cada região, e a frequência elétrica é de $60 \mathrm{~Hz}$. Assim, aplicando a norma para a rede elétrica brasileira, os valores limites são:

Tabela 7.1 Valores limites para a frequência e a tensão elétrica.

\begin{tabular}{ccc}
\hline & $\mathbf{f}(\mathbf{H z})$ & $\mathbf{V}(\mathbf{V})$ \\
\hline Mínimo & 58,8 & 104,5 \\
Máximo & 61,2 & 115,5 \\
\hline
\end{tabular}

Portanto, o sistema de controle é fundamental para que a energia produzida pela máquina seja aproveitável, garantindo que a frequência elétrica e a tensão de saída permaneçam dentro dos limites apresentados na tabela acima.

O diagrama de blocos do sistema de controle é apresentado na Figura 7.1.

Observa-se na Figura 7.1 que o sistema de controle proposto neste trabalho é por retroalimentação, isto é, de acordo com medidas do sistema feitas pelo observador, o controlador atua sobre o mesmo. Em conjunto com o sistema de controle, deve-se utilizar válvulas de segurança para evitar pressões e velocidades excessivas.

Para simplificar o projeto do sistema de controle, assume-se que as respostas dos sensores e dos atuadores são muito mais rápidas do que a do sistema, desprezando suas dinâmicas. Também foi considerado que não há a saturação dos atuadores. 


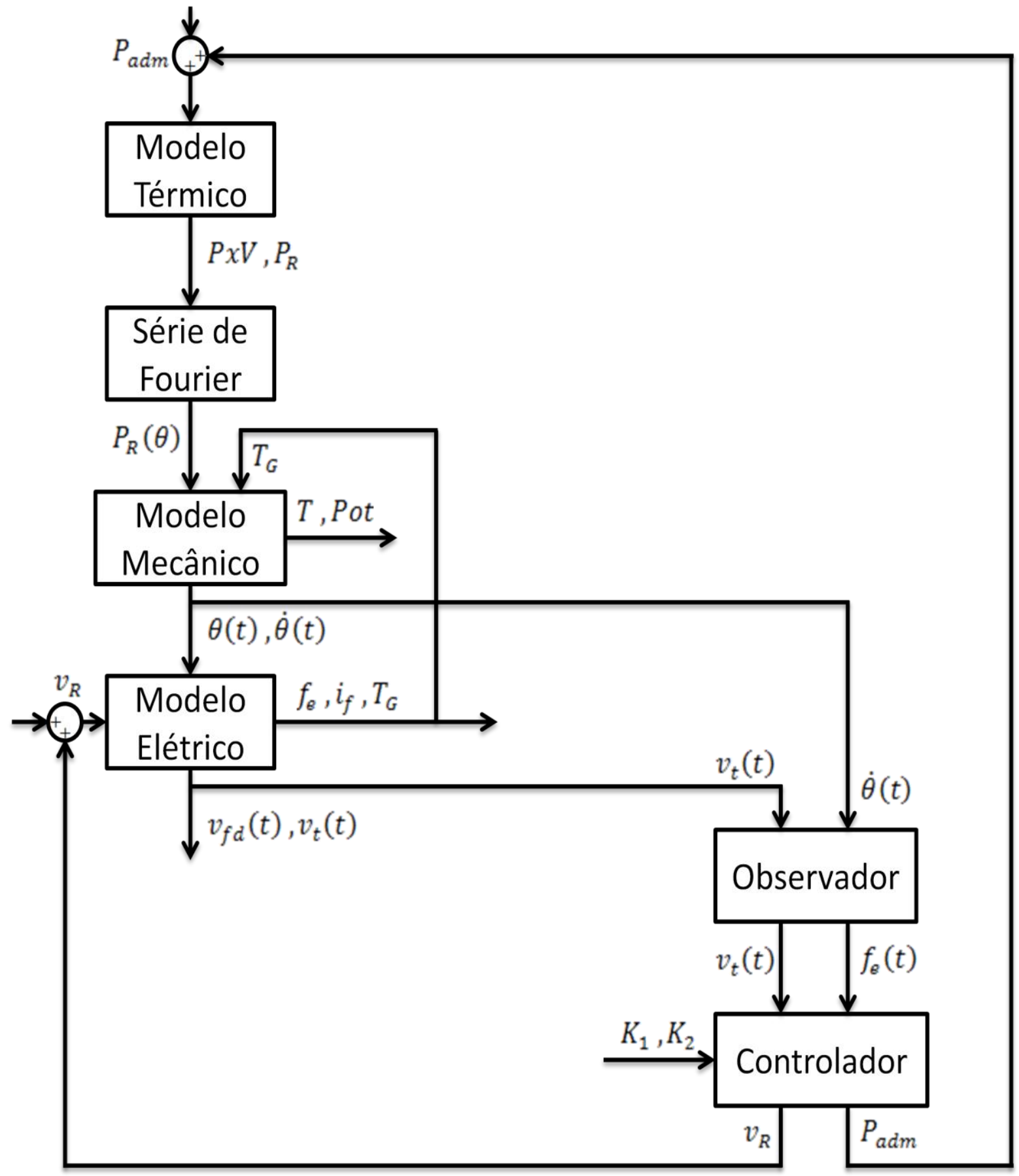

Figura 7.1 - Diagrama de blocos do sistema de controle. 


\subsection{Sensores}

O sensor é um equipamento que mede quantitativamente grandezas físicas convertendo para um sinal que pode ser lido. Logo o observador do sistema de controle é constituído de sensores. Para o sistema em questão, será necessário medir a velocidade angular da máquina e a tensão de saída do gerador; os sensores correspondentes serão abordados a seguir.

\subsubsection{Tacômetro}

O tacômetro, também conhecido como taquímetro, é um instrumento de medição do número de rotações por minuto. Um exemplo de um tacômetro é mostrado na Figura 7.2:

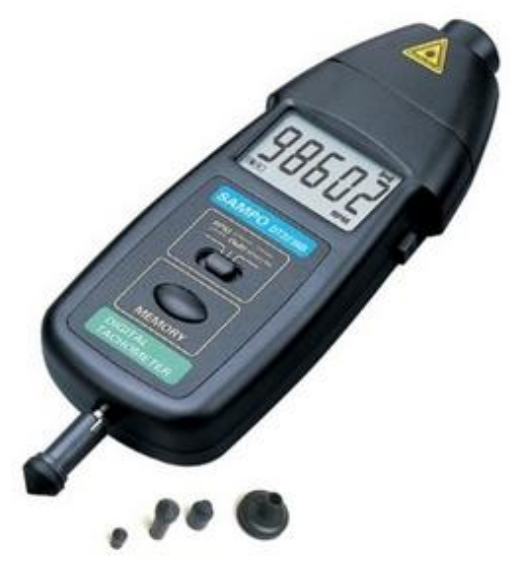

Figura 7.2 - Exemplo de tacômetro.

Utilizando o tacômetro na extremidade do eixo da roda de inércia é possível medir a velocidade angular da máquina. 


\subsubsection{Voltímetro}

O voltímetro é um aparelho que realiza medições de tensão elétrica em um circuito. Um exemplo de um voltímetro é mostrado na Figura 7.3:

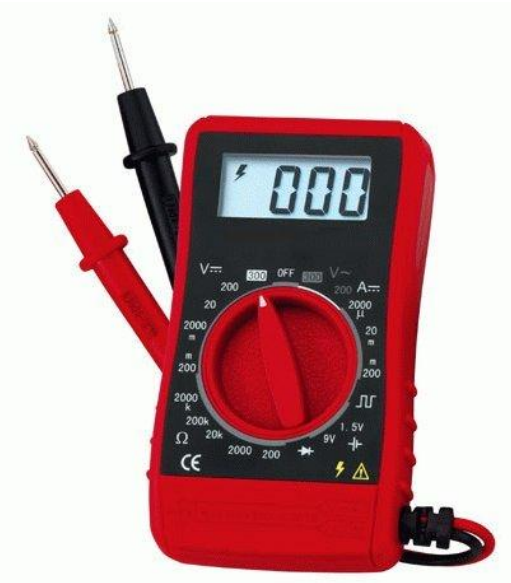

Figura 7.3 - Exemplo de voltímetro.

Utilizando o voltímetro em paralelo à saída do gerador é possível medir a tensão do mesmo.

\subsection{Atuadores}

O atuador é um equipamento que produz uma alteração sobre o sistema atendendo comandos externos. Logo o controlador do sistema de controle é constituído de atuadores. Para o sistema em questão, será necessário atuar sobre a pressão de entrada da máquina e sobre a tensão de entrada da excitatriz. Estes atuadores serão abordados a seguir. 


\subsubsection{Válvula Reguladora de Pressão}

A válvula reguladora de pressão abre ou fecha, alterando a pressão de entrada, de acordo com a referência externa. Um exemplo de uma válvula reguladora é mostrado na Figura 7.4:

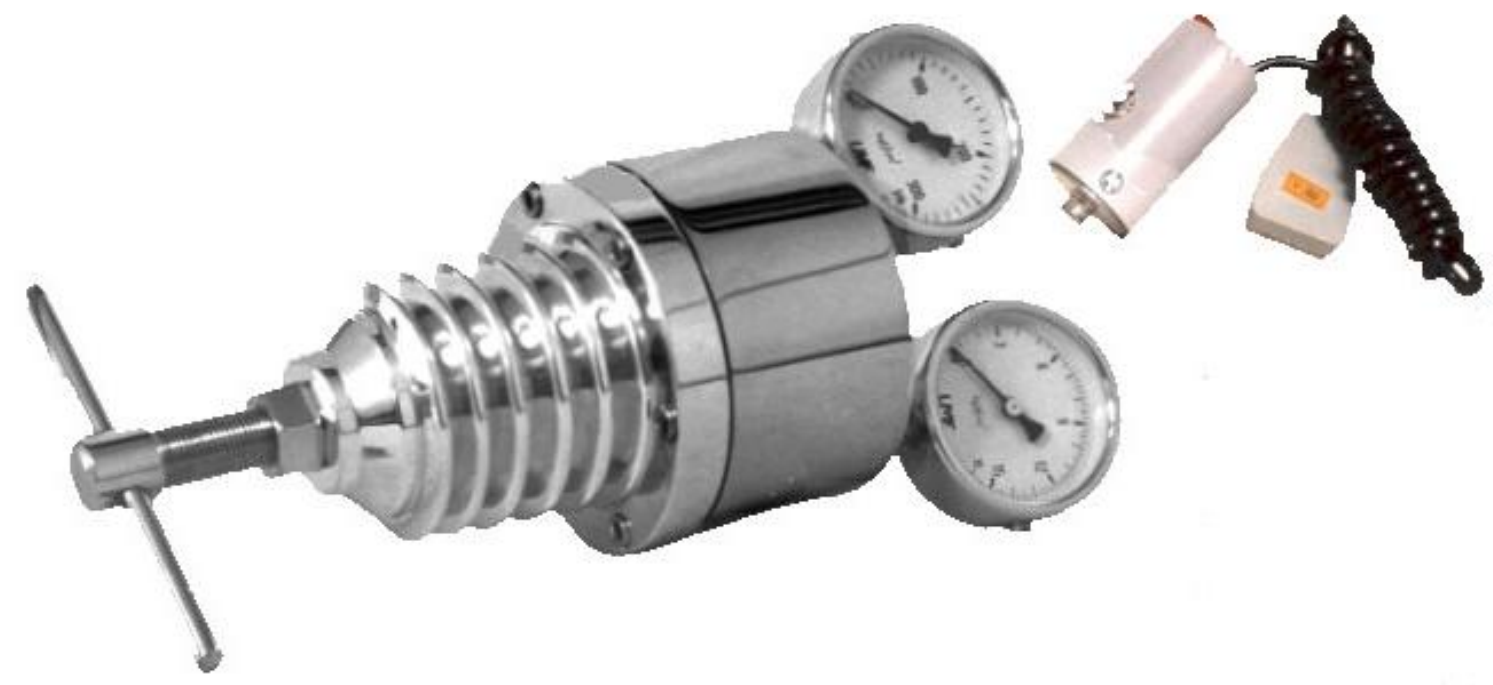

Figura 7.4 - Exemplo de válvula reguladora de pressão.

A válvula reguladora de pressão deverá ser colocada na tubulação de entrada. A partir das medidas da velocidade angular pelo tacômetro e um ganho específico, a válvula irá atuar sobre a pressão de entrada regulando a velocidade da máquina. 


\subsubsection{Amplificador de Tensão}

O circuito da excitatriz permite alterar a condição de operação do gerador. Com auxílio de retificadores, parte da energia elétrica gerada é convertida de corrente alternada para contínua, passando por um amplificador que atuará sobre a tensão de entrada de acordo com a referência. O circuito utilizado se encontra na Figura 7.5:

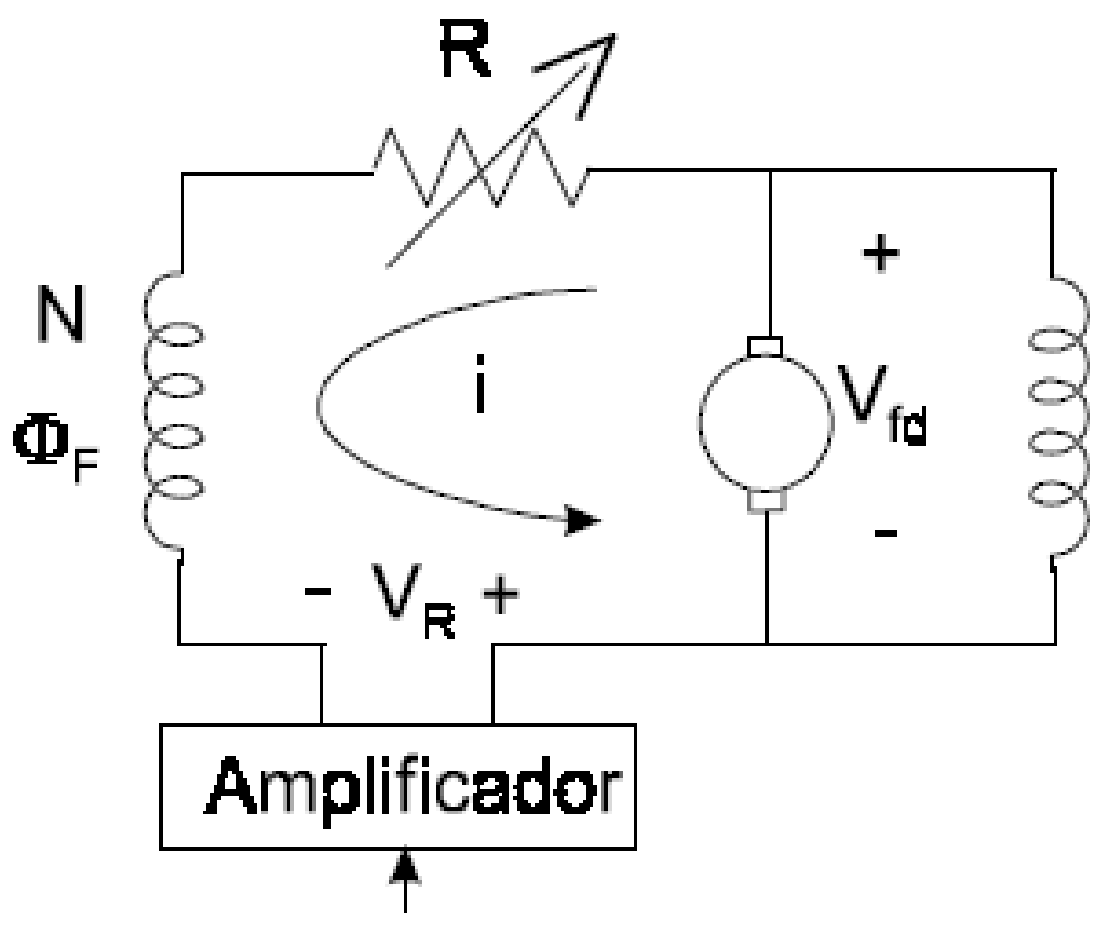

Figura 7.5 - Circuito excitatriz.

A partir das medidas da tensão do gerador pelo voltímetro e um ganho específico, o amplificador irá alterar a tensão de entrada da excitatriz, regulando a tensão de saída do gerador. 


\subsection{Cálculo dos Ganhos}

O modelo proposto é não-linear e não há um ponto de equilíbrio, impossibilitando sua linearização, o que motivou a utilização da metodologia apresentada a seguir.

Primeiramente, é necessário aumentar o momento de inércia para reduzir a amplitude das oscilações da velocidade angular. Propõe-se então o aumento da roda de inércia, pois o sistema de controle não atua sobre o perfil de pressão resultante no pistão, que causa as oscilações. Com o aumento de 10 vezes do momento de inércia, a redução da amplitude da oscilação já é satisfatória.

Define-se K1 como o ganho da pressão de entrada e K2 como o ganho de tensão. Realizando a simulação do sistema de controle para um ganho unitário (APÊNDICE B - ALGORITMO DAS SIMULAÇÕES EM MATLAB), isto é, K1 = 1,0 e $K 2=1,0$, foram obtidos as seguintes respostas:

$$
\begin{aligned}
& f_{\text {med }}=60,81(\mathrm{~Hz}) \\
& V_{\text {med }}=104,27(\mathrm{~V})
\end{aligned}
$$

Observa-se que a frequência está levemente acima do valor de referência, e a tensão abaixo. Mantendo K2 = 1,0 e variando K1 até 1,4 com passo de 0,1; obtémse os resultados da Tabela 7.2:

Tabela 7.2 Respostas variando o ganho de pressão.

\begin{tabular}{c|cccc}
\hline $\mathbf{K} \mathbf{1}$ & $\mathbf{f}_{\text {med }}(\mathbf{H z})$ & $\mathbf{V}_{\text {med }}(\mathbf{V})$ & $\mathbf{\Delta} \mathbf{f}(\mathbf{H z})$ & $\mathbf{\Delta} \mathbf{V}(\mathbf{V})$ \\
\hline $\mathbf{1 , 1}$ & 66,40 & 108,92 & 5,59 & 4,66 \\
\hline $\mathbf{1 , 2}$ & 70,71 & 112,46 & 9,90 & 8,20 \\
\hline $\mathbf{1 , 3}$ & 74,23 & 115,21 & 13,42 & 10,94 \\
\hline $\mathbf{1 , 4}$ & 78,21 & 118,08 & 17,40 & 13,81 \\
\hline
\end{tabular}

Logo, conclui-se que o aumento do ganho de pressão de entrada aumenta tanto a frequência quanto a tensão, conforme o esperado. Utilizando os dados da Tabela 7.2, obtém-se o gráfico da Figura 7.6. 


\section{Ganho da Pressão de Entrada}

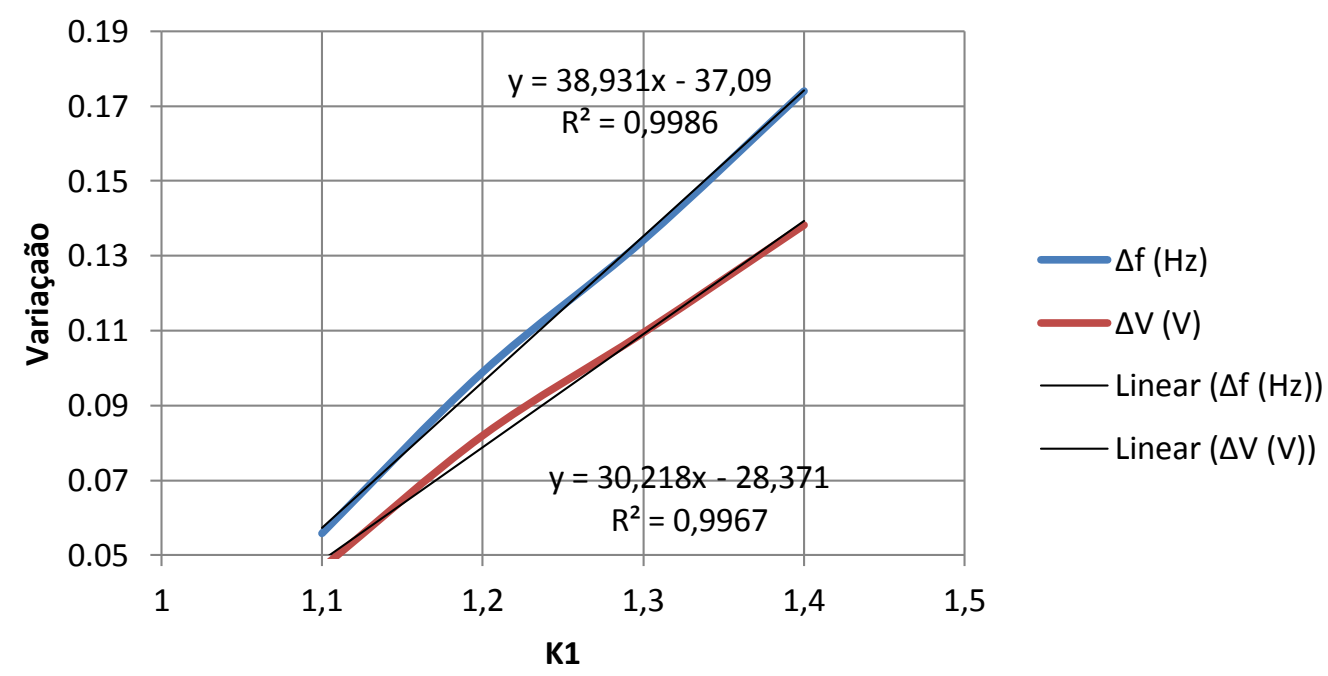

Figura 7.6 - Regressão linear da variação da resposta pelo ganho de pressão.

Fazendo a regressão linear da variação de frequência e tensão em função do ganho de pressão:

$$
\begin{aligned}
& 38,931 \cdot K 1-37,090=\Delta f \\
& 30,218 \cdot K 1-28,371=\Delta V
\end{aligned}
$$

Analogamente, mantendo $\mathrm{K} 1=1,0$ e variando $\mathrm{K} 2$ até 1,4 com passo de 0,1; obtém-se os resultados da Tabela 7.3:

Tabela 7.3 Respostas variando o ganho de tensão.

\begin{tabular}{c|cccc}
\hline $\mathbf{K} 2$ & $\mathbf{f}_{\text {med }}(\mathbf{H z})$ & $\mathbf{V}_{\text {med }}(\mathbf{V})$ & $\mathbf{\Delta f} \mathbf{( H z )}$ & $\boldsymbol{\Delta} \mathbf{V}(\mathbf{V})$ \\
\hline $\mathbf{1 , 1}$ & 58,24 & 106,72 & $-2,57$ & 2,45 \\
\hline $\mathbf{1 , 2}$ & 56,10 & 109,34 & $-4,71$ & 5,07 \\
\hline $\mathbf{1 , 3}$ & 53,91 & 111,34 & $-6,90$ & 7,07 \\
\hline $\mathbf{1 , 4}$ & 51,38 & 112,73 & $-9,43$ & 8,46 \\
\hline
\end{tabular}

Logo, conclui-se que o aumento do ganho da tensão de entrada reduz a frequência e aumenta a tensão. Utilizando os dados da Tabela 7.3, obtém-se o gráfico da Figura 7.7. 


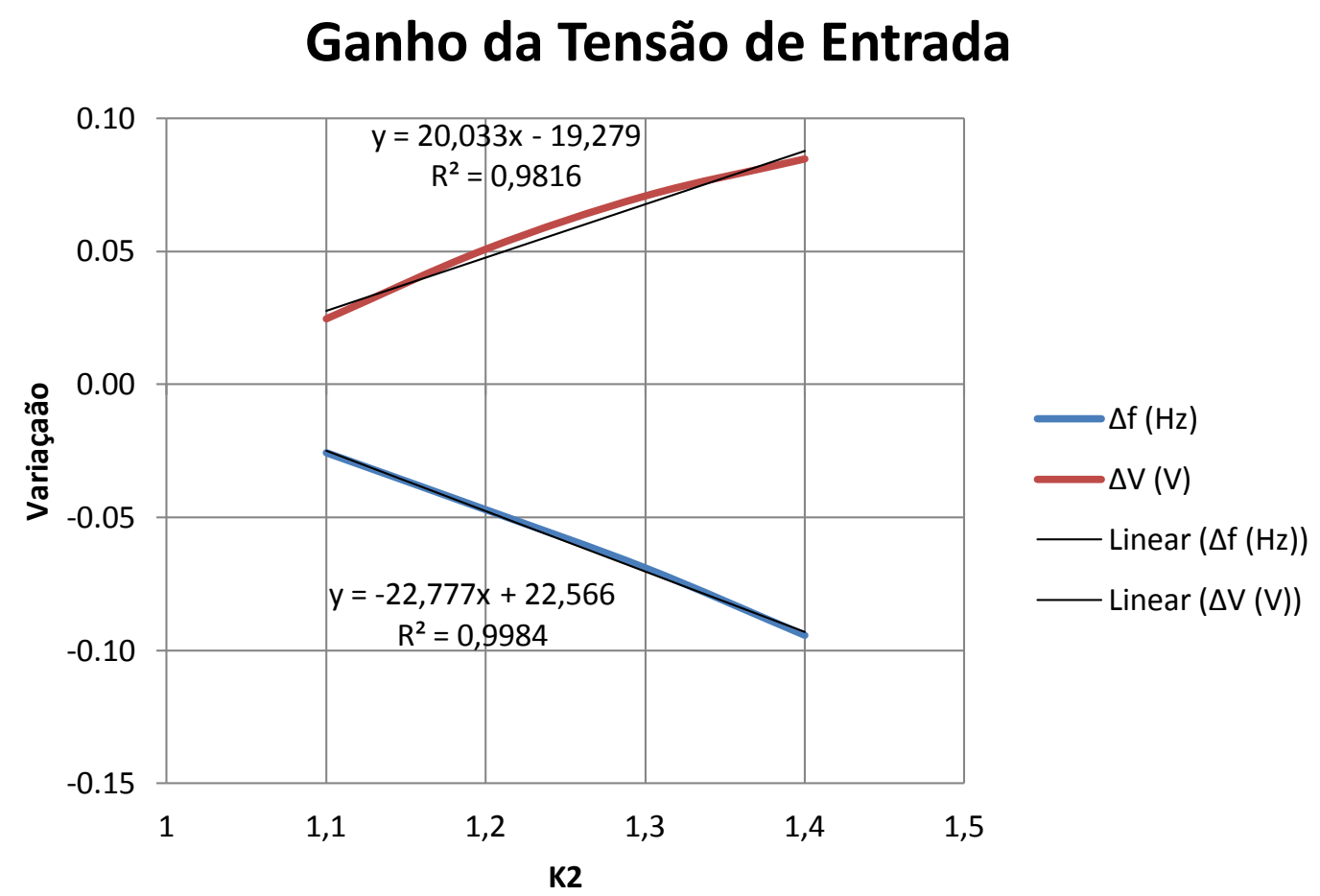

Figura 7.7 - Regressão linear da variação da resposta pelo ganho de tensão.

Fazendo a regressão linear da variação de frequência e tensão em função do ganho de tensão:

$$
\begin{aligned}
-22,777 \cdot K 2+22,566 & =\Delta f \\
20,033 \cdot K 2-19,279 & =\Delta V
\end{aligned}
$$

Considerando que a variação da resposta em função do ganho seja linear localmente, pode-se assumir que a sobreposição de efeitos também é linear, obtendo as seguintes equações:

$$
\begin{aligned}
& 38,931 \cdot K 1-22,777 \cdot K 2=\Delta f+14,524 \\
& 30,218 \cdot K 1+20,033 \cdot K 2=\Delta V+47,650
\end{aligned}
$$


Resolvendo o sistema linear:

$$
\begin{aligned}
& K 2=-\frac{\Delta f-1,290 . \Delta V-46,944}{48,6194} \\
& K 1=\frac{\Delta V-20,033 \cdot K 2+47,650}{30,218}
\end{aligned}
$$

Durante os 120 segundos iniciais, o sistema é simulado com ganhos unitários. O gerador e o controle da válvula reguladora de pressão são acionados aos 20 segundos, e o controle da excitatriz aos 80 segundos. Após os 120 segundos iniciais, os ganhos são iterados a cada 60 segundos, tempo necessário para o sistema entrar em regime permanente. O critério de convergência utilizado é um desvio máximo de até $0,1 \%$ sobre a frequência e tensão. Portanto, obtém-se a Tabela 7.4:

Tabela 7.4 Ganhos e respostas para cada iteração.

\begin{tabular}{c|cccc}
\hline Iterações & $\mathbf{K} \mathbf{K}$ & $\mathbf{K} \mathbf{}$ & $\mathbf{f}_{\text {med }}(\mathbf{H z})$ & $\mathbf{V}_{\text {med }}(\mathbf{V})$ \\
\hline $\mathbf{0}$ & 1,0000 & 1,0000 & 60,80 & 104,25 \\
$\mathbf{1}$ & 1,0149 & 1,1346 & 58,19 & 108,67 \\
$\mathbf{2}$ & 1,0601 & 1,1326 & 60,21 & 110,45 \\
$\mathbf{3}$ & 1,0503 & 1,1249 & 60,00 & 109,94 \\
$\mathbf{4}$ & 1,0503 & 1,1249 & 60,09 & 109,94 \\
$\mathbf{5}$ & 1,0500 & 1,1281 & 60,11 & 110,09 \\
$\mathbf{6}$ & 1,0472 & 1,1281 & 59,91 & 110,01 \\
$\mathbf{7}$ & 1,0482 & 1,1260 & 60,01 & 109,96 \\
$\mathbf{8}$ & 1,0482 & 1,1260 & 60,05 & 109,97 \\
$\mathbf{9}$ & 1,0482 & 1,1260 & 59,96 & 109,95 \\
\hline
\end{tabular}

Os valores da Tabela 7.4 que se encontram dentro do desvio de $0,1 \%$, foram destacados em cinza. Conclui-se que a partir da segunda iteração (após 4 minutos) os valores de frequência e de tensão estão próximos aos valores de referência. Os ganhos convergem a partir da sétima iteração (após 9 minutos), e seus valores se encontram a seguir:

$$
\begin{aligned}
& K 1=1,0482 \\
& K 2=1,1260
\end{aligned}
$$


A resposta da velocidade angular ao longo de todas as iterações é apresentada no gráfico da Figura 7.8:

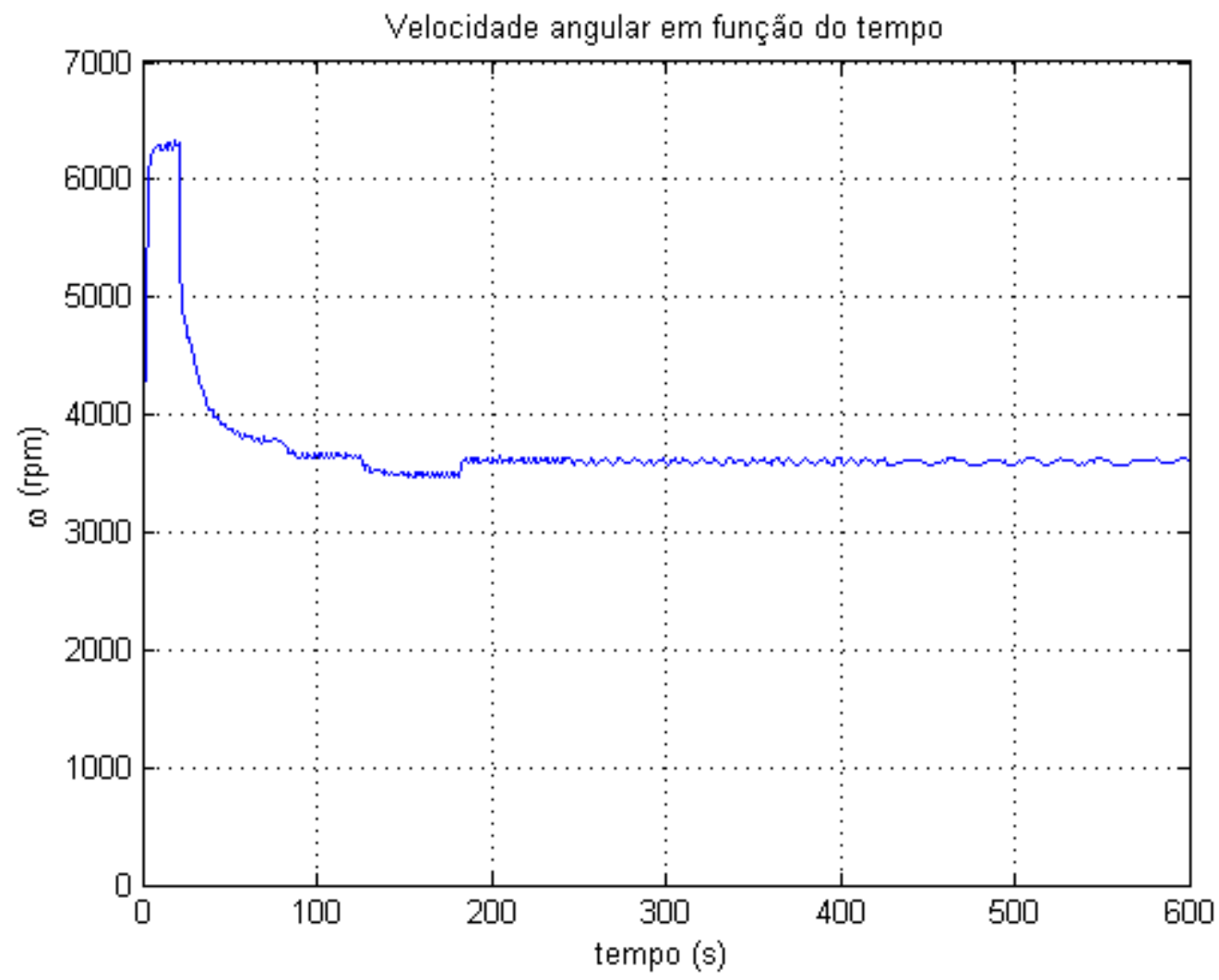

Figura 7.8 - Velocidade angular para cada iteração.

Observa-se que as maiores mudanças ocorrem durante os 120 segundos iniciais, pois neste período ocorrem os acionamentos do gerador e dos controladores. Entre o tempo de 120 segundos e 200 segundos, verifica-se que há uma grande variação dos ganhos e, consequentemente, acarretando em variações na velocidade angular. Após os 200 segundos, as variações são pequenas, ocorrendo a sintonia fina dos ganhos. 
A partir da resposta da velocidade angular, obtém-se a frequência elétrica, que é apresentada no gráfico da Figura 7.9:

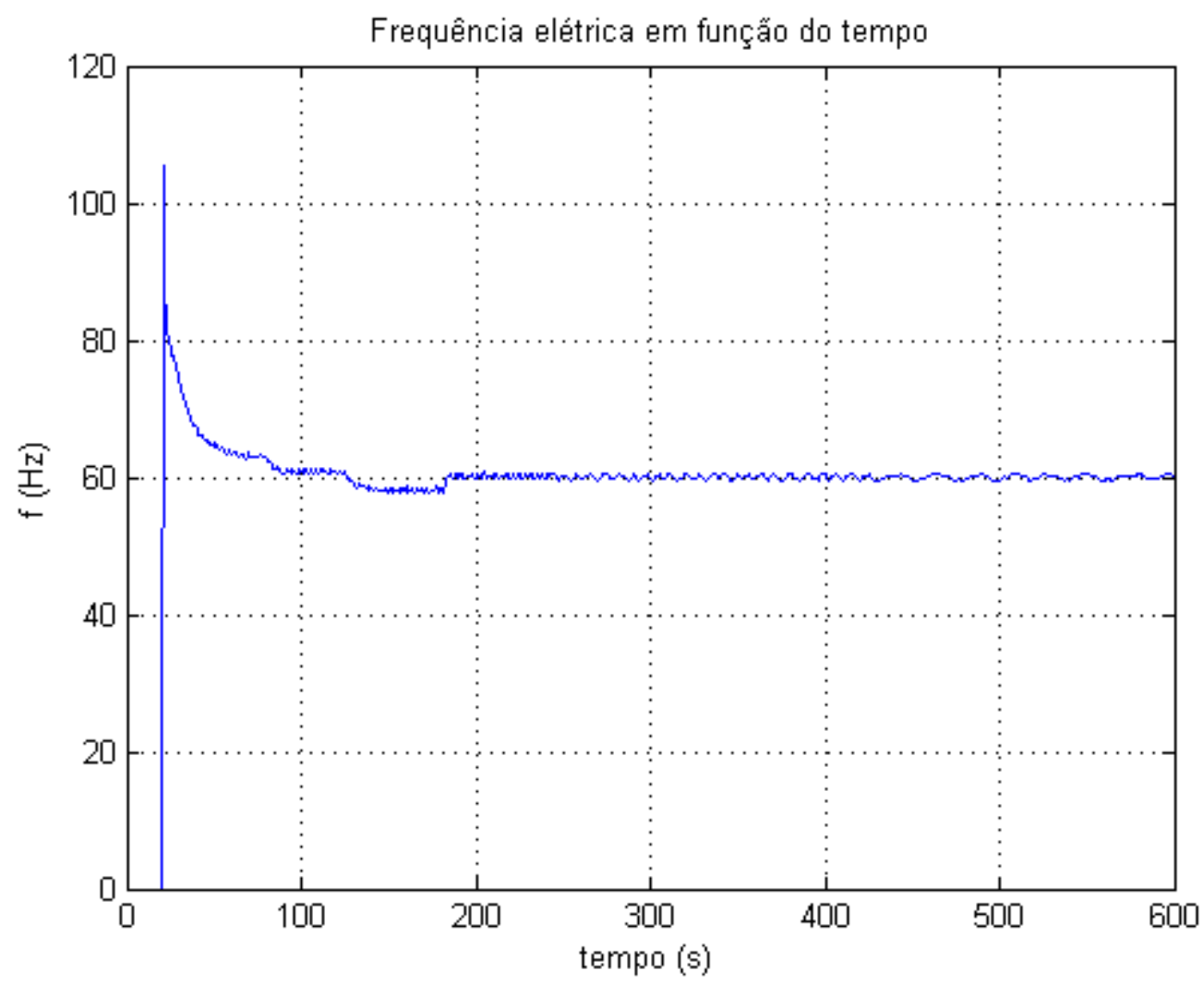

Figura 7.9 - Frequência elétrica para cada iteração.

Analogamente à velocidade angular, a frequência elétrica sofre as principais mudanças durante os 120 segundos iniciais. Após 400 segundos, a frequência se estabiliza em $60 \mathrm{~Hz}$. 
A resposta da tensão, tanto da excitatriz quanto do gerador, ao longo de todas as iterações é apresentada no gráfico da Figura 7.10:

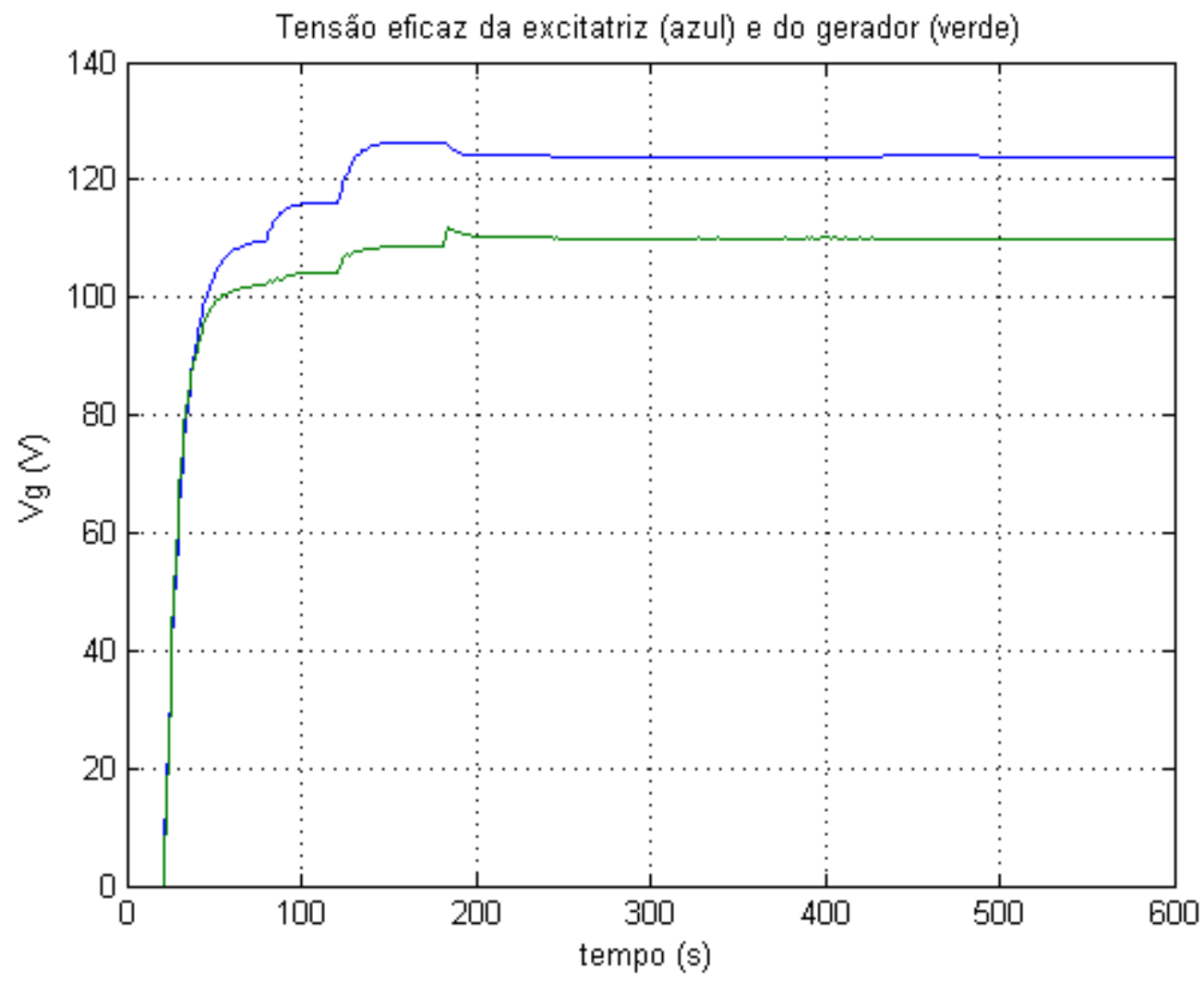

Figura 7.10 - Tensão eficaz para cada iteração.

A curva da tensão da excitatriz possui três degraus, sendo o primeiro causado pelo início do controlador elétrico. Já os dois últimos são relacionados às iterações dos ganhos.

A tensão do gerador apresenta pequenos acréscimos nas primeiras iterações e se estabiliza em 110 V após 200 segundos. 
A partir da tensão do gerador, obtém-se a corrente elétrica eficaz, que é apresentada no gráfico da Figura 7.11:

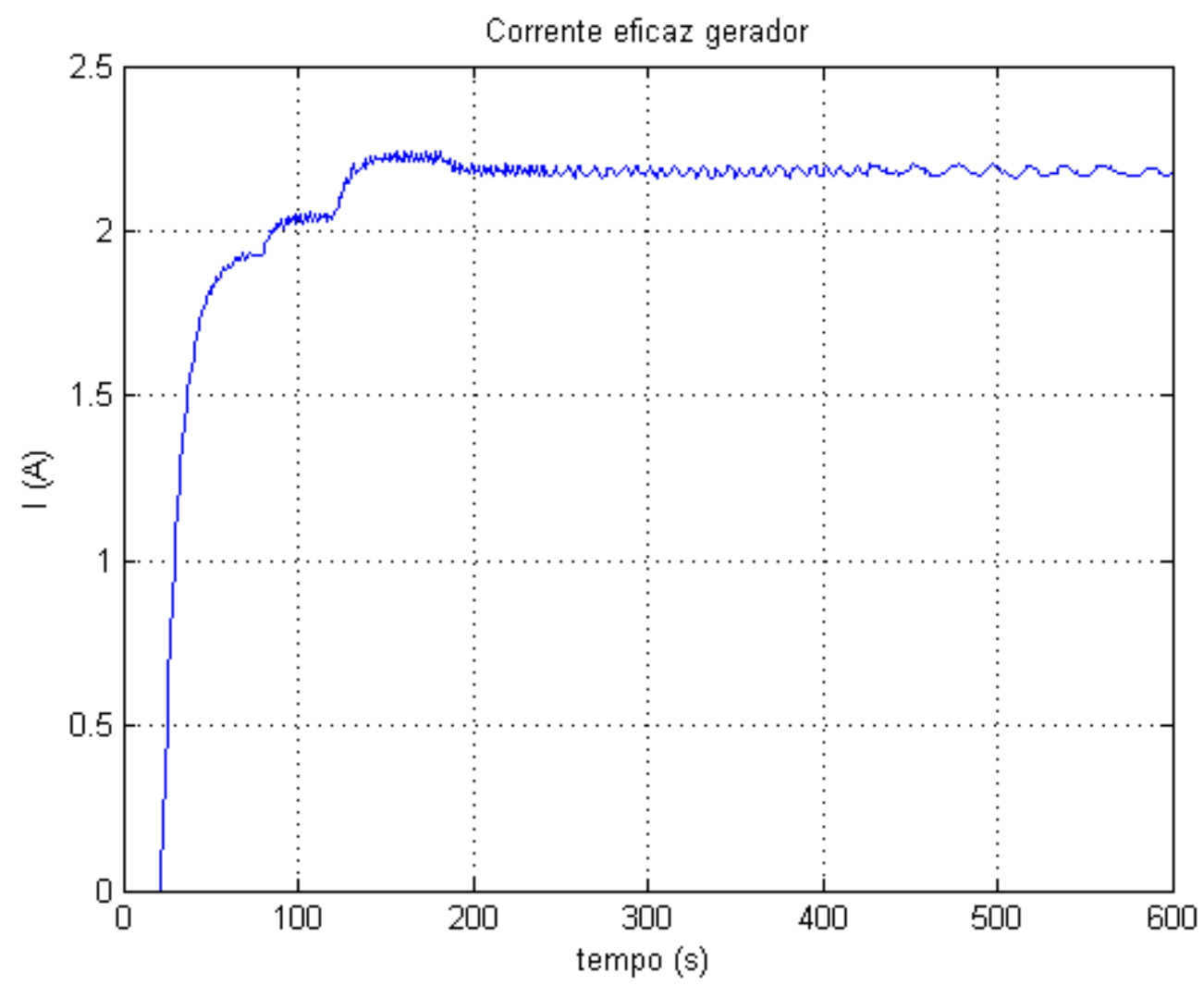

Figura 7.11 - Corrente eficaz para cada iteração.

Analogamente à tensão, a corrente eficaz possui três patamares, sendo o primeiro causado pelo início do controlador elétrico. Os dois últimos são relacionados às iterações dos ganhos. A corrente eficaz se estabiliza por volta de 2,2 A após 200 segundos. 


\subsection{Resultados}

Os ganhos calculados anteriormente convergiram para:

$$
\begin{aligned}
& K 1=1,0482 \\
& K 2=1,1260
\end{aligned}
$$

Simulando o sistema de controle em malha fechada com os valores dos ganhos apresentados, obtém-se a frequência elétrica mostrada na Figura 7.12 e a tensão elétrica na Figura 7.13.

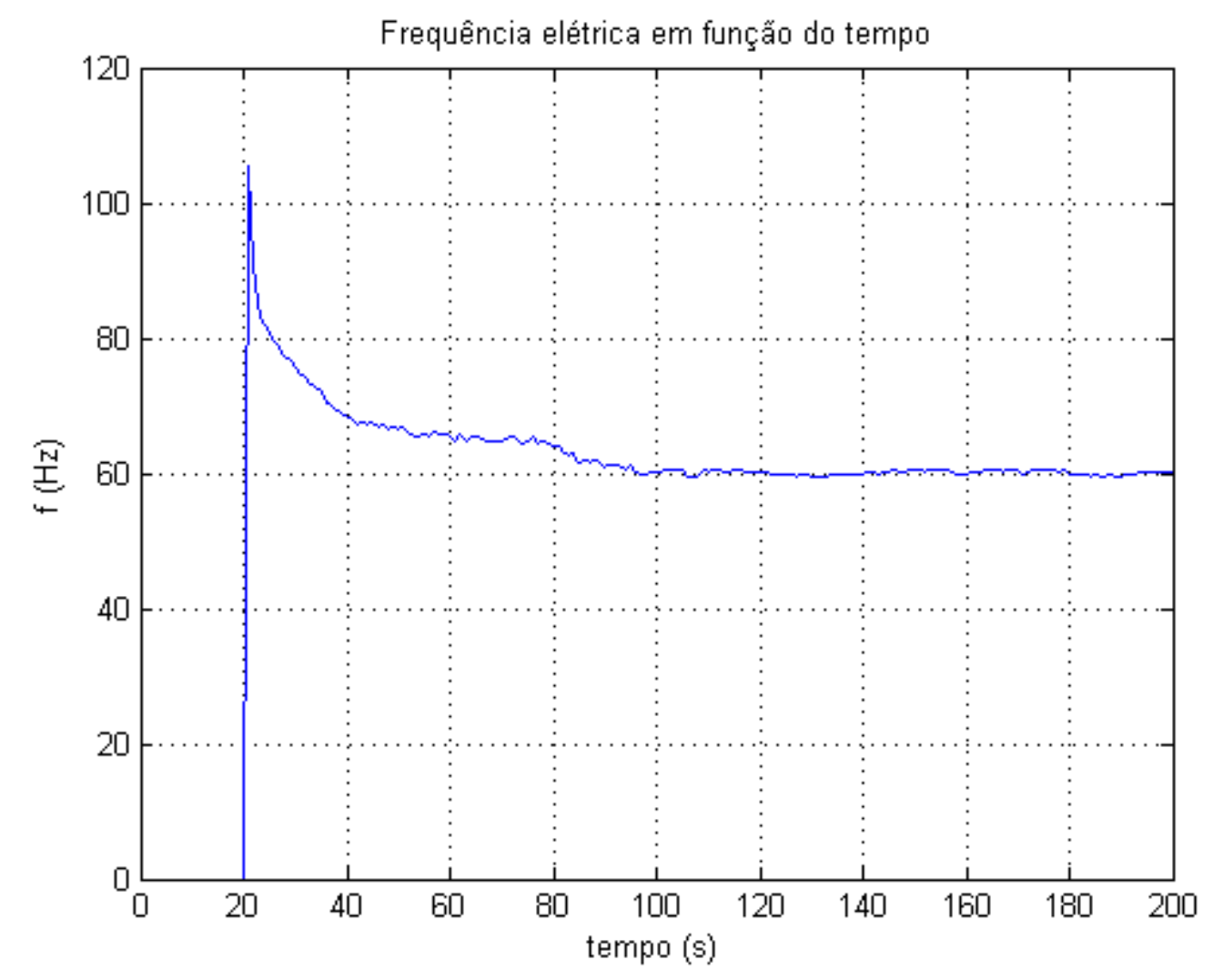

Figura 7.12 - Frequência elétrica controlada.

Observa-se que a frequência elétrica estabiliza-se em $60 \mathrm{~Hz}$ após aproximadamente 100 segundos. Portanto, pode-se garantir que em menos de 2 minutos a frequência elétrica já é adequada. 


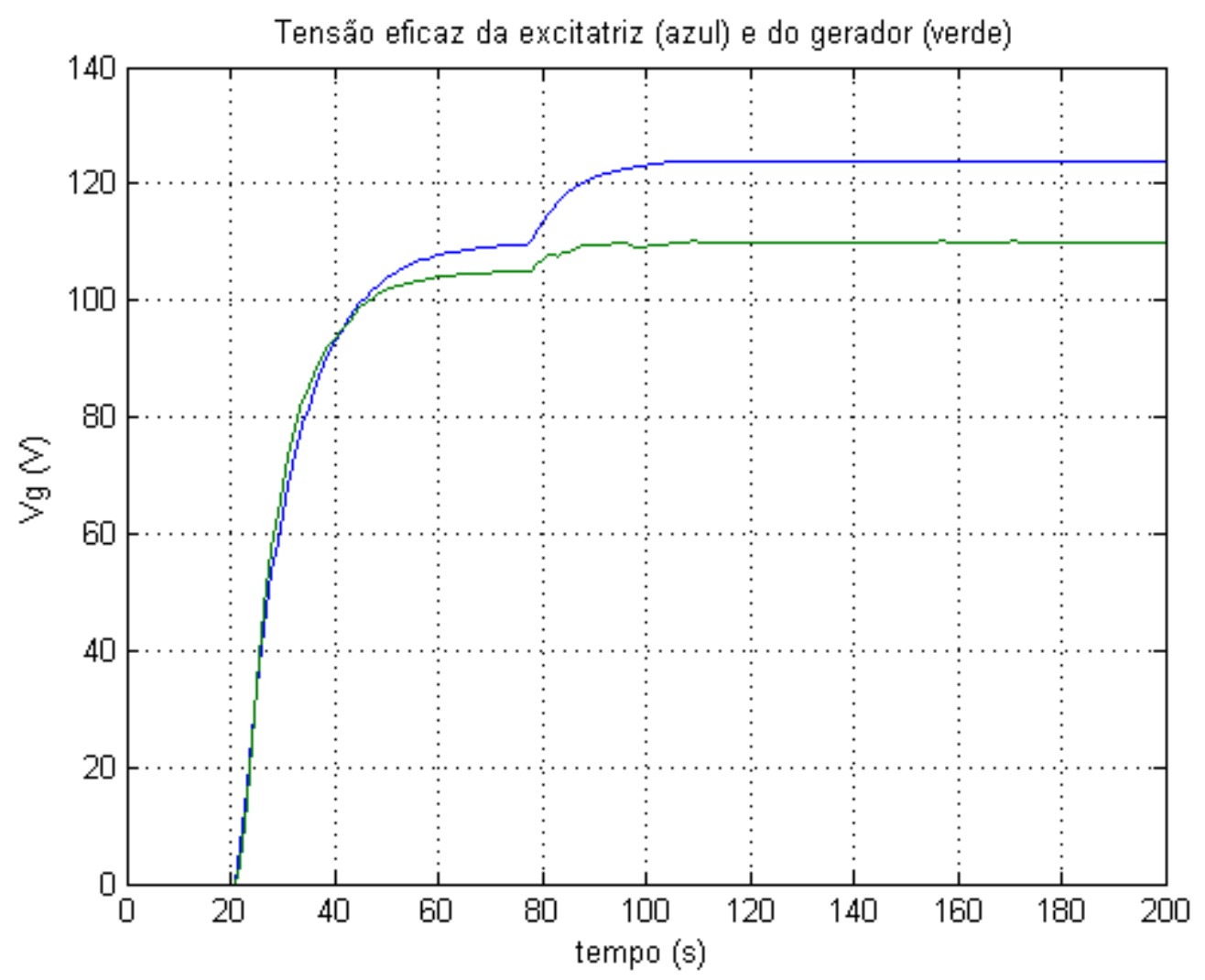

Figura 7.13 - Tensão elétrica controlada.

Observa-se que a tensão elétrica estabiliza-se em $110 \quad \mathrm{~V}$ após aproximadamente $110 \mathrm{~s}$. Portanto, pode-se garantir que em menos de 2 minutos a tensão elétrica já é satisfatória.

Os valores médios da frequência e tensão em regime são:

$$
\begin{aligned}
& f_{\text {med }}=60,04(\mathrm{~Hz}) \\
& V_{\text {med }}=109,97(\mathrm{~V})
\end{aligned}
$$

Logo, os valores de frequência e tensão obtidos com o sistema de controle encontram-se dentro do $0,1 \%$ de desvio proposto inicialmente, levando menos de 2 minutos para entrar em regime permanente e, desta forma, viabiliza-se a geração de aproximadamente $200 \mathrm{~W}$ de energia elétrica através da micromáquina a vapor. 


\section{CONCLUSÕES E TRABALHOS FUTUROS}

Foi apresentado o modelo matemático de uma micromáquina a vapor, composto por um modelo teórico do ciclo termodinâmico, um modelo do sistema mecânico e a correspondente equação diferencial do movimento e um modelo de gerador elétrico; também foi desenvolvido o projeto de um sistema de controle do equipamento.

A simulação do modelo permitiu calcular a velocidade de operação da máquina, o seu torque, a potência de eixo, o rendimento e demais características operacionais relevantes.

No modelo teórico, atribuiu-se as perdas mecânicas do sistema a um amortecedor viscoso linear equivalente, cujo coeficiente deve ser estimado empiricamente.

Uma breve análise de vibrações justificou a adoção de um sistema de apenas um grau de liberdade para representar a máquina completa.

Foi projetado um sistema de controle cuja implementação, suposta a validade do modelo teórico, atenderia a norma internacional IEC 60034-1:2004, viabilizando a geração de aproximadamente $200 \mathrm{~W}$ de energia elétrica.

Foi realizada uma análise de sensibilidade para identificar os efeitos da variação de parâmetros relevantes no projeto da máquina sobre a sua operação:

- A variação do momento polar da roda de inércia afetou a amplitude da oscilação da velocidade de operação da máquina;

- O coeficiente de atrito viscoso equivalente afetou significativamente a velocidade de operação da máquina;

- A pressão de admissão de ar comprimido afetou a pressão resultante na câmara e o próprio aspecto do diagrama PxV, e consequentemente, a rotação, o torque e a potência;

- A tensão de entrada da excitatriz afetou todas as características da máquina (velocidade angular, tensão da excitatriz, tensão do gerador, frequência elétrica e corrente). 
A validação experimental do modelo teórico requereu a reconstrução de uma micromáquina a vapor já existente, que teve seu projeto original modificado para tornar a máquina mais robusta e possibilitar a operação com pressões de admissão de ar mais elevadas. Diversos componentes da máquina antiga que não haviam sidos danificados foram aproveitados por se supor que suportariam as novas condições de operação. Concretamente, a biela do mecanismo da válvula, que aparentemente não aparentava fragilidade, deformou-se e chegou a romper, impossibilitando a realização de ensaios com pressões superiores a 2,53 bar.

Deve-se ressaltar que, as modificações feitas no projeto da máquina diminuíram significativamente as suas perdas mecânicas, além de melhorarem a sua vedação, de modo que a máquina gerou valores de torque e potência muito superiores aos previstos a partir dos valores de torque e potência do protótipo anterior. Ou seja, o desempenho da máquina ficou tão superior que as peças que foram reaproveitadas do protótipo antigo não suportaram os novos carregamentos.

Nessas condições a comparação entre os resultados teóricos e experimentais foi bastante prejudicada pela incompatibilidade entre os valores de pressão requeridos para a simulação do modelo teórico e os valores de pressão suportados pela máquina.

Apesar da grande disparidade de valores entre as grandezas medidas e calculadas, as tendências observadas nos gráficos que descrevem tais grandezas são muito semelhantes. Embora não tenha sido possível confirmar a estimativa do valor do coeficiente de atrito viscoso equivalente, a operação da máquina e a potência atingida permitem concluir que as perdas mecânicas são extremamente baixas, e que o valor adotado para o coeficiente de atrito, de 0,002 N.m.s/rad é bastante conservador, ou seja, superior ao real.

Quanto ao projeto do experimento, os procedimentos adotados para a calibração dos sensores e a metodologia de medição de resultados garantem a validade dos mesmos, a menos das imprecisões decorrentes do uso do freio de Prony. 
Finalmente, propõe-se as seguintes sugestões para dar continuidade ao trabalho:

- Substituir a adoção de um diagrama PxV teórico do ciclo da máquina pela simulação de seus processos através de um programa que possibilite 0 cálculo das propriedades do fluido de trabalho;

- Introduzir um modelo de válvula que permita simular a variação da vazão do fluido durante a sua abertura e fechamento;

- Reprojetar e construir um novo eixo de manivelas;

- Substituir o freio de Prony por um gerador para efetuar as medidas de torque. 


\section{REFERÊNCIAS BIBLIOGRÁFICAS}

ALANNE, K.; SAARI, K.; KUOSA, M.; JOKISALO, J.; MARTIN, A. R. Thermoeconomic analysis of a microcogeneration system based on a rotary steam engine (RSE). Applied Thermal Engineering, V. 44, p. 11-20, 2012.

ANTONELLI, M.; MARTORANO, L. A study on the Rotary steam engine for distributed generation in small size power plants. Applied Energy, V.27, p. 642647, 2012.

ASSOCIAÇÃO BRASILEIRA DE NORMAS TÉCNICAS. NBR ISO 5167-1 (1994): Medição de vazão de fluidos por meio de instrumentos de pressão - Parte 1: Placas de orifício, bocais e tubos de Venturi em seção transversal circular de condutos forçados. Rio de Janeiro, 1994.

BADR, O.; NAIK, S.; O'CALLAGHAN, P. W.; PROBERT, S. D. Expansion machine for a low power-output steam Rankine-cycle. Applied energy, v. 39, p. 93-116, 1991.

BAEK, J. S.; GROLL, E. A.; LAWLESS, P.B. Piston-cylinder work producing expansion device in a transcritical carbon dioxide cycle. Part II: theoretical model. International Journal of Refrigeration, v. 28, p. 152-164, 2005.

BASBOUS, T.; YOUNES, R. ILINCA, A.; PERRON, J. F. A new hybrid pneumatic combustion engine to improve fuel consumptions of wind-diesel power system for noninterconnected areas. Applied Energy, V. 96, p. 459-476, 2012. 
BASSI, L. A. F.; MACHADO, R. A., Projeto e construção de um protótipo de máquina a vapor. Trabalho apresentado no $19^{\circ}$ SIICUSP - Simpósio Internacional de Iniciação Científica, São Carlos, 2011.

BIM, E. Máquinas Elétricas e Acionamento. Campinas: Unicamp. Disponível em:

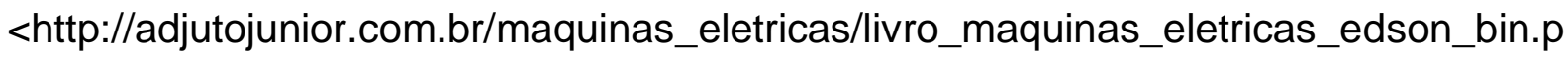
df>. Acesso em: 4 out. 2014.

BOURNE, J. Handbook of the Steam-Engine. BiblioLife, 2009.

CLAUSIUS, R. Mechanical Theory of Heat, Applications to the steam-engine. London, 1822.

COSTA, A. J. A. S.; SILVA, A. S. Controle e Estabilidade de Sistemas Elétricos de Potência. Universidade Federal de Santa Catarina, Florianópolis, 2000.

FALCONE, A. G. Eletromecânica. 1. ed. Edgard Blucher, 1985.

FAREY, J. Treatise on the Steam Engine. London, Longman, 1827.

FARIA, V. P. Modelagem e Controle de Microturbina a Gás do Tipo Split-Shaft. São Paulo, 2009. 
FITZGERALD, A. E.; KINGSLEY, C.; UMANS S. D. Máquinas Elétricas. 6. ed. Artmed, 2006.

FRANÇA, L. N.; MATSUMURA, A. Z. Mecânica Geral. 2. ed. São Paulo, Edgar Blücher, 2004.

GARCIA, C. Modelagem e Simulação de Processos Industriais e de Sistemas Eletromecânicos. 2. ed. São Paulo, EDUSP, 2009.

INTERNATIONAL STANDARD. IEC 60034-1:2004: Rotating electrical machines part 1: rating and performance. Eleventh edition, 2004-04, $69 \mathrm{p}$.

KEENAN, J. H. Thermodynamics. Edicion Revolucionaria, La Habana, Cuba, 1966.

KEILHOLTZ, P. O. ANGULAR VARIATION IN STEAM ENGINE. $157^{\text {th }}$ Meeting of the American Institute of Electrical Engineers, New York, 1901.

MARIÑO, R. Termodinâmica Tecnica. Segunda Edição. Dossat. Madrid. 1948.

MEIROVITCH, L. Fundamentals of Vibration. International Edition, McGraw-Hill, 2001.

MESNY, M. Máquinas de Vapor: descripcion, teoria, ensavo y mantenimiento. Buenos Aires, Albatros, 1949. 
OGATA, K. Engenharia de Controle Moderno. 4. ed. Prentice-Hall, 2004.

PRASAD, S. B. Steam Engine Characteristics and Theoretical Performance. Energy Convers. Mgmt Vol. 34, No. 12, pp. 1323-1333, 1993.

SIMÕES, A. J. A. C.; SILVA, A. S. Controle e Estabilidade de Sistemas

Elétricos de Potência. Universidade Federal Santa Catarina, Florianópolis, Santa Catarina, 2000.

SOUZA, A. S. Análise do Desempenho do Gerador de Alta Tensão Powerformer - Em Comparação a uma Máquina Convencional. Tese de Mestrado - Universidade Federal do Rio de Janeiro, Rio de Janeiro, 2005.

SPIEGEL, M. Análise de Fourier. McGraw-Hill, São Paulo, 1976.

TRAJKOVIC, S. The Pneumatic Hybrid Vehicle: A New Concept for Fuel Consumption Reduction. Tese de Doutorado - Faculty of Engineering, Lund University, Lund, Sweden, 2010.

UNZUETA, R. B. A Proposed Theoretical Standard Cycle for a Reciprocating Steam Engine. Brazilian Congress of Thermal Sciences and Engineering Proceedings, Rio de Janeiro, 2012.

WEALE, J. The Theory of the Steam Engine. London, 1889. 
WEG. Características e Especificações de Geradores. Disponível em: $<$ http://catalogo.weg.com.br/files/wegnet/WEG-curso-dt-5-caracteristicas-eespecificacoes-de-geradores-artigo-tecnico-portugues-br.pdf>. Acesso em: 4 out. 2014.

WYLEN, G. J. V.; SONNTAG, R. E.; BORGNAKKE, C. Fundamentos da Termodinâmica. Tradução da 6. ed. americana, São Paulo, Edgar Blücher, 2003.

ZAK, S. H. Systems and Control. New York ,Oxford University Press, 2003. 


\section{Artigos publicados pelo autor:}

MADIO, R.; ZACHARIADIS, D. C. ; SIMÕES-MOREIRA, J. R. Análise de Sensibilidade de uma Micromáquina a Vapor para Geração de Eletricidade. In: CONEM 2016 - Congresso Nacional de Engenharia Mecânica, 2016, Fortaleza. Anais do IX Congresso Nacional de Engenharia Mecânica, 2016.

MADIO, R.; ZACHARIADIS, D. C. ; SIMÕES-MOREIRA, J. R. Modelagem de uma Micromáquina a Vapor para Geração de Eletricidade. In: 10o AGRENER Congresso sobre Geração Distribuída e Energia no Meio Rural, 2015, São Paulo. Anais do 10o AGRENER - Congresso sobre Geração Distribuída e Energia no Meio Rural, 2015. 


\section{APÊNDICE A - PROJETO DA MÁQUINA}

Os detalhes das modificações, as funções, os materiais, os desenhos e as fotos dos componentes alterados são apresentados a seguir:

\section{Pistão bipartido com anel de Teflon:}

Para facilitar a montagem e substituição do anel de Teflon, foi proposto que o pistão seja bipartido.

Embora haja restrição à temperatura de operação, o anel de Teflon possui diversas qualidades como:

- Baixíssimo coeficiente de atrito;

- Boa vedação;

- Evita o desgaste do pistão e da câmara;

- Fácil manutenção, bastando apenas trocar o anel em caso de desgaste.

Visando manter o diâmetro e a espessura do pistão antigo, o desenho técnico do pistão bipartido e do anel de Teflon é mostrado na Figura A.1:

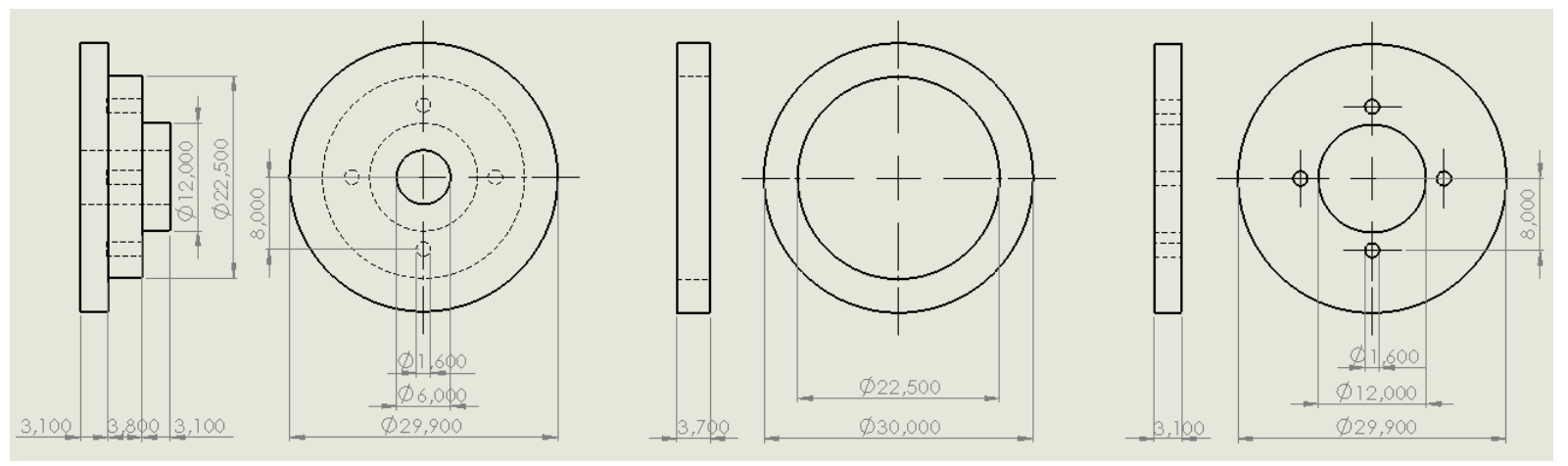

Figura A.1 - Projeto do pistão bipartido com anel de Teflon. 
A partir do projeto, o pistão bipartido foi usinado em latão, e o anel, em Teflon, conforme mostrado na foto da Figura A.2:

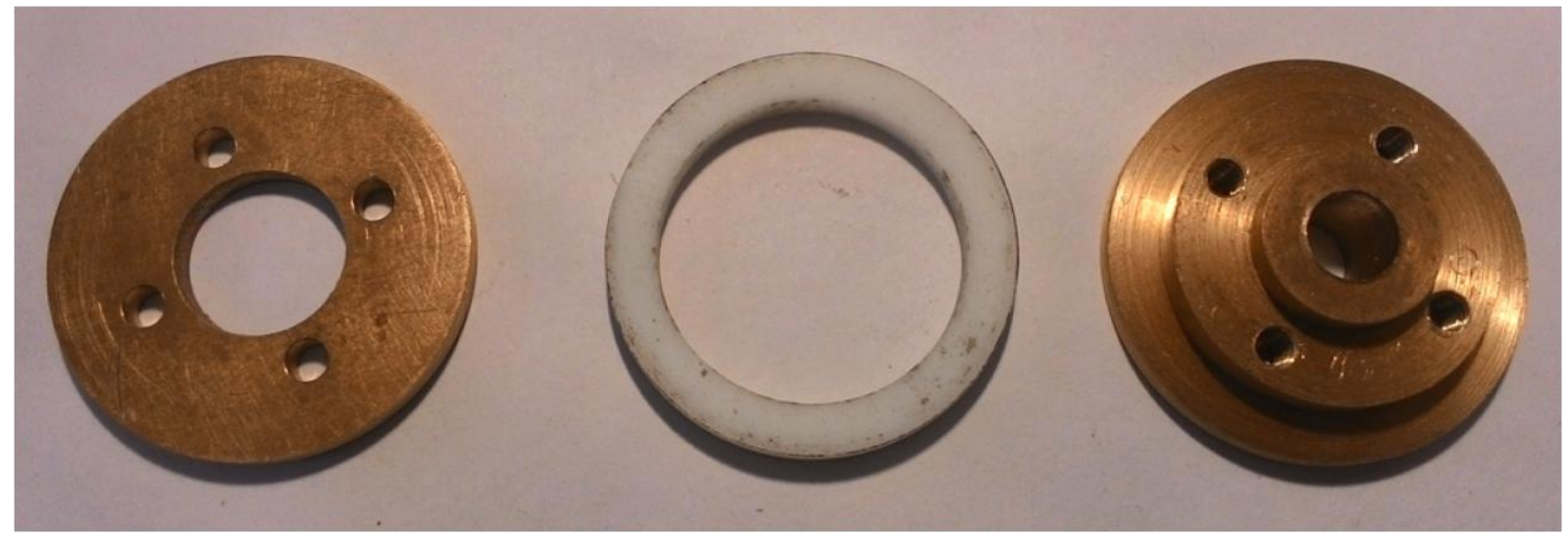

Figura A.2 - Pistão bipartido com anel de Teflon.

O pistão montado com a haste é exibido na Figura A.3:

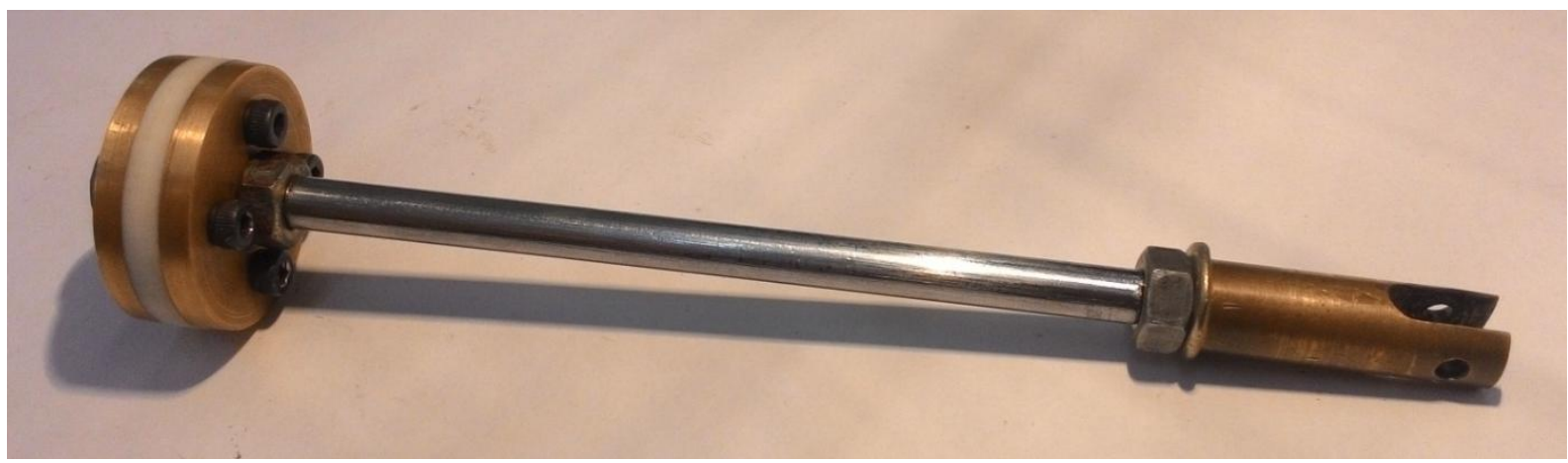

Figura A.3 - Pistão montado.

Tampa do pistão com O-ring e anel de Teflon:

Devido ao aumento do diâmetro da haste do pistão, foi necessário alterar o furo da tampa e de seu anexo.

Para a vedação (estática) entre a tampa e a câmara foi utilizado um O-ring. Já para a vedação (dinâmica) entre a tampa e a haste foi utilizado um anel de Teflon, pois também apresenta baixo coeficiente de atrito.

O anel de Teflon é inserido na tampa e selado pelo anexo da tampa, como mostrado na Figura A.5. 
Com o objetivo de preservar as principais características da tampa e ser compatível com a nova haste, o desenho técnico da tampa do pistão e do anel de Teflon é apresentado na Figura A.4:

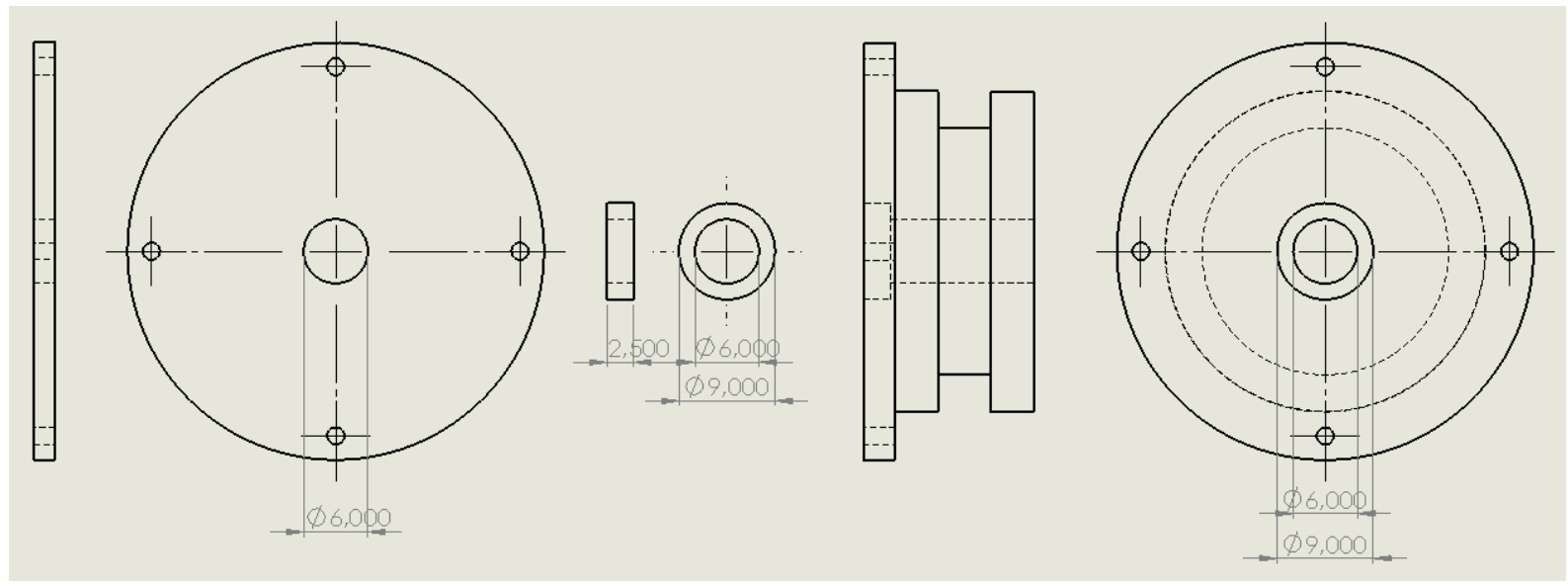

Figura A.4 - Projeto da tampa do pistão com O-ring e anel de Teflon.

Baseando-se no projeto, a tampa foi usinada em latão, e o anel, em Teflon; ambos são mostrados na foto da Figura A.5:

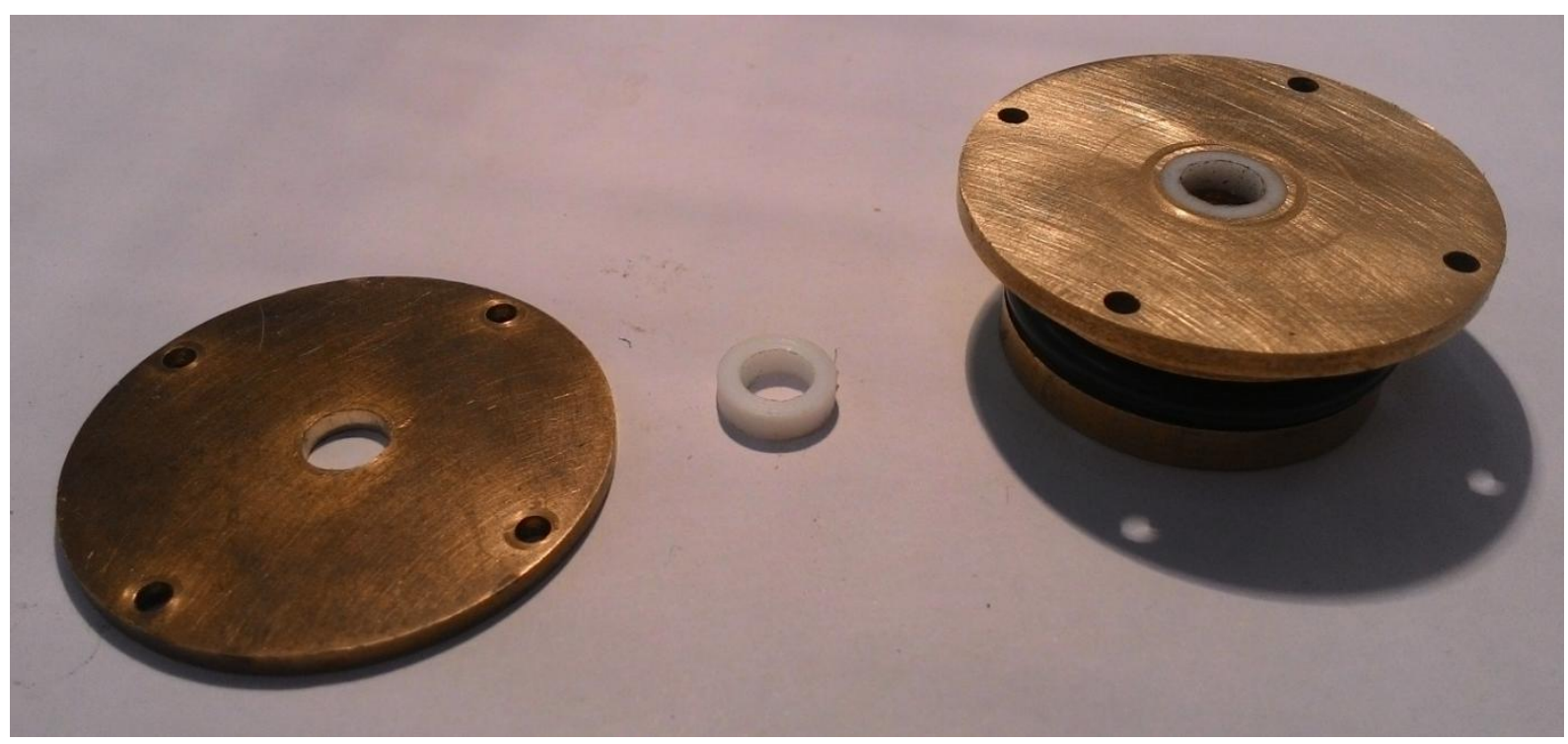

Figura A.5 - Tampa do pistão com O-ring e anel de Teflon. 


\section{Haste do pistão feita com eixo retificado de aço:}

Para suportar esforços mais elevados, foi proposto aumentar o diâmetro da haste e trocar o material, de latão para aço.

Visando possibilitar a instalação do mancal linear, foi necessário aumentar o comprimento da haste.

A haste foi feita a partir do eixo retificado de aço, com o propósito de melhorar o deslizamento da haste no rolamento linear e na tampa, isto é, reduzir o atrito.

Aumentou-se tanto o diâmetro quanto o comprimento, mantendo as demais características. O desenho técnico da haste do pistão é mostrado na Figura A.6:

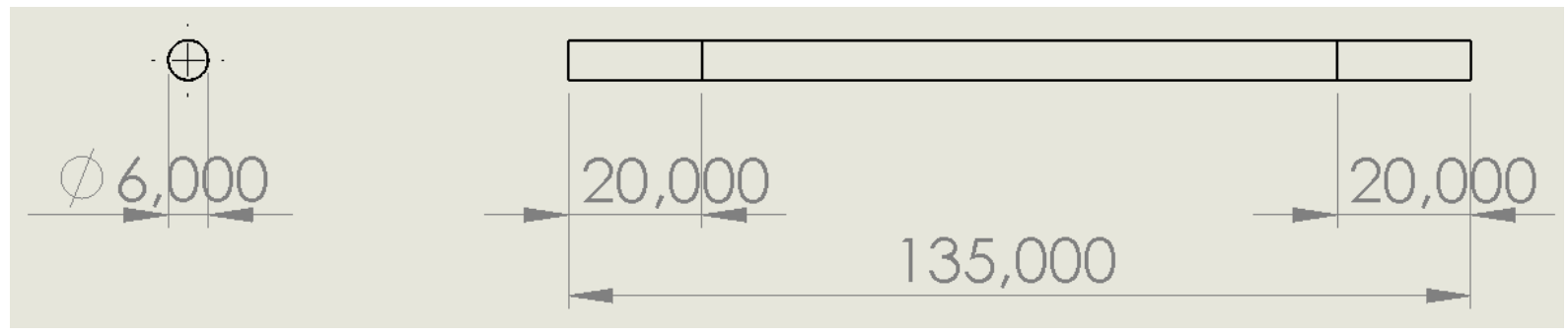

Figura A.6 - Projeto da haste do pistão.

A partir do projeto, a haste foi usinada com eixo retificado de aço, conforme mostrado na foto da Figura A.7:

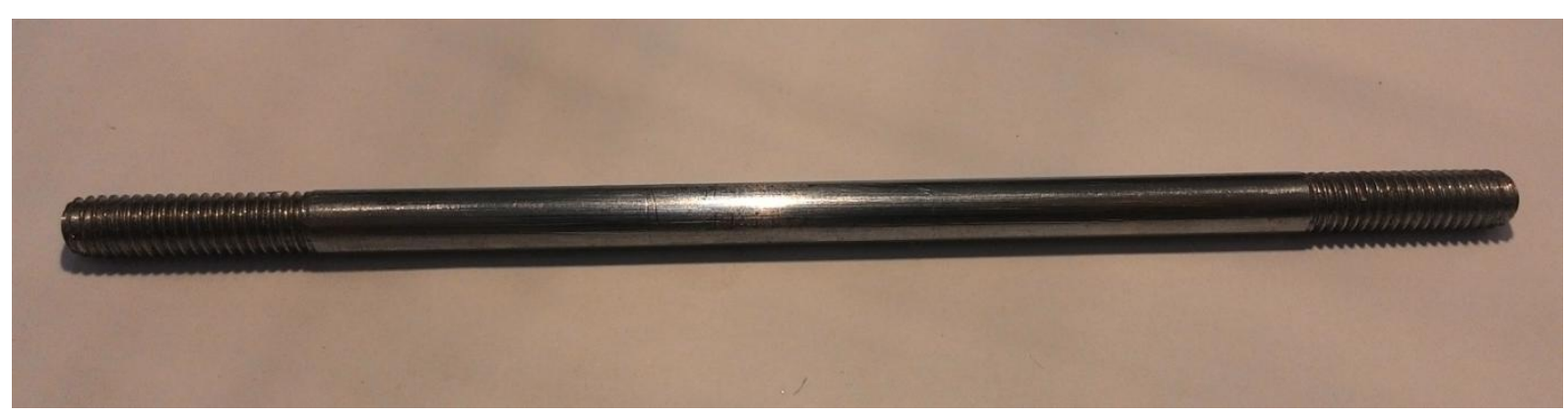

Figura A.7 - Haste do pistão feito com eixo retificado de aço. 


\section{Mancal com rolamento linear:}

O mancal linear tem como objetivos:

- Suportar esforços;

- Garantir o movimento linear do pistão;

- Possuir baixo atrito;

- Reduzir os esforços sobre a tampa do pistão e, consequentemente, seu desgaste.

O rolamento linear (modelo LM06UU), cujo mancal deve ser projetado para alojá-lo, é apresentado na Figura A.8 juntamente com suas principais dimensões:

$$
\begin{gathered}
d_{\text {int }}=6 \mathrm{~mm} \\
d_{\text {ext }}=12 \mathrm{~mm} \\
L=19 \mathrm{~mm}
\end{gathered}
$$

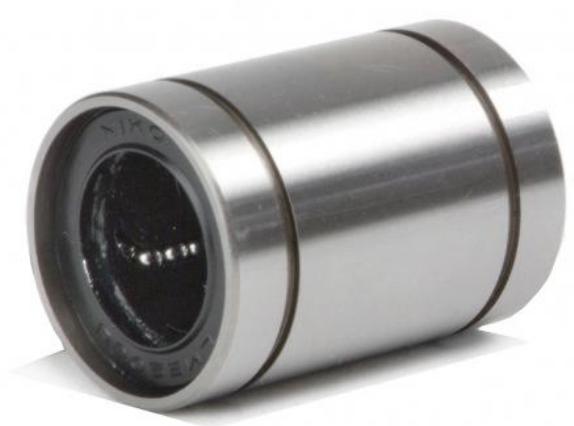

Figura A.8 - Rolamento linear LM06UU. 
O projeto do mancal linear foi inspirado nos demais mancais já presentes na máquina e é mostrado na Figura A.9:

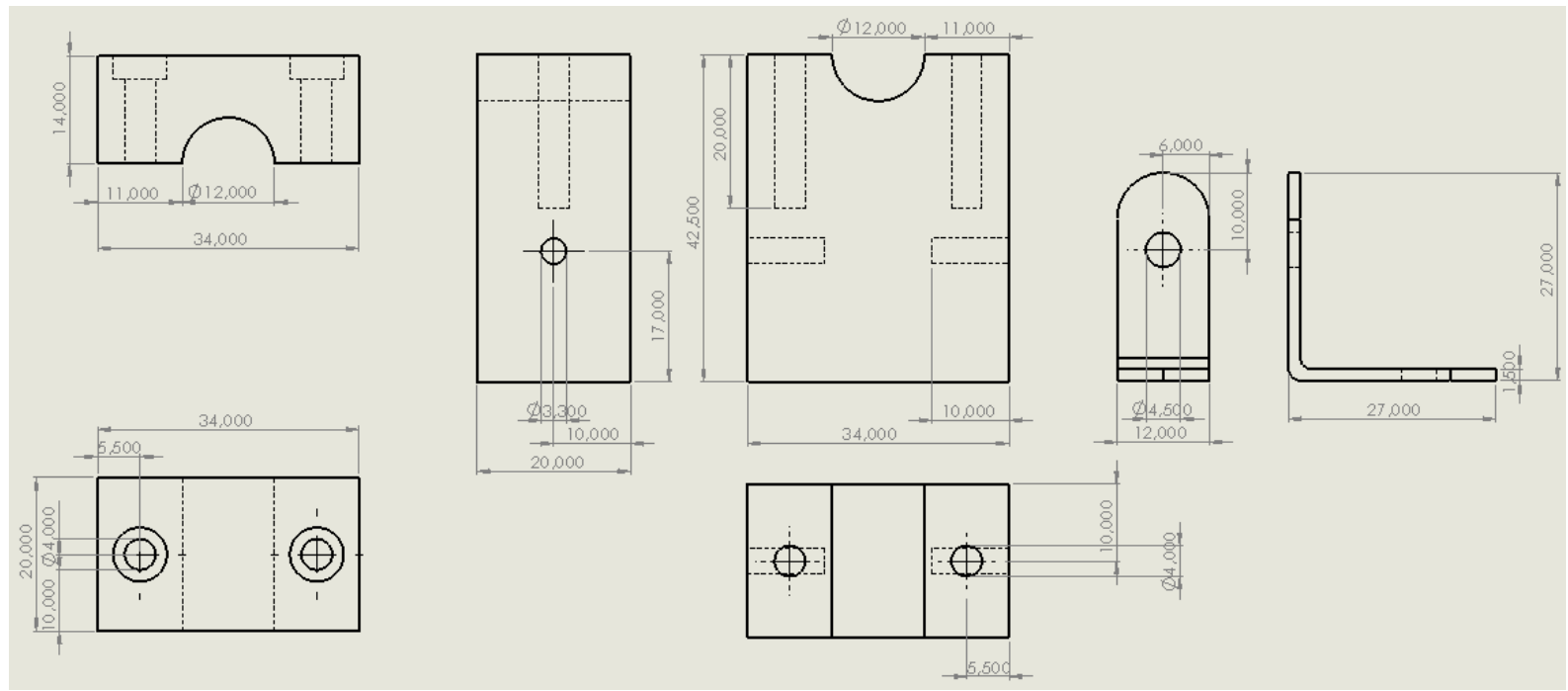

Figura A.9 - Projeto do mancal linear.

O mancal montado com o rolamento linear é visto na Figura A.10:

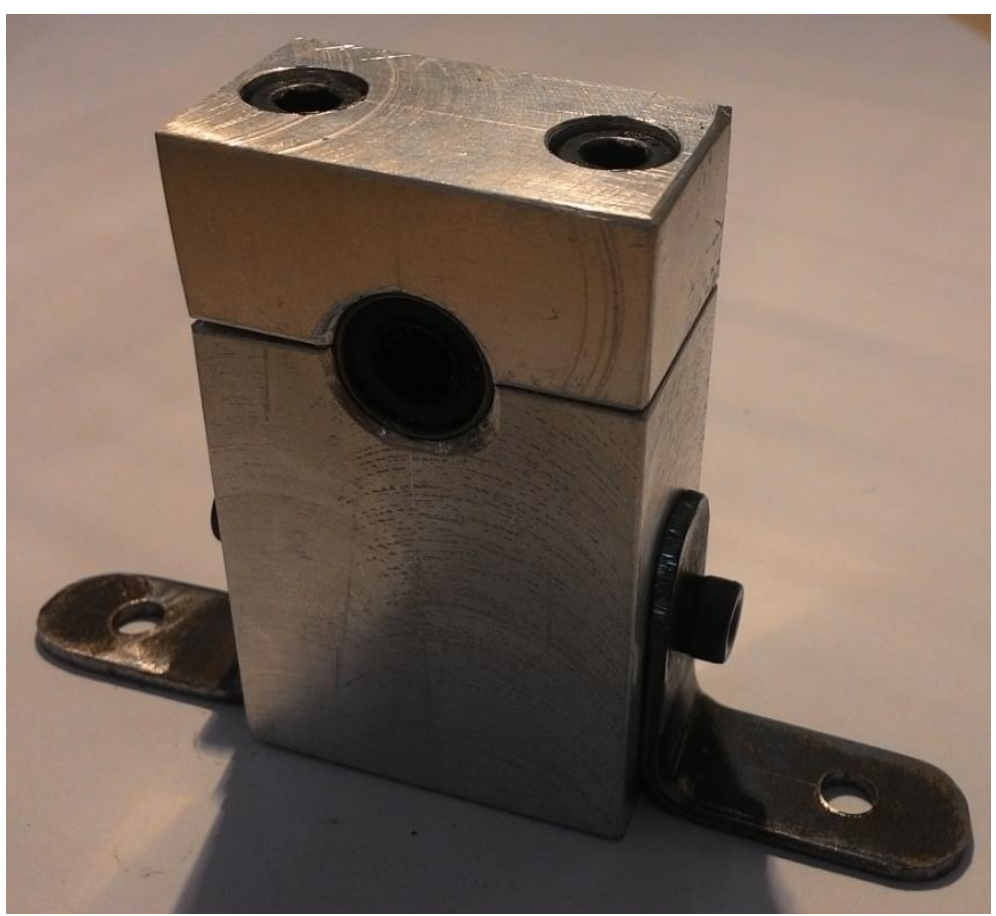

Figura A.10 - Mancal com rolamento linear. 


\section{Tampa da válvula com O-ring e anel de Teflon:}

O projeto e execução da tampa da válvula é análogo ao da tampa do pistão.

Portanto, com o objetivo de preservar as principais características da tampa e ser compatível com a nova haste, o desenho técnico da tampa da válvula e do anel de Teflon é apresentado na Figura A.11:

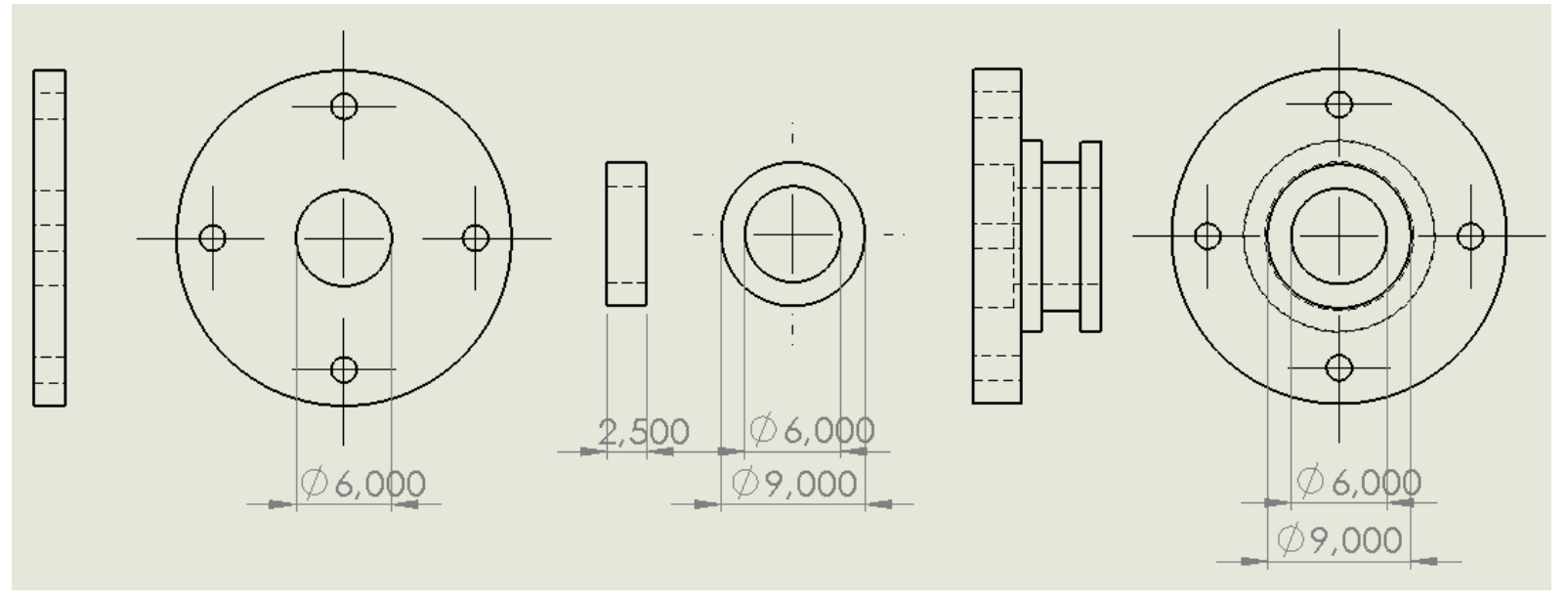

Figura A.11 - Projeto da tampa da válvula com 0-ring e anel de Teflon.

Baseando-se no projeto, a tampa foi usinada em latão, e o anel, em Teflon; ambos são mostrados na foto da Figura A.12:

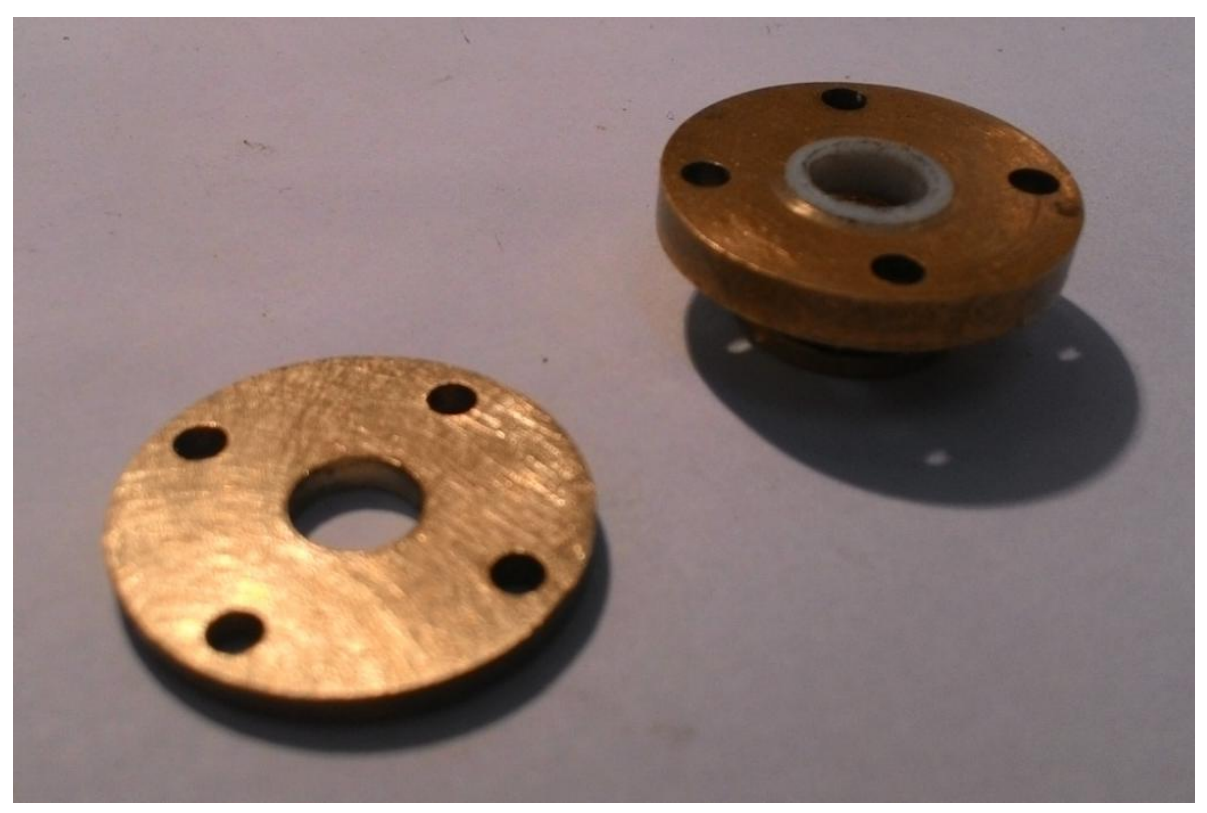

Figura A.12 - Tampa da válvula com 0-ring e anel de Teflon. 


\section{Haste da válvula feita com eixo retificado de aço:}

Para suportar esforços mais elevados, foi proposto aumentar o diâmetro da haste e trocar o material, de latão para aço.

A haste foi feita a partir do eixo retificado de aço, com o propósito de melhorar o deslizamento da haste na tampa, isto é, reduzir o atrito.

Aumentou-se o diâmetro e manteve-se as demais características. O desenho técnico da haste da válvula é mostrado na Figura A.13:

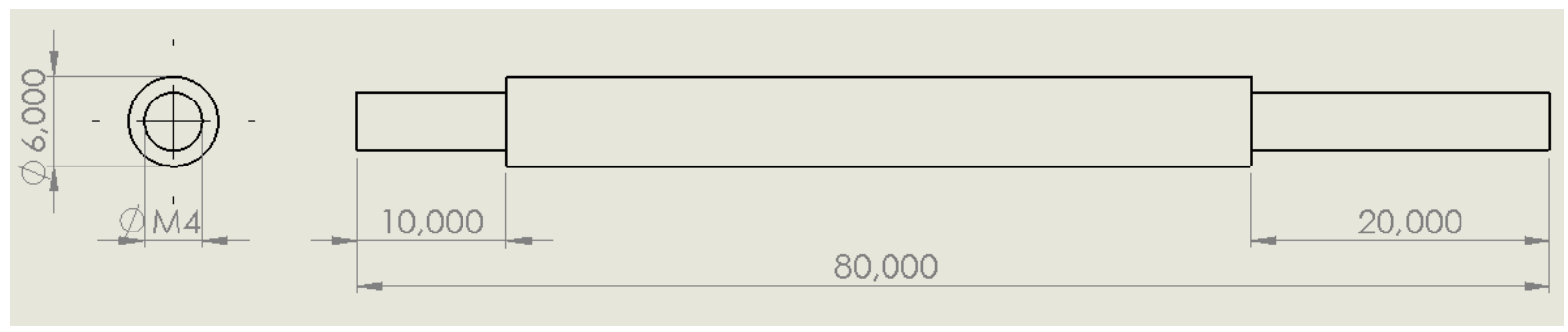

Figura A.13 - Projeto da haste da válvula.

A partir do projeto, a haste foi usinada com eixo retificado de aço, tal como mostrada na foto da Figura A.14:

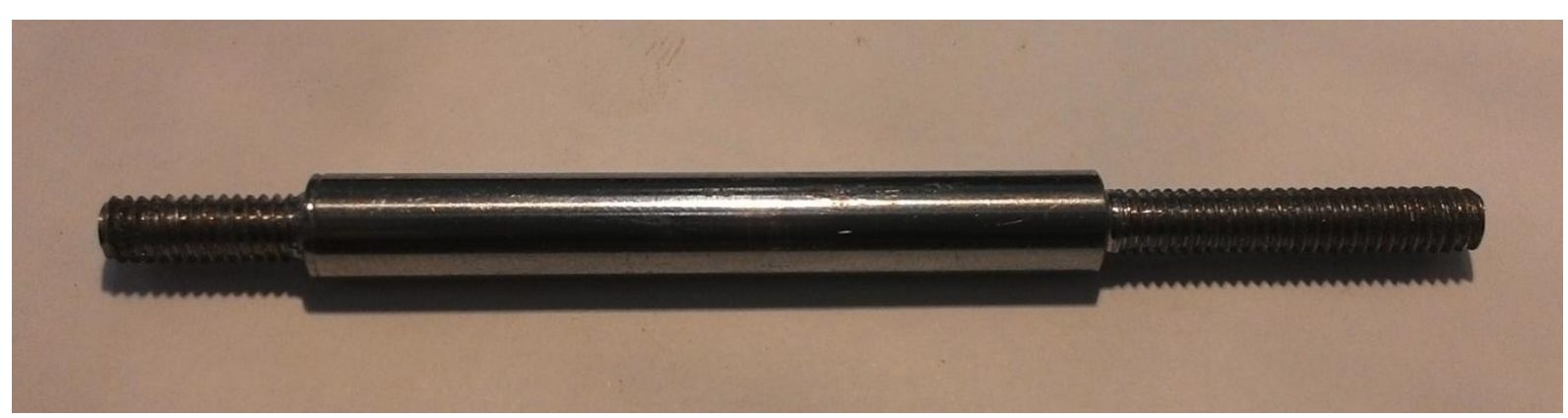

Figura A.14 - Haste da válvula feito com eixo retificado de aço. 


\section{Biela de aço com anéis de latão:}

Devido ao aumento do comprimento da haste do pistão para a instalação do mancal linear, é necessário reduzir o comprimento da biela, o que acarreta na redução do momento fletor e, portanto, a flexão da biela.

Para suportar maiores esforços, reduzir a flexão e possuir maior durabilidade em relação ao desgaste, o material da biela foi trocado de alumínio para aço.

Os anéis de latão tem como finalidade evitar o desgaste da biela e do eixo. Devido aos esforços e alta rotação, os anéis foram feitos em latão, ao invés de Teflon, para possuir maior durabilidade.

Reduziu-se o comprimento da biela e manteve-se as demais características. O desenho técnico da biela e dos anéis é mostrado na Figura A.15:

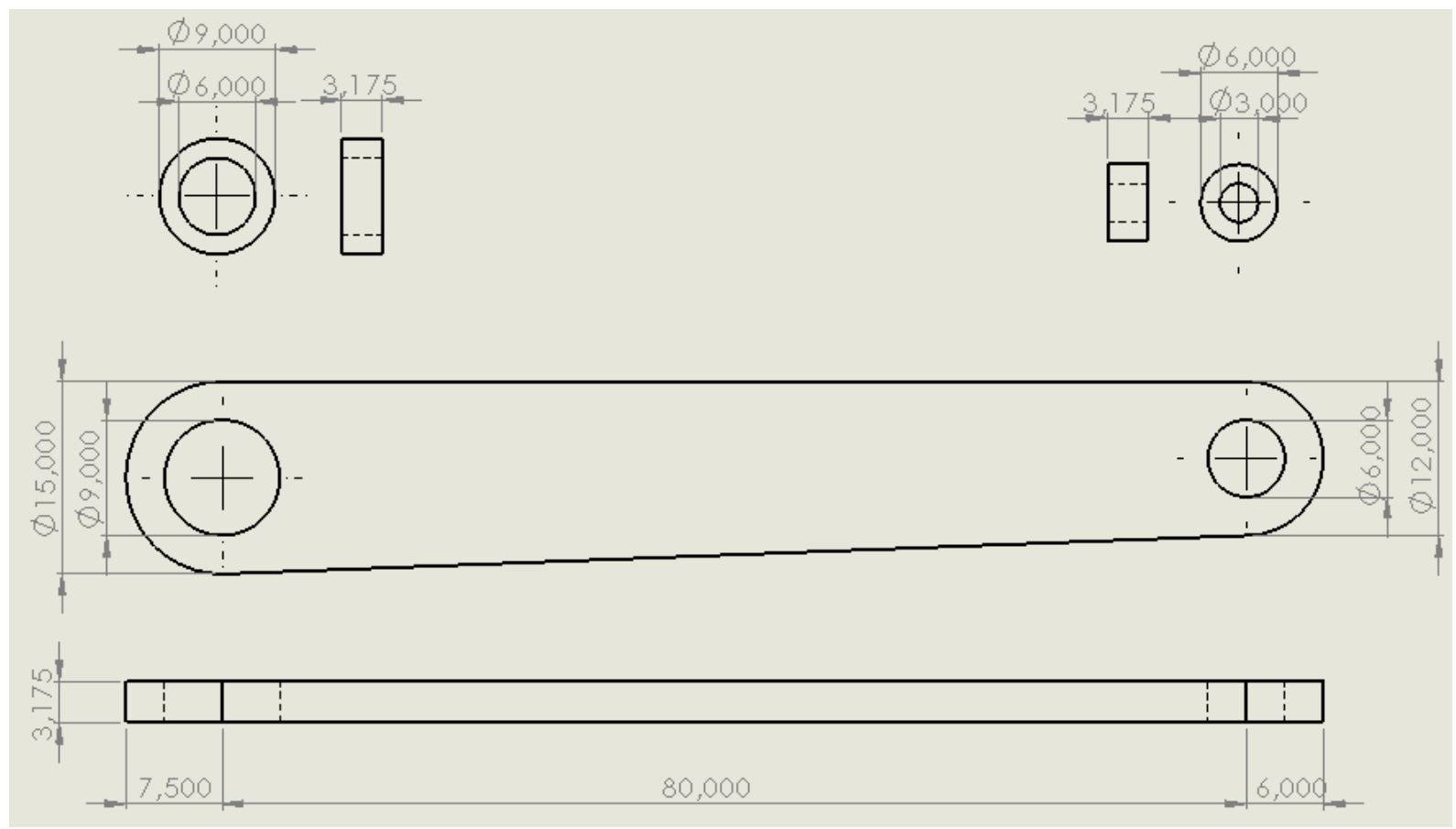

Figura A.15 - Projeto da biela de aço com anéis de latão. 
Baseando-se no projeto, a biela foi usinada em aço, e os anéis, em latão, tal como mostrado na foto da Figura A.16:

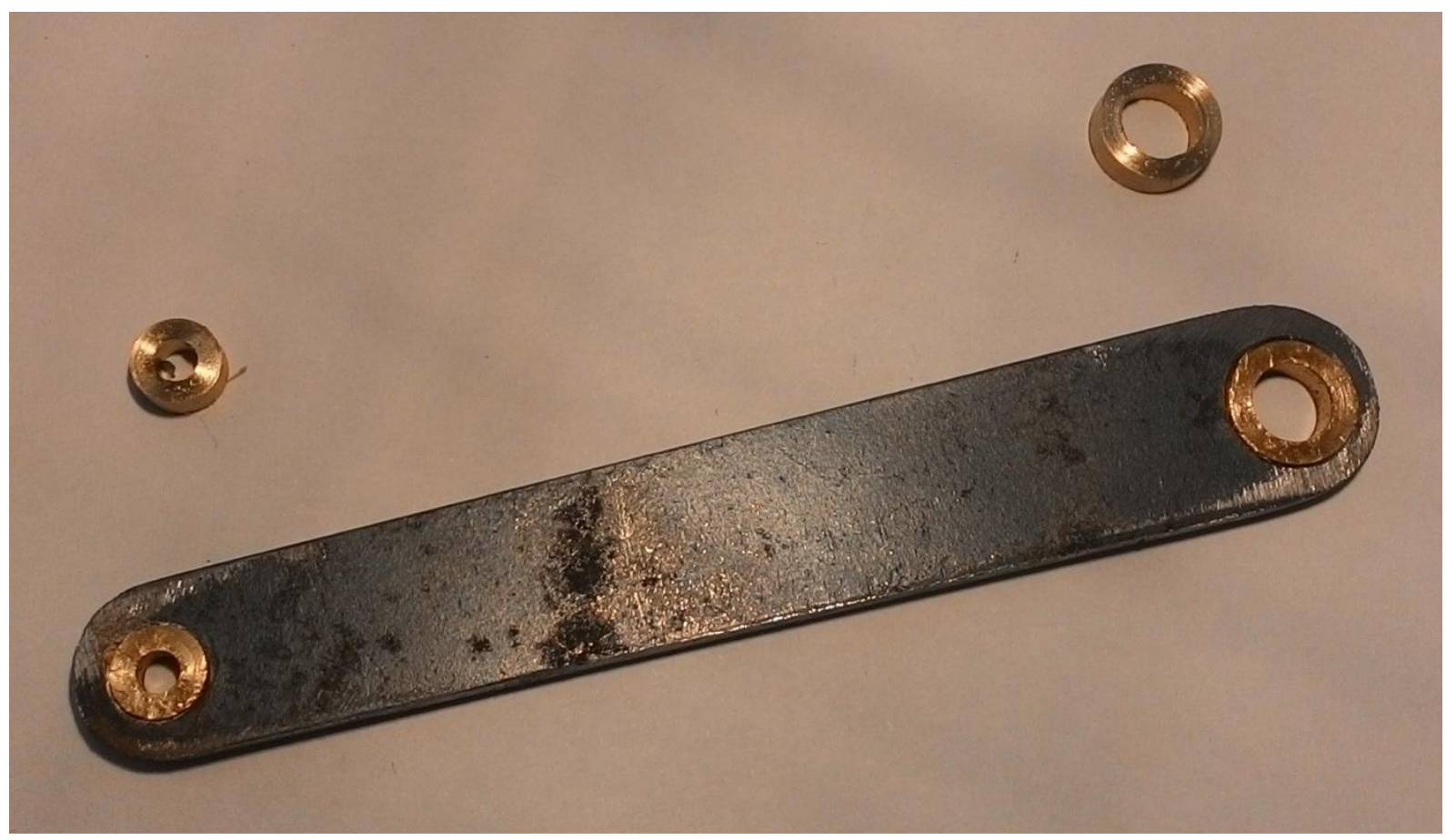

Figura A.16 - Biela de aço com anéis de latão.

\section{Espaçadores da biela feitos em latão:}

Os espaçadores têm como objetivo manter a biela alinhada à haste do pistão. Foram feitos de latão para possuir alta durabilidade e evitar o desgaste da biela, da manivela e do eixo.

Com base no diâmetro do eixo da biela e nas distâncias entre a biela (alinhada à haste) e as manivelas, o desenho técnico dos espaçadores é mostrado na Figura A.17. 


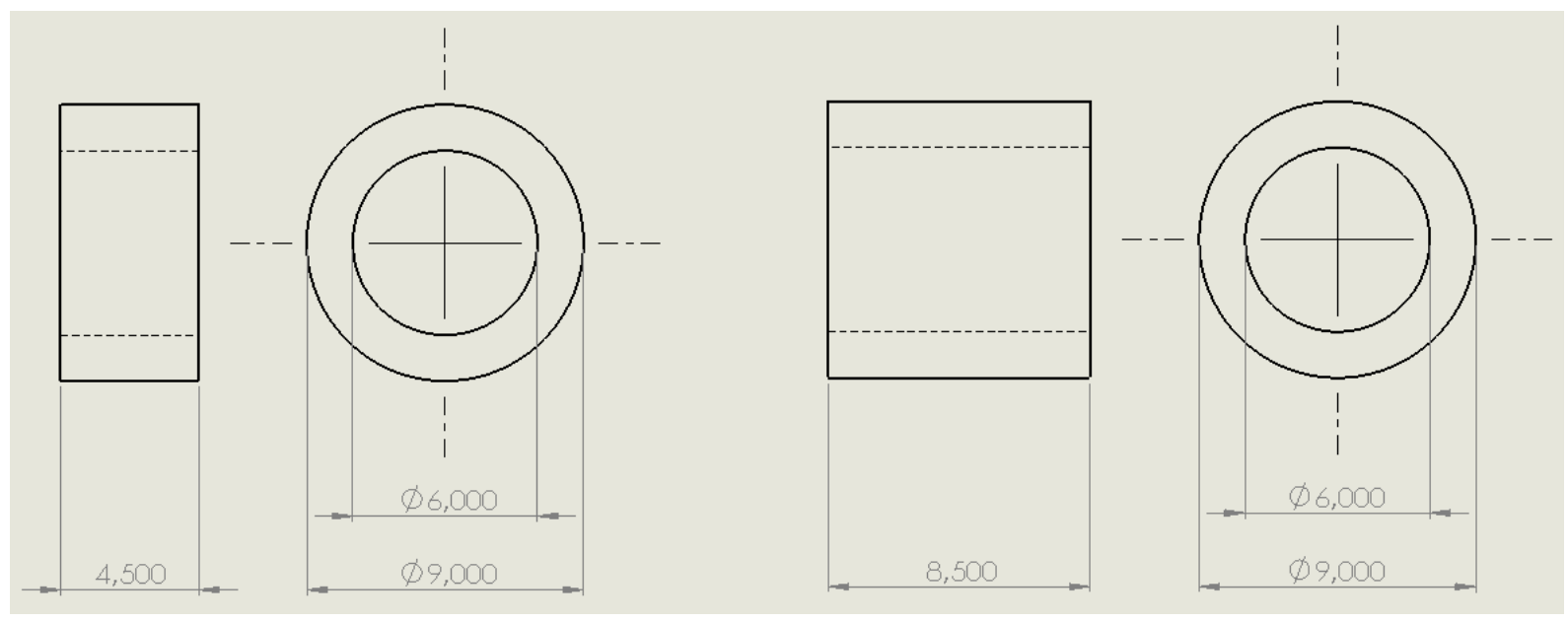

Figura A.17 - Projeto dos espaçadores da biela feito em latão.

Os espaçadores montados com a biela são exibidos na foto da Figura A.18:

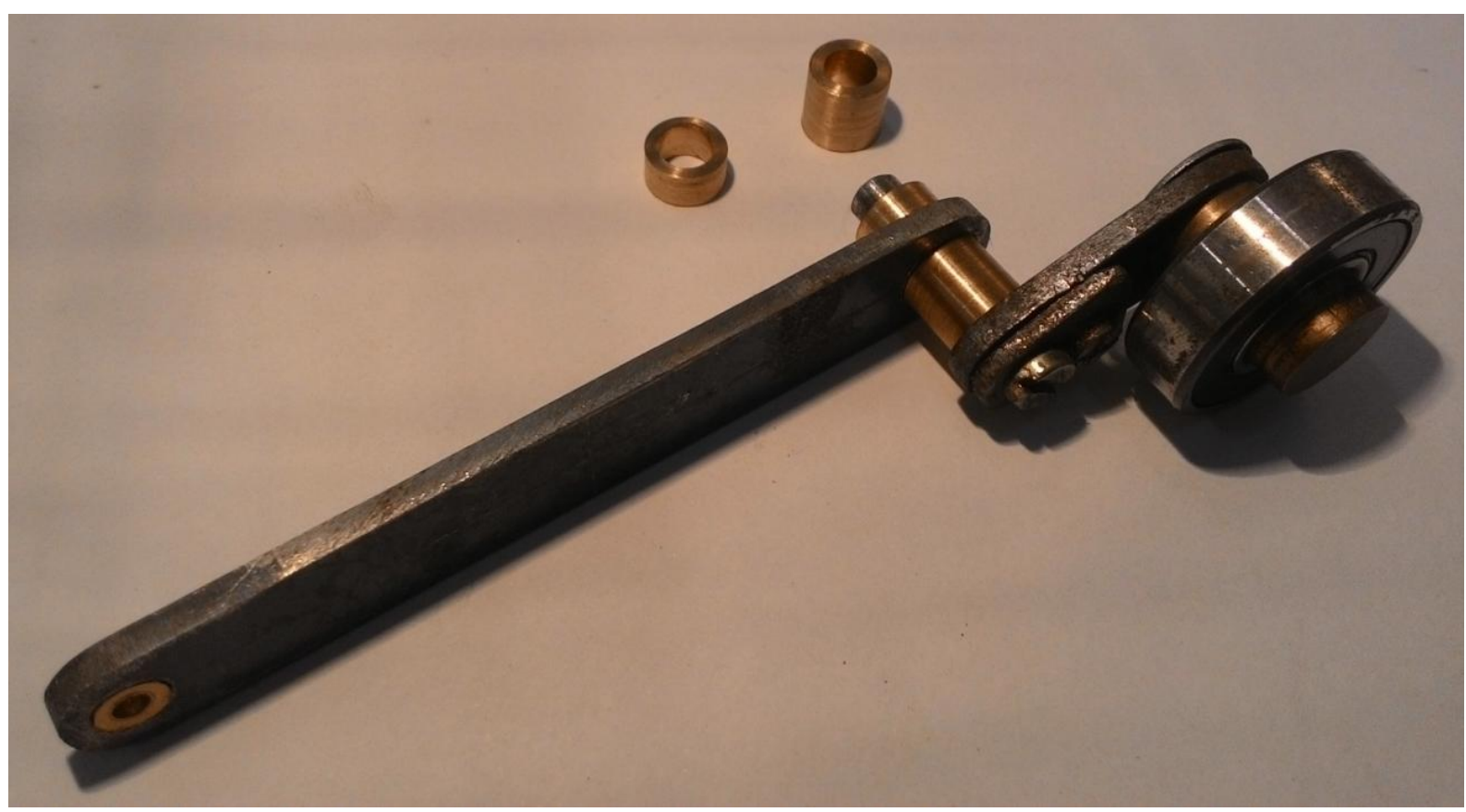

Figura A.18 - Espaçadores da biela feito em latão.

\section{Anéis elásticos para fixação dos rolamentos:}

Foram acrescentados anéis elásticos para fixar o rolamento ao eixo, evitando o deslocamento axial.

Foram selecionados anéis elásticos para eixo de $12 \mathrm{~mm}$, fabricados em aço mola de acordo com a norma DIN 471, os quais são mostrados na Figura A.19. 


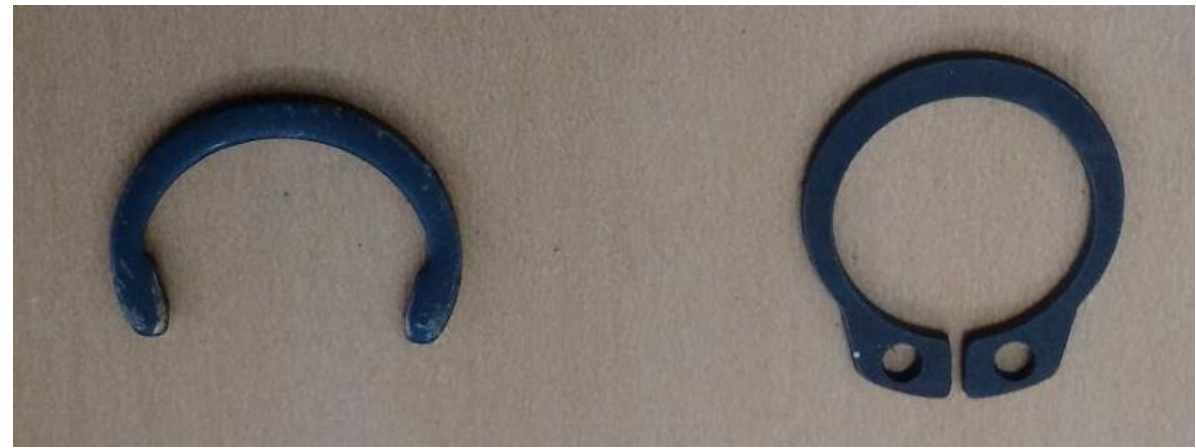

Figura A.19 - Anel elástico de encaixe forçado e de encaixe com alicate.

Devido ao pequeno espaçamento entre as peças, optou-se por utilizar os anéis elásticos de encaixe forçado. Os rolamentos já fixados pelos anéis elásticos são mostrados na foto da Figura A.20:

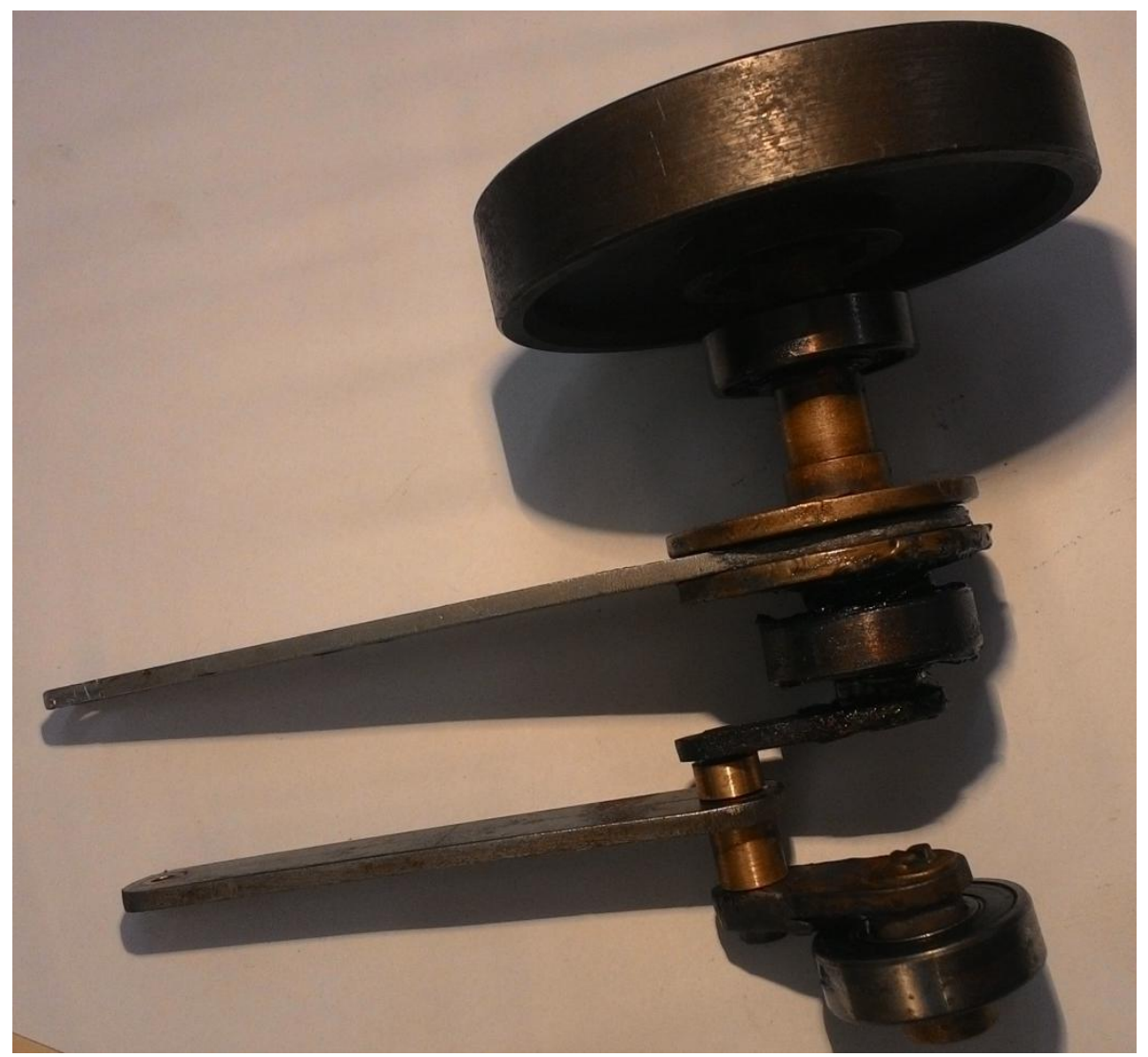

Figura A.20 - Anéis elásticos montados. 


\section{Batente de borracha:}

Foi constatado que, ocasionalmente, pode ocorrer a entrada de pequenos detritos pela tubulação de entrada do ar comprimido. Tais detritos podem colidir com o fundo da câmara e com o pistão, danificando-os.

Colou-se então um batente feito de borracha ao fundo da câmara, com a finalidade de amortecer estas possíveis colisões.

Sabendo-se o diâmetro da câmara do pistão, o desenho técnico do batente de borracha é mostrado na Figura A.21:

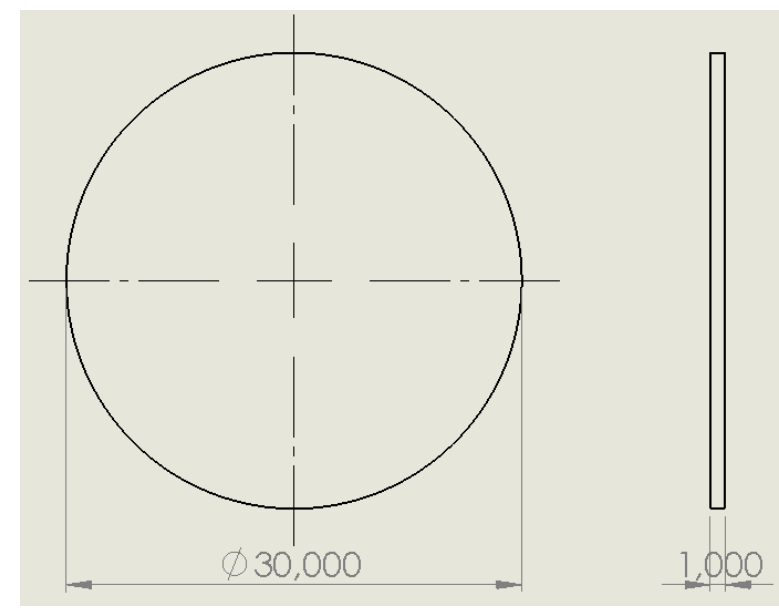

Figura A.21 - Projeto do batente de borracha.

O batente de borracha é exibido na foto da Figura A.22:

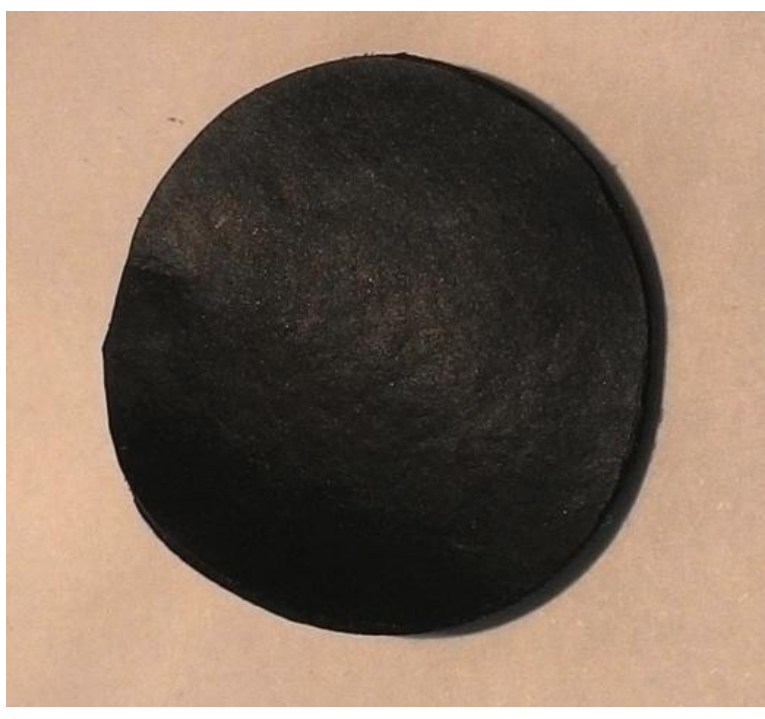

Figura A.22 - Batente de borracha. 


\section{Máquina completa:}

No novo projeto do protótipo para o estudo experimental, foram mantidas as principais características do antigo projeto, porém foram feitas algumas modificações visando suportar mais esforços, melhorar a vedação e reduzir as perdas por atrito.

O modelo em 3D do projeto é apresentado na Figura A.23:

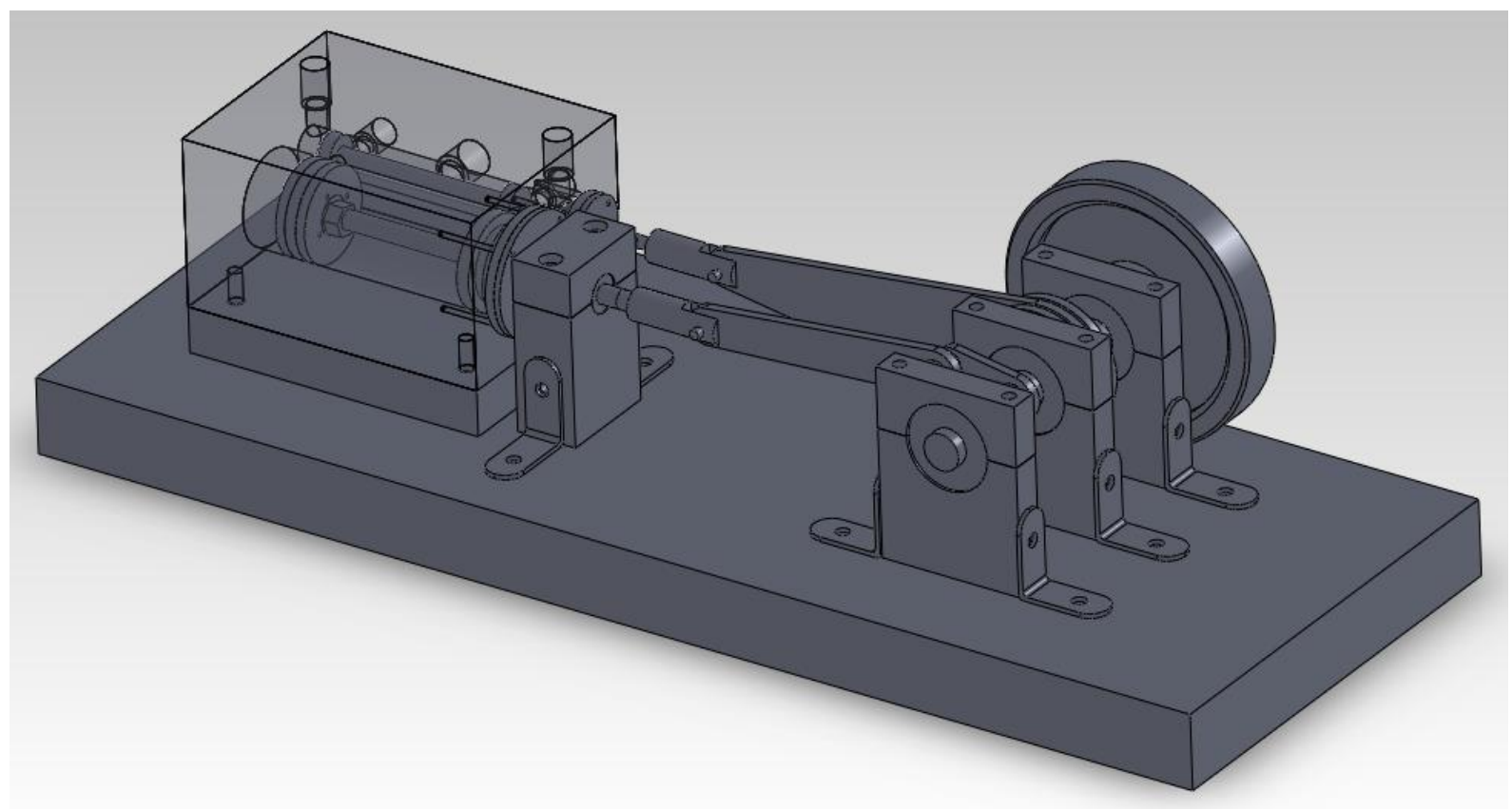

Figura A.23 - Projeto da micromáquina a vapor.

Após a usinagem e montagem de cada peça, o novo protótipo é mostrado na Figura A.24.

Visando reduzir o atrito, aumentar a durabilidade das peças em relação ao desgaste e melhorar a eficiência da máquina, foi utilizado óleo lubrificante e graxa para rolamentos de acordo com cada tipo de peça.

O óleo lubrificante foi utilizado nas seguintes partes:

- Câmara do pistão;

- Pistão;

- Haste do pistão;

- Tampa do pistão; 
- Câmara da válvula;

- Válvula;

- Haste da válvula;

- Tampa da válvula.

A graxa para rolamento foi utilizada nas seguintes partes:

- Biela;

- Espaçadores de latão;

- Eixo;

- Excêntrico;

- Biela do excêntrico;

- Anéis das bielas;

- Pinos da haste.

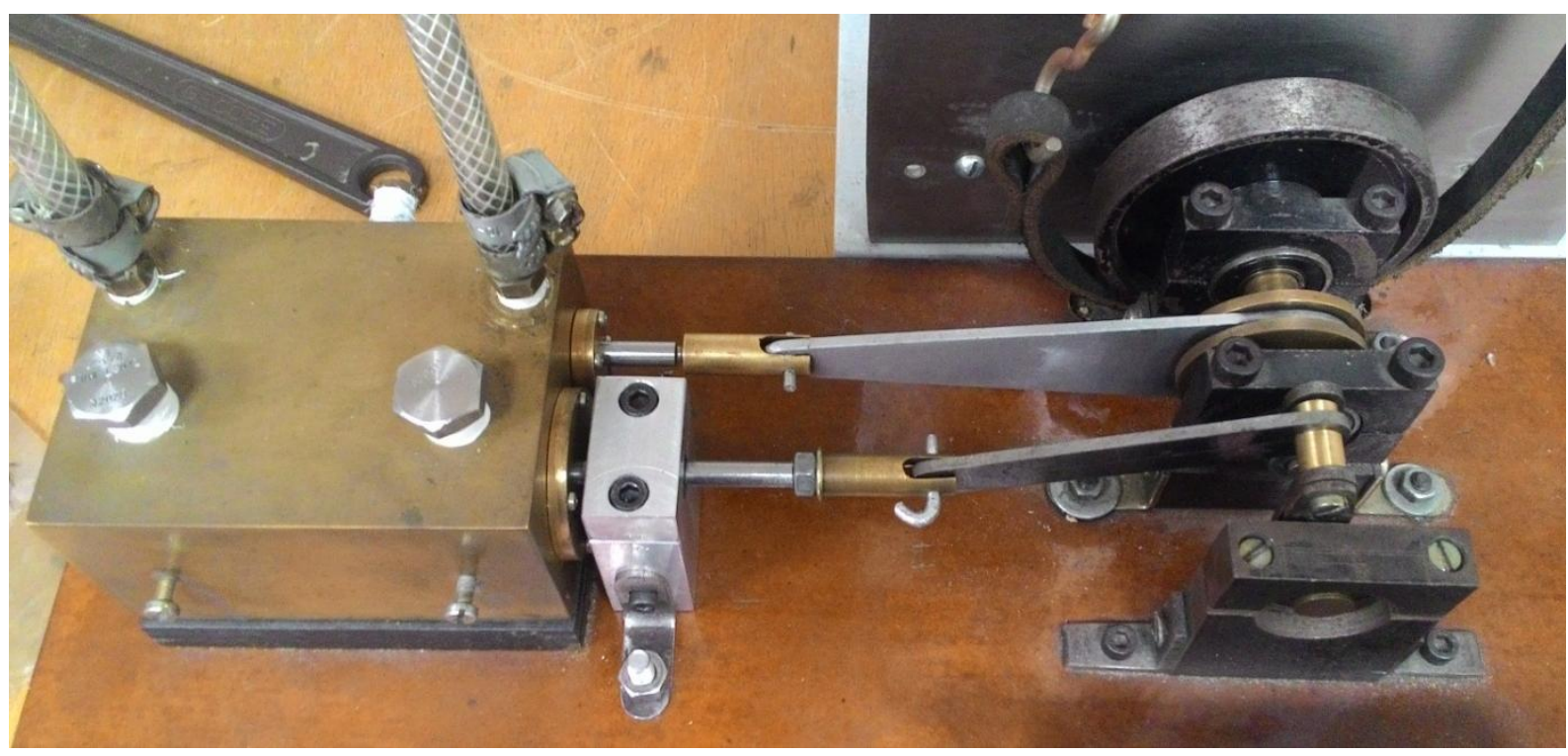

Figura A.24 - Micromáquina a vapor. 


\section{APÊNDICE B - ALGORITMO DAS SIMULAÇÕES EM MATLAB}

Para realizar as simulações do modelo proposto, foi desenvolvido um algoritmo no Matlab. No primeiro bloco do algoritmo devem ser definidos os parâmetros da micromáquina a vapor e as variáveis das condições de simulação.

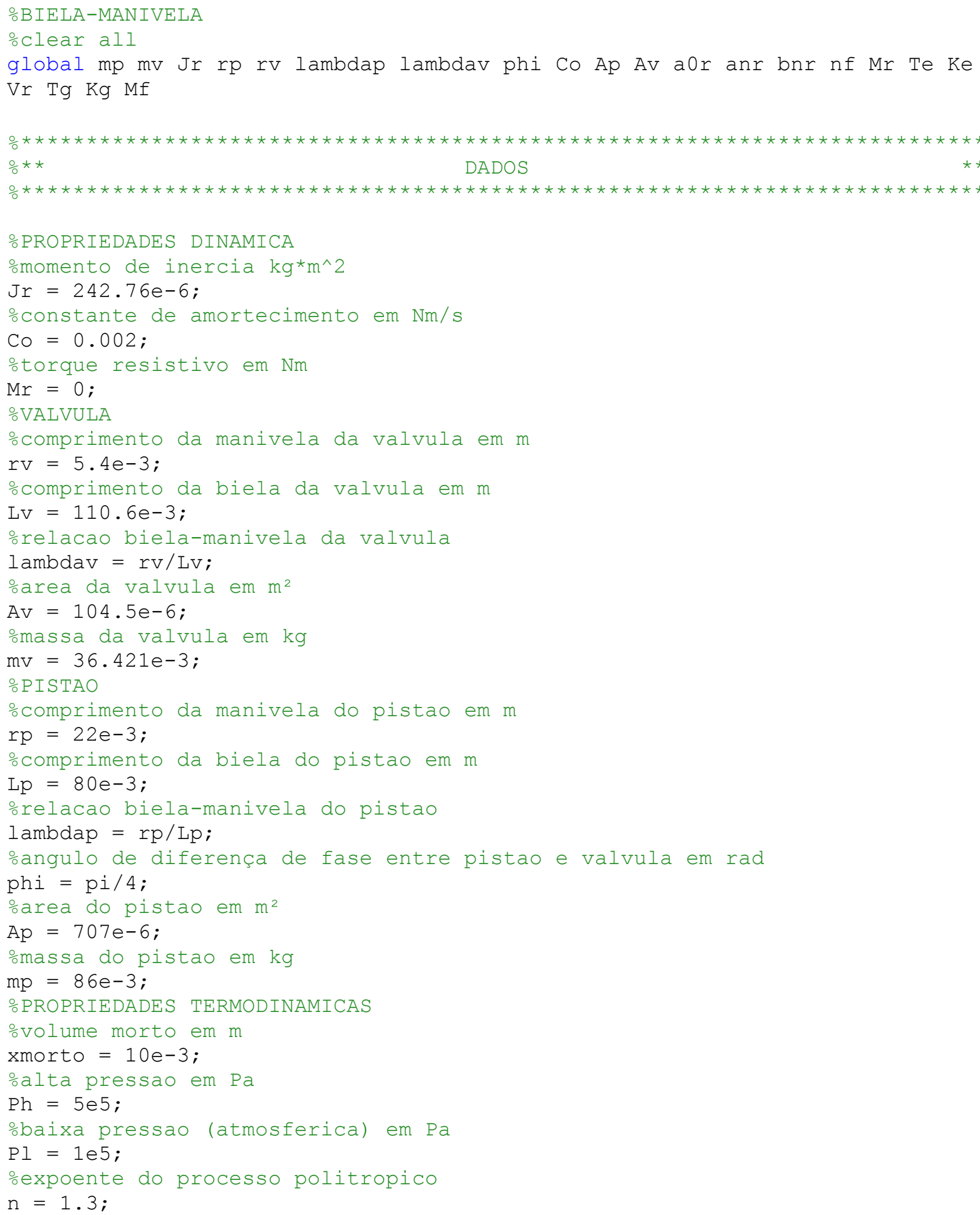




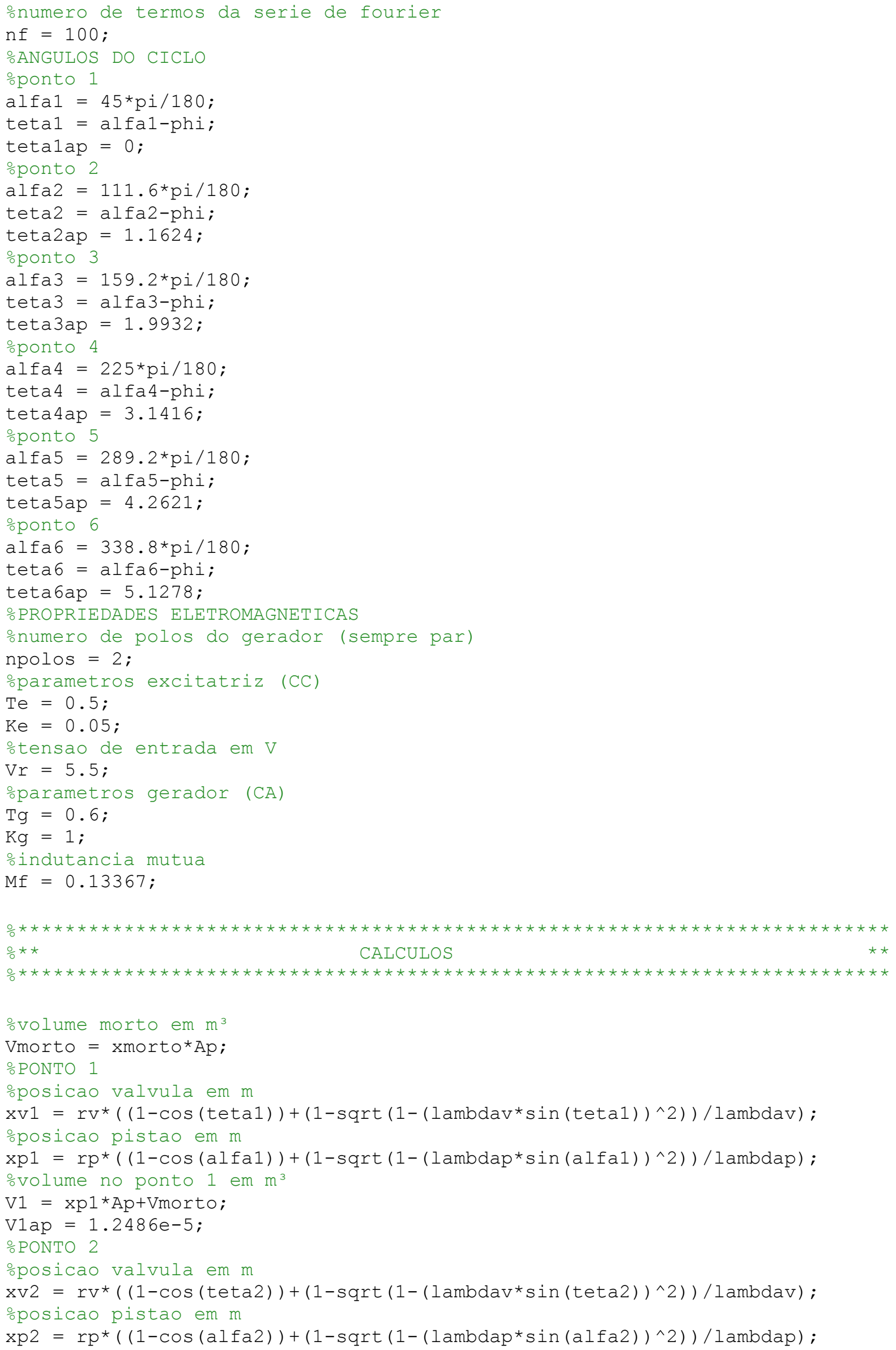




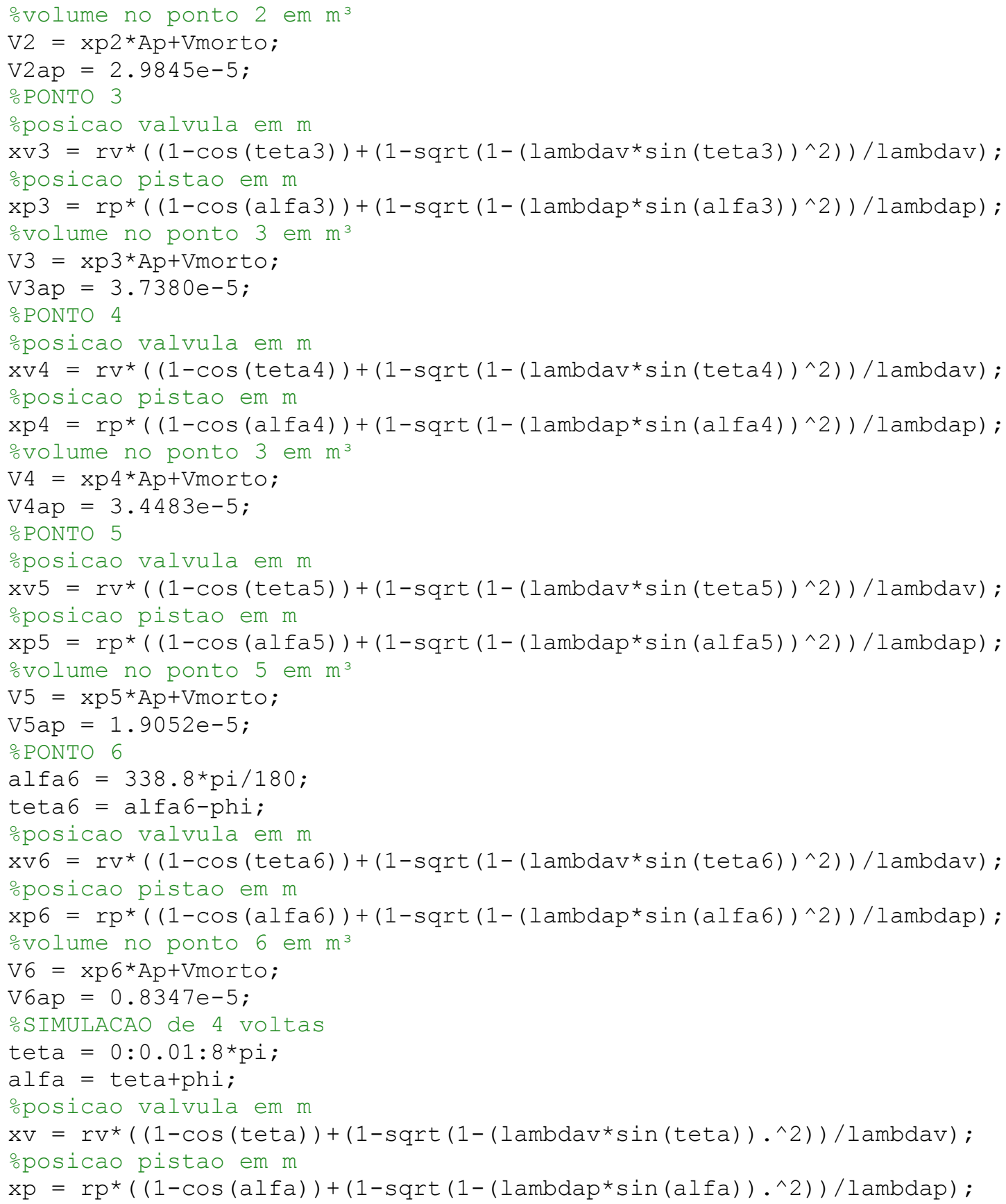


end

$i=i+1 ;$

oprocesso 2-3

for $\mathrm{Vp} 23=\mathrm{V} 2 \mathrm{ap}+\mathrm{passoV}$ :passoV:V3ap

$\mathrm{PV}(1, \mathrm{i})=\mathrm{Ph} *(\mathrm{~V} 2 / \mathrm{Vp} 23)^{\wedge} \mathrm{n}$;

$\operatorname{Vp}(1, i)=\operatorname{Vp} 23$;

$\mathrm{WV}=\mathrm{WV}+\mathrm{PV}(1, i){ }^{*}$ passoV;

$i=i+1 ;$

end

oprocesso $3-4$

$\mathrm{P} 3=\mathrm{Ph} *(\mathrm{~V} 2 / \mathrm{V} 3)^{\wedge} \mathrm{n}$;

for $\mathrm{Vp} 34=\mathrm{V} 3 \mathrm{ap}-\mathrm{passoV}:-$ passoV:V4ap

$\mathrm{PV}(1, \mathrm{i})=(\mathrm{P} 1-\mathrm{P} 3) *(\mathrm{Vp} 34-\mathrm{V} 3) /(\mathrm{V} 4-\mathrm{V} 3)+\mathrm{P} 3$;

$\operatorname{Vp}(1, i)=\operatorname{Vp} 34 ;$

$W V=W V-P V(1, i) *$ passoV;

$i=i+1$;

end

oprocesso $4-5$

for Vp45 = V4ap-passoV:-passoV:V5ap

$\mathrm{PV}(1, i)=\mathrm{Pl}$;

$\operatorname{Vp}(1, i)=\operatorname{Vp} 45 ;$

$W V=W V-P V(1, i) *$ passoV;

$i=i+1$;

end

oprocesso $5-6$

for Vp56 = V5ap-passoV:-passoV:V6ap

$\mathrm{PV}(1, \mathrm{i})=\mathrm{Pl}$ * $(\mathrm{V} 5 / \mathrm{Vp} 56)^{\wedge} \mathrm{n}$;

$\operatorname{Vp}(1, i)=\operatorname{Vp} 56$;

$W V=W V-P V(1, i) *$ passoV;

$i=i+1$;

end

oprocesso $6-1$

$\mathrm{P} 6=\mathrm{Pl} *(\mathrm{~V} 5 / \mathrm{V} 6)^{\wedge} \mathrm{n} ;$

for $\mathrm{Vp} 61=\mathrm{V} 6 \mathrm{ap}+\mathrm{passoV}$ :passoV:V1ap

$\mathrm{PV}(1, \mathrm{i})=(\mathrm{Ph}-\mathrm{P} 6)$ * $(\mathrm{Vp} 61-\mathrm{V} 6) /(\mathrm{V} 1-\mathrm{V} 6)+\mathrm{P} 6$;

$\operatorname{Vp}(1, i)=\operatorname{Vp} 61$;

$\mathrm{WV}=\mathrm{WV}+\mathrm{PV}(1, i) *$ passoV;

$i=i+1$;

end

OPRESSAO RESULTANTE E DO TRABALHO REALIZADO

$\operatorname{PVr}=\operatorname{zeros}(1, i-1) ;$

$\mathrm{WVr}=0$;

for $j=1: 1: i-1$

$i=i-1$;

$\operatorname{PVr}(1, j)=\operatorname{PV}(1, j)-P V(1, i)$;

$W V r=W V r+\operatorname{abs}(\operatorname{PVr}(1, j) *$ passoV $)$;

end

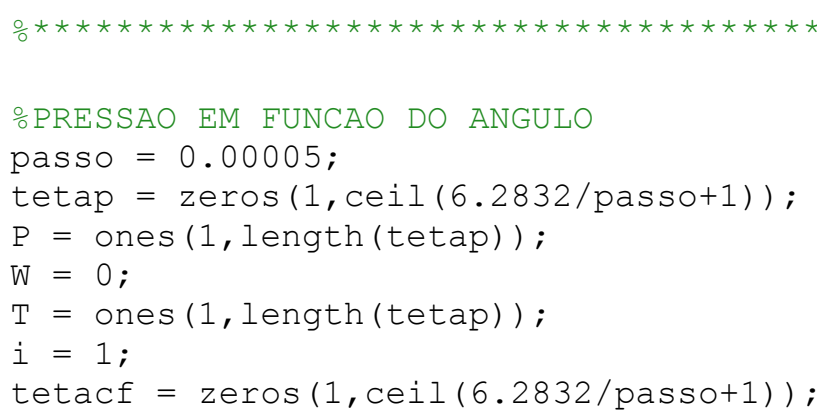




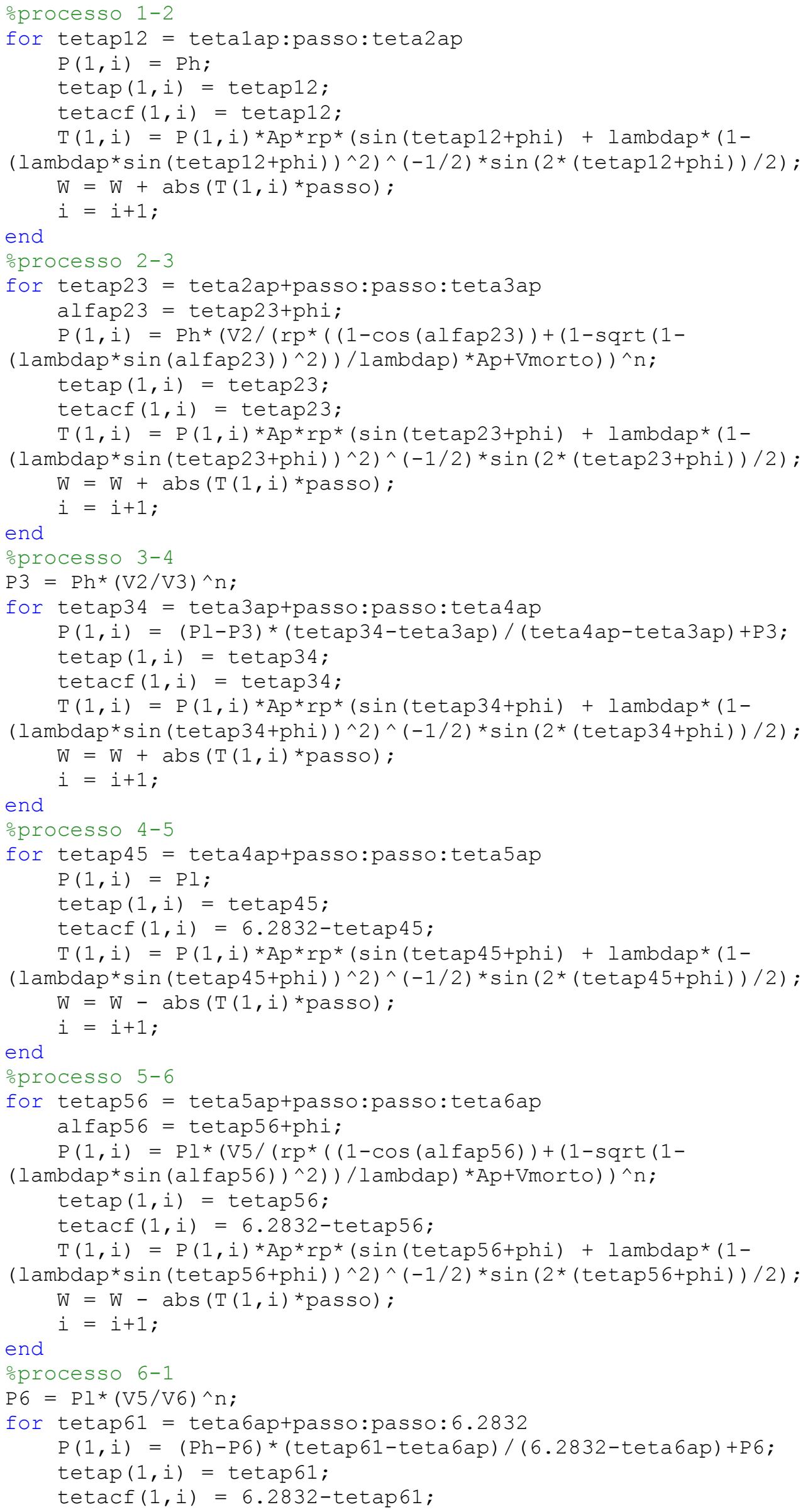




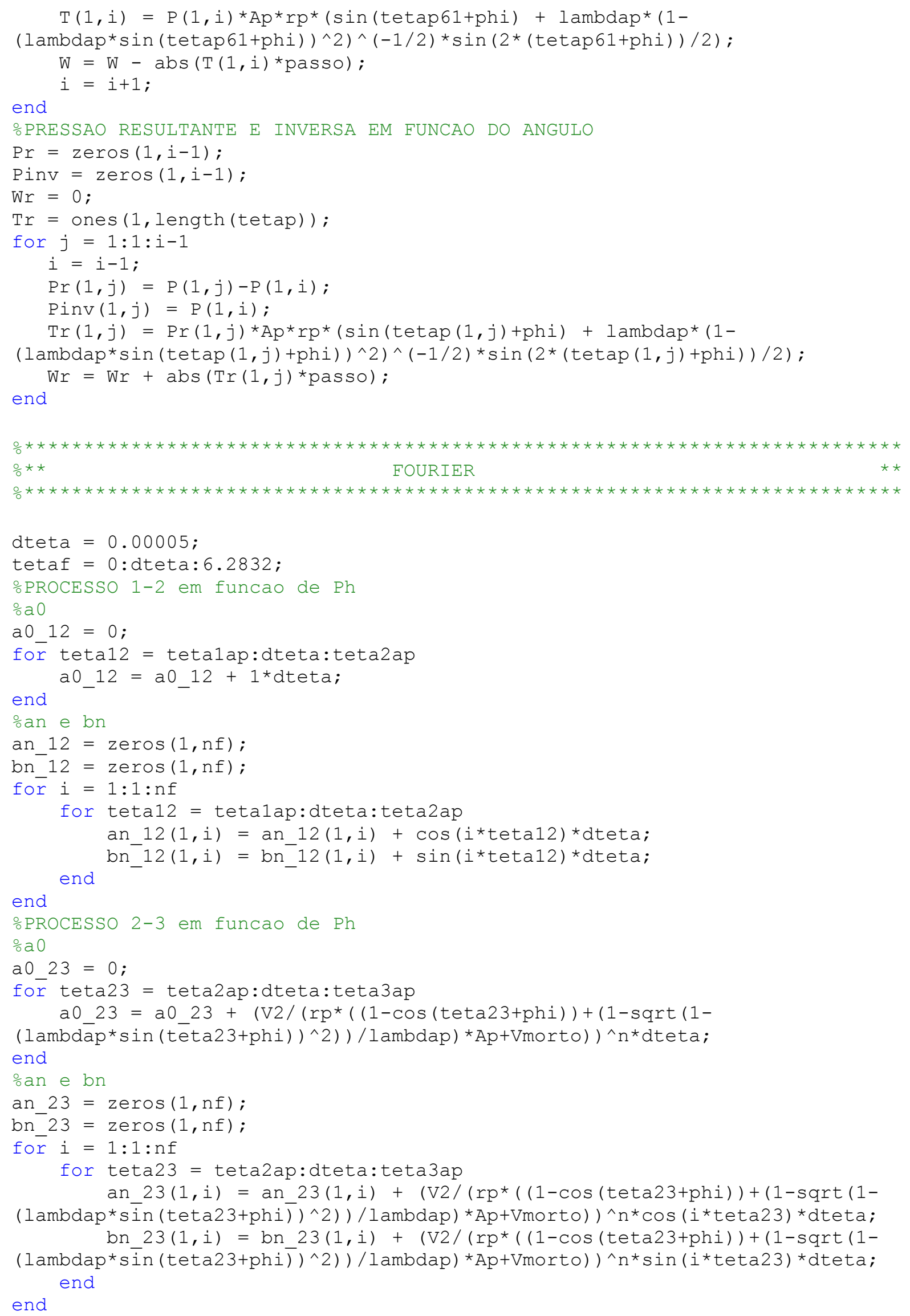




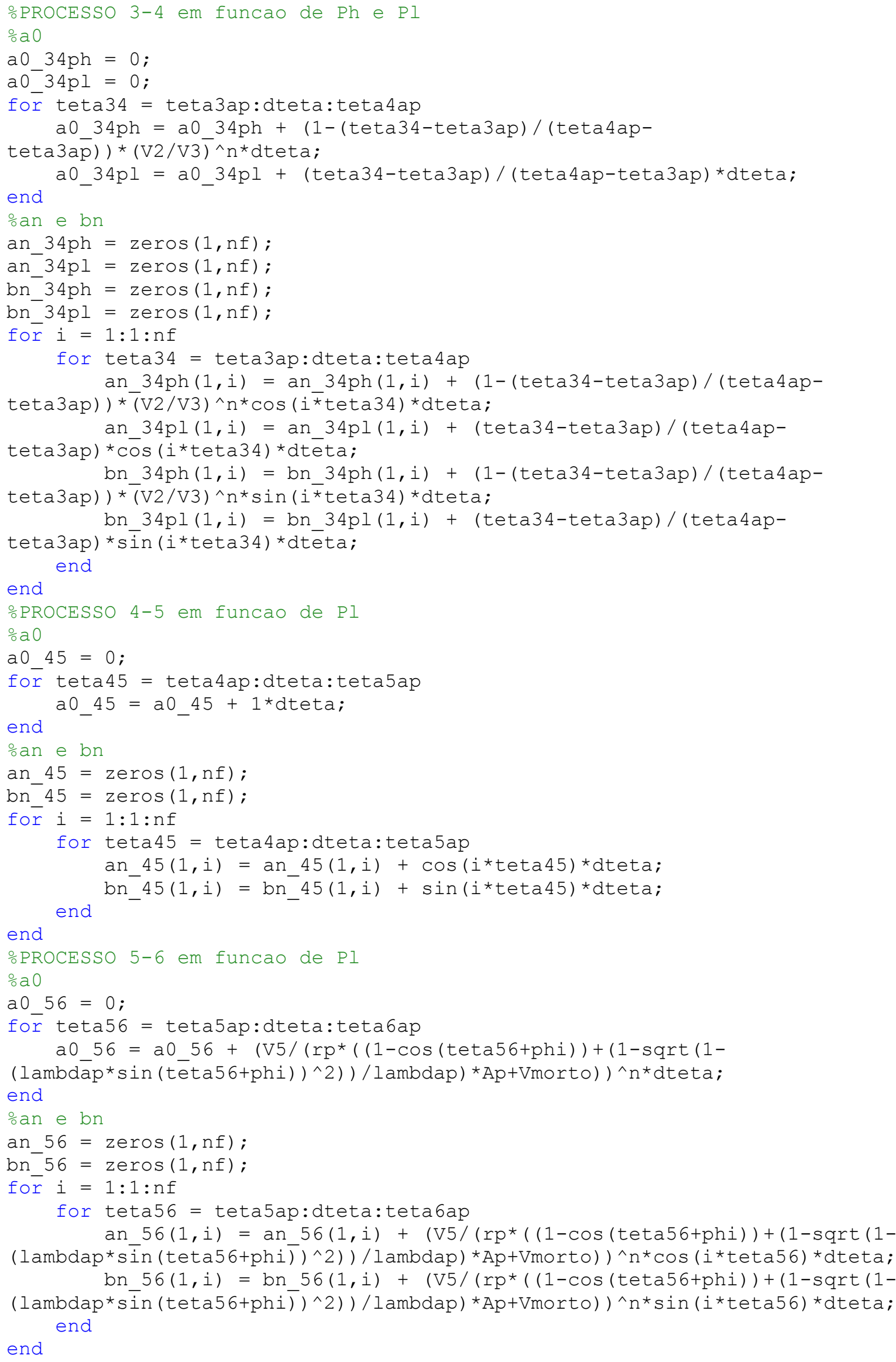




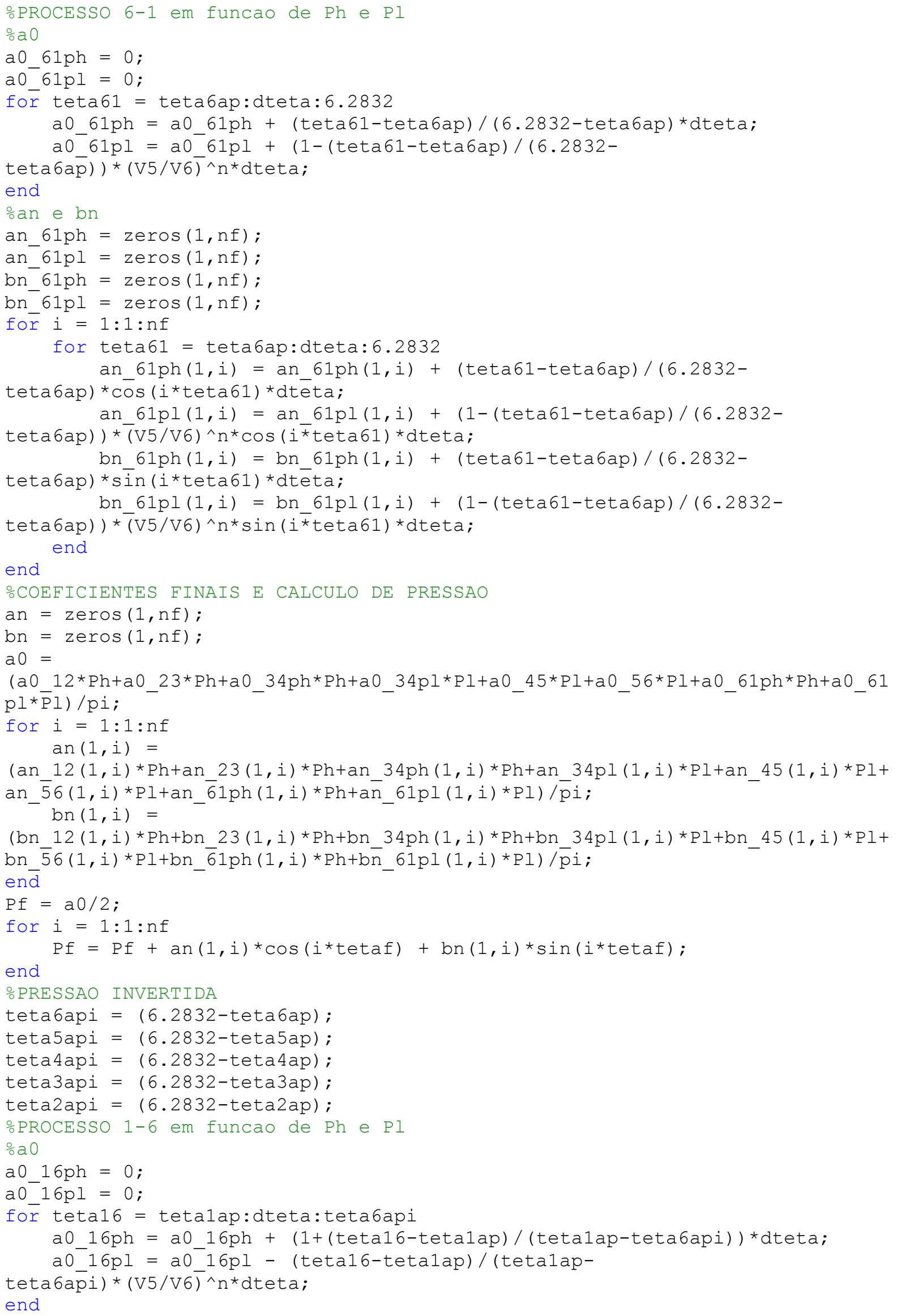




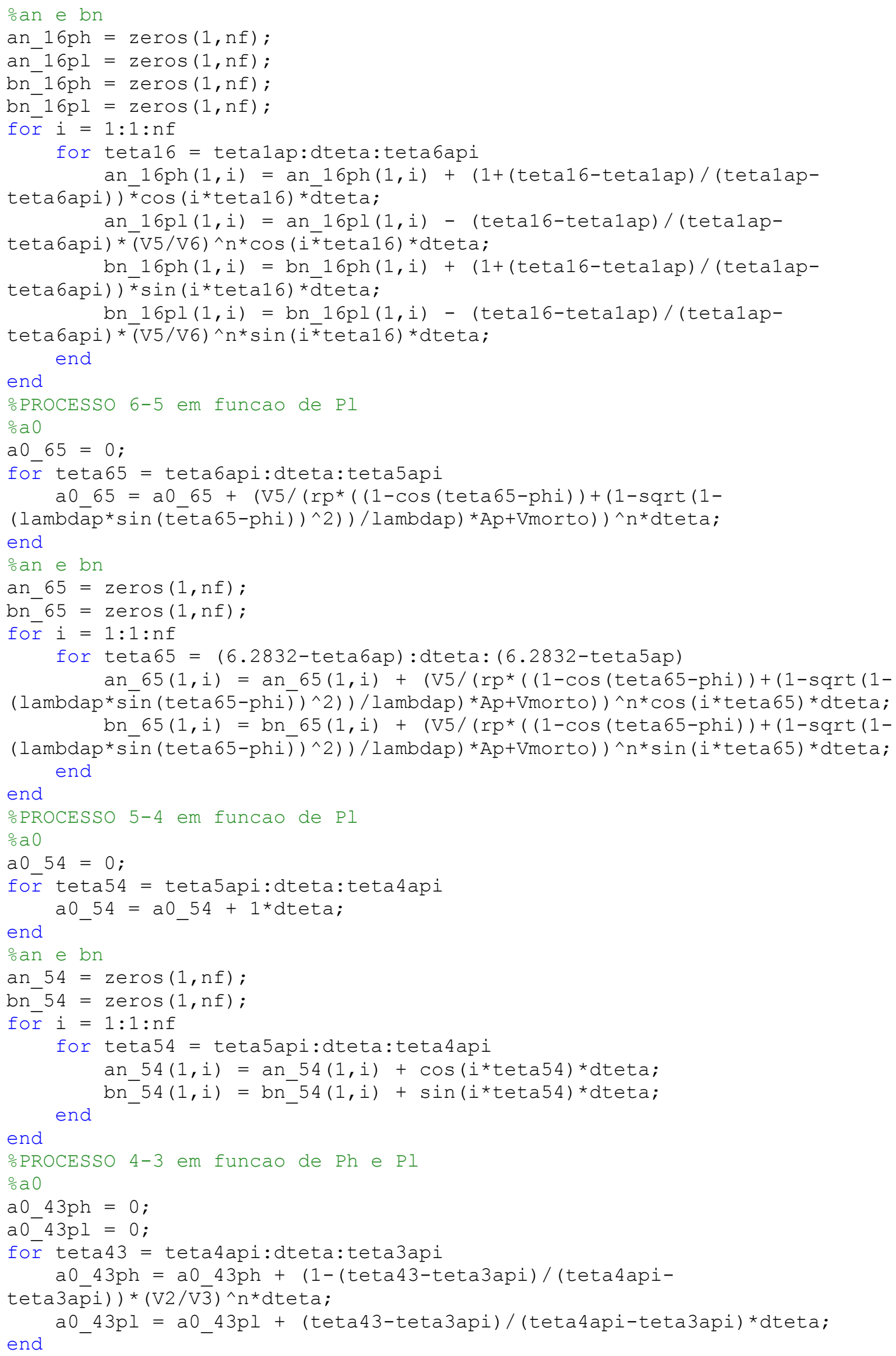




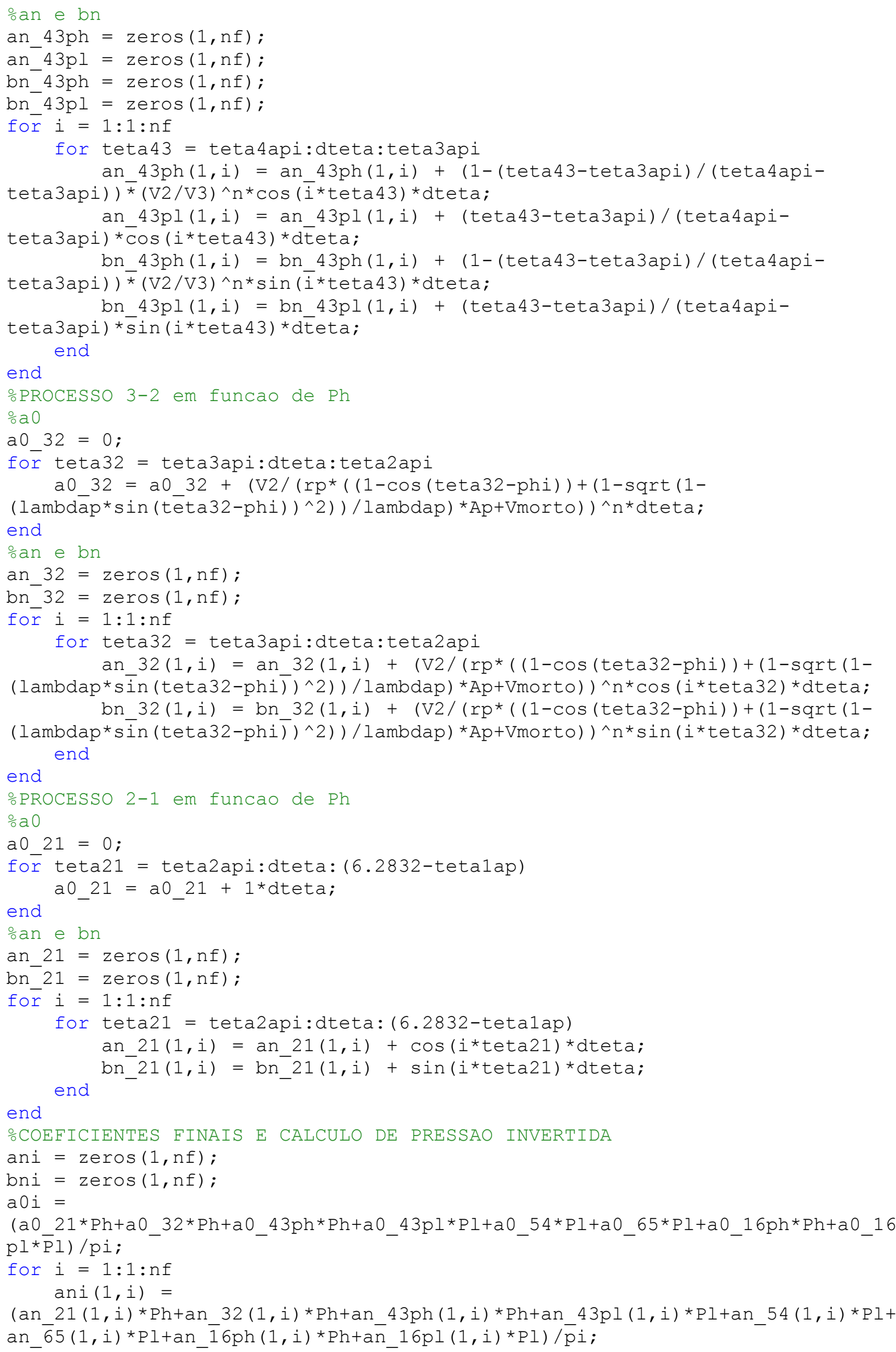


$\operatorname{bni}(1, i)=$

$($ bn_21 (1,i) *Ph+bn_32(1,i) *Ph+bn_43ph (1,i) *Ph+bn_43pl (1,i) *Pl+bn_54 (1, i) *Pl+ bn $\overline{6} 5(1, i) * \mathrm{Pl}+\mathrm{bn} \overline{1} 6 \mathrm{ph}(1, i) * \mathrm{Ph}+\mathrm{b} \overline{\mathrm{n}} 16 \mathrm{pl}(1, i) * \mathrm{Pl}) / \overline{\mathrm{p}} \mathrm{i}$

end

$\operatorname{Pfi}=\mathrm{a} 0 \mathrm{i} / 2$;

for $i=1: 1: n f$

$\operatorname{Pfi}=\operatorname{Pfi}+\operatorname{ani}(1, i) * \cos (i * \operatorname{tetaf})+\operatorname{bn} i(1, i) * \sin (i * \operatorname{tetaf})$

end

○COEFICIENTES FINAIS E CALCULO DE PRESSAO RESULTANTE

$\operatorname{anr}=\operatorname{zeros}(1, \mathrm{nf})$;

bnr $=\operatorname{zeros}(1, \mathrm{nf})$;

aOr $=$ a0-a0i;

for $i=1: 1: n f$

$\operatorname{anr}(1, i)=\operatorname{an}(1, i)-\operatorname{ani}(1, i)$;

bnr $(1, i)=$ bn $(1, i)-b n i(1, i)$;

end

$\operatorname{Pfr}=\mathrm{aOr} / 2$;

for $i=1: 1: \mathrm{nf}$

$\operatorname{Pfr}=\operatorname{Pfr}+\operatorname{anr}(1, i) * \cos (i * \operatorname{tetaf})+\operatorname{bnr}(1, i) * \sin (i * \operatorname{tetaf})$

end

OFUNCAO ERRO DA PRESSAO DE FOURIER

$\mathrm{k}=$ length $(\mathrm{Pf})$

$\mathrm{Pe}=\operatorname{zeros}(1, \mathrm{k})$;

for $i=1: 1: \mathrm{k}$

end

$\operatorname{Pe}(1, i)=\operatorname{Pr}(1, i)-\operatorname{Pfr}(1, i) ;$

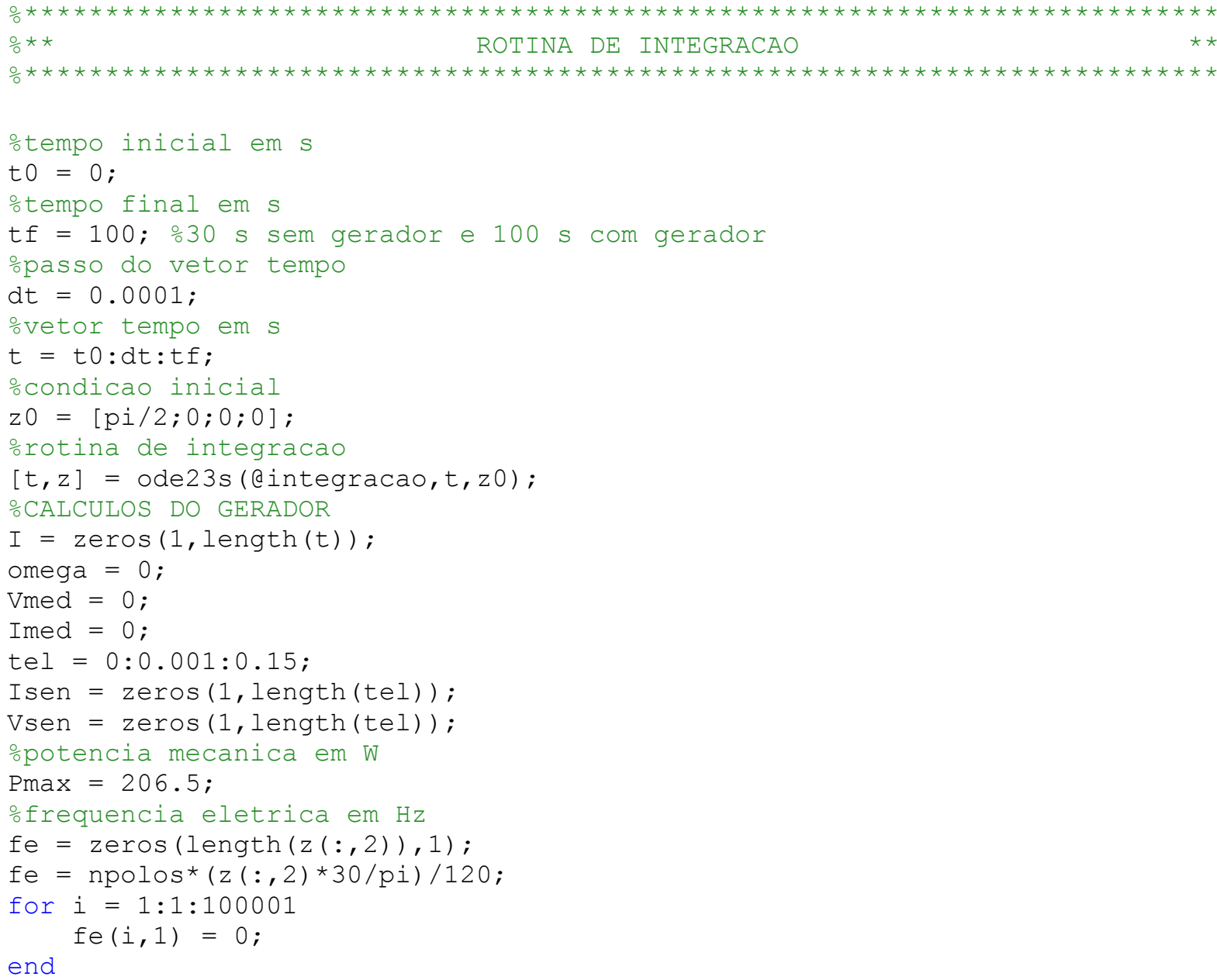




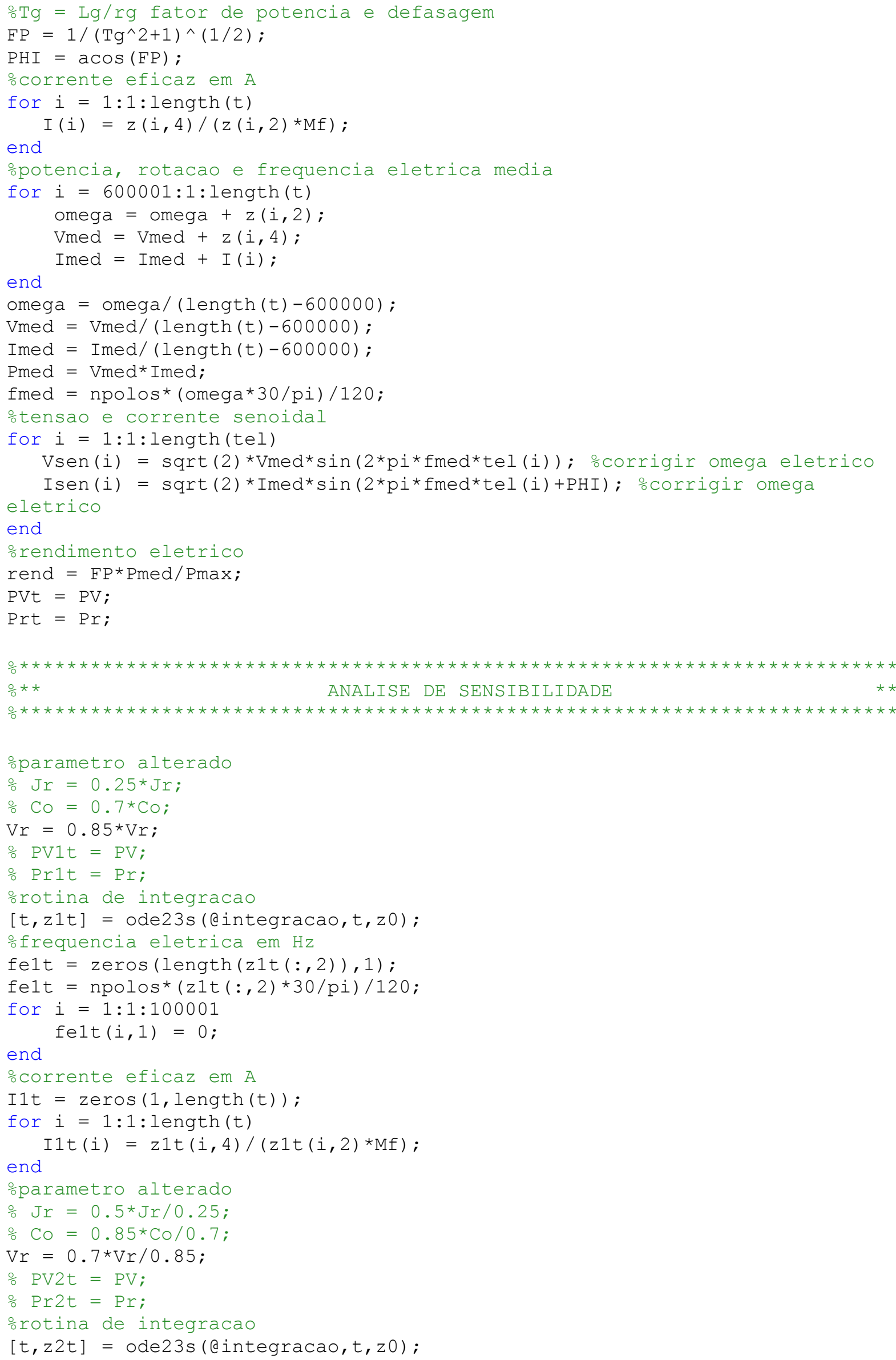




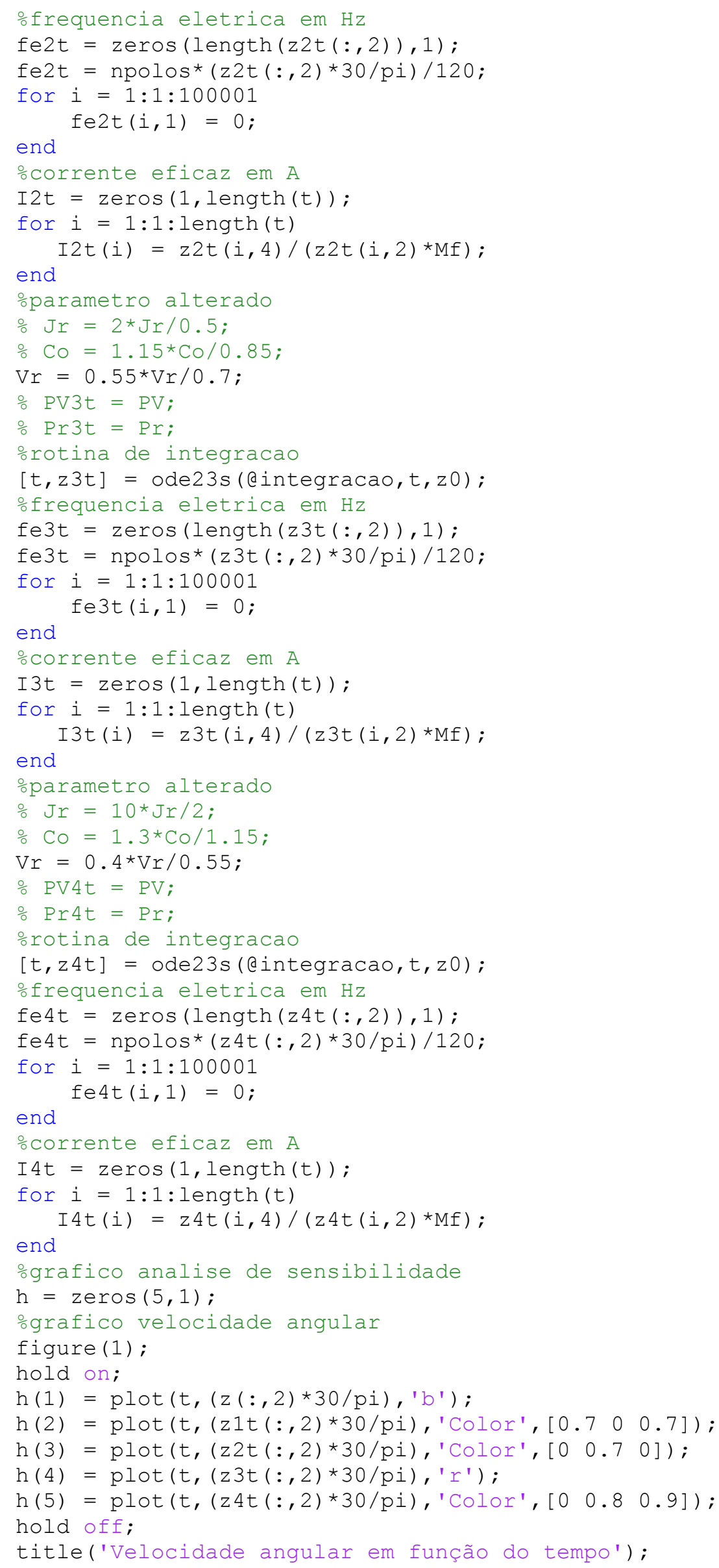




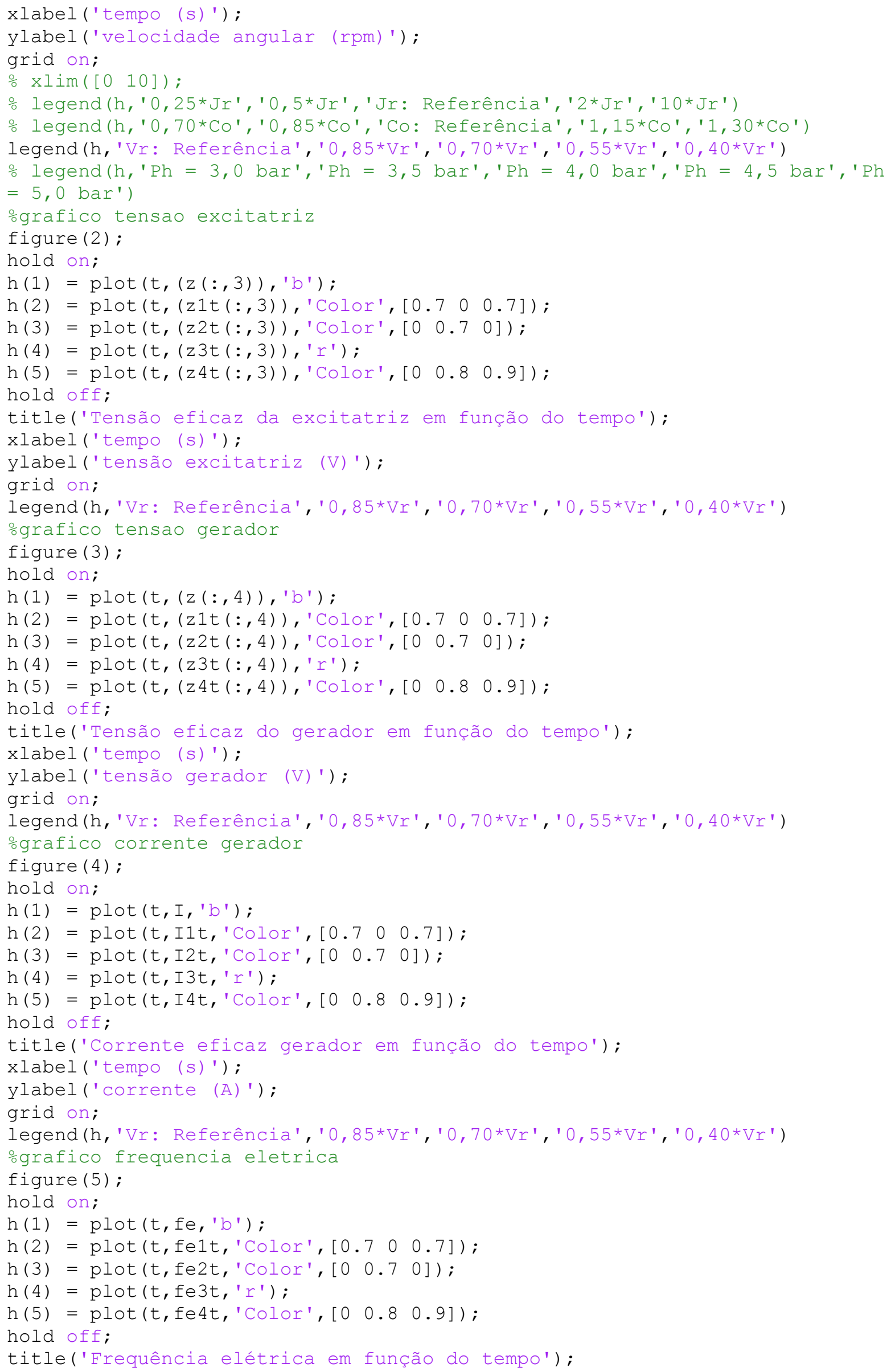


xlabel ('tempo (s)');

ylabel ('frequência (Hz)') ;

grid on;

legend (h, 'Vr: Referência', '0,85*Vr', '0,70*Vr', '0,55*Vr', '0,40*Vr')

ografico pressao x volume

figure (6);

hold on;

$h(1)=\operatorname{plot}\left(V p, P V t, b^{\prime}\right)$;

$h(2)=\operatorname{plot}\left(V p, P V 1 t,{ }^{\prime C O l o r '},\left[\begin{array}{llll}0.7 & 0 & 0.7\end{array}\right)\right.$;

$h(3)=\operatorname{plot}\left(\mathrm{Vp}, \mathrm{PV} 2 \mathrm{t}\right.$, 'Color' $\left.^{\prime}\left[\begin{array}{lll}0 & 0.7 & 0\end{array}\right]\right)$;

$h(4)=\operatorname{plot}\left(V p, P V 3 t,{ }^{\prime}{ }^{\prime}\right)$;

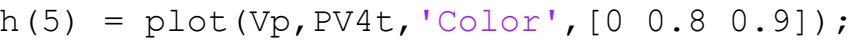

hold off;

title('Pressão em função do volume do pistão');

xlabel ('volume $\left(\mathrm{m}^{3}\right)$ ') ;

ylabel ('pressão (Pa)') ;

grid on;

$y \lim ([0.5 e 55.5 e 5])$;

legend (h, 'Ph = 3,0 bar', 'Ph = 3,5 bar','Ph = 4,0 bar', 'Ph = 4,5 bar', 'Ph = 5,0 bar')

ografico pressao resultante $x$ teta

figure (7);

hold on;

$\mathrm{h}(1)=$ plot (tetap, Prt, 'b');

$h(2)=$ plot (tetap, Prlt, 'Color', $\left.\left[\begin{array}{lll}0.7 & 0 & 0.7\end{array}\right]\right)$;

$h(3)=$ plot (tetap, Pr2t, 'Color', $\left.\left[\begin{array}{lll}0 & 0.7 & 0\end{array}\right]\right)$;

$h(4)=$ plot (tetap, Pr3t, 'r');

$h(5)=$ plot (tetap, Pr4t,'Color', $\left.\left[\begin{array}{lll}0 & 0.8 & 0.9\end{array}\right]\right)$;

hold off;

title('Pressão resultante em função do ângulo');

xlabel ('ângulo roda de inércia (rad)');

ylabel ('pressão (Pa)') ;

grid on;

$x \lim \left(\left[\begin{array}{ll}0 & 2 * \mathrm{pi}\end{array}\right]\right)$;

legend (h,'Ph = 3,0 bar','Ph = 3,5 bar','Ph=4,0 bar', 'Ph = 4,5 bar', 'Ph = 5, 0 bar')

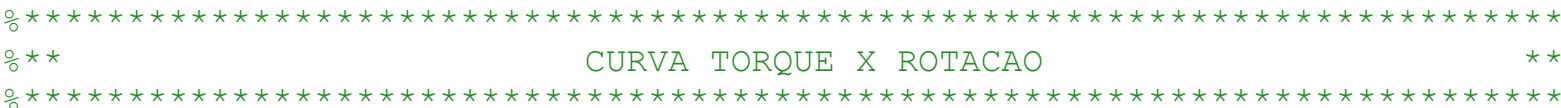

otempo inicial em s

to $=10$

otempo final em s

tf $=30$;

opasso do vetor tempo

$d t=0.0001$;

ovetor tempo em s

$t=t 0: d t: t f ;$

ocondicao inicial

$\mathrm{z} 0=[\mathrm{pi} / 2 ; 200 ; 0 ; 0]$;

otorques e rotacoes

$\mathrm{TxPxR}=\operatorname{zeros}(11,4)$;

for $i=1: 1: 11$

otorque resistivo em Nm (3.0-0.262/3.5-0.481/4.0-0.703/4.5

$-0.926 / 5.0-1.151 / 6.0-1.602$ torque maximo)

$\mathrm{Mr}=0.262-(i-1) * 0.262 / 10$;

orotina de integracao

$[t, z]=$ ode23s (@integracao, t, z0) 


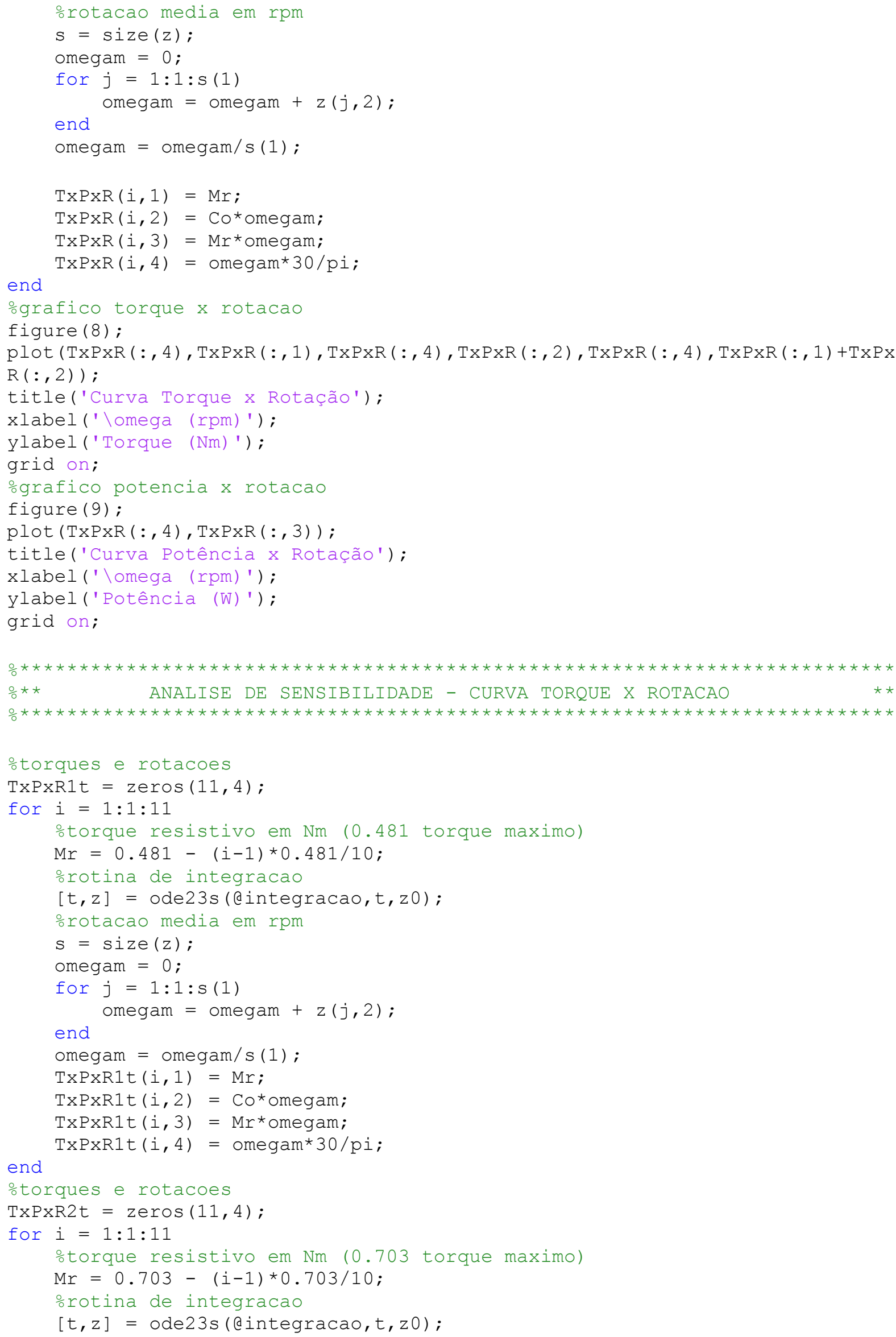




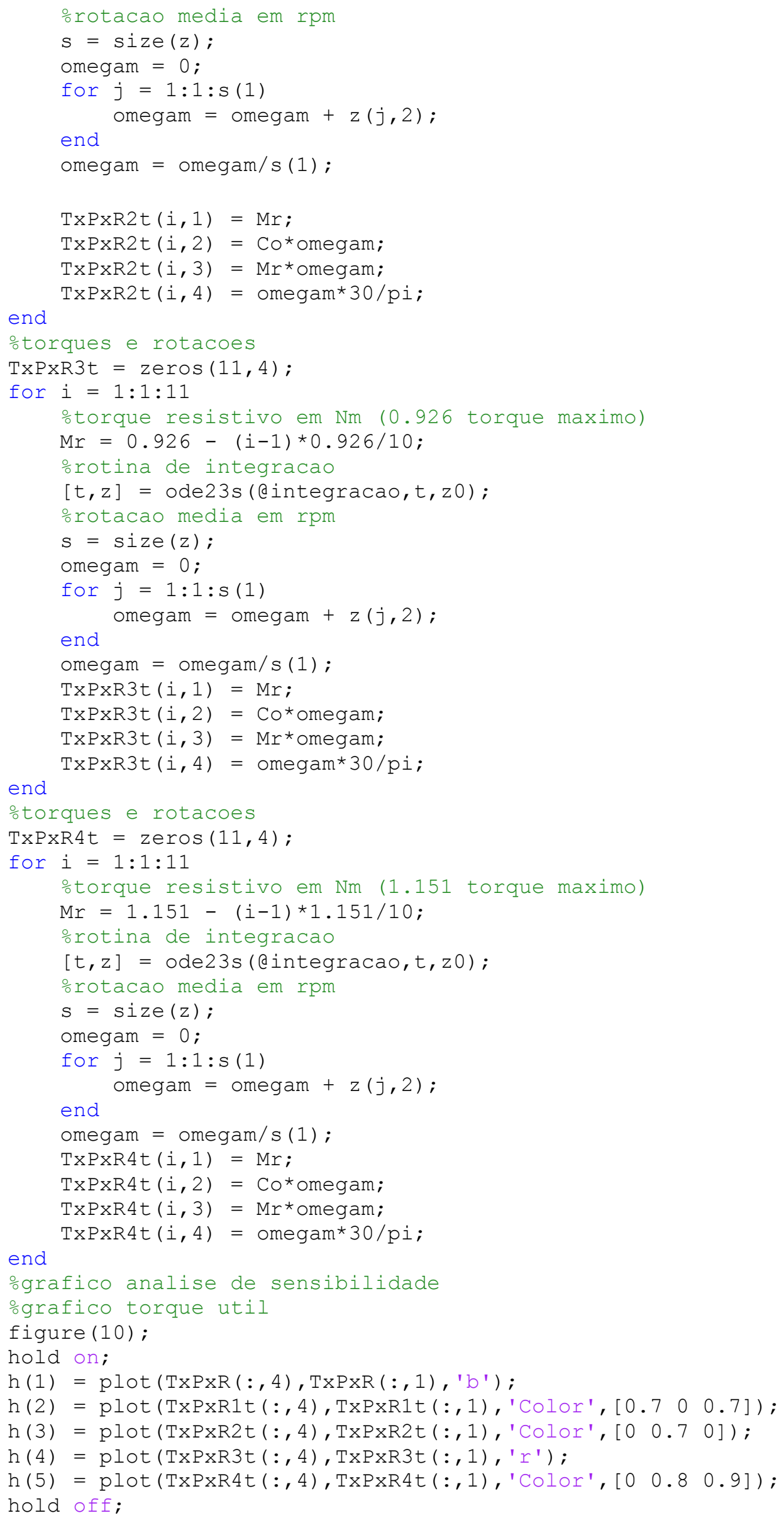


title('Torque Útil');

xlabel ('velocidade angular (rpm)');

ylabel ('torque (Nm)') ;

grid on;

legend ( $h, ' P h=3,0$ bar', 'Ph = 3,5 bar','Ph=4,0 bar', 'Ph = 4,5 bar', 'Ph = 5, 0 bar')

ografico torque perdas

figure (11);

plot $(\operatorname{TxPxR}(:, 4), \operatorname{TxPxR}(:, 2), \operatorname{TxP} \operatorname{Px} 1 t(:, 4), \operatorname{TxPxR} 1 t(:, 2), \operatorname{Tx} \operatorname{PxR} 2 t(:, 4), \operatorname{TxP} \operatorname{Pr} 2 t(:$ ,2)) ;

title('Torque Perdas');

xlabel ('\omega (rpm)');

ylabel ('Torque (Nm)');

grid on;

ografico torque total

figure (12);

plot $(\operatorname{Tx} \operatorname{PxR}(:, 4), \operatorname{Tx} \operatorname{PxR}(:, 1)+\operatorname{Tx} \operatorname{PxR}(:, 2), \operatorname{TxP} \operatorname{Px} 1 t(:, 4), \operatorname{Tx} \operatorname{PxR} 1 t(:, 1)+\operatorname{Tx} \operatorname{PxR} 1 t(:, 2$ )$, \operatorname{TxP} \operatorname{Re} 2 t(:, 4), \operatorname{TxP} \operatorname{Re} 2 t(:, 1)+\operatorname{Tx} \operatorname{PxR} 2 t(:, 2))$;

title('Torque Total');

xlabel ('\omega (rpm)');

ylabel ('Torque (Nm)');

grid on;

ografico potencia

figure (13);

hold on;

$h(1)=\operatorname{plot}\left(\operatorname{TxPxR}(:, 4), \operatorname{Tx} \operatorname{PxR}(:, 3), \mathrm{b}^{\prime}\right)$;

$h(2)=\operatorname{plot}\left(\operatorname{TxPxR} 1 t(:, 4), \operatorname{TxPxR} 1 t(:, 3)\right.$, 'Color' $\left[\begin{array}{llll}0.7 & 0 & 0.7\end{array}\right)$;

$h(3)=\operatorname{plot}\left(\operatorname{TxP} x R 2 t(:, 4), \operatorname{TxP} x R 2 t(:, 3), \operatorname{CO}^{\prime}{ }^{\prime},\left[\begin{array}{lll}0 & 0.7 & 0\end{array}\right]\right)$;

$h(4)=\operatorname{plot}\left(\operatorname{TxP} \operatorname{Re} 3 t(:, 4), \operatorname{TxPxR} 3 t(:, 3), \mathbf{r}^{\prime}\right)$;

$h(5)=\operatorname{plot}\left(\operatorname{TxPxR} 4 t(:, 4), \operatorname{TxPxR} 4 t(:, 3)\right.$, 'Color' $\left.\left[\begin{array}{lll}0 & 0.8 & 0.9\end{array}\right]\right)$;

hold off;

title('Curva Potência x Rotação');

xlabel ('velocidade angular (rpm)');

ylabel ('potência (W)');

grid on;

legend (h, 'Ph = 3,0 bar', 'Ph = 3,5 bar','Ph = 4,0 bar', 'Ph = 4,5 bar', 'Ph = 5,0 bar')

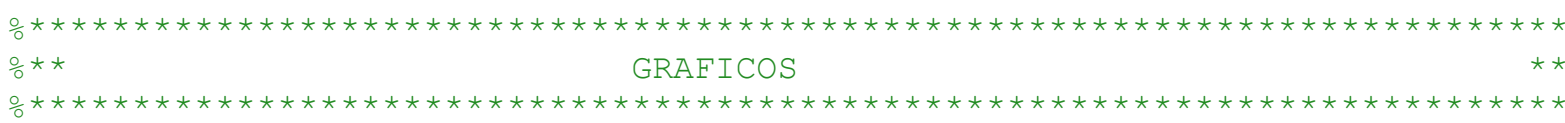

ografico cinematica biela-manivela

figure (14);

plot (teta, xv, teta, xp) ;

title('Posição do pistão (verde) e da válvula (azul) em função do ângulo'); xlabel ('\theta (rad)');

ylabel ('Posição (m) ') ;

grid on;

$x \lim \left(\left[\begin{array}{ll}0 & 25\end{array}\right]\right)$;

ografico pressao x volume

figure (15);

plot (Vp, PV) ;

title('Pressão em função do volume do pistão');

xlabel ('Volume $\left(\mathrm{m}^{3}\right)$ ') ;

ylabel ('Pressão (Pa)');

grid on;

$y \lim ([0.5 e 55.5 e 5])$; 


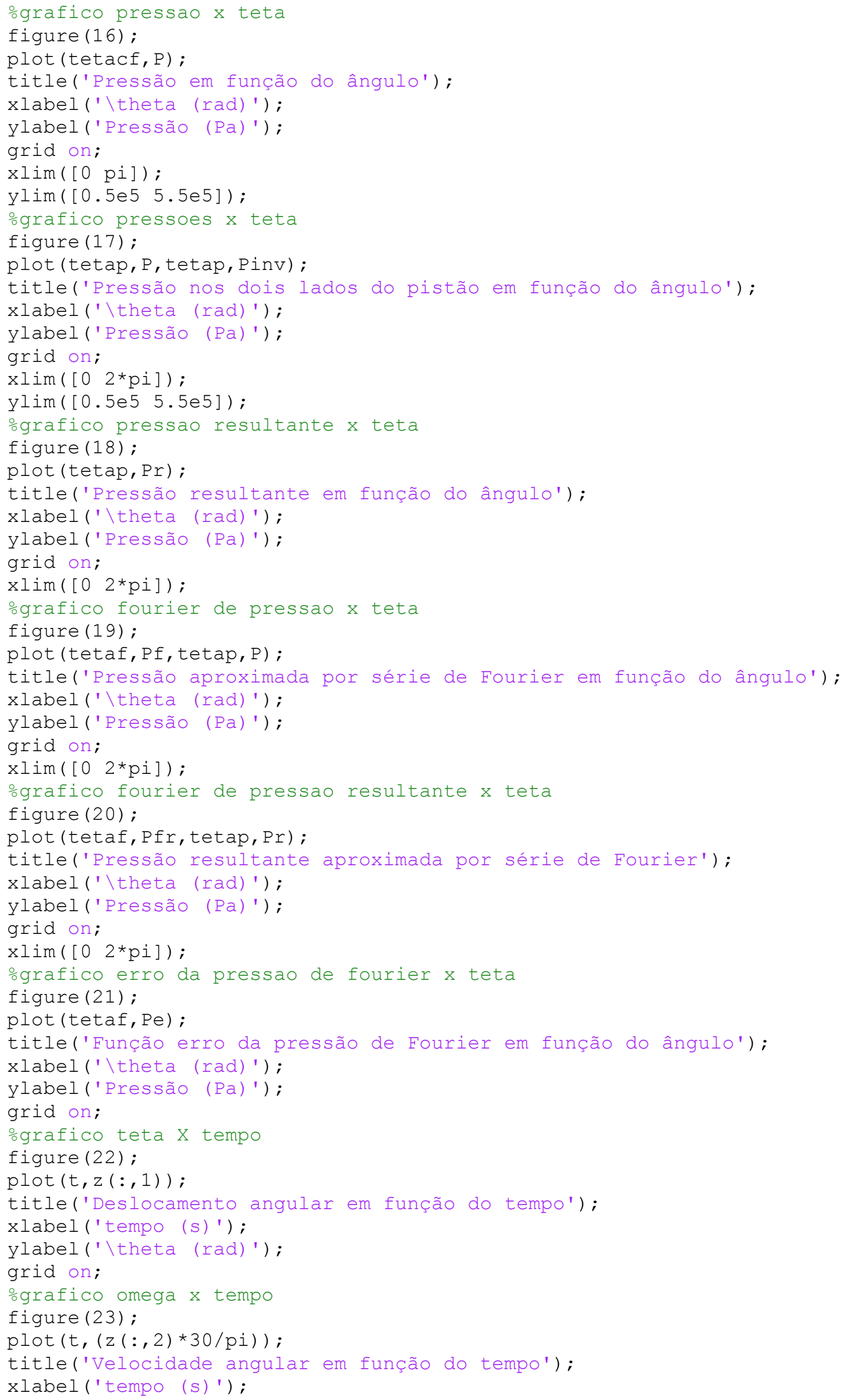




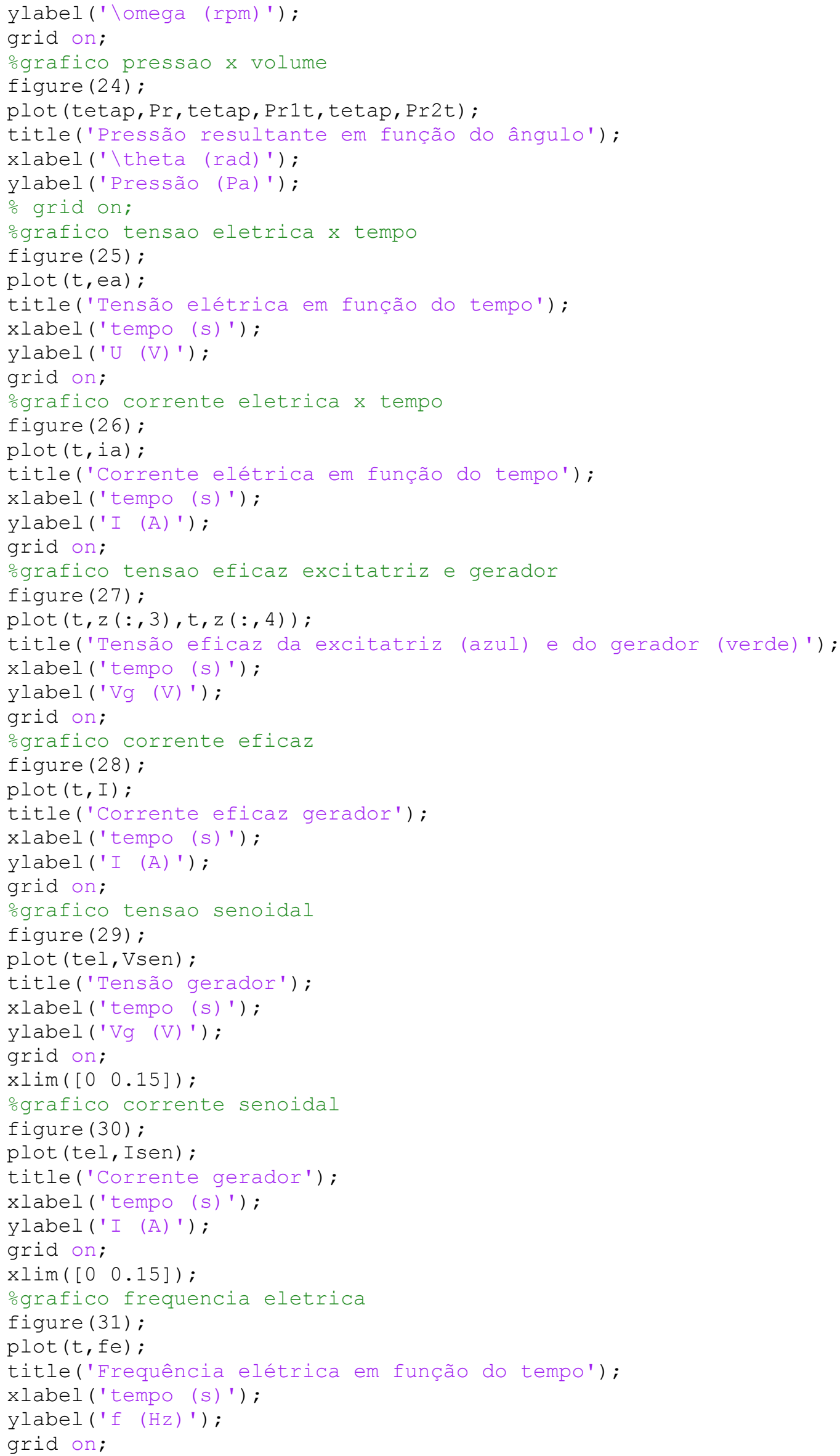




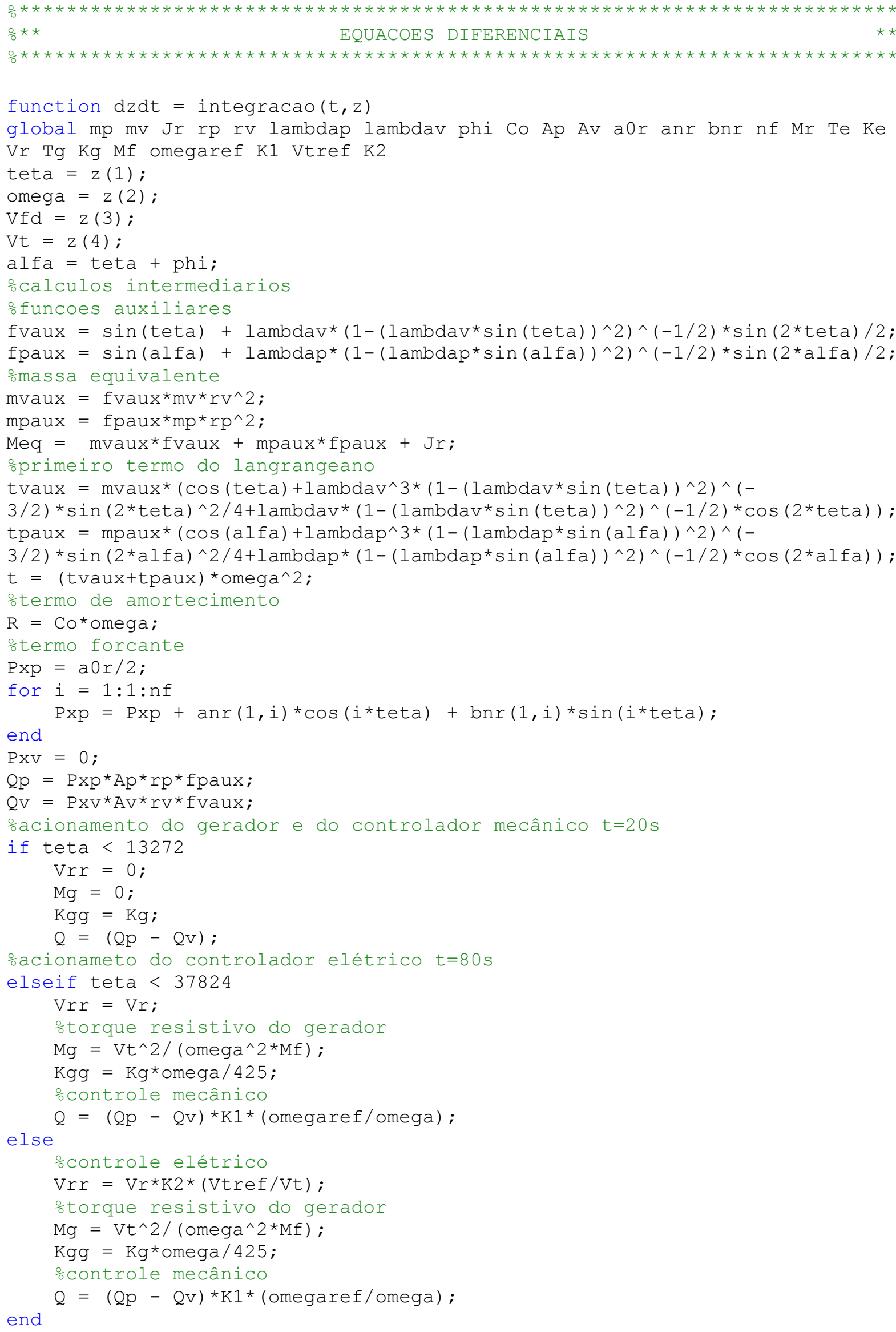




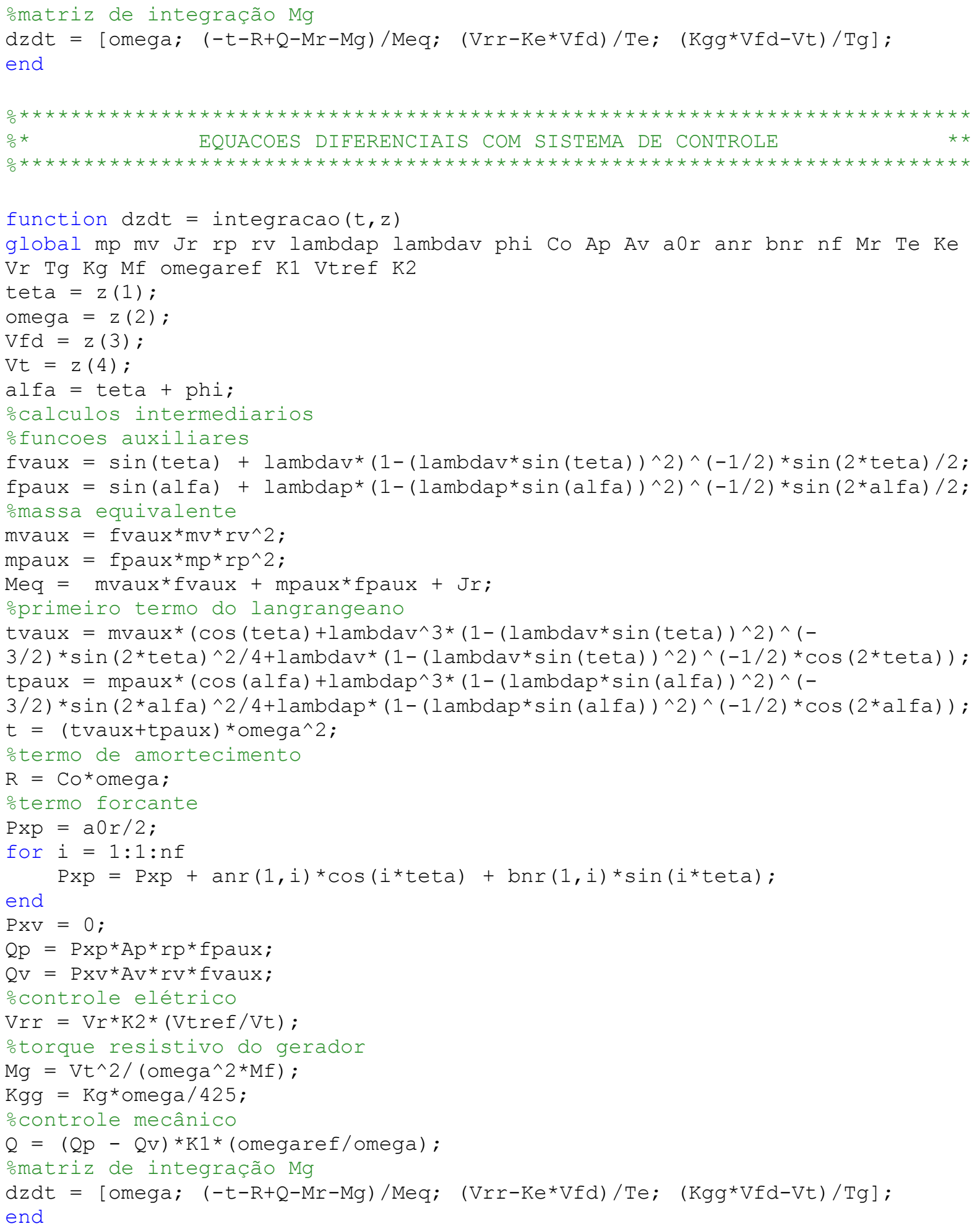




\section{APÊNDICE C - PARÂMETROS DAS SIMULAÇÕES}

Compilando todos os parâmetros utilizados nas simulações, obtém-se a Tabela C.1:

Tabela C.1 - Principais resultados da análise de sensibilidade.

\begin{tabular}{|c|c|c|c|c|c|}
\hline \multicolumn{6}{|c|}{ Sistema Térmico } \\
\hline Parâmetro & Valor & Unidade & Parâmetro & Valor & Unidade \\
\hline Ponto 1 & 0,0 & $\circ$ & $P_{a d m}$ & 3,0 & bar \\
\hline Ponto 2 & 66,6 & $\circ$ & $P_{e s c}$ & 1,0 & bar \\
\hline Ponto 3 & 114,2 & $\circ$ & $\mathrm{k}$ & 1,4 & - \\
\hline Ponto 4 & 180,0 & $\circ$ & $x_{m}$ & 10,0 & $\mathrm{~mm}$ \\
\hline Ponto 5 & 244,2 & $\circ$ & $d_{p}$ & 30,0 & $\mathrm{~mm}$ \\
\hline Ponto 6 & 293,8 & $\circ$ & $V_{m}$ & $7,07 \cdot 10^{-6}$ & $\mathrm{~m}^{3}$ \\
\hline \multicolumn{6}{|c|}{ Sistema Mecânico } \\
\hline Parâmetro & Valor & Unidade & Parâmetro & Valor & Unidade \\
\hline$r_{v}$ & 5,4 & $\mathrm{~mm}$ & $r_{p}$ & 22,0 & $\mathrm{~mm}$ \\
\hline$L_{v}$ & 110,6 & $\mathrm{~mm}$ & $L_{p}$ & 80,0 & $\mathrm{~mm}$ \\
\hline$d_{v}$ & 11,5 & $\mathrm{~mm}$ & $d_{p}$ & 30,0 & $\mathrm{~mm}$ \\
\hline$A_{v}$ & $104,5.10^{-6}$ & $m^{2}$ & $A_{p}$ & $707.10^{-6}$ & $\mathrm{~m}^{2}$ \\
\hline$V_{v}$ & $4,235.10^{-6}$ & $\mathrm{~m}^{3}$ & $V_{p}$ & $10,0.10^{-6}$ & $\mathrm{~m}^{3}$ \\
\hline$\rho_{\text {latão }}$ & 8600 & $\mathrm{~kg} / \mathrm{m}^{3}$ & $m_{p}$ & $86,0.10^{-3}$ & $\mathrm{~kg}$ \\
\hline$m_{v}$ & $36,42 \cdot 10^{-3}$ & $\mathrm{~kg}$ & $\rho_{a c ̧ o}$ & 7860 & $\mathrm{~kg} / \mathrm{m}^{3}$ \\
\hline$\varphi$ & 45 & $\circ$ & $J_{r i}$ & $242,8 \cdot 10^{-6}$ & $\mathrm{~kg} \cdot \mathrm{m}^{2}$ \\
\hline$c_{\theta}$ & 0,002 & N.m.s/rad & & & \\
\hline \multicolumn{6}{|c|}{ Vibração do Pistão } \\
\hline Parâmetro & Valor & Unidade & Parâmetro & Valor & Unidade \\
\hline$L_{h}$ & 155,0 & $\mathrm{~mm}$ & $E$ & 64,0 & $\mathrm{GPa}$ \\
\hline$A_{h}$ & 12,57 & $\mathrm{~mm}^{2}$ & K & $5,19 \cdot 10^{6}$ & $\mathrm{~N} / \mathrm{m}$ \\
\hline$m_{1}$ & 69,2 & g & $\omega_{n}$ & $2,63 \cdot 10^{4}$ & $\mathrm{rad} / \mathrm{s}$ \\
\hline$m_{2}$ & 8,4 & $g$ & $r$ & 0,0072 & - \\
\hline \multicolumn{6}{|c|}{ Sistema Elétrico } \\
\hline Parâmetro & Valor & Unidade & Parâmetro & Valor & Unidade \\
\hline$T_{E}$ & 0,5 & - & $T_{G}$ & 0,6 & - \\
\hline$K_{E}$ & 0,05 & - & $K_{G}$ & 1,0 & - \\
\hline$v_{R}$ & 5,5 & V & & & \\
\hline
\end{tabular}




\section{APÊNDICE D - TABELAS DE CALIBRAÇÃO}

\section{Manômetro}

Para validar a calibração do manômetro foram feitas três sequências de onze medidas. As três sequência de medidas obtidas são mostradas na Tabela D.1, na Tabela D.2 e na Tabela D.3.

Tabela D.1 - Primeira sequência de teste para a calibração do manômetro.

\begin{tabular}{c|cc}
\hline Referência (bar) & Pressão Absoluta (bar) & Manômetro (kgf/cm $\mathbf{~})$ \\
\hline $\mathbf{0 , 5}$ & 1,15 & 0,50 \\
\hline $\mathbf{1 , 0}$ & 1,70 & 1,00 \\
\hline $\mathbf{1 , 5}$ & 2,20 & 1,60 \\
\hline $\mathbf{2 , 0}$ & 2,55 & 1,95 \\
\hline $\mathbf{2 , 5}$ & 3,20 & 2,60 \\
\hline $\mathbf{3 , 0}$ & 3,55 & 3,00 \\
\hline $\mathbf{3 , 5}$ & 4,05 & 3,50 \\
\hline $\mathbf{4 , 0}$ & 4,40 & 3,85 \\
\hline $\mathbf{4 , 5}$ & 4,85 & 4,35 \\
\hline $\mathbf{5 , 0}$ & 5,50 & 5,00 \\
\hline $\mathbf{5 , 5}$ & 5,75 & 5,30 \\
\hline
\end{tabular}

Tabela D.2 - Segunda sequência de teste para a calibração do manômetro.

\begin{tabular}{c|cc}
\hline Referência (bar) & Pressão Absoluta (bar) & Manômetro (kgf $\left./ \mathbf{c m}^{\mathbf{2}}\right)$ \\
\hline $\mathbf{0 , 5}$ & 1,15 & 0,50 \\
\hline $\mathbf{1 , 0}$ & 1,65 & 1,00 \\
\hline $\mathbf{1 , 5}$ & 2,15 & 1,50 \\
\hline $\mathbf{2 , 0}$ & 2,60 & 2,00 \\
\hline $\mathbf{2 , 5}$ & 3,00 & 2,40 \\
\hline $\mathbf{3 , 0}$ & 3,50 & 2,90 \\
\hline $\mathbf{3 , 5}$ & 4,00 & 3,40 \\
\hline $\mathbf{4 , 0}$ & 4,55 & 4,00 \\
\hline $\mathbf{4 , 5}$ & 5,00 & 4,50 \\
\hline $\mathbf{5 , 0}$ & 5,45 & 4,90 \\
\hline $\mathbf{5 , 5}$ & 5,70 & 5,20 \\
\hline
\end{tabular}


Tabela D.3 - Terceira sequência de teste para a calibração do manômetro.

\begin{tabular}{|c|c|c|}
\hline Referência (bar) & Pressão Absoluta (bar) & Manômetro (kgf/cm²) \\
\hline 0,5 & 1,20 & 0,50 \\
\hline 1,0 & 1,70 & 1,00 \\
\hline 1,5 & 2,20 & 1,60 \\
\hline 2,0 & 2,75 & 2,10 \\
\hline 2,5 & 3,15 & 2,55 \\
\hline 3,0 & 3,65 & 3,05 \\
\hline 3,5 & 4,20 & 3,50 \\
\hline 4,0 & 4,45 & 3,95 \\
\hline 4,5 & 4,90 & 4,40 \\
\hline 5,0 & 5,40 & 4,90 \\
\hline 5,5 & 5,65 & 5,15 \\
\hline
\end{tabular}




\section{Termopares}

Para validar a calibração foram feitas três sequências de medidas. As três sequência de medidas obtidas são mostradas na Tabela D.4, na Tabela D.5 e na Tabela D.6.

Tabela D.4 - Primeira sequência de teste para a calibração dos termopares.

\begin{tabular}{c|cccc}
\hline $\begin{array}{c}\text { Referência } \\
\left({ }^{\circ} \mathbf{C}\right)\end{array}$ & $\begin{array}{c}\text { Medida Absoluta } \\
\left({ }^{\circ} \mathbf{C}\right)\end{array}$ & $\begin{array}{c}\text { Termopar 1 } \\
\left({ }^{\circ} \mathbf{C}\right)\end{array}$ & $\begin{array}{c}\text { Termopar 2 } \\
\left({ }^{\circ} \mathbf{C}\right)\end{array}$ & $\begin{array}{c}\text { Termopar 3 } \\
\left({ }^{\circ} \mathbf{C}\right)\end{array}$ \\
\hline $\mathbf{0}$ & 0,2 & 0,9 & 1,9 & 2,0 \\
\hline $\mathbf{5}$ & 4,5 & 5,2 & 6,5 & 7,1 \\
\hline $\mathbf{1 0}$ & 14,2 & 14,2 & 15,5 & 14,8 \\
\hline $\mathbf{1 5}$ & 19,9 & 19,3 & 21,8 & 20,5 \\
\hline $\mathbf{2 0}$ & 21,3 & 20,3 & 22,4 & 20,9 \\
\hline $\mathbf{2 5}$ & 25,0 & 23,1 & 23,8 & 23,2 \\
\hline $\mathbf{3 0}$ & 33,8 & 33,2 & 33,6 & 34,1 \\
\hline $\mathbf{3 5}$ & 38,2 & 37,8 & 38,4 & 38,1 \\
\hline $\mathbf{4 0}$ & 39,8 & 39,2 & 39,6 & 40,2 \\
\hline $\mathbf{4 5}$ & 45,2 & 44,6 & 45,1 & 45,6 \\
\hline $\mathbf{5 0}$ & 49,6 & 49,0 & 49,4 & 49,6 \\
\hline $\mathbf{5 5}$ & 53,9 & 53,5 & 54,1 & 54,6 \\
\hline $\mathbf{6 0}$ & 60,0 & 59,5 & 60,0 & 60,3 \\
\hline $\mathbf{6 5}$ & 64,5 & 64,1 & 64,9 & 65,9 \\
\hline $\mathbf{7 0}$ & 68,5 & 68,0 & 68,1 & 69,1 \\
\hline $\mathbf{7 5}$ & 74,4 & 74,3 & 74,6 & 75,0 \\
\hline $\mathbf{8 0}$ & 78,8 & 78,2 & 78,8 & 78,9 \\
\hline $\mathbf{8 5}$ & 84,2 & 83,5 & 84,0 & 84,4 \\
\hline $\mathbf{9 0}$ & 90,2 & 89,5 & 89,7 & 90,3 \\
\hline $\mathbf{9 5}$ & 92,7 & 92,9 & 93,0 & 93,1 \\
\hline $\mathbf{P E}$ & 97,7 & 97,5 & 97,7 & 98,1 \\
\hline & & & & \\
\hline
\end{tabular}


Tabela D.5 - Segunda sequência de teste para a calibração dos termopares.

\begin{tabular}{c|cccc}
\hline $\begin{array}{c}\text { Referência } \\
\left({ }^{\circ} \mathbf{C}\right)\end{array}$ & $\begin{array}{c}\text { Medida Absoluta } \\
\left({ }^{\circ} \mathbf{C}\right)\end{array}$ & $\begin{array}{c}\text { Termopar 1 } \\
\left({ }^{\circ} \mathbf{C}\right)\end{array}$ & $\begin{array}{c}\text { Termopar 2 } \\
\left({ }^{\circ} \mathbf{C}\right)\end{array}$ & $\begin{array}{c}\text { Termopar 3 } \\
\left({ }^{\circ} \mathbf{C}\right)\end{array}$ \\
\hline $\mathbf{0}$ & 1,0 & 0,9 & 2,1 & 2,1 \\
\hline $\mathbf{5}$ & 6,4 & 6,1 & 7,6 & 7,3 \\
\hline $\mathbf{1 0}$ & 10,1 & 9,1 & 10,7 & 10,9 \\
\hline $\mathbf{1 5}$ & 14,6 & 14,1 & 15,5 & 15,5 \\
\hline $\mathbf{2 0}$ & 19,1 & 18,9 & 19,9 & 20,1 \\
\hline $\mathbf{2 5}$ & 25,1 & 24,8 & 25,4 & 25,9 \\
\hline $\mathbf{3 0}$ & 29,6 & 29,3 & 30,1 & 30,5 \\
\hline $\mathbf{3 5}$ & 36,0 & 35,7 & 36,1 & 36,6 \\
\hline $\mathbf{4 0}$ & 39,8 & 39,3 & 40,1 & 40,4 \\
\hline $\mathbf{4 5}$ & 45,1 & 44,6 & 45,2 & 45,9 \\
\hline $\mathbf{5 0}$ & 50,5 & 49,9 & 50,5 & 51,0 \\
\hline $\mathbf{5 5}$ & 54,0 & 53,8 & 54,3 & 54,4 \\
\hline $\mathbf{6 0}$ & 58,2 & 57,5 & 58,4 & 58,5 \\
\hline $\mathbf{6 5}$ & 65,7 & 65,3 & 65,9 & 66,2 \\
\hline $\mathbf{7 0}$ & 69,6 & 69,1 & 69,8 & 69,9 \\
\hline $\mathbf{7 5}$ & 74,1 & 73,9 & 74,3 & 74,5 \\
\hline $\mathbf{8 0}$ & 79,3 & 79,0 & 79,5 & 79,5 \\
\hline $\mathbf{8 5}$ & 84,7 & 84,4 & 84,7 & 84,7 \\
\hline $\mathbf{9 0}$ & 91,1 & 90,7 & 90,9 & 91,1 \\
\hline $\mathbf{9 5}$ & 93,9 & 93,5 & 93,5 & 94,3 \\
\hline $\mathbf{P E}$ & 97,7 & 97,1 & 97,8 & 98,1 \\
\hline
\end{tabular}


Tabela D.6 - Terceira sequência de teste para a calibração dos termopares.

\begin{tabular}{c|cccc}
\hline $\begin{array}{c}\text { Referência } \\
\left({ }^{\circ} \mathbf{C}\right)\end{array}$ & $\begin{array}{c}\text { Medida Absoluta } \\
\left({ }^{\circ} \mathbf{C}\right)\end{array}$ & $\begin{array}{c}\text { Termopar 1 } \\
\left({ }^{\circ} \mathbf{C}\right)\end{array}$ & $\begin{array}{c}\text { Termopar 2 } \\
\left({ }^{\circ} \mathbf{C}\right)\end{array}$ & $\begin{array}{c}\text { Termopar 3 } \\
\left({ }^{\circ} \mathbf{C}\right)\end{array}$ \\
\hline $\mathbf{0}$ & 0,3 & 0,1 & 2,3 & 2,8 \\
\hline $\mathbf{5}$ & 6,1 & 5,7 & 7,1 & 7,1 \\
\hline $\mathbf{1 0}$ & 11,0 & 10,9 & 12,0 & 12,0 \\
\hline $\mathbf{1 5}$ & 14,1 & 13,9 & 14,7 & 14,7 \\
\hline $\mathbf{2 0}$ & 18,1 & 18,0 & 18,9 & 19,0 \\
\hline $\mathbf{2 5}$ & 24,6 & 24,4 & 25,2 & 25,2 \\
\hline $\mathbf{3 0}$ & 29,4 & 29,4 & 29,8 & 29,9 \\
\hline $\mathbf{3 5}$ & 34,8 & 34,8 & 35,0 & 35,1 \\
\hline $\mathbf{4 0}$ & 41,4 & 41,2 & 41,8 & 41,8 \\
\hline $\mathbf{4 5}$ & 45,6 & 45,6 & 46,1 & 46,0 \\
\hline $\mathbf{5 0}$ & 49,9 & 49,8 & 50,1 & 50,0 \\
\hline $\mathbf{5 5}$ & 54,1 & 54,1 & 54,7 & 54,8 \\
\hline $\mathbf{6 0}$ & 58,4 & 58,1 & 58,8 & 59,0 \\
\hline $\mathbf{6 5}$ & 65,5 & 65,3 & 65,9 & 66,0 \\
\hline $\mathbf{7 0}$ & 70,1 & 69,9 & 70,3 & 70,3 \\
\hline $\mathbf{7 5}$ & 74,5 & 74,5 & 74,8 & 74,8 \\
\hline $\mathbf{8 0}$ & 79,7 & 79,6 & 79,9 & 79,9 \\
\hline $\mathbf{8 5}$ & 84,9 & 84,4 & 85,2 & 85,2 \\
\hline $\mathbf{9 0}$ & 89,0 & 88,8 & 89,0 & 89,0 \\
\hline $\mathbf{9 5}$ & 93,4 & 93,2 & 93,5 & 93,7 \\
\hline $\mathbf{P E}$ & 97,7 & 97,5 & 98,1 & 98,2 \\
\hline
\end{tabular}




\section{Tacômetro}

Para validar a calibração foram feitas três sequências de nove medidas. As três sequência de medidas obtidas são mostradas na Tabela D.7, na Tabela D.8 e na Tabela D.9.

Tabela D.7 - Primeira sequência de teste para a calibração do tacômetro.

\begin{tabular}{cc}
\hline Referência $(\mathbf{r p m})$ & Tacômetro $(\mathbf{r p m})$ \\
\hline 100 & 109,3 \\
256 & 278,9 \\
405 & 438,3 \\
630 & 680,3 \\
1000 & 1078,5 \\
1250 & 1227,0 \\
1600 & 1659,6 \\
2000 & 2006,0 \\
2500 & 2614,9 \\
\hline
\end{tabular}

Tabela D.8 - Segunda sequência de teste para a calibração do tacômetro.

\begin{tabular}{cc}
\hline Referência (rpm) & Tacômetro (rpm) \\
\hline 100 & 109,4 \\
256 & 278,8 \\
405 & 438,1 \\
630 & 679,4 \\
1000 & 1078,8 \\
1250 & 1224,4 \\
1600 & 1663,3 \\
2000 & 2004,5 \\
2500 & 2596,7 \\
\hline
\end{tabular}


Tabela D.9 - Terceira sequência de teste para a calibração dos termopares.

\begin{tabular}{cc}
\hline Referência (rpm) & Tacômetro (rpm) \\
\hline 100 & 109,4 \\
256 & 278,9 \\
405 & 438,0 \\
630 & 678,7 \\
1000 & 1078,5 \\
1250 & 1224,9 \\
1600 & 1662,3 \\
2000 & 2003,5 \\
2500 & 2612,1 \\
\hline
\end{tabular}

